\title{
ANT DIVERSITY, FUNCTION AND SERVICES ACROSS TROPICAL LAND-USE SYSTEMS IN INDONESIA
}

\author{
Dissertation \\ for the award of the degree \\ "Doctor of Philosophy" (Ph.D. Division of Mathematics and Natural \\ Sciences) \\ of the Georg-August-Universität Göttingen
}

within the doctoral program: Biodiversity and Ecology

submitted by

M.Sc. Lisa Helen Denmead

from Blenheim (New Zealand)

Göttingen, 2016 



\section{Thesis Committee}

Prof. Dr. Teja Tscharntke

(Dept. Crop Sciences / Agroecology)

Prof. Dr. Stefan Vidal

(Dept. of Crop Sciences / Agroentomology)

Prof. Dr. Kerstin Wiegand

(Dept. of Ecosystem Modelling/ A.-v.-H. Institute for Plant Sciences)

Members of the Examination Board

Prof. Dr. Teja Tscharntke

(Dept. Crop Sciences / Agroecology)

Prof. Dr. Stefan Vidal

(Dept. of Crop Sciences / Agroentomology)

Prof. Dr. Kerstin Wiegand

(Dept. of Ecosystem Modelling/ A.-v.-H. Institute for Plant Sciences)

Dr Yann Clough

(Dept. Crop Sciences / Agroecology and Centre for Environmental and Climate Research, Lund University)

Prof. Dr. Holger Kreft

(Free Floater Research Group - Biodiversity, Macroecology \& Conservation Biogeography Group)

Prof. Dr Hermann Behling

(Dept. of Palynology and Climate Dynamics)

Date of the oral examination: 17.03.2016 



\section{Table of contents}

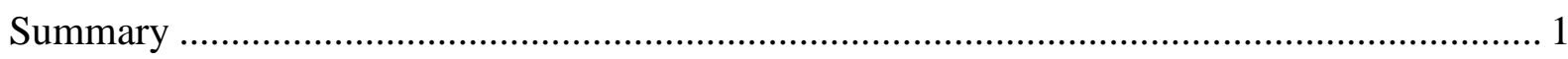

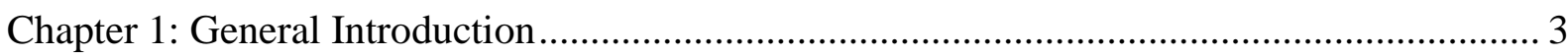

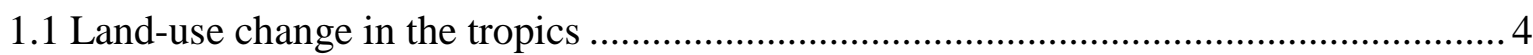

1.2 Consequences of land-use change on biodiversity and ecosystem functioning .............. 5

1.3 Potential factors influencing maintenance of biodiversity and ecosystem functions in

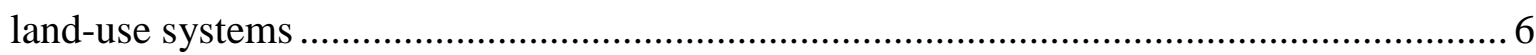

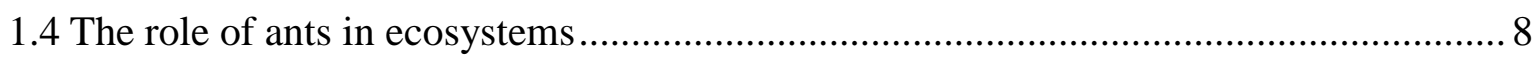

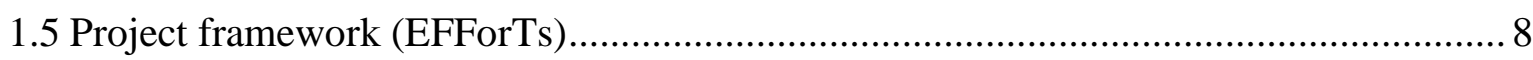

1.6 Thesis objectives.......................................................................................

Chapter 2: Agricultural land use alters species composition but not species richness of ant

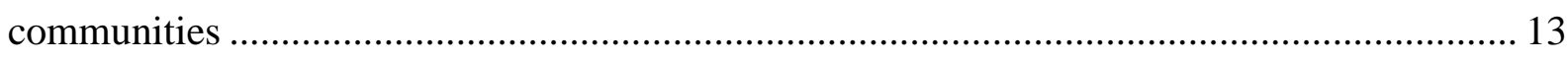



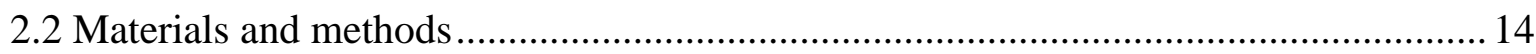

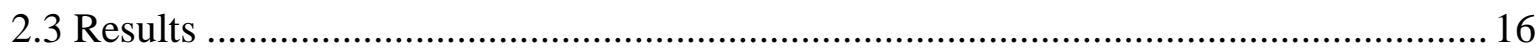

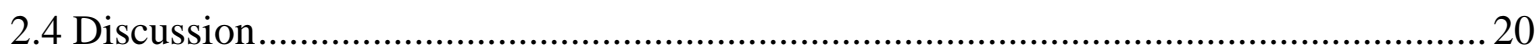

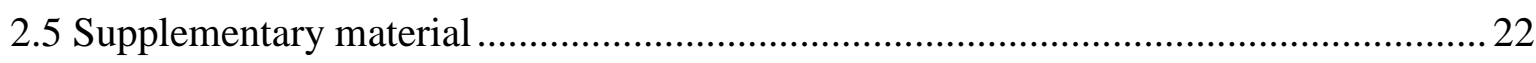

Chapter 3: Single- and multi-trait measures reveal widespread functional diversity loss in human-modified tropical landscapes.............................................................................. 27

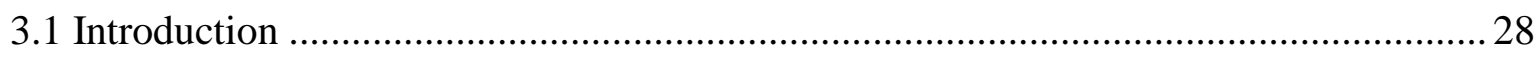

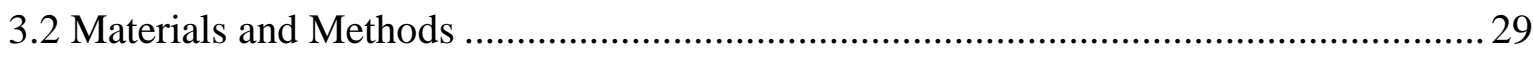

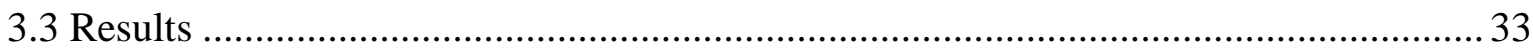

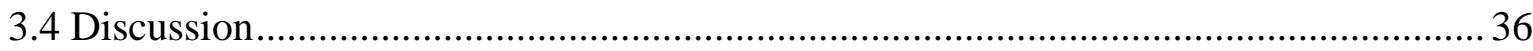

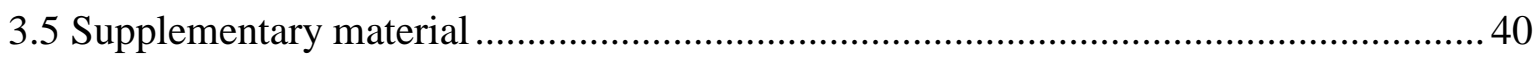

Chapter 4: Local and landscape drivers of arthropod diversity and decomposition processes in

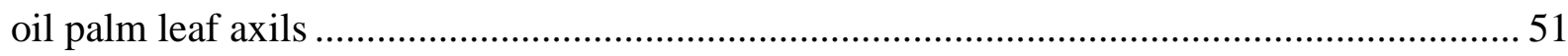

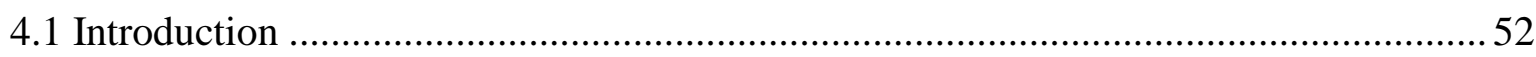

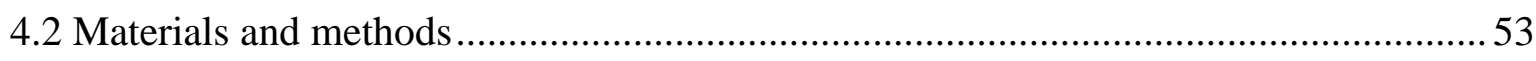

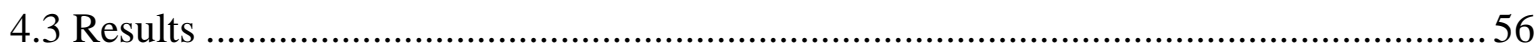

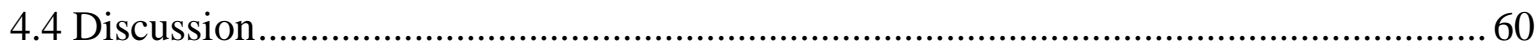

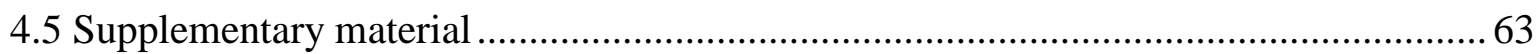

Chapter 5: Biological control in oil palm is enhanced by landscape context........................... 73 


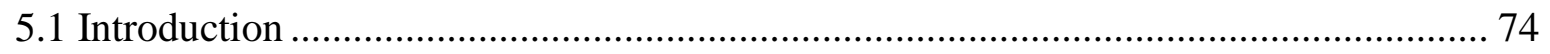

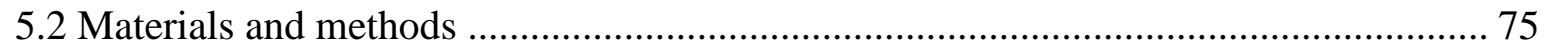

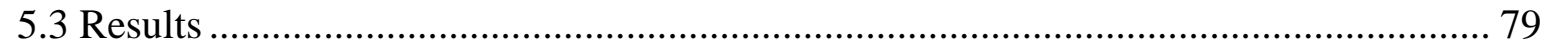

5.4 Discussion

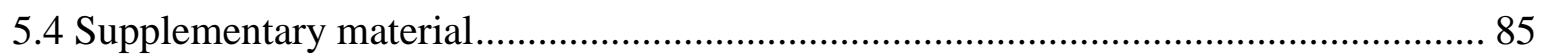

Chapter 6: Ants affect belowground invertebrate communities and associated functions across

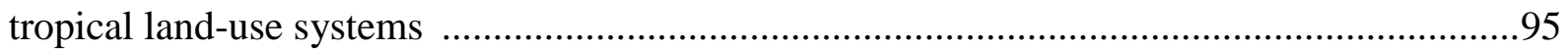

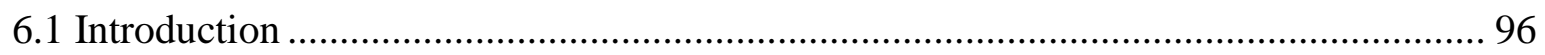

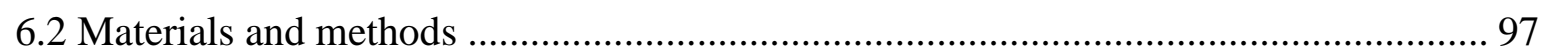

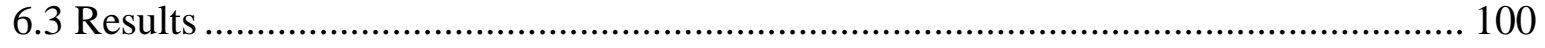

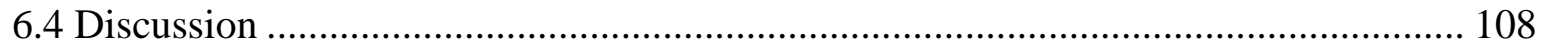

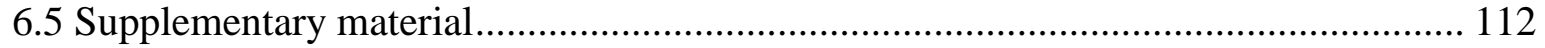

Chapter 7: The role of ants, birds and bats for ecosystem functions and services in oil palm

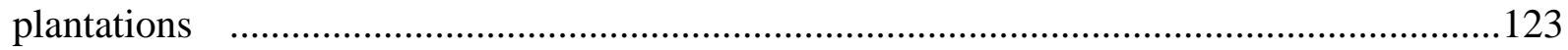

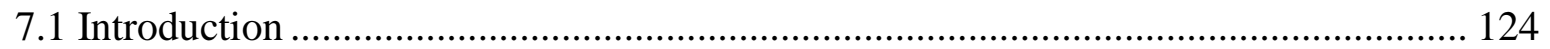

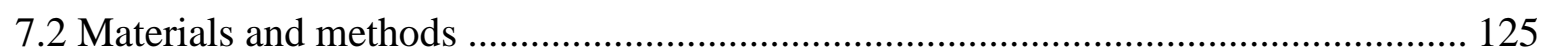

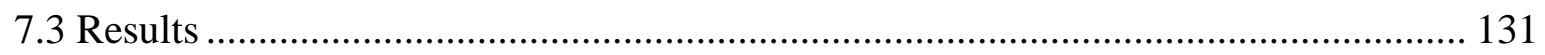

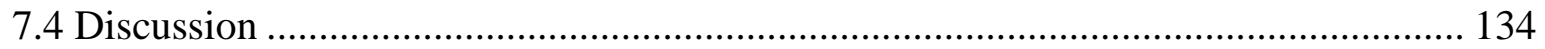

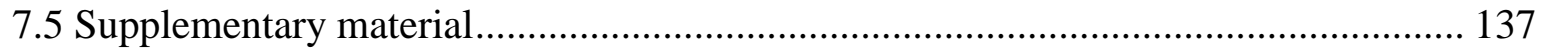

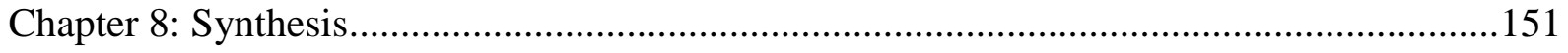

8.1 Objective 1: Understand ant taxonomic and functional diversity responses to land-use change

8.2 Objective 2: Investigate the response of ant communities and associated functions to landscape context and local management in oil palm plantations.

8.3 Objective 3: Examine the role of ant communities in shaping arthropod communities and

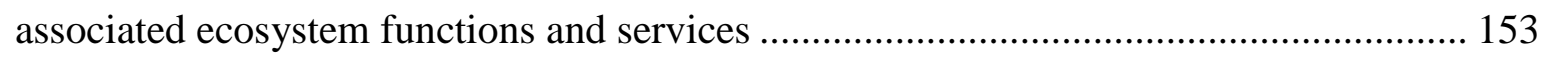

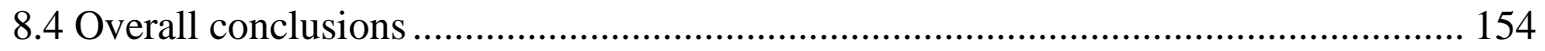

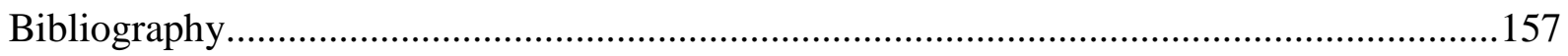

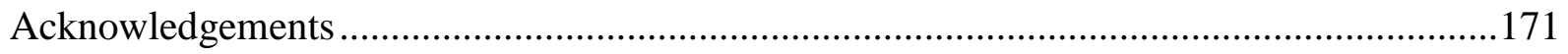

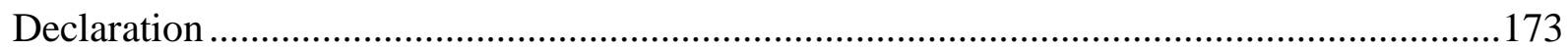

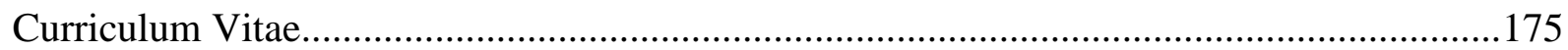

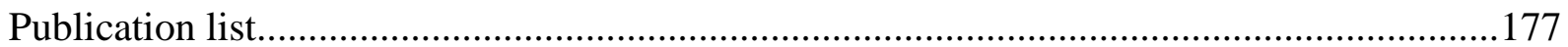




\section{Summary}

Land-use change due to agricultural expansion is one of the greatest global threats to biodiversity and associated ecosystem functions and services. In the tropics in particular, conversion of forest and agroforests into monoculture agriculture such as oil palm is happening at an extremely rapid rate, leading to highly simplified landscapes. In Indonesia, currently the world's leading palm oil producer, oil palm plantation crop cover was nine million hectares in 2010 with a projected increase to 18 million hectares by 2020 . The predicted further large-scale expansion of oil palm plantations and other high-intensity agricultural systems has extensive implications for biodiversity loss. In agricultural production systems, loss of economically important functional groups can lead to decreases in essential ecosystem services such as pollination, biocontrol and soil turnover. Ants for example, dominate terrestrial biomass and are important for number of ecosystem services that are crucial in agriculture and have been shown to influence yield. In this thesis I aim to understand 1) how ant communities respond to land-use change, 2) if certain factors can alter their response, and 3) if changes in the ant community can alter their influence on biodiversity, ecosystem functions and yield.

In chapter 2 and 3 of this thesis I investigated land-use change effects on the taxonomic and functional diversity of ant communities in lowland forest, jungle rubber, monoculture rubber and oil palm plantation sites. In chapter 2 I focus on changes in species richness and composition and in chapter 3 changes in functional diversity and composition, including also birds and leaf-litter invertebrates in the analysis to broaden the study. The results show that ant species richness responded contrary to expected to land-use change, either increasing or not changing from forest to the agricultural systems studied dependent on the sampling methods used. However, species composition changed considerably and few ant species were shared among different land-use types. These results suggest land-use change would result in a net loss of ant species, even though ant species richness in plantations and forested habitats are similar. Furthermore, there was a linear relationship between species richness and functional diversity for ants, birds and leaf-litter invertebrates, indicating low redundancy in these systems. Finally, the functional composition of all three animal groups also changed with land-change. In particular, species from higher trophic guilds decreased from forest to oil palm. The observed decrease changes in species composition from rainforest to monoculture plantations, along with the tightly coupled decreases in functional diversity and low functional redundancy, could threaten long-term ecosystem stability through potential consequences for ecosystem processes

The results from chapter 2 and 3 provide strong evidence that overall impacts of conversion from natural ecosystems to land-use systems on ant communities are negative. However, there are factors which can influence the severity of these impacts. Therefore, in chapter 4 and 5 I investigate the response of ant communities and associated functions to landscape context and local management in oil palm plantations. In chapter 4 I examined the effects of location within the plantation (edge vs centre) and local characteristics (epiphyte cover, herbicide use, and local microclimate) on ant and other arthropod 
communities and litter decomposition in oil palm leaf axils. Arthropod abundance and taxa richness were higher at the edge of plantations than in the centre. Moreover, organic matter mass and height of the leaf axil were more important for arthropod communities and decomposition rate than epiphyte or ground vegetation cover. In chapter 5 I investigated the effect of surrounding landscape and distance from the edge on predation rates and predator occurrences in oil palm plantations. Predation rates were $\sim 70 \%$ higher in non-oil palm habitat. This effect spilled over into the oil palm plantations, where predation increased by $55-100 \% 20 \mathrm{~m}$ from the edge of the plantation and by $40-55 \% 50 \mathrm{~m}$ from the edge when surrounded by a land-use other than oil palm. Taken together, chapters 4 and 5 show that oil palm plantations adjacent to different land-use systems have enhanced biodiversity and associated functioning, though this effect quickly declines with distance from the edge. Furthermore, local management of ground cover has mixed effects on arthropods and epiphyte management is unlikely to influence ant communities.

In chapter 6 and 7 I look further into the changes in ant communities shown in Chapter 1 and 2 by investigating the role of ant communities in shaping arthropod communities and associated ecosystem functions and services. In chapter 6 I studied the influence of ants on both above- and belowground invertebrate communities, soil and litter variables and decomposition across different land-use systems using ant suppression plots at forest, jungle rubber, rubber and oil palm sites. Belowground invertebrates, i.e. collembola, had 30\% lower biomass in ant suppression plots. However, soil and litter variables and above-ground invertebrates were mostly unaffected. Rather, differences in local conditions between the four studies land-use systems were generally the most important predictors. Most notably, effects on decomposition rates were context-dependent, whereby ant suppression reduced decomposition in the forest sites only. Therefore, differences in ant communities between land-use systems alter their relationship to decomposition processes, however, the underlying drivers of these effects require further investigation. In chapter 7 I manipulated ant as well as flying vertebrate (birds and bats) access in only oil palm sites and measured effects on arthropod communities, related ecosystem functions (herbivory, predation, decomposition and pollination) and crop yield. Non-ant arthropod predator populations increased in response to reductions in ant and bird access, and the net effect of experimental manipulations on ecosystem functioning was minimal. Similarly, effects on yield were not significant. Chapter 7 shows that ecosystem functions and productivity in oil palm are, under current levels of pest pressure and pollinator populations, robust to large changes in the communities of major predator groups.

In conclusion, although forest conversion to oil palm and other agricultural systems in Indonesia has wide-ranging negative influences on biodiversity and function, there is the opportunity to enrich biodiversity in these systems. In oil palm plantations in particular this should be encouraged as changes in biodiversity do not compromise production. 


\section{Chapter 1}

\section{General Introduction}

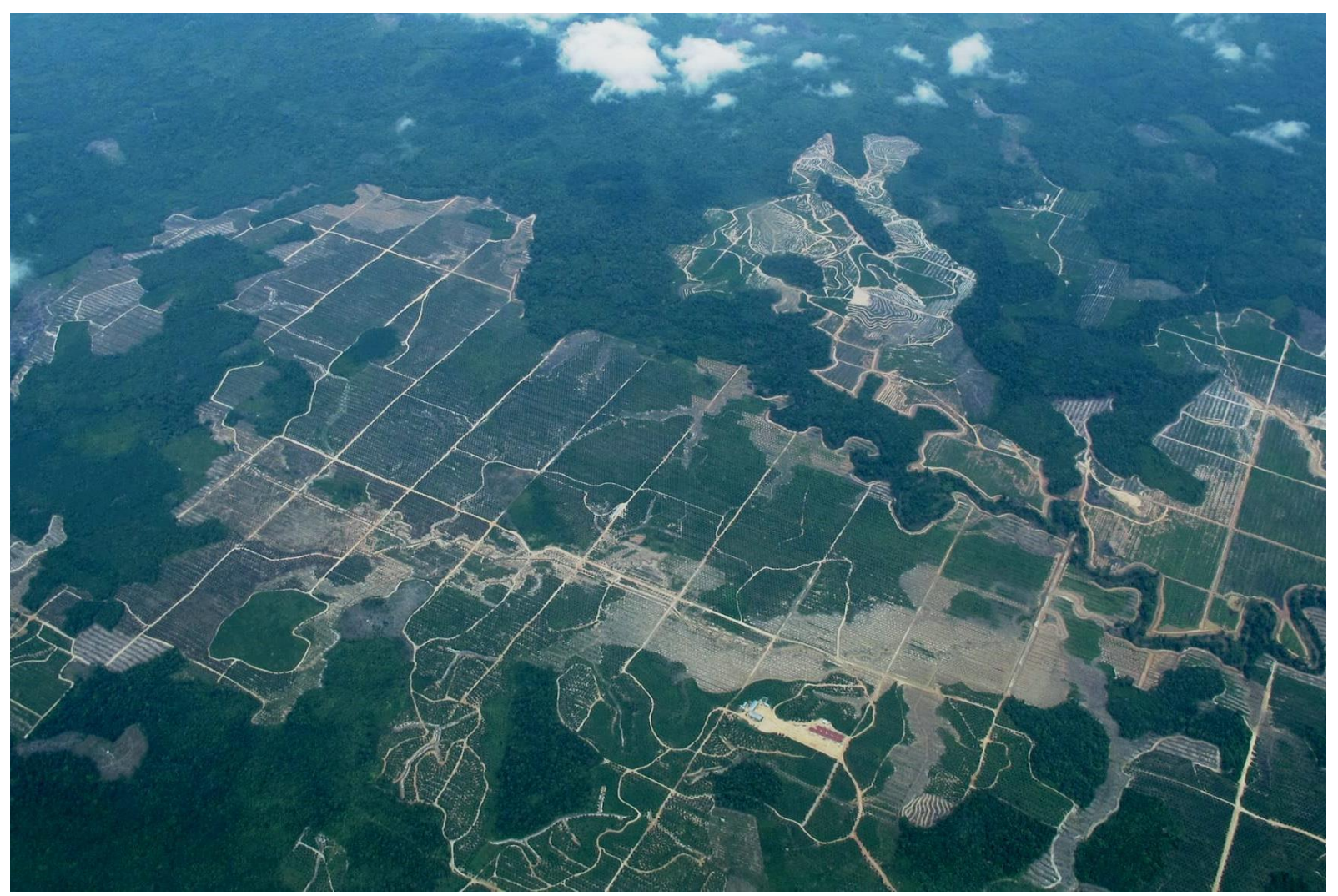

A typical Jambi landscape: oil palm plantations expanding into lowland forest. (Photo credit: Ana Meijide) 


\subsection{Land-use change in the tropics}

Tropical forests may only cover $\sim 5 \%$ of the Earth surface, however, they harbour at least two thirds of the world's terrestrial species (Gardner et al. 2009). Additionally, tropical forests have the largest annual rate of carbon sequestration among terrestrial ecosystems, produce around $20 \%$ of the world's oxygen and maintain the water cycle through transpiration and evaporation (Foley et al. 2007; Pan et al. 2011). Therefore, tropical forests play a key role in regulating global and regional climate systems (Fearnside 2000; Foley et al. 2007). Tropical forest are also important for number of other essential ecological services for human populations such as medicine production, supplying food and timber products, erosion prevention, flood control, pollination, and support for local communities (Grimes et al. 1994; Wright 2010; Laurance et al. 2014). Deforestation of tropical forests and the subsequent loss of the wide range of important services they provide is therefore one of the major global change drivers worldwide.

Tropical deforestation has resulted in only 11 million $\mathrm{km}^{2}$ of the original 17 million $\mathrm{km}^{2}$ of tropical forest left globally (Laurance et al. 2014). The extensive deforestation is only going to increase as the need for agricultural land grows with increasing human population (Laurance et al. 2014). Tropical forests were the primary source for newly established agricultural land between 1980 and 2000 with more than $80 \%$ of the land established at the expense of forests (Gibbs et al. 2010). The clearing of tropical forest for the expansion of agriculture is expected to continue, with the demand for agricultural products to increase by approximately $50 \%$ by 2050 and the majority of these products likely to come from tropical countries where there is weak environmental protection and low cost production (Gibbs et al. 2010; Lambin and Meyfroidt 2011; Laurance et al. 2014).

Presently, deforestation rates are particularly concerning in South-East Asia where peak deforestation rates have shifted from the Amazon basin in recent years (Miettinen et al. 2011; Margono et al. 2014). In 2012 Indonesia surpassed Brazil as the country with the highest deforestation rates worldwide, losing 0.85 Mha of primary forest in that year alone (Margono et al. 2014). The total forest lost in Indonesia from 2000 to 2012 totalled more than 6.02 Mha, and actually increased yearly by an average of 47,600 ha per year (Margono et al. 2014). Lowland Sumatra is one the key areas for deforestation, and two provinces in particular, Riau and Jambi, have had devastating forest loss, with forest cover declining from 93 to 38\% between 1977 and 2009 (Ekadinata and Vincent 2011). Agriculturally driven forest conversion is going to continue this trend, particularly due to $35 \%$ of the remaining forest in Indonesia being located within industrial concessions (Abood et al. 2015).

Human modification of forest in Indonesia has spanned centuries, first with hunting and gathering activities followed by slash and burn agriculture for many food crops, but in particular for upland rice (Gouyon et al. 1993; Feintrenie and Levang 2009). The swidden agriculture was abandoned after one to two years of cultivation then left as fallow land for 15 to 20 years. In the early $1900 \mathrm{~s}$ however, the exotic Para rubber (Hevea brasiliensis) was introduced to Indonesia to meet the growing demands from Europe and North America (Feintrenie and Levang 2009). Rubber seedlings were planted in the swidden among the rice, then once the plot was left to fallow the rubber seedlings grew along with 
the secondary forest regrowth, leading to rubber agroforests (commonly known now as "jungle rubber"). However, monoculture plantations of rubber produce higher yields than rubber agroforestry leading a growing preference for plantations over agroforesty (Feintrenie and Levang 2009; Ekadinata and Vincent 2011). Oil palm (Elaeis guineensis) was also introduced to Indonesia at the beginning of the 1900s, and in the second half of last century monoculture plantations began to dominate Indonesian landscapes, to the detriment of the more ecologically friendly agroforestry systems (e.g. jungle rubber, Feintrenie and Levang 2009).

Alarmingly, the area under oil palm plantations in Indonesia has increased exponentially from 673,000 to 7.0 million ha in the past 30 years (FAO 2015). The exponential increase in oil palm stems from large growth in the smallholder sector (190\% growth in the past decade) (Lee et al. 2014) and the Indonesian government granting large concessions to private enterprises (Jepson et al. 2001). Subsequently, in 2008 Indonesia surpassed Malaysia to become the number one producer of palm oil worldwide (FAO 2015). The alarming expansion of oil palm plantations in Indonesia is only going to continue with the Indonesians governments plan to double production between 2010 and 2020 (Koh and Ghazoul 2010). The continued deforestation and increased dominance of monoculture agriculture in Indonesia highlights the need to understand the effect these land-use changes will have on the long-term sustainability of both natural and agriculture systems in the region.

\subsection{Consequences of land-use change on biodiversity and ecosystem}

\section{functioning}

Land-use change in the tropics, either from conversion of natural to man-made ecosystems or through changing management practices to create more intensive agricultural systems, is of major concern to global biodiversity (Gardner et al. 2009; Gibson et al. 2011). The severe declines in biodiversity (including species richness, functional diversity and genetic diversity) recorded as a consequence of conversion to agriculture and agricultural intensification (Turner 1996; Vellend 2004; Flynn et al. 2009) arise from simplification, fragmentation and degradation of habitat, loss of resources, use of fertilisers and chemicals (e.g. herbicides and insecticides), and alteration in local climate (Sala et al. 2000; Foley et al. 2005). Biodiversity loss is strongly linked to a loss of ecosystem functions and services, many of which are essential for production and sustainability in agricultural systems and therefore human wellbeing. For example, 35\% of global crop production depends on animal pollination (Klein et al. 2007), however, there is substantial evidence of both wild and domestic pollinator species decline in many ecosystems (Kremen et al. 2002; Klein et al. 2007; Potts et al. 2010). Furthermore, native biocontrol agents (e.g. insect predators and parasitoids) are extremely susceptible to decline, as species from higher trophic guilds are more vulnerable to disturbances such as land-use change (Klein et al. 2002; Cagnolo et al. 2009; Holt 2009). For example, Cagnolo et al. (2009) found that parasitoids were more strongly affected by fragmentation than their leaf-miner prey and plants and Klein et al. (2002) found a reduced predator-prey ratio with increased intensification of cocoa. The loss of native 
biocontrol agents can have negative effects on production and lead to increased chemical use in agricultural landscapes causing further negative effects on biodiversity (Isaacs et al. 2008; Landis et al. 2008). As there is no sign of land-use change decreasing in the near future, research needs to focus on how to increase and maintain biodiversity in the altered landscapes or the long-term sustainability of most agricultural systems is in jeopardy.

Conversion of forest to oil palm plantations is a major threat to biodiversity in the tropics. Many recent studies have shown a general decline in species richness from primary or even logged forest to oil palm plantations across numerous taxa, including bats, leaf-litter invertebrates, dung beetles, ants, amphibians, lizards, birds, and plants (Fitzherbert et al. 2008; Danielsen et al. 2009; Foster et al. 2011; Savilaakso et al. 2014; Barnes et al. 2014). Furthermore, there is evidence for functional diversity loss and trait-dependent declines with conversion to oil palm plantation, with forest specialists, large-bodied species and species from higher trophic guilds particularly sensitive (Fitzherbert et al. 2008; Senior et al. 2013; Edwards et al. 2014a). For example Fitzherbert et al (2008) found only 15\% of forest specialists also occurred in oil palm plantations. One caveat to the extensive research on biodiversity loss in oil palm plantations is that the majority of research has been conducted in large-scale industrial plantations not smallholdings (Savilaakso et al. 2014), which due to their (small) size and likely lower intensification are expected to maintain higher biodiversity. Furthermore, there is still only a small amount of research investigating the links between the known losses in biodiversity and the potential effects on ecosystem functioning in the plantations (Koh 2008a; Gray et al. 2014; Barnes et al. 2014), in particular functions important for sustainability of the plantations such as soil fertility, pollination and biocontrol (Foster et al. 2011).

\subsection{Potential factors influencing maintenance of biodiversity and ecosystem functions in land-use systems}

Overall the ecological impacts of conversion from natural ecosystems to land-use systems are negative, however, there are factors which can influence the severity of these impacts (Fischer et al. 2006; Fahrig et al. 2011). In particular, landscape context and local management (Landis et al. 2000) can influence the potential for maintenance of biodiversity and ecosystem functions in land-use systems.

\section{Local management}

The local management practices in agricultural systems can have a major influence on the persistence of biodiversity in production landscapes (Landis et al. 2000). One of the major outcomes of land-use intensification is simplification of habitats, for example, highly intensive crop systems can have almost no other plant species than the crop itself as well as having low architectural complexity (Foster et al. 2011). A simplified agricultural system can lack resources such as habitat and food for natural enemies, alternative prey and hosts and refuges from disturbance events such as pesticide use and extreme environmental events (Landis et al. 2000; Tscharntke et al. 2007). Management practices such as the planting of flower strips, intercropping, decreasing the amount of weed management to increase 
ground cover, altered harvesting practices (e.g. not harvesting entire fields at one time) have be used to increase heterogeneity in agricultural systems and as such are often linked to positive effects on biodiversity and ecosystem services (Capinera et al. 1985; Landis et al. 2000; Lee and Heimpel 2005; Koh 2008b).

Oil palm plantations are highly simplified agricultural monocultures, however, dependent on plantation management there is the potential for structural and biological diversity due to the long-lived nature of oil palm trees, the possibility for complex ground cover and the potential for a diverse epiphyte community (e.g. in Malaysia half of the lowland epiphyte species have also been recorded in oil palm plantations) (Foster et al. 2011). Epiphyte removal and intensive weed management are common management practices in oil palm plantations, however, one of the main reasons for these management options is ease of harvesting (though there is evidence understory vegetation (but not epiphytes) can affect yield) and therefore they are not key for oil palm production and could be reduced or not used at all. Epiphytes and increased weed cover can provide resources, suitable microclimates in otherwise hot and dry plantations and increased habitat heterogeneity in these highly simplified systems. For example, Koh (2008b) found increased weed cover and epiphyte presence had positive (though small) impacts on butterflies and birds respectively oil palm plantations in Sabah, Malaysia. However, links to biodiversity alone may not be enough to change a farmers management practices, rather relating these management practices to ecosystem services such as increased biocontrol agents as seen in other agricultural systems is crucial.

\section{Landscape context}

Increased heterogeneity in agricultural landscapes through such approaches as maintaining riparian buffers and conserving patches of natural forest and other complex vegetation (e.g. shrub or agroforestry) can highly enhance biodiversity on production lands (Bennett et al 2006; Steckel et al. 2014). A mosaic landscape with different land-use types provides a wide range of resources for local biodiversity. More favourable habitats can act as source habitats from which there is spill-over of individuals into the less favourable agricultural systems (Tscharntke et al. 2012b; Edwards et al. 2014b). Furthermore, increased connectivity between suitable habitat types often results in less fluctuation in population size than for isolated populations (Burel and Baudry 2003; Fraterrigo et al. 2009). As well as increases in overall species richness, more specifically, maintaining natural habitat surrounding agricultural systems can support beneficial species (e.g. natural enemies for pest and disease biocontrol) and therefore help maintain essential ecosystem services (Bianchi et al. 2006; Chaplin-Kramer et al. 2011).

The patch size of an agricultural field or plantation influences the overall effect of the surrounding landscape, due to the decline in effect with increased distance from the edge of the patch . For oil palm plantations this can be very important with large-scale plantations owned by private enterprises being the dominant plantation type in countries such as Malaysia and Indonesia. In these plantations which can be up to 40,000 ha in Indonesia (Lee et al. 2014), the surrounding landscape is unlikely to play a major role in the biodiversity or functions persisting in the majority of the plantation 
due to the low percentage of the total area actually adjacent to other land-uses. However, smallholder plantations are becoming increasingly important, already accounting for more than $40 \%$ of total oil palm land in Indonesia (Lee et al. 2014; Euler et al. 2015). Smallholder plantations are considerably smaller (defined as <50 ha, on average 2 ha, Vermeulen and Goad 2006) than large-scale plantations are often part of multifunctional landscapes with other agriculture (e.g. rubber and jungle rubber) and nonagricultural systems (e.g shrub and secondary forest) in the immediate surroundings. Therefore it is possible there is potential for the enhancement of biodiversity and ecosystem functions in these smallholder plantations through maintenance of a heterogeneous landscape (Koh 2008b; Lucey and Hill 2012).

\subsection{The role of ants in ecosystems}

In many terrestrial ecosystems ants dominate the biomass and play an important role in ecosystem functioning (Lach et al. 2010). Furthermore, unlike many other animal groups, although community composition and evenness is altered, ants often maintain or even sometimes increase biomass and species richness in agricultural systems and therefore retain a key role in the ecosystems (Folgarait 1998; Pfeiffer et al. 2008). Ants can be omnivores, herbivores and opportunistic feeders, but also, many are specialist or generalist invertebrate predators (Hölldobler and Wilson 1994). Ants also influence animal food webs due to their sheer voracity, mutualisms with other animals and plants, existence as prolific food source and their dominance altering species interactions (Folgarait 1998; Gaume et al. 1998; Lach et al. 2010). Ants are important for a number of ecosystem services that are crucial in agriculture systems such as predation (biocontrol), soil aeration and nutrient cycling (Folgarait 1998; Vandermeer et al. 2002). Furthermore, a number of previous studies have shown that ants can affect crop yield (Bharti and Silla 2011; Pierre and Idris 2013; Wielgoss et al. 2014). For example, Wielgoss et al (2014) found that ant exclusion from cacao trees decreased yield by $27 \%$, and Bharti and Silla (2011) found that the average yield per mango tree was $12 \mathrm{~kg}$ more from trees with weaver ant (Oecophylla smaragdina) nests than without.

\subsection{Project framework (EFForTs)}

The research in this thesis was conducted within the framework of the DFG funded Collaborative Research Centre 990 (CRC 990), entitled Ecological and Socioeconomic Functions of Tropical Lowland Rainforest Transformation Systems (EEFForTs). EEFForTs is a long-term interdisciplinary project including the University of Göttingen and three Indonesian Universities (Tadulako University, Bogor Agricultural University and University of Jambi) that investigates the effects of land-use change on environmental processes, biodiversity and human dimensions. It aims to provide science-based knowledge on how to protect and enhance the ecological functions of tropical forests and agricultural systems at a landscape scale, while improving human welfare. 
The EEFForTs project sites are located in Jambi Province, Sumatra Indonesia within two main research regions, Bukit Duabelas and Harapan in the Sarolangun and Batanghari regencies respectively. To determine the consequences of land-use change four land-use systems important in the study area were chosen to be the focus of the study; lowland rainforest, jungle rubber, rubber and oil palm (Figure 1.1). The project consists of 26 subprojects investigating a very broad range of environmental and social factors, including belowground and aboveground plant, animal and microbial taxonomic and functional diversity, water use, soil fertility, greenhouse gas fluxes, and social, economic and political issues. Although the majority of the work within this thesis is embedded within the subproject "B09: Aboveground patterns of biodiversity and associated ecosystem processes across tropical rainforest transformations", the broad range of subprojects and research provides an excellent opportunity for interdisciplinary studies (e.g. Chapter 3; Chapter 6; Clough et al., in revision; Toledo-Hernández et al., in revision).

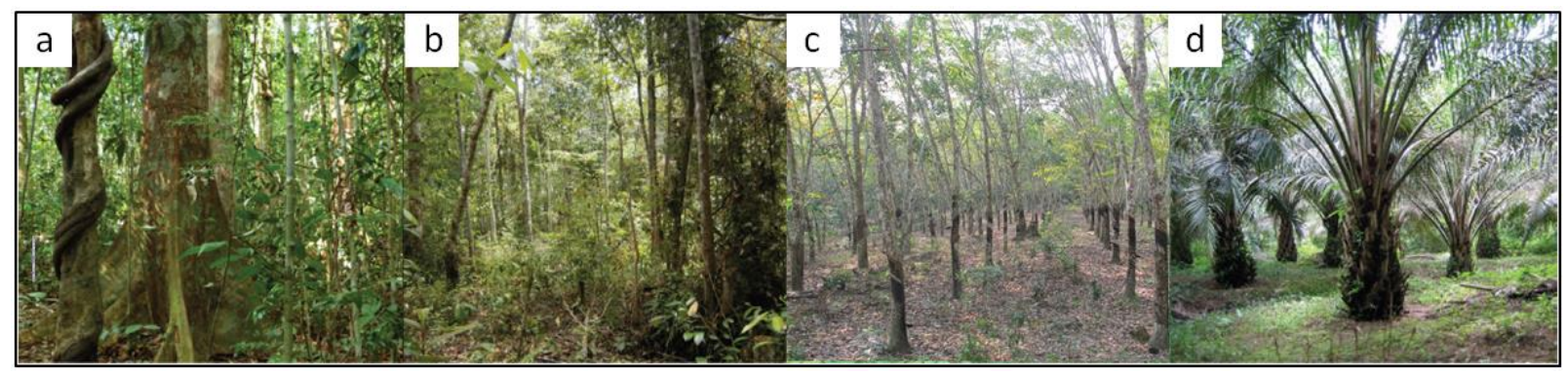

Figure 1.1. The four land-use systems included in the EEFForTs project; (a) forest, (b) jungle rubber, (c) rubber plantation and (d) oil palm plantation.

\subsection{Thesis objectives}

The overall aim of this thesis is to understand the response of ant diversity and function to land-use change from forest to three important agricultural systems in Sumatra, Indonesia; jungle rubber, rubber and oil palm. However, due to the increasing dominance of oil palm in Indonesia and elsewhere the need for research in this major crop is a priority and therefore, although three of the chapters will investigate all four land-uses (Chapters two, three and six), the other three chapters will investigate oil palm plantations solely (Chapters four, five and seven). Furthermore, due to the interdisciplinary nature of the EEFforTs project, I was able to work with colleagues researching other taxonomic groups for three of the chapters (Chapter three, six and seven) which allowed more extensive research into the topics covered. To investigate the overall aim of this thesis I will investigate three main objectives, each of which with two research chapters:

\section{Understand ant taxonomic and functional diversity responses to land-use change}

Chapter 2: Agricultural land use alters species composition but not species richness of ant communities

In Chapter 2 I aimed to understand the effects of land-use change on ant communities. More specifically, this initial study looked at the species richness, community composition and dominance 
patterns of ant communities in our four study land-use systems, forest, jungle rubber, rubber and oil palm.

Chapter 3: Single- and multi-trait measures reveal widespread functional diversity loss in humanmodified tropical landscapes

To take the ant community composition analysis a step further, in Chapter 3 I aimed to understand the effects of land-use change on ant functional diversity. More specifically we quantified functional diversity and single- and multi-trait functional indices for ants and two other animal groups (leaf-litter invertebrates and birds) in our four study land-use systems.

\section{Investigate the response of ant communities and associated functions to landscape context and local management in oil palm plantations}

Chapter 4: Local and landscape drivers of arthropod diversity and decomposition processes in oil palm leaf axils

In the first two chapters I established the taxonomic and functional changes in ant communities with conversion from forest to oil palm, in Chapter 4 we aim to determine if landscape context and local management can alter the ant communities or associated ecosystem functions that are retained in oil palm plantations. More specifically we surveyed ants and other arthropods and measured decomposition rates in oil palm leaf axils to assess their response to the epiphyte communities on the oil palms and the vegetation surrounding the oil palm plantations.

Chapter 5: Landscape context affects insect biocontrol in oil palm plantations

To build on the previous chapter and gain an understanding of a key ecosystem function in agricultural systems, in Chapter 5 I aimed to determine the effect of landscape context on insect biocontrol in oil palm plantations. More specifically we determined predation rates (with a focus on ants and Orthoptera as the predators) in oil palm plantations with differing vegetation in the surrounding borders.

\section{Examine the role of ant communities in shaping arthropod communities and associated ecosystem functions and services}

Chapter 6: Effects of ant exclusion on above- and belowground invertebrate communities and associated ecosystem processes across land-use systems

Also following on from the first two chapters and the establishment of changes in ant communities between the four land-use systems, in Chapter 6, I aim to determine if the relative effect of ants on above- and below-ground arthropods and associated ecosystem functions changes as well between the different land-use systems. More specifically, I established ant suppression and control plots in our four study systems and sampled arthropod communities, soil, litter and vegetation and measured decomposition rates in experimental plots.

Chapter 7: The role of ants, birds and bats in oil palm plantations 
Finally, to look more closely at the influence ant communities and two other major predator groups have in these agricultural landscapes, in Chapter 7 I aimed to determine the role of ants, birds and bats for arthropod communities, ecosystem functions and yield in oil palm plantations. More specifically, we established a large-scale full factorial ant and flying vertebrate exclusion experiment in young oil palm plantations and surveyed arthropods, four ecosystem functions (decomposition, herbivory, pollination and predation) and yield at the sites. 


\title{
Chapter 2
}

\section{Agricultural land use alters species composition but not species richness of ant communities}

\author{
Ratna Rubiana, Akhmad Rizali, Lisa H. Denmead, Winda Alamasari, Purnama Hidayat, Pudjianto, \\ Dadan Hindayana, Yann Clough, Teja Tscharntke, Damayanti Buchori
}

Asian Myrmecology, 2015, Vol. 7, p. 73 - 85

\begin{abstract}
Land-use change causes undesirable effects such as biodiversity decline, altered community structure and reduced ecosystem services. Changes in species composition and disrupted trophic interactions between pests and their natural enemies may also result causing decreased ecosystem services. We studied the effects of forest habitat transformation on the community structure of ants, which include major biological control agents. We focused on four types of land use around Harapan Forest (Harapan) and Bukit Duabelas National Park (BDNP), Jambi, Sumatra, Indonesia: forest, jungle rubber, rubber plantations and oil palm plantations. Four replicate patches of each land-use type were sampled, with plot sizes of $50 \times 50 \mathrm{~m}$ at each of the 32 sites. Ants were collected by hand in combination with tuna and sugar baiting on three strata i.e. leaf litter, soil and tree. We found 104 ant species in total. Surprisingly, ant species richness per plot was not significantly different among land-use types, both in Harapan and BDNP. However, few ant species were shared among different land-use types. Forest and jungle rubber communities are relatively similar to each other (but still different), and distinct from communities in oil palm and rubber plantations. We conclude that conversion of remnant forested habitats to plantations would result in a net loss of ant species, even though ant species richness in plantations and forested habitats are similar.
\end{abstract}




\subsection{Introduction}

Habitat transformation is an unfortunate consequence of human population increase. Natural habitats ever-growing are being altered by anthropogenic activities (Morris 2010). Habitat transformation degrades natural habitats and interferes with the resources necessary for the survival of many organisms (Pringle 2007). When their habitat is destroyed, plants and animals that had occupied the habitat are often displaced or destroyed, thus reducing biodiversity and enhancing the likelihood of extinction (Swift et al. 2004). Therefore, habitat transformation is one of the major causes of biodiversity decline along with climate change, nitrogen deposition and increased atmospheric $\mathrm{CO}_{2}$ concentration (Sala et al. 2000).

Biodiversity is important in regulating and sustaining the direct and indirect contributions of ecosystems to human (ecosystem services) (Alberti 2005). The reduction of species richness often causes decreases in ecosystem services (Naeem et al. 1999). In agricultural production systems, insects provide ecosystem services such as pest control, pollination, and soil fertility (Power 2010). Decreasing the number of species in economically important functional groups may lead to increased pest density, reduced pollinator and natural enemies services (Tscharntke et al. 2012a). Ants (Hymenoptera: Formicidae) provide important ecosystem services including biological pest control, seed dispersal, and soil modification (Hill and Hoy 2003; Gammans et al. 2005; Lach et al. 2010; Philpott et al. 2010). However, ants are sensitive to changes in their environment including changes in dominant vegetation structure, food availability, and nesting resources (Andersen 2000). The changes of vegetation structure resulting from forest transformation usually experience changes in ant community structure (Nakamura et al. 2007). Habitat transformation may severely impact the abundance, community structure, and interaction 14ehaviour of ants toward each other and other organisms (e.g. avoidance of predators and parasitism) (Kaspari et al. 2003). Due to the benefits of ants for ecosystem services (Wielgoss et al. 2014), as well as their sensitivity to change, they are an ideal focus group to investigate the impacts of habitat transformation.

Here, we compare ant communities in remnant forested habitats of Jambi province, Sumatra, with those found in several common agricultural land-use types: rubber agroforests with diverse vegetation (jungle rubber), monoculture rubber and oil palm plantations. The objectives of this research were to (1) compare the diversity of ants in the different types of land use, (2) compare the species composition and community structure across the different habitat types, and (3) investigate changes in ant dominance patterns resulting from transformation of their habitat.

\subsection{Materials and methods}

\section{Study sites}

Fieldwork was conducted in the tropical lowland rainforest in Jambi Province in southwest Sumatra, Indonesia (Fig. 2.1). Two sites were chosen for this research: Bukit Duabelas National Park (BDNP) and Harapan Forest (Harapan). The habitat transformation systems investigated consisted of lowland rainforest, jungle rubber (extensively managed rubber plantations, which have been logged at 
least once, but usually more often), and intensive rubber and oil palm plantations. In each of the two areas, four sites (plot size 50 x $50 \mathrm{~m}$ ) in each type of land use were established, for a total of 32 study plots. Each plot had five sub-plots $(5 \times 5 \mathrm{~m})$ defined for sample collection. Subplot location was determined randomly, and was reassigned for every plot.

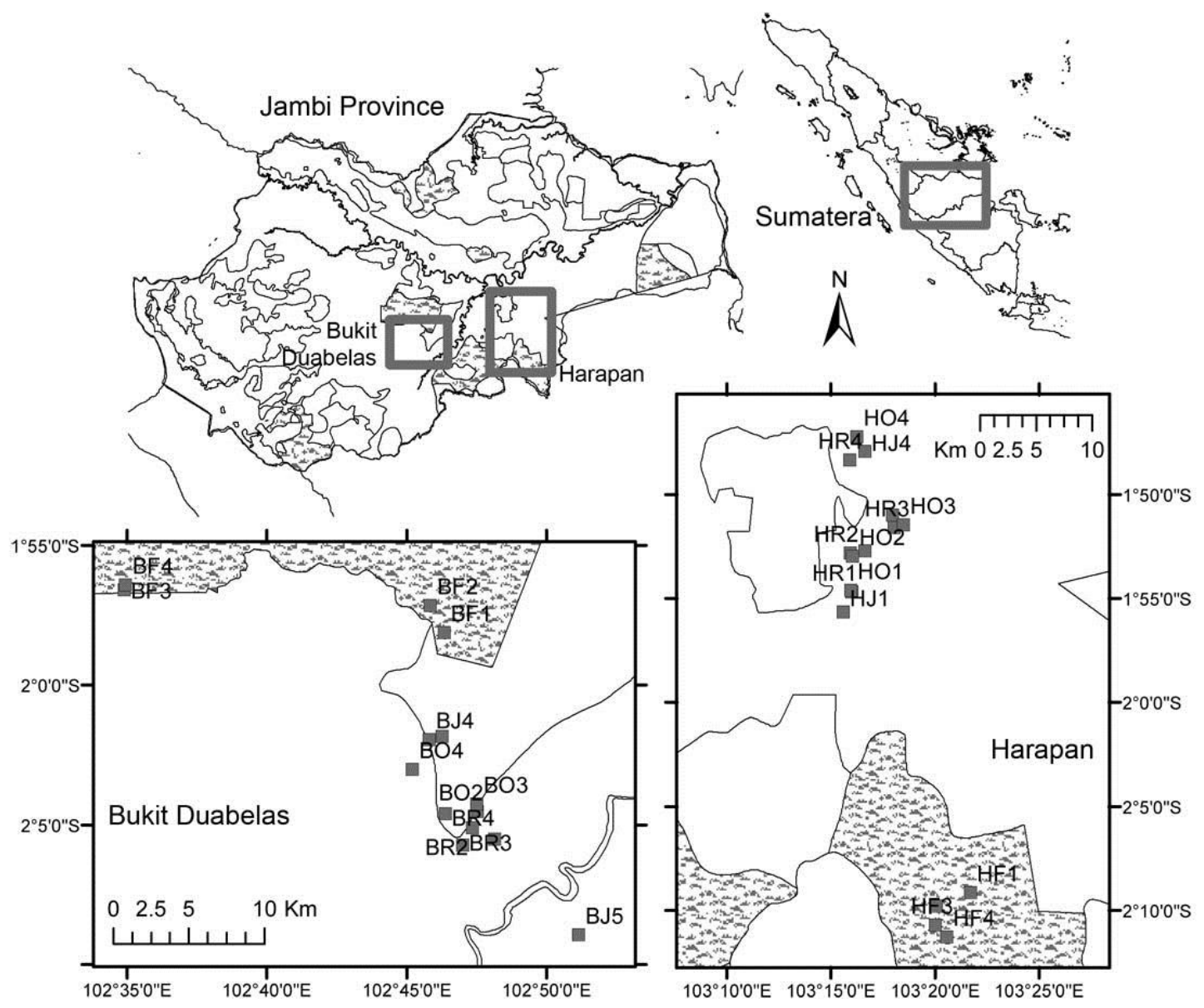

Figure 2.1 Study area in two sites of Bukit Duabelas and Harapan in Jambi Province, Sumatra. Gray colour indicates forest.

\section{Sample collection and identification}

We used both direct sampling and baiting of ants. Direct sampling allowed estimation of the number of ant species per unit area. Direct sampling in each stratum (leaf litter, soil, and tree) lasted 5 $10 \mathrm{~min}$. Leaf litter was separated into coarse and fine litter and ants were taken from the fine litter in the tray. For the soil strata, ants were collected directly from the ground with forceps. Sampling on trees was combined with baiting, using tuna and sugar bait to attract the ants (Bestelmeyer et al. 2000). Sugar water and canned tuna were put in a plastic plate with a diameter of $20 \mathrm{~cm}$ with 4 bait containers with a diameter of $2 \mathrm{~cm}$. Sugar water was absorbed into a foam that was placed in the container. Baits were installed for one hour. Ant sampling was completed between 09.00 and 11.00 am from 22 February to 31 March 2013 and only carried out during sunny weather.

All specimens were stored in $70 \%$ ethanol and were identified to morphospecies using a stereo microscope and an identification guide for Bornean Ants (Hashimoto 2003). 


\section{Data Analysis}

To understand whether ant species richness differed between habitat types, we used an analysis of variance (ANOVA). Ant community structure was compared between different land-use types within each study area based on Bray-Curtis dissimilarity index and further analyzed using non-metric multidimensional scaling (NMDS). Significance tests for differences in community composition between land-use types were performed using the analysis of similarity test (ANOSIM: Clarke 1993). All analyses were performed using R statistic (R Core Team 2014).

\subsection{Results}

A total of 104 ant species were collected, representing six subfamilies and 52 genera (Table 2.1, Table S2.1). Species richness in the BDNP site (86 species) was slightly higher than in Harapan site (81 species). There were no significant differences in ant species richness between land-use types, neither in $\operatorname{BDNP}\left(\right.$ ANOVA, $\mathrm{F}_{3,10}=1.26, \mathrm{P}=0.340$ ) nor in Harapan (ANOVA, $\mathrm{F}_{3,15}=0.37, \mathrm{P}=0.779$ ).

Nevertheless, species accumulation curves show differences in ant species diversity between the different sites and land-use types (Fig. 2.2).

Sites within each land-use type had a higher similarity of ant species composition than sites from different land-use types (Table 2.2). NMDS ordination analysis showed that there were significant differences in ant community structure between land-use types in both, BDNP (ANOSIM, R = 0.737, P = 0.001) and Harapan (ANOSIM, R = 0.652, P = 0.001) sites (Fig. 2.3).

In both, BDNP and Harapan sites, nine ant species were recorded in all habitat types, i.e. forest, jungle rubber, rubber plantations and palm oil plantations (Fig. 2.4). Several ant species dominated the study plots (Fig. 2.5) that are mostly categorized by Brül \& Eltz (2010) as non-forest species and do not normally occur in forest habitats, i.e. Anoplolepis gracilipes (Smith, 1857), Dolichoderus sp. 01 and 02, Odontoponera denticulate (Smith, 1858), Monomorium sp. 02, Technomyrmex sp. 02, Oecophylla smaragdina (Fabricius, 1775), Nylanderia sp. 02, and Crematogaster sp. 01. 
Table 2.1 Ant species richness in four land-use types in Bukit Duabelas National Park (BDNP) and Harapan Forest. The difference of ant species richness between land-use types on each site was tested using ANOVA.

\begin{tabular}{lccccc}
\hline Land-use & Subfamily & Genus & Species & Average & Statistic \\
\hline BDNP & & & & & \\
Primary forest & 5 & 27 & 42 & 17.5 & \\
Jungle rubber & 5 & 22 & 31 & 14.0 & $F_{3,10}=1.26$ \\
Rubber plantation & 5 & 29 & 45 & 21.5 & $P=0.340$ \\
Oil palm plantation & 5 & 27 & 40 & 21.3 & \\
Sub total & 6 & 50 & 86 & 39.5 & \\
Harapan Forest & & & & & \\
Primary forest & 5 & 26 & 42 & 19.3 & \\
Jungle rubber & 5 & 29 & 48 & 19.5 & $F_{3,15}=0.37$ \\
Rubber plantation & 5 & 25 & 45 & 20.5 & $P=0.779$ \\
Oil palm plantation & 5 & 25 & 43 & 17.8 & \\
Sub total & 5 & 38 & 81 & 44.5 & \\
\hline Total & 6 & 52 & 104 & & \\
\hline
\end{tabular}

Table 2.2 Dissimilarity of ant species (Bray-Curtis index) between different land-use types in Bukit Duabelas and Harapan sites. The first letter indicates landscape (B: Bukit Duabelas, H: Harapan) and the second letter indicates the land-use type (F: forest, J: jungle rubber, O: oil palm, R: rubber)

\begin{tabular}{lcccccccc}
\hline Land-use & BF & BJ & BO & BR & HF & HJ & HO & HR \\
\hline BF & 0 & & & & & & & \\
BJ & 0.45 & 0 & & & & & & \\
BO & 0.61 & 0.61 & 0 & & & & & \\
BR & 0.54 & 0.53 & 0.48 & 0 & & & & \\
HF & 0.36 & 0.36 & 0.51 & 0.49 & 0 & & & \\
HJ & 0.52 & 0.53 & 0.53 & 0.47 & 0.45 & 0 & & \\
HO & 0.53 & 0.49 & 0.37 & 0.39 & 0.58 & 0.50 & 0 & \\
HR & 0.56 & 0.47 & 0.43 & 0.27 & 0.42 & 0.44 & 0.30 & 0 \\
\hline
\end{tabular}




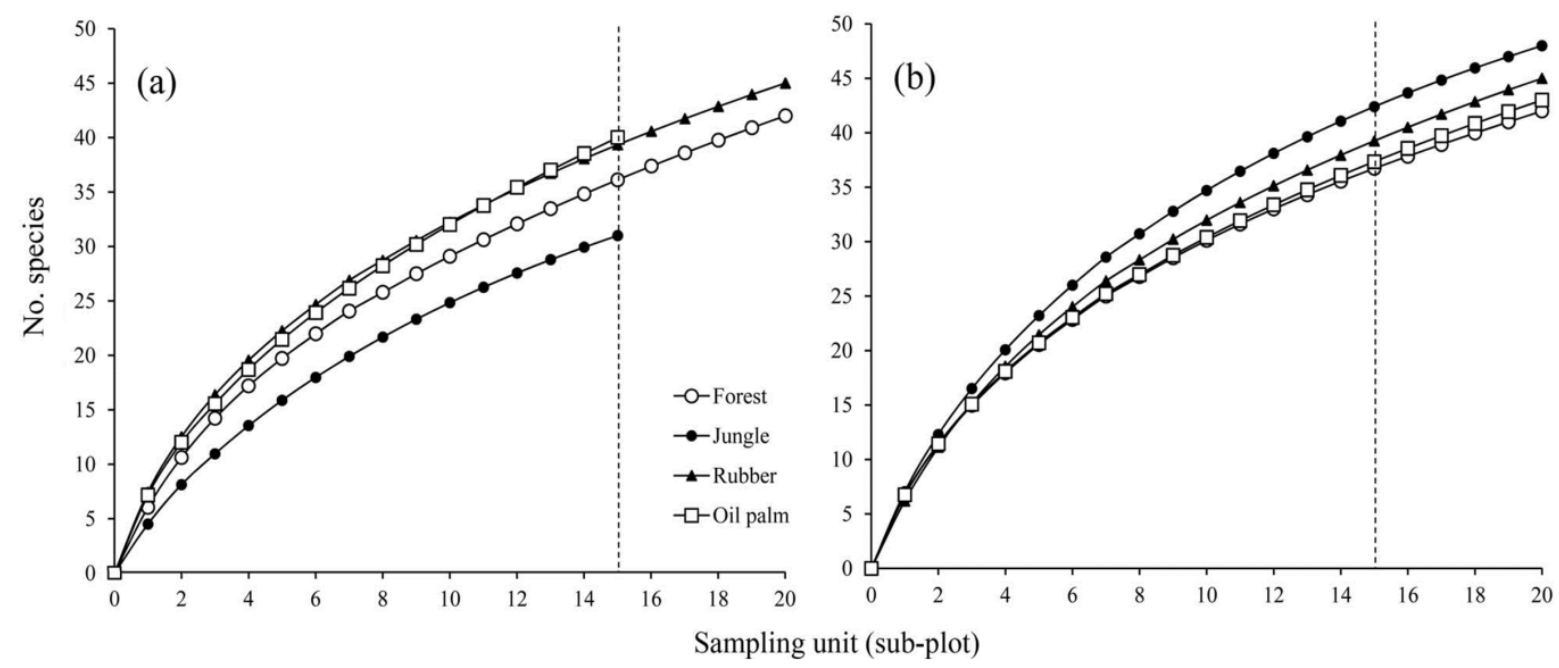

Figure 2.2 Species accumulation curves of ant species found four land use types within the two study sites, (a) Bukit Duabelas National Park and (b) Harapan Forest. The dashed line indicates ant species richness from 15 sub-plots.

(a)

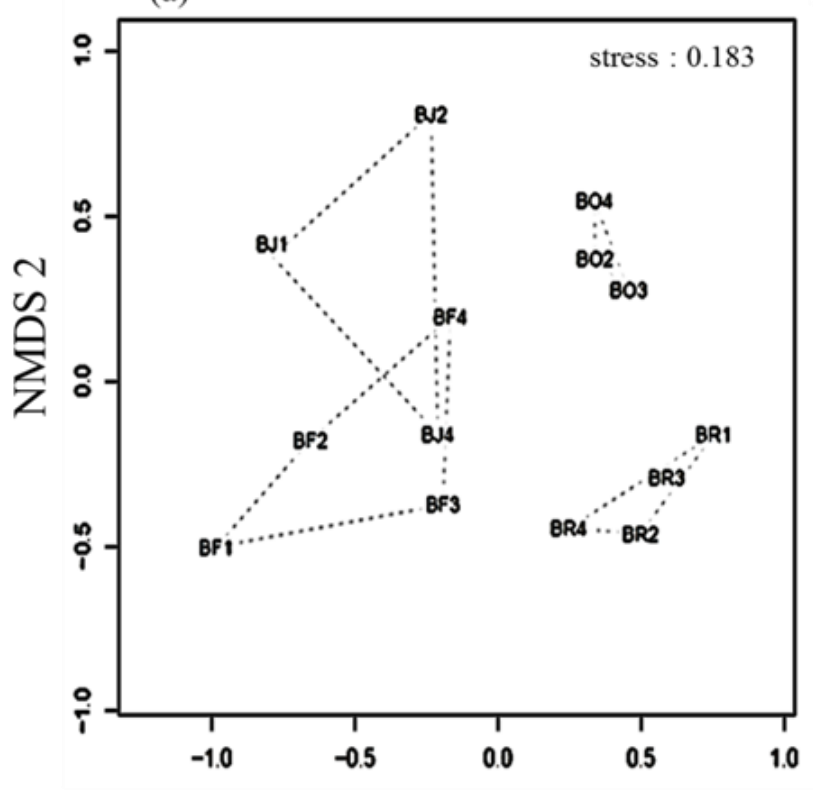

(b)



Figure 2.3 Variation in ant community structure between study sites in the two study areas (a) BDNP and (b) Harapan, in non-metric multidimensional scaling (NMDS) ordination (based on abundance data and a Bray-Curtis distance metric). Forest sites are denoted by an F as the second letter, Jungle Rubber sites with J, Rubber sites with R and Oil Palm sites by an O. Stress values are given for a 2 dimensional NMDS. 
(a)

Crematogaster sp. 03

Odontomachus sp. 01

Technomyrmex sp. 01

Tapinoma sp. 01

Aphaenogaster sp. 01

Tetramorium sp. 01

Camponotus sp. 02

Crematogaster sp. 04

Polyrhachis sp. 02

(b)

Tapinoma sp. 01

Tetramorium sp. 01

Crematogaster sp. 03

Pheidole sp. 04

Odontomachus sp. 01

Crematogaster sp. 04

Technomyrmex sp. 01

Nylanderia sp. 07

Polyrhachis sp. 01
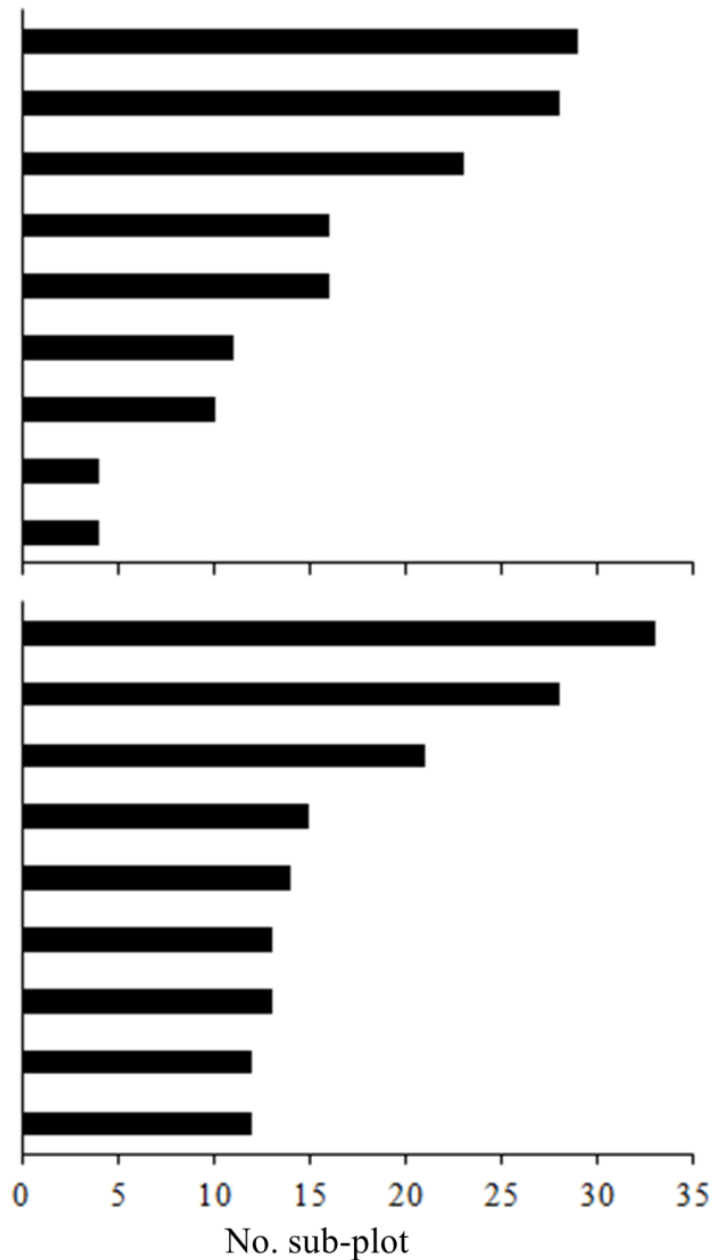

Figure 2.4 Common ant species recorded from all land use types in (a) Bukit Duabelas and (b) Harapan area.

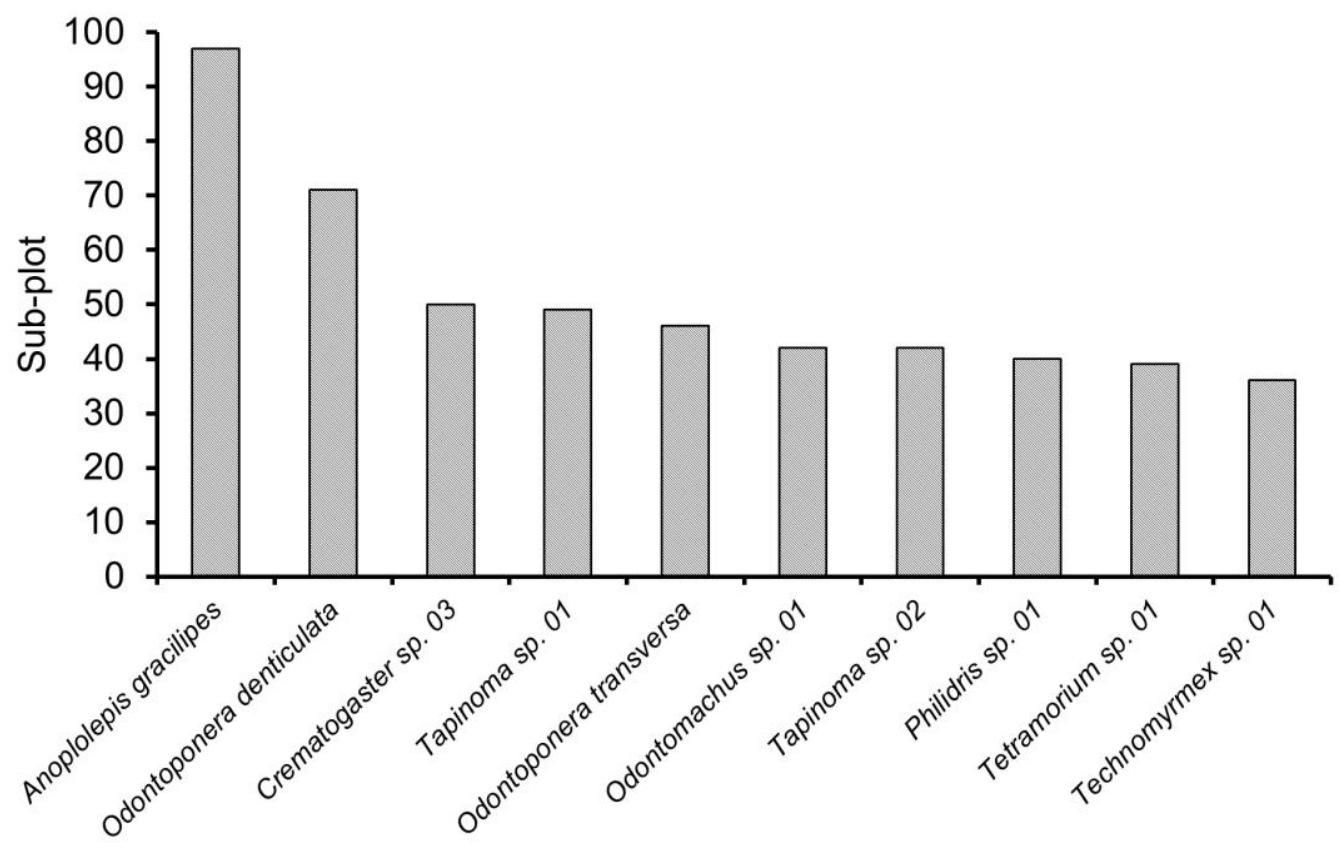

Figure 2.5 The most abundant ant species based on number of subplots collected from Bukit Duabelas and Harapan sites. 


\subsection{Discussion}

Transformation of near-primary forests to agroforests and plantations is often accompanied by drastic changes in biodiversity. Against our expectation, species richness did not differ significantly between the forest, jungle rubber, rubber and oil palm sites. However, species composition differed strongly between land-use types. Ant communities in rubber and oil palm plantations, both in the BDNP and Harapan sites, could be clearly distinguished from forest and jungle rubber communities. Forest and jungle rubber sites were more similar, even partly overlapping in one of the two areas studied.

The absence of significant differences in ant species richness between forests and agricultural land-uses could be due to the fact that the remaining dry lowland forests in the region are not primary but secondary forests. Similarly, most forests that were transformed into palm oil plantations were not primary but secondary forest (as the forest plots in our project area are), which had previously been used for logging, or as agroforests (Koh and Wilcove 2008), so that the ant species pool may already be eroded at the regional level by past land-use changes. However, as we discuss below, our results suggest that a fairly large number of common and generalist ant species, tolerant of, or specialized to, open land and monoculture plantations, inhabit the man-made habitats.

In contrast to species richness, ant community structure greatly differed between all land use types, with differences most evident between forests and agroforests on one hand, and the monoculture plantations on the other. The direct effects of the present habitat, such as differences in available resources (food, shelter, potential nesting sites), environmental conditions (temperature, light), the open land phase of establishment of monocultures, and indirect effects mediated by a shift towards dominant, invasive species are likely to explain these patterns. Ant communities in BDNP oil palm plantations showed high similarities among plots compared to other habitats including oil palm in Harapan, which may be due to the homogeneous understory vegetation in oil palm plantations in the BDNP site.

The species of ants found in all four land-use types can be characterized as generalists, and are probably species that originate from primary forest and tolerate the transformation to plantations (Perfecto and Vandermeer 2006). Species in the genera Crematogaster and Pheidole were present in all four land-use types and are often generalist species. The subfamily Myrmicinae, in which the majority of ants species collected are included, harbours many common ant species that are widespread in warmer habitats, and includes more than 900 described species worldwide (Eguchi et al. 2006). There is often competition between these generalist species and species of the Dolichoderinae subfamily (Andersen 2000), represented here for example by ants of the genera Tapinoma and Technomyrmex, that are also present in the four land-use types studied here. Ant species that were dominant in oil palm and rubber plantation are generally tramp species, i.e. species that benefit from habitat degradation and human association (McGlynn 1999). These include species of the genus Pheidole and Tetramorium that are found in this study, which can be invasive (Schultz and McGlynn 2000).

One of the species that is present in three types of agricultural land use (jungle rubber, oil palm and rubber plantations) but not the forest is A. gracilipes. This species is well-known as invasive species 
and thrives in disturbed areas, but not forest. Brühl et al. (2003) also found that A. gracilipes is the most common species on $70 \%$ of all baits placed in oil palm plantations in Sabah, Malaysia. A. gracilipes is one of the most invasive species in the Indonesian cocoa plantations and is associated with land-use systems with low tree canopy cover and a small number of forest ant species (Bos et al. 2008).

Overall, the most dominant ant species are invasive non-forest ants such as A. gracilipes and Odontoponera denticulata. In oil palm and rubber plantations, $O$. denticulata replaced a species of the same genus found in forest and jungle rubber, Odontoponera transversa, These two related species can be used as bio-indicators, because they seem to have different adaptability and different habit preferences, as already suggested by a previous study, in which $O$. denticulata were only found in urban areas, while $O$. transversa were found only in relatively intact forests (Rizali et al. 2008).

Forest ant species in the genera Cataulacus, Tetraponera and Polyrhachis were not commonly found in any of the plots, not even regularly in the forest. This could be because it is more difficult to sample the complete ant fauna in a forest because of its high microhabitat heterogeneity. Tapinoma sp. 01 is abundant and very active in Harapan site. When Tapinoma sp. 01 is abundant, other ant species were unlikely to be present, even physically large ant species such as Camponotus gigas and Polyrhachis spp.. In habitats where dolichoderine species were not found, we found many individuals of small species such as Monomorium and large species such as Oecophylla and Tetraponera, suggesting that dolichoderines outcompete species from other subfamilies.

To conclude, the conversion of forested habitat results in severe changes in ant communities. While our study suggests this needs not be accompanied by a decrease in species richness, the identity of the species, the abundance of tramp and invasive ants, and the dominance patterns are different in agricultural habitats. The functional consequences are not clear, but in terms of large-scale biodiversity, our results suggests that any further losses of forest habitat, including conversion to jungle rubber, would result in a decrease in regional biological diversity, as those species dependent on forested habitats cannot persist in monoculture plantations.

\section{Acknowledgements}

This research was funded by Deutsche Forschungsgemeinschaft Germany (DFG) through a Collaborative Research Centre (CRC 990 - EFForTS) - Ecological and Socioeconomic Functions of Tropical Lowland Rainforest Transformation Systems. We would like to thank the field assistants and the administration staff of CRC 990 Jambi Office. We are grateful David Lohman and a further anonymous reviewer for their comments on our manuscript. 


\subsection{Supplementary material}

Table S2.1. Ant species sampled in different land-use regimes from Harapan Forest and Bukit Duabelas National Park (+ means present). ${ }^{\mathrm{a}} \mathrm{F}=$ Forest, $\mathrm{J}=$ Jungle Rubber, $\mathrm{R}=$ Rubber plantation, $\mathrm{O}=$ Oil palm plantation.

\begin{tabular}{|c|c|c|c|c|c|c|c|c|c|}
\hline \multirow{3}{*}{ No } & \multirow{3}{*}{$\begin{array}{l}\text { Subfamily } \\
\text { Species }\end{array}$} & \multicolumn{4}{|c|}{ Harapan Forest } & \multicolumn{4}{|c|}{ Bukit Duabelas N.P } \\
\hline & & \multicolumn{4}{|c|}{ Land-use $^{\mathrm{a}}$} & \multicolumn{4}{|c|}{ Land-use $^{\mathrm{a}}$} \\
\hline & & $\mathrm{F}$ & $\mathrm{J}$ & $\mathrm{R}$ & $\mathrm{O}$ & $\mathrm{F}$ & $\mathrm{J}$ & $\mathrm{R}$ & $\mathrm{O}$ \\
\hline \multicolumn{10}{|c|}{ Dolichoderinae (Forel, 1878) } \\
\hline 1 & Dolichoderus sp. 01 & + & + & + & & & & & \\
\hline 2 & Dolichoderus sp. 02 & + & & + & + & & & & \\
\hline 3 & Iridomyrmex sp. 01 & + & & & & & & & \\
\hline 4 & Loweriella sp. 01 & + & + & & & & & + & \\
\hline 5 & Philidris sp. 01 & + & + & + & & + & + & + & \\
\hline 6 & Philidris sp. 03 & & + & & & & & & \\
\hline 7 & Philidris sp. 06 & + & & & & & & & \\
\hline 8 & Tapinoma sp. 01 & + & + & + & + & + & + & + & + \\
\hline 9 & Tapinoma sp. 02 & & + & + & + & + & & + & + \\
\hline 10 & Tapinoma sp. 03 & & + & + & + & & & & \\
\hline 11 & Tapinoma sp. 04 & & + & + & & & & & \\
\hline 12 & Tapinoma sp. 05 & + & & & & & & & \\
\hline 13 & Technomyrmex sp. 01 & + & + & + & + & + & + & + & + \\
\hline 14 & Technomyrmex sp. 02 & & & & & & + & + & \\
\hline 15 & Technomyrmex sp. 03 & & + & + & & & & & \\
\hline
\end{tabular}

Dorylinae (Leach, 1815)

16 Dorylus sp. 01

17 Dorylus sp.02

Formicinae (Latreille, 1809)

18 Acropyga sp. 01

19 Anoplolepis gracilipes (Smith, 1857)

20 Camponotus gigas (Latreille, 1802)

21 Camponotus sp. 02

22 Camponotus sp. 03

23 Camponotus sp. 05

$24 \quad$ Camponotus sp. 07

25 Camponotus sp. 08

26 Echinopla sp. 01

$27 \quad$ Echinopla sp. 02

$28 \quad$ Nylanderia sp. 01

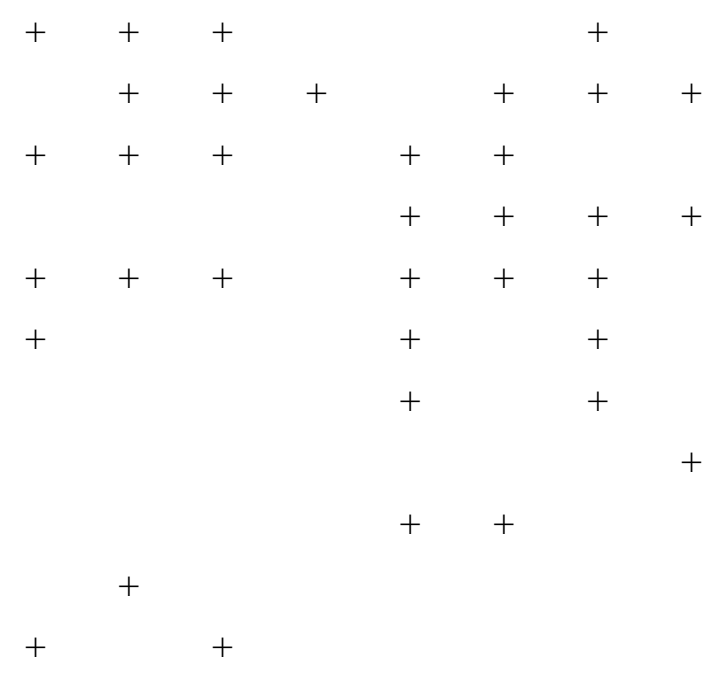




\begin{tabular}{|c|c|c|c|c|c|c|c|c|c|}
\hline \multirow{3}{*}{ No } & \multirow{3}{*}{$\begin{array}{l}\text { Subfamily } \\
\text { Species }\end{array}$} & \multicolumn{4}{|c|}{ Harapan Forest } & \multicolumn{4}{|c|}{ Bukit Duabelas N.P } \\
\hline & & \multicolumn{4}{|c|}{ Land-use $^{\mathrm{a}}$} & \multicolumn{4}{|c|}{ Land-use $^{\mathrm{a}}$} \\
\hline & & $\mathrm{F}$ & $\mathrm{J}$ & $\mathrm{R}$ & $\mathrm{O}$ & $\mathrm{F}$ & $\mathbf{J}$ & $\mathrm{R}$ & $\mathrm{O}$ \\
\hline 29 & Nylanderia sp. 02 & & & & & & & & \\
\hline 30 & Nylanderia sp. 03 & + & & + & + & & & & \\
\hline 31 & Nylanderia sp. 04 & + & & & & & & & \\
\hline 32 & Nylanderia sp. 05 & & & + & & & & + & \\
\hline 33 & Nylanderia sp. 07 & + & + & + & + & & & & \\
\hline 34 & Nylanderia sp. 08 & & + & & & & & & \\
\hline 35 & $\begin{array}{l}\text { Oecophylla smaragdina (Fabricius, } \\
1775)\end{array}$ & & & + & + & & & & \\
\hline 36 & $\begin{array}{l}\text { Paratrechina longicornis (Latreille, } \\
\text { 1802) }\end{array}$ & & + & & & & & & \\
\hline 37 & Plagiolepis sp. 01 & + & + & + & + & & & + & \\
\hline 38 & Polyrhachis sp. 01 & & & & & + & & + & + \\
\hline 39 & Polyrhachis sp. 02 & + & & + & + & + & + & + & + \\
\hline 40 & Polyrhachis sp. 04 & + & & + & + & & + & & + \\
\hline 41 & Polyrhachis sp. 05 & + & + & & & + & & & \\
\hline 42 & Polyrhachis sp. 06 & & & & & & & & + \\
\hline & Myrmicinae & & & & & & & & \\
\hline 43 & Acanthomyrmex sp. 01 & + & + & & & & & & \\
\hline 44 & Acanthomyrmex sp. 02 & + & & & & & & & \\
\hline 45 & Acanthomyrmex sp. 03 & & & & & + & & & \\
\hline 46 & Aphaenogaster sp. 01 & + & + & & + & + & + & + & + \\
\hline 47 & Calyptomyrmex sp. 01 & & & & & & & & + \\
\hline 48 & Cardiocondyla sp. 01 & & + & + & + & & + & + & \\
\hline 49 & Cardiocondyla sp. 02 & & & + & + & & & & \\
\hline 50 & Cataulacus sp. 01 & + & + & & & & + & & \\
\hline 51 & Crematogaster sp. 01 & & & & & + & & & \\
\hline 52 & Crematogaster sp. 02 & + & & + & + & & + & + & + \\
\hline 53 & Crematogaster sp. 03 & + & + & + & + & + & + & + & + \\
\hline 54 & Crematogaster sp. 04 & + & + & + & + & + & + & + & + \\
\hline 55 & Crematogaster sp. 05 & & + & & & & & & \\
\hline 56 & Crematogaster sp. 14 & & + & & & & & & \\
\hline 57 & Lophomyrmex sp. 01 & & & + & + & & & + & \\
\hline 58 & Lophomyrmex sp. 02 & + & & + & + & & & & \\
\hline 59 & Lordomyrma sp. 01 & & & + & & & & & \\
\hline 60 & Lordomyrma sp. 02 & & & + & & & & & \\
\hline 61 & Lordomyrma sp. 03 & & & + & & & & & + \\
\hline 62 & Meranoplus sp. 01 & + & & & & + & & & \\
\hline
\end{tabular}









\begin{tabular}{|c|c|c|c|c|c|c|c|c|c|}
\hline \multirow{3}{*}{ No } & \multirow{3}{*}{$\begin{array}{l}\text { Subfamily } \\
\text { Species }\end{array}$} & \multicolumn{4}{|c|}{ Harapan Forest } & \multicolumn{4}{|c|}{ Bukit Duabelas N.P } \\
\hline & & \multicolumn{4}{|c|}{ Land-use $^{\mathrm{a}}$} & \multicolumn{4}{|c|}{ Land-use $^{\mathrm{a}}$} \\
\hline & & $\mathrm{F}$ & $\mathrm{J}$ & $\mathrm{R}$ & $\mathrm{O}$ & $\mathrm{F}$ & $\mathrm{J}$ & $\mathrm{R}$ & $\mathrm{O}$ \\
\hline 97 & $\begin{array}{l}\text { Odontoponera denticulata (Smith, } \\
\text { 1858) }\end{array}$ & & & + & + & & & + & + \\
\hline 98 & $\begin{array}{l}\text { Odontoponera transversa (Smith, } \\
\text { 1857) }\end{array}$ & & & & & + & + & & \\
\hline 99 & Platythyrea sp. 01 & & & & & & + & & \\
\hline 100 & Platythyrea sp. 02 & & & & & & + & & \\
\hline 101 & Ponera sp. 01 & & & + & + & & & + & + \\
\hline 102 & Ponera sp. 02 & & & & + & & & & \\
\hline & Pseudomyrmecinae & & & & & & & & \\
\hline 103 & Tetraponera sp. 01 & + & + & + & & + & + & + & \\
\hline 104 & Tetraponera sp. 03 & & & + & + & & & & \\
\hline
\end{tabular}




\title{
Chapter 3
}

\section{Single- and multi-trait measures reveal widespread functional diversity loss in human-modified tropical landscapes}

\author{
Lisa H. Denmead, Kevin Darras, Yann Clough, Ingo Grass, Andrew D. Barnes, Ulrich Brose, \\ Damayanti Buchori, Malte Jochum, Holger Kreft, Steffen Mumme, Walesa Edho Prabowo, Akhmad \\ Rizali, Teja Tscharntke
}

In review, Ecosphere, submitted: $7^{\text {th }}$ December 2015

\begin{abstract}
In the tropics, land-use transformation from rainforest to monoculture agriculture such as oil palm and rubber plantations is happening at a rapid rate causing considerable species loss. Patterns of species loss with land-use change are comparatively well studied, but this is in contrast to the building evidence that functional diversity, and not species richness per se, is the main driver of ecosystem functioning and stability. To comprehensively investigate the effects of land-use change on species richness and functional diversity, as well as the relationship between the two, we surveyed birds, arboreal ants and leaf-litter invertebrates across 32 lowland rainforest, jungle rubber, monoculture rubber and oil palm plantation sites in Sumatra, Indonesia. We quantified species richness, functional diversity and singleand multi-trait functional indices (community-weighted mean and variance, functional dispersion, functional evenness and functional divergence) for each taxonomic group using feeding guild, dispersal and biomass traits. We found linear relationships between species richness and functional diversity across all taxa, indicating low functional redundancy in these systems. Also, species richness and functional diversity declined from forest to oil palm for birds and leaf-litter invertebrates, with intermediate responses in the rubber systems. Ants however, had higher diversity in oil palm compared with forest and jungle rubber. There were few significant responses to land-use change for multi-trait indices, but noteworthy responses for single-trait indices. In particular, for all taxa species from higher trophic guilds decreased from forest to oil palm. The observed decrease in species richness from rainforest to monoculture plantations across multiple taxa, along with the tightly coupled decreases in functional diversity and low functional redundancy, could threaten long-term ecosystem stability through potential consequences for ecosystem processes. The complementary results from using multiple functional indices emphasizes the need to combine different multi-trait and single-trait measures to better understand the effects of land-use change on communities and associated functions.
\end{abstract}




\subsection{Introduction}

Land-use change due to agricultural expansion is causing considerable species loss worldwide (Foley et al. 2005; Newbold et al. 2015). In tropical regions in particular, conversion of forest and agroforests into monoculture agriculture such as oil palm is happening at an extremely rapid rate, leading to highly simplified landscapes (Fitzherbert et al. 2008). In Indonesia, currently the world's leading palm oil producer, oil palm plantation crop cover was nine million hectares in 2010 with a projected increase to 18 million hectares by 2020 (Koh and Ghazoul 2010). The predicted further large-scale expansion of oil palm plantations and other high-intensity agricultural systems has extensive implications for species loss and subsequent alteration of ecosystem functions and services (Fitzherbert et al. 2008).

Although patterns of species loss with land-use change are relatively well studied (Fitzherbert et al. 2008), it is now widely understood that functional diversity, and not species richness per se, is the main driver of ecosystem functioning and stability (Tilman et al. 1997; Lefcheck and Duffy 2015; Gagic et al. 2015). Functional diversity refers to a component of biodiversity that measures the variation in the functionally relevant traits present in a community (Petchey and Gaston 2006). Trait-based diversity indices provided higher explanatory power than species-based diversity indices (e.g. species richness and Shannon diversity) for predicting seven ecosystem functions' responses in a recent study by Gagic et al. (2015). Also, multifunctionality of ecosystems (rates of multiple processes) was only directly affected by variation in functional diversity measures rather than taxonomic diversity in a grassland biodiversity experiment (Mouillot et al. 2011). Understanding the response of functional diversity to land-use change will be extremely important if we are to fully grasp the long-term consequences on ecosystem functioning (Senior et al. 2013).

Quantifying functional diversity also enables the investigation of the relationship between species richness and functional diversity. Functional diversity and species richness are often correlated (Flynn et al. 2009; Bihn et al. 2010), but the relationship between the two is not necessarily linear. Its shape has important implications for functional redundancy and complementarity (Flynn et al. 2009). For example, species may be lost without an equivalent loss in functional diversity if a number of species have similar traits within the community, indicating functional redundancy and the possibility of community resilience to disturbance. Alternatively, if functionally unique species are lost there could first be a sharp decline in functional diversity with only a small reduction in species richness. For example, species with large body sizes, small geographic ranges and high trophic position are often more sensitive to disturbance and are therefore lost first in disturbed ecosystems with potential serious consequences for the ecosystem functions they perform (Henle et al. 2004; Larsen et al. 2005).

Functional responses can be assessed using indices based on single-traits (e.g. communityweighted mean (CWM), Sonnier et al. 2010) or multiple traits (e.g. functional dispersion, the mean distance of each species trait values to the community trait space centroid, Laliberté and Legendre 2010). Recently, there has been a growing body of research investigating the relative benefit of different functional indices and which best predict ecosystem functioning (e.g. Mouillot et al. 2011; Butterfield 
and Suding 2013; Gagic et al. 2015). However, it is still unclear if single-trait, multi-trait or combinations of both provide the most appropriate or informative data for understanding changes in functional diversity or the consequences of those changes. A number of studies investigating both singletrait and multi-trait functional indices in plants have found that a single-trait index (CWM) better predicts measured ecosystem functions (e.g. Butterfield and Suding 2013). Correspondingly, Gagic et al. (2015) found that, of the reviewed studies that considered both single- and multi-trait indices, $73 \%$ demonstrated certain single-trait indices were better at predicting ecosystem functioning than multi-trait indices.

However, others claim that only considering one type of index is insufficient, and that both are needed to gain a comprehensive understanding of community functional diversity (Gagic et al. 2015).

Although there is an increasing amount of research that investigates both taxonomic and functional diversity in the context of land-use change, studies across multiple taxa and in different landuse systems are still rare (but see Flynn et al. 2009; Senior et al. 2013; Gagic et al. 2015). In the present study, we use community and trait data from arboreal ants, leaf-litter macro-invertebrates and birds to study functional diversity responses to land-use change in Sumatra, Indonesia. We assess four land-use systems important to the study region, lowland rainforest, jungle rubber, rubber and oil palm. To comprehensively assess changes in functional diversity, we estimate the relationships between taxonomic and functional diversity and the responses of multiple single and multi-trait functional indices to land-use change, and compare the relative value of single or multi-trait indices. Understanding functional diversity loss in these systems is important for predicting effects on ecosystem functioning and for understanding the overall consequences of land-use change.

\subsection{Materials and Methods}

\section{Study Area}

Our study was carried out within two lowland regions in the Batanghari and Sarolangun Regencies of Jambi Province, Sumatra, Indonesia at elevations of 40-100 m a.s.l. These regions were adjacent to two protected areas, the Bukit Duabelas National Park and the Harapan Rainforest (Fig. S3.1). This area is typical of lowland Sumatra in that it has undergone extensive selective logging and deforestation, especially over the past 50 years as a result of the increasing expansion of agricultural land (Laumonier et al. 2010). In particular, rubber is the most dominant crop in the province with a land cover of 650,000 ha in 2011 . However, over the past 20 years oil palm has become increasingly dominant, increasing almost 4-fold from 150,000 ha to 550,000 ha in the period from 1996 to 2011 (Gatto et al. 2015).

\section{Study design}

Between October 2012 and August 2014 sampling was conducted across four land-use systems: degraded lowland rainforest, jungle rubber, rubber plantation and oil palm plantation. In the two study regions, each land-use system was replicated four times $(\mathrm{n}=32)$. At each of the 32 study sites, a $50 \mathrm{~m} \mathrm{x}$ $50 \mathrm{~m}$ sampling plot was defined, which included five randomly assigned $5 \mathrm{~m}$ x $5 \mathrm{~m}$ subplots. All sites 
were on little or no slope, had comparable soil and mircoclimate conditions within a region, and the plantations were of similar age. The mean pair-wise distance between sites was $11.5 \mathrm{~km}$ and $18.2 \mathrm{~km}$ for Bukit Duabelas and Harapan regions, respectively). The rainforest sites were within Bukit Duabelas National Park and Harapan Rainforest and, although protected, have been selectively logged in the past. Jungle rubber represents an agroforestry system consisting of degraded forest with rubber trees between the native vegetation and minimal management (e.g. minimal mechanical weeding but typically no fertilizer application). The rubber and oil palm plantations, in contrast, were intensively managed monoculture systems. For a detailed description of the study site management practices see Allen et al. (2015).

\section{Sampling methods and trait determination}

\section{Arboreal ants}

We used plastic observation plates with two baits of $2 \mathrm{~cm}^{3}$ of tuna in oil and two sponges saturated with $70 \%$ sucrose solution attached to sample arboreal ant species (hereafter, "ants") (Wielgoss et al. 2010). One plate was tied at breast height on each of two randomly selected trees in all five subplots at each site (total of 10 trees per site). If there were not two trees in a subplot (often the case in oil palm plantations), the closest trees to the subplot were chosen. At 15, 30, 45 and 60 minutes after placing the plates on the trees, the abundance of each ant species present on the plate (separately for ants feeding on sugar or tuna) was recorded. Specimens were collected from each ant species present where possible without disrupting recruitment. Surveys were conducted at each site four times during the study period (first: October 2012, second: February-March 2013, third: September-October 2013, fourth: February 2014), between 9:00 am and 11:00 am. No sampling was conducted during or immediately after rain due to a reduction in ant activity under wet conditions. All ants collected were identified to genus level (Fayle et al. 2014). We identified specimens to species level where possible and assigned the remainder to morphospecies. Ant abundance per species at a given site was defined as the mean of the maximum number of each species on each plate (at any time measurement) used at a site (over the whole survey). By taking the mean abundance from the maximum at any given time during the surveys we took into account the possibility of competition that could disadvantage subdominant species if only looking at the abundance after 60 minutes.

Three traits were defined for each ant species present: head length (as an indicator of body mass), protein/carbohydrate preference ratio (feeding type) and relative leg length (dispersal) (Bihn et al. 2010). Head and leg length (combined tibia and femur) were measured to the nearest $0.01 \mathrm{~mm}$ on between one and five individuals from each species at each site and a mean was used for analysis. Relative leg length was calculated by dividing by head length. The protein/carbohydrate preference ratio for each species was determined by dividing the total abundance of the species counted at the protein baits (tuna) by the total abundance of the species at both baits (higher ratio indicates increased predator abundance). 


\section{Leaf-litter macro-invertebrates}

In each of three (out of the possible five) randomly chosen subplots at each site we sieved $1 \mathrm{~m}^{2}$ of leaf-litter over a coarse sieve (mesh width of $2 \mathrm{~cm}$ ). Macro-invertebrates were then hand-collected from the sieved litter. Samples were collected in October and November 2012. Specimens were identified to morphospecies based on consistent morphological characteristics.

Three traits were defined for each morphospecies of leaf-litter macro-invertebrate (hereafter, “invertebrates"): body mass, feeding guild and dispersal capacity (Mumme 2014). Body mass was calculated from individual body lengths using length-mass regressions from the literature (for details see Mumme 2014). Each morphospecies was assigned to one of three feeding guilds: primary consumers (herbivores and detritivores), omnivores and predators, based on a combination of literature, taxonomy and morphology. To enable the analysis of categorical traits, each feeding guild was given a score between 0 and 1 for analysis; primary consumers were scored as 0 , omnivores as 0.5 and predators as 1 . Dispersal capacity was assessed by allocating morphospecies into two groups according to whether they were winged (scored as 1 for analysis) or wingless (0).

Birds

Bird data were collected using standardized point counts and passive acoustic monitoring stations. The point counts were completed at the center of each plot and all birds within the plot were observed (using 7 x $40 \mathrm{~mm}$ Nikon Monarch binoculars) and recorded for 20 minutes between 6:00 and 10:00 from June-July 2013. The timing of bird data collection alternated between early and late morning and all plots were visited 3 times (60 min sampling per plot in total). Individuals flying above the canopy were excluded, and unfamiliar bird calls were recorded using a directional microphone (Sennheiser ME66/K6). The recordings were compared with an online bird call database (Xeno-Canto) for confirmation. Bird species identification follows Birdlife International (BirdLife International 2015) (97.4\% of observed birds were identified to species level). Additionally, we recorded sound for 20 minutes after sunset at $44100 \mathrm{~Hz}$ on two channels using sound recorders (SM2+ recorder with 2 SMX-II microphones, Wildlife acoustics ( $)$ ) which were attached to a tree at the center of the plot at 2-2.5m. Eight plots could be sampled simultaneously, so sampling all 32 plots took 4 days (10th and 13th of May for Harapan region, and the 3rd and 7th of June 2013 for Bukit Duabelas). Recordings were uploaded to a website (http://soundefforts.uni-goettingen.de/) where two independent ornithologists tagged all audible bird calls within an estimated $35 \mathrm{~m}$ radius with the corresponding species name. A third ornithologist reviewed all identifications. Bird data from sound recordings and point counts were subsequently merged.

Three traits were defined for each bird species present: body mass, feeding guild and relative wing length (dispersal). Body mass and feeding guild were obtained from Wilman et al. (2014) and wing length data from Robinson \& Chasen (1927). The bird species were assigned to one of three feeding guilds: herbivores (frugivore, nectivore, granivore, scored as 1), omnivores (0.5) and predators (mostly insectivores, 0 ). Relative wing length was calculated by dividing wing length by body mass.

\section{Functional diversity indices}


We calculated functional diversity (FD) in each site for each taxonomic group (community) to directly compare it with species richness (SR) and determine the relationship between the two (Flynn et al. 2009). FD is a dendrogram-based index calculated as the total branch length of the community functional dendrogram following Petchey \& Gaston (2002). FD is one of the most commonly used traitbased measures of functional diversity and, as suggested by Flynn et al. (2009), can be related to species richness to assess the functional redundancy within a system (Flynn et al. 2009; Brown et al. 2011). FD calculations were computed based on presence/absence data and standardized trait values in R 3.2.0 ( $\mathrm{R}$ Core Team 2015).

To compare community trait composition across land-use systems, we calculated three multi-trait functional indices that are based on how species are distributed within a multi-dimensional functional trait space (trait-space based indices): functional evenness (FEve), functional divergence (FDiv) and functional dispersion (FDis) (Villéger et al. 2008; Laliberté and Legendre 2010). FEve measures the evenness of abundance distributions within the total trait space. FDiv describes the proportion of the total abundance that includes species with extreme traits. Finally, FDis is the abundance-weighted mean distance of each species trait values to the community trait space centroid. We calculated the three indices with abundance data and standardized trait values using the dbFD function in the FD package in R 3.2.0 (Laliberté and Legendre 2010; Laliberté and Shipley 2014; R Core Team 2015).

To determine if important functional responses are lost when combining traits into multitrait indices of functional diversity, we also calculated two single-trait indices for each trait studied; community weighted mean (CWM) and community weighted variance (CWV) (Sonnier et al. 2010; Butterfield and Suding 2013). CWM is the abundance-weighted mean trait values for a community, whereas CWV is the variability of the trait values around the mean community value.

\section{Statistical analysis}

\section{Relationship between species richness and functional diversity}

Under the assumption that land-use system is driving both SR and FD, we tested for differences between the SR and FD response to land-use system (and therefore a presumed non-linear relationship between the two) by directly testing for the presence of an interaction between the type of diversity measure used (SR or FD) and land-use system. For each taxonomic group, we therefore compared two linear mixed-effects models (LMEs) (fitted by maximum likelihood) testing for the effect of land-use system on diversity (including both diversity types in the data); one with diversity type included as a predictor with an interaction term, and one without. Study site nested within region was included as a random effect in both models. The statistical notation of the models thus read as

(1) Diversity $\sim$ land-use type $\times$ diversity type + random $=\sim 1$ region/site

(2) Diversity $\sim$ land-use type + random $=\sim 1 \mid$ region/site

where diversity is the standardized SR and FD values and diversity type is either SR or FD. If $\triangle \mathrm{AICc} \geq$ 2, the model with the lowest AICc (small sample size corrected Akaike information criterion's scores) 
was considered the best supported model. We also considered Akaike weight when determining the best supported model. If the best supported model did not include the interaction term then a linear relationship between species richness and functional diversity was assumed. The best-fit model, refitted using restricted maximum likelihood, was then used to determine the effect of land-use system on overall diversity (both SR and FD). Tukey post-hoc tests with Bonferroni correction were used to test for significant differences among the systems. Apart from FD, FDis has also been used to investigate relationships between species richness and functional diversity (Luck et al. 2013; Grass et al. 2014a). To corroborate our findings based on FD, we also tested for differences between SR and FDis responses to land-use system, using the same modelling framework as with FD. LMEs, AICc score calculations and post-hoc tests were conducted using the nlme (Pinheiro et al. 2015), AICcmodavg (Mazerolle 2015) and multcomp (Hothorn et al. 2008) packages in R 3.2.0 (R Core Team 2015).

Responses of functional diversity indices to land-use change

We used LMEs to determine the effect of land-use system on FEve, FDiv, FDis, CWM and $\mathrm{CWV}$, with region specified as a random effect. When LMEs contained a significant effect of land-use system on the response variable, we performed a Tukey post-hoc test (with Bonferroni correction) to test for significant pair-wise differences among land-use systems. To meet assumptions of normality all biomass CWM and CWV values were log transformed prior to analysis.

\subsection{Results}

\section{Relationships between taxonomic and functional diversity}

For all taxonomic groups (ants, invertebrates, birds), the model testing the response of SR and FD to land-use change without an interaction with diversity type included as a predictor was the bestsupported model based on AICc (Fig. 3.1, Table S3.1). The supplementary analyses comparing species richness with FDis showed similar results (Table B1).

When testing the response of overall diversity (SR and FD) to land-use system using the bestsupported model, we found that all taxonomic groups responded significantly to land-use change, although directions of the effect varied (Fig. 3.1, Table S3.2). Both birds and invertebrates showed a significant decline in both taxonomic and functional diversity across the land-use gradient (Fig. 3.1, Table S3.3). Ants conversely had significantly lower SR and FD values in forest and jungle rubber compared with oil palm and significantly lower values in rubber compared with jungle rubber (Fig. 3.1, Table S3.3). SR and FD of invertebrates were significantly lower in oil palm, compared with all the other land-use systems, which had similar values except for a marginally significantly higher diversity in forest than jungle rubber (Fig. 3.1, Table S3.3). SR and FD were significantly higher in forest than oil palm for birds, with the rubber systems having intermediate values (Fig. 3.1, Table S3.3). 

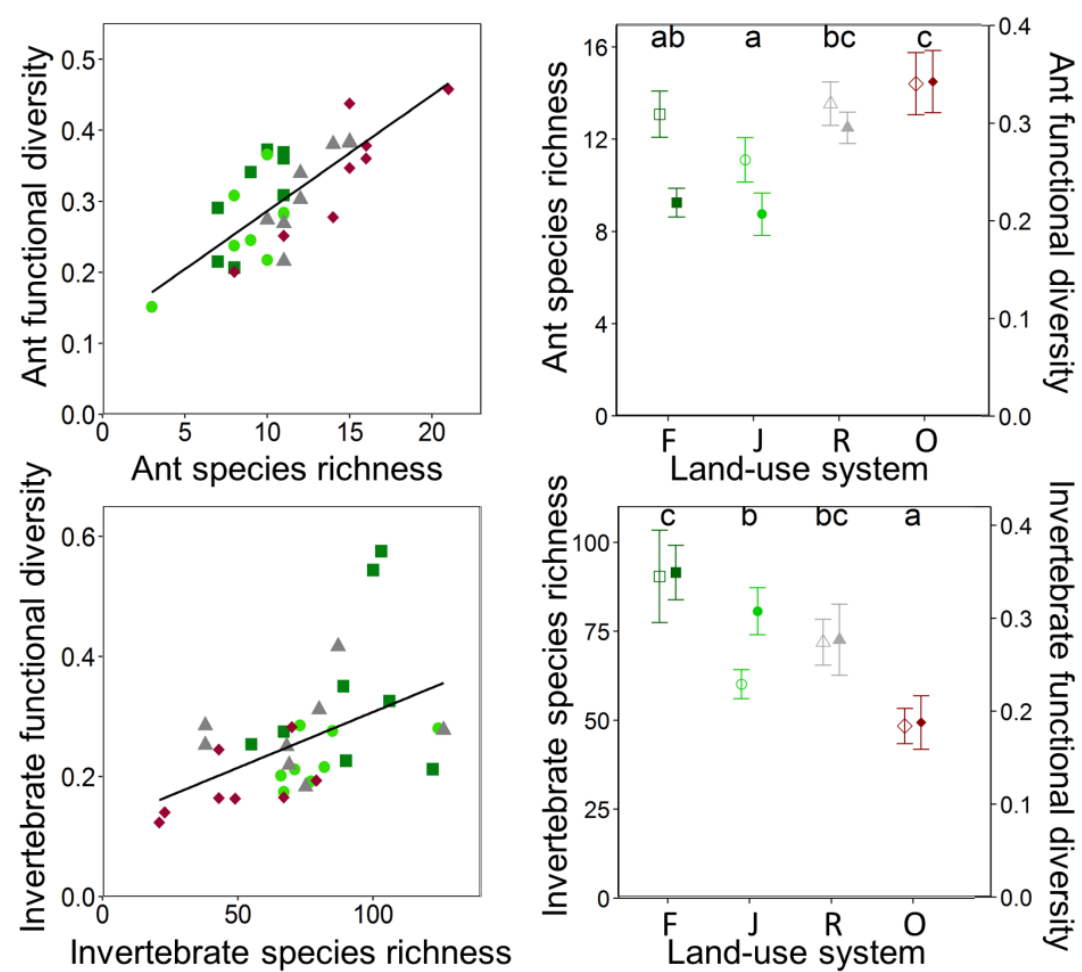

Forest

- Jungle rubber

A Rubber

- Oil palm

Species richness

中 Functional diversity
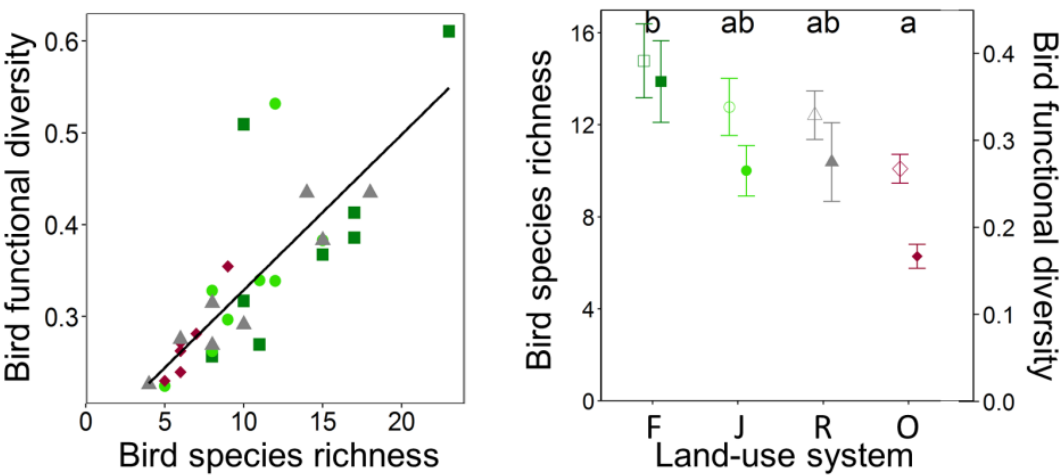

Figure 3.1. The relationship between species richness and functional diversity (left column) and response of species richness and functional diversity to land-use system (right column) for ants, leaf-litter macro-invertebrates and birds. Means (SR and FD) with different letters are significantly different (Tukey's HSD, $\mathrm{p} \leq 0.05$ ). Error bars indicate standard error. $\mathrm{F}=$ forest, $\mathrm{J}=$ jungle rubber, $\mathrm{R}=$ rubber, $\mathrm{O}=$ oil palm. $\mathrm{SR}=$ Species richness, $\mathrm{FD}=$ Functional diversity.

Functional diversity responses to land-use change

\section{Multi-trait functional indices}

FDiv and FDis did not respond significantly to land-use change for both birds and invertebrates, however, for ants there significant differences between land-use systems for FDiv and FDis (Table S3.4). More specifically, ant FDiv was significantly higher in jungle rubber and oil palm compared with forest (Fig. 3.2, Table S3.5) and ants had significantly higher FDis values in oil palm than in forest with intermediate values for the rubber systems (Fig. 3.2, Table S3.5). FEve was only significantly different between land-uses for birds (Table S3.4), with oil palm having significantly lower FEve values than the other three land-uses which had similar values (Fig. 3.2, Table S3.5). 


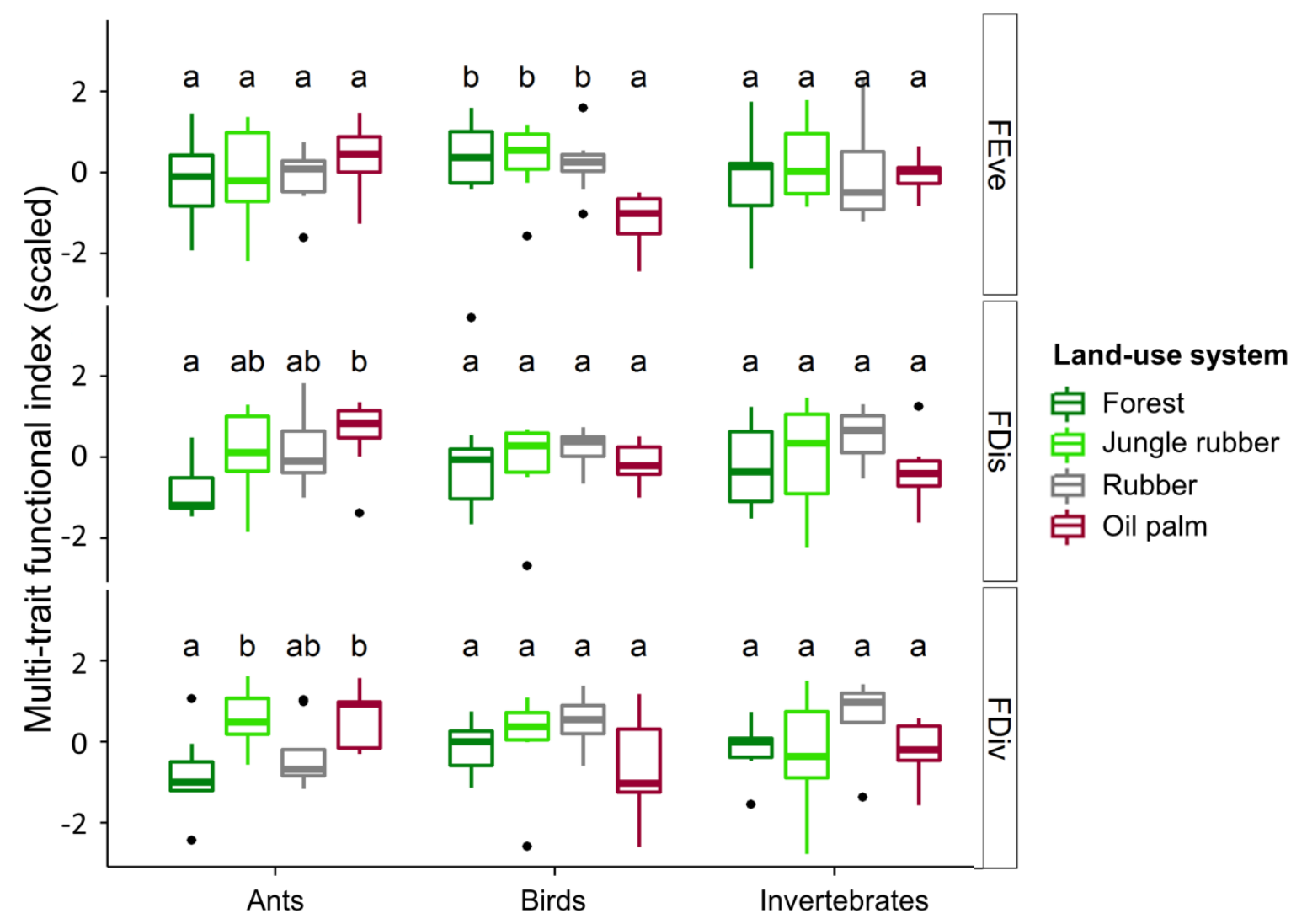

Figure 3.2. The response of ant, leaf-litter macro invertebrate and bird multi-trait (trait-space based) functional indices (functional evenness (FEve), functional dispersion (FDis) and functional divergence (FDiv)) to land-use system. Means with different letters within taxonomic group are significantly different (Tukey's HSD, $\mathrm{p} \leq 0.05$ ).

\section{Single-trait functional indices}

The CWM and CWV values for the animal biomass traits for each taxonomic group (ant head length, invertebrate body mass, bird body mass) showed a significant response to land-use change for invertebrates but not for ants or birds (Table S3.6). More specifically, CWM and CWV values for invertebrates were both significantly lower in oil palm than forest and rubber, with CWV values also significantly lower in jungle rubber than forest (Fig. 3.3, Table S3.7).

Ant, invertebrate and bird CWM values for trophic guild measures (ant protein/carbohydrate preference ratios and invertebrate and bird trophic guild) significantly decreased across the land-use gradient, with oil palm having significantly lower values than forest in all cases and the rubber systems having intermediate values (Fig. 3.3, Tables S3.8+S3.9). This indicates a decrease in the presence of species at high trophic levels (i.e. predators) from forest to oil palm. Trophic guild CWV values did not differ significantly between land-uses for any of the taxonomic groups (Table S3.8).

The CWM and CWV values for the animal mobility traits (ant leg length, invertebrate mobility and bird relative wing length) showed a significant response to land-use change for ants and birds (only CWM), but not invertebrates (Table S3.10). Ant leg length CWM was significantly higher in oil palm than rubber, and higher in jungle rubber than forest. Also, bird relative wing length CWM was significantly lower in forest than in jungle rubber and rubber, with intermediate values for oil palm (Fig. 
3.3, Table S3.11). The ant CWV values were significantly lower in forest than in any of the other landuse systems (Fig. 3.3, Table S3.11).

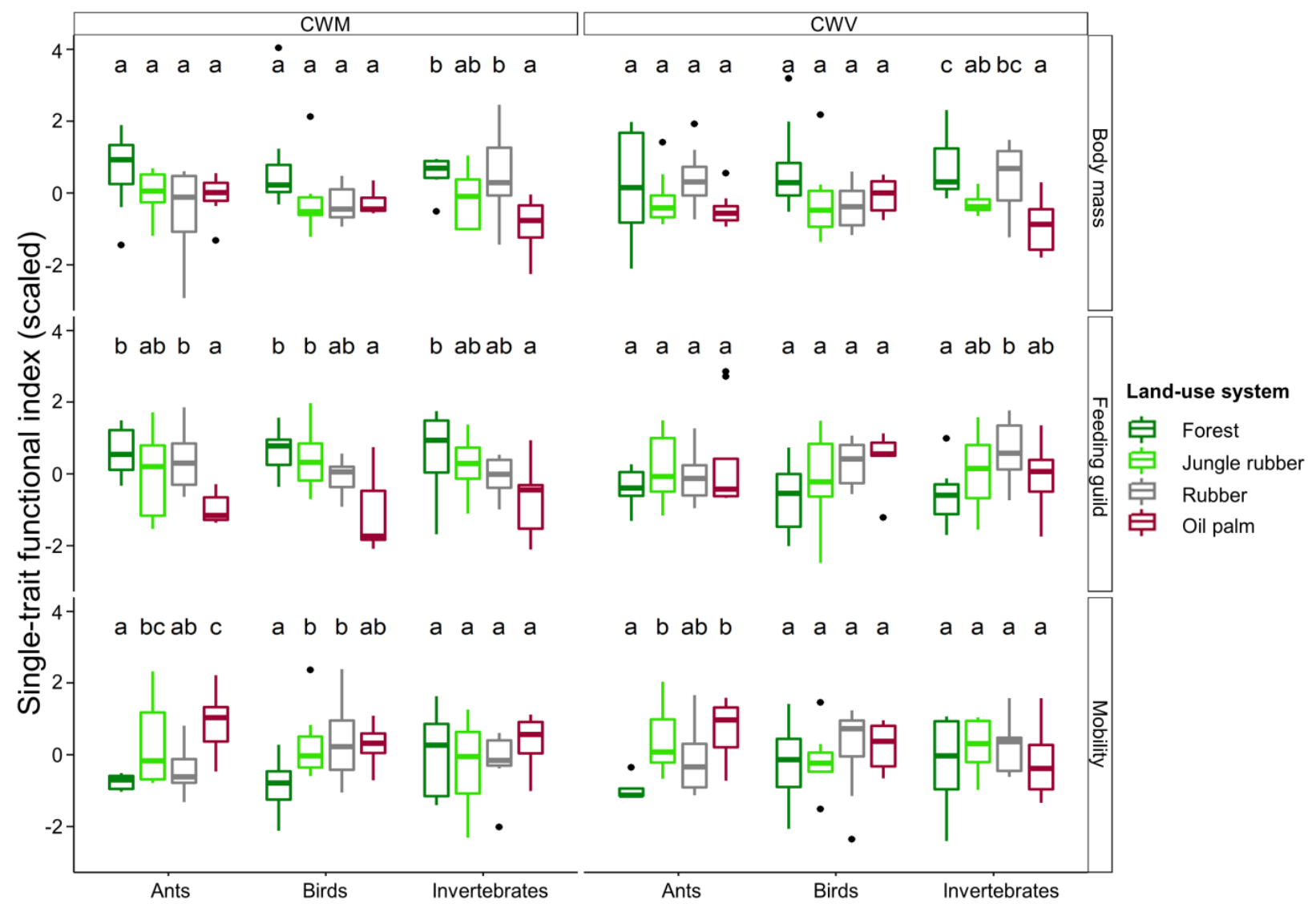

Figure. 3.3. The response of the community weighted mean (CWM) and community weighted variance (CWV) of ant, leaf-litter macro invertebrate and bird biomass, feeding guild and mobility traits to landuse system. Means with different letters within taxonomic group are significantly different (Tukey's HSD, $\mathrm{p} \leq 0.05)$.

\subsection{Discussion}

We studied the relationship between taxonomic and functional diversity as well as the changes in functional diversity of multiple taxa with tropical rainforest transformation using several single and multi-trait indices of functional diversity. We found a linear relationship between species richness and functional diversity across all taxa, suggesting low functional redundancy in the land-use systems studied. The use of both dendrogram based and trait-space based multi-trait indices, along with singletrait indices, provided complementary results describing animal functional responses to land-use change and their implications. We found a general negative effect of land-use change on species richness and functional diversity, in particular for oil palm plantations. In addition, we established that higher trophic guilds were most vulnerable to land-use change; dispersal ability and to a lesser extent body mass were also important traits for determining animal responses to disturbance.

Our results showed a consistent linear relationship between species richness and functional diversity across three different taxonomic groups; ants, invertebrates and birds. The linear relationship 
implies low functional redundancy in the studied systems, which occurs when many of the species present in a community have a unique combination of traits (Flynn et al. 2009). Low functional redundancy has also been found in a number of other studies (e.g. Micheli and Halpern 2005; Petchey et al. 2007; Laliberte et al. 2010). For example, Petchey et al. (2007) found functional diversity changes were almost exactly proportional to species richness in British bird assemblages. In communities with low functional redundancy, even a relatively small decrease in species richness can decrease functional diversity which can have potential dramatic consequences for ecosystem functioning (Micheli and Halpern 2005). Due to this, redundancy is also linked with an ecosystem's resilience to disturbance and stability (Laliberte et al. 2010). Thus in our study, the low functional redundancy across a large number of different taxa points towards a much reduced resilience of the studied land-use systems towards future anthropogenic pressures.

As expected, due to the highly simplified habitat and intensive management of monoculture plantations, we also found a general decrease in functional diversity and species richness for birds and leaf-litter invertebrates from lowland rainforest towards monoculture production systems. The general decline, however, did not hold for arboreal ant species, which showed the highest biodiversity in the monoculture plantations, in particular oil palm. This could be due to a sampling bias because of the differences in vegetation density between the systems. However, a detailed study on the ant communities at the same sites also did not find a decline in species richness with land-use change (Rubiana et al. 2015), and similarly, Luke et al. (2014) found comparable occurrences of ants between oil palm and old growth forest in Malaysian Borneo. Nevertheless, both studies still concluded ant communities are changed from forest to oil palm due to the large differences in community composition. The observed alteration of species richness with land-use change, along with the tightly coupled decreases in functional diversity and low functional redundancy, threatens long-term stability through potential consequences for ecosystem processes vital to the sustainability of agricultural systems such as biocontrol, decomposition and nutrient cycling.

We found that the majority of trait-space based functional indices showed no response to landuse change, with only three out of the nine measures used showing significant responses. The minimal response however, is in contrast to expectation as there are still large changes in the species richness and dendrogram based functional diversity of communities between these systems. However, using multitrait indices may mask the underlying changes if different traits have varying responses; for example, if one trait responds positively to change and the other negatively then combining them could mask those responses entirely (Spasojevic and Suding 2012). By looking at each trait separately, we may gain more understanding about the specific changes in these communities.

Our investigation of each trait using single-trait functional indices yielded important results that would be masked by using multi-trait indices alone. In particular, we found a decline in the higher trophic guilds (predators) for all taxa from forest to oil palm plantations. Theory predicts losses of higher trophic guilds, in particular predators, with disturbances such as fragmentation and land-use change, and that these losses precede those of species at lower trophic levels (Holt 2009). However, empirical 
research demonstrating this is still uncommon and mostly restricted to a few specific taxa (in particular, parasitoid-host relationships) (van Nouhuys 2005; Cagnolo et al. 2009). In the land-use systems we investigated, however, there was a consistent loss of predators with land-use change, which threatens the long-term sustainability of the agricultural systems due to the potential decrease in important ecosystem services they provide; in particular, biocontrol. For example, it is established that birds and bats control arthropods in agroforestry systems and therefore impact herbivory and, often subsequently, yield (Maas et al. 2015).

Interestingly, we also found unexpected results for ant and bird community-weighted mean biomass data, in that there were no significant differences between land-use systems. The results highlight that although species with large body sizes are often sensitive to disturbance, overall community biomass may not decrease with disturbance due to the persistence of large and/or very common generalist species. Ant communities in the plantations for example, are dominated by the medium-sized invasive species and generalists such as the very common Anoplolepis gracilipes. In contrast, comparatively larger forest specialists (e.g. Camponotus gigas and Polyrachis spp.) only occur in low numbers (Rubiana et al. 2015). Similarly, many of the birds that are able to persist in the plantations are large-bodied omnivores (e.g. Bulbuls and doves), which may better be able to use disturbed land-use systems due to their less specialized resource use (Newbold et al. 2013; Grass et al. 2014b).

Both ant and bird communities became dominated by more mobile species from forest to one or more of the agricultural systems. Also, ant leg length had higher variability in all agricultural systems compared with forest. Species with high mobility are often associated with disturbed or non-natural habitats (Driscoll and Weir 2005). For example, the highly invasive ant A. gracilipes has the largest relative leg length of any ant species in the study, a trait which positively relates to locomotion and foraging efficiency (Bihn et al. 2010). Increased dispersal capability is a common trait in species that persist in disturbed habitats due to improved resource acquisition abilities where resources may be scarcer than in natural habitats (Barnes et al. 2014). In summary, we found that using single-trait functional indices allowed us to understand how species traits such as trophic guild position, biomass and dispersal capacity mediate species' responses to land-use change, shaping the trajectory of local community assembly and the taxonomic and functional diversity in different land-uses.

\section{Conclusions}

The low functional redundancy seen here implies that even relatively small losses in biodiversity may impact ecosystem functioning. This finding suggests strong effects from biodiversity losses following rainforest transformation, particularly towards monoculture production systems. Ecosystem processes associated with higher trophic guilds are most vulnerable, indicating non-random simplification of food webs which may imperil ecosystem stability in the long-term. Single-trait functional indices provided information about important changes in the studied animal groups that were masked by most multi-trait indices. However, the comparison of multi-trait indices with species richness 
yields conclusions about the level of redundancy in a system. The few unexpected results along with the differing complementary applications of the different functional indices emphasize the need to investigate many aspects of taxonomic diversity, functional diversity and community composition if we want to fully understand the overall effects of land-use change on animal and plant communities.

\section{Acknowledgements}

We thank Winda Alasmari, Rico Fardiansah, Derly Hartika, Marisi Italiansia, Rizky Nazarreta, Ratna Rubiana, Alfianis Rumede, Leonarda Situmorang and other assistants for all their help in the lab and the field. We thank Martyna Kotowska and Katja Rembold for comments on earlier versions of the manuscript. We thank the following for granting us the use of their properties: village leaders, local plot owners, PT REKI and Bukit Duabelas National Park. This study was financed by the Deutsche Forschungsgemeinschaft (DFG) in the framework of the collaborative German - Indonesian research project Collaborative Research Centre 990: Ecological and Socioeconomic Functions of Tropical Lowland Rainforest Transformation Systems (Sumatra, Indonesia). 


\subsection{Supplementary material}

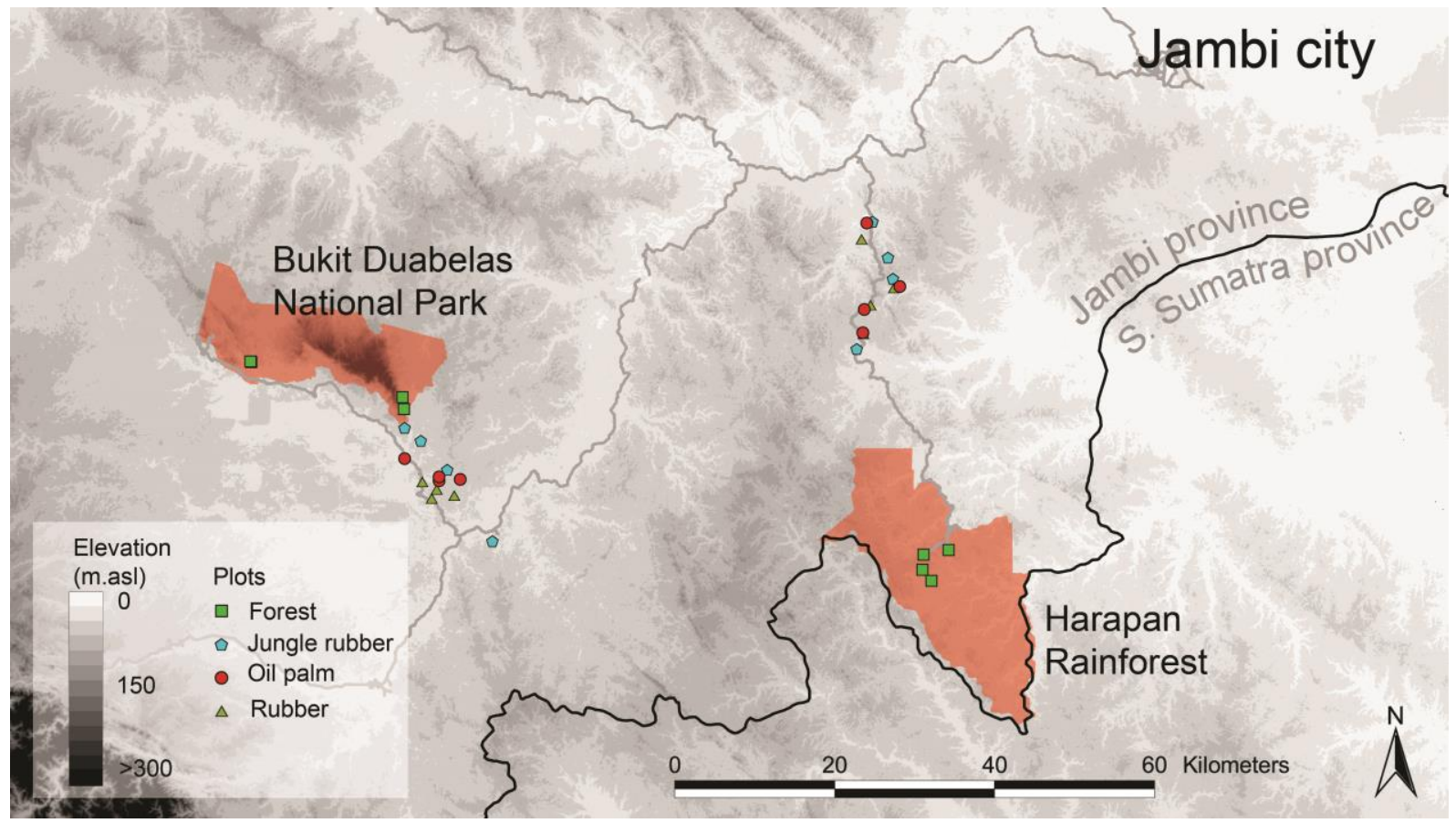

Figure S3.1. Map of study area located in Jambi, Sumatra, Indonesia. In the two study regions, each land-use system was replicated four times. The regions were adjacent to two protected areas, the Bukit Duabelas National Park and the Harapan rainforest (area shaded in orange). Figure modified from Allen et al (2015). 
Table S3.1. AICc table for comparison of fits of linear mixed effects models testing the effect of landuse change on overall diversity (species richness and functional diversity/functional dispersion). The two models tested for (a) arboreal ant, (b) leaf-litter invertebrate and (c) bird overall diversity (both species richness and functional diversity or functional dispersion) are shown with $\mathrm{K}$ (number of parameters in the model), AICc (AIC adjusted for bias due to small sample size), $\triangle \mathrm{AICc}$ (change in AICc, models with $\Delta \mathrm{AICc}<2$ have an equal likelihood of being the model that best explains the response variable), and Akaike weight (relative probability of each model being the best model). The best supported models are indicated in bold. LUS is land-use system and DivType is diversity type.

\begin{tabular}{|c|c|c|c|c|c|c|c|c|c|}
\hline & \multirow[b]{2}{*}{ Response variable } & \multicolumn{5}{|c|}{ Functional diversity } & \multicolumn{3}{|c|}{ Functional dispersion } \\
\hline & & $\mathrm{K}$ & $\mathrm{AICc}$ & $\triangle \mathrm{AICc}$ & Akaike Wt & $\mathrm{K}$ & $\mathrm{AICc}$ & $\Delta \mathrm{AICc}$ & Akaike Wt \\
\hline \multirow[t]{3}{*}{ (a) } & Ant & & & & & & & & \\
\hline & LUS & 7 & 174.54 & 0.00 & 0.97 & 7 & 170.28 & 0.00 & 0.92 \\
\hline & LUS*DivType & 11 & 181.68 & 7.15 & 0.03 & 11 & 175.07 & 4.79 & 0.08 \\
\hline \multirow[t]{3}{*}{ (b) } & Invertebrate & & & & & & & & \\
\hline & LUS & 7 & 170.58 & 0.00 & 0.99 & 7 & 184.58 & 0.00 & 0.78 \\
\hline & LUS*DivType & 11 & 179.13 & 8.56 & 0.01 & 11 & 184.06 & 2.48 & 0.22 \\
\hline \multirow[t]{3}{*}{ (c) } & Bird & & & & & & & & \\
\hline & LUS & 7 & 169.37 & 0.00 & 1.00 & 7 & 180.64 & 0.00 & 0.94 \\
\hline & LUS*DivType & 11 & 180.13 & 10.76 & 0.00 & 11 & 186.12 & 5.47 & 0.06 \\
\hline
\end{tabular}

Table S3.2. Linear mixed effect model ANOVA outputs testing for a significant effect of land-use system on overall diversity (species richness and functional diversity). The best-fit linear mixed effects models which determined the effect of land-use change on (a) arboreal ant, (b) leaf-litter invertebrate and (c) bird overall diversity (both species richness and functional diversity) (Table S1). Significant $P$-values are indicated in bold $(P=\leq 0.05)$.

\begin{tabular}{llrrr}
\hline Response variable & Effect & df & F-value & P-value \\
\hline (a) Ant diversity & Land-use system & 59 & 3.606 & $\mathbf{0 . 0 1 8}$ \\
(b) Invertebrate diversity & Land-use system & 59 & 9.565 & $<\mathbf{0 . 0 0 1}$ \\
(c) Bird diversity & Land-use system & 57 & 7.333 & $<\mathbf{0 . 0 0 1}$ \\
\hline
\end{tabular}


able S3.3. Summary statistics of Tukey post-hoc tests testing for significant differences in overall diversity (species richness and functional diversity) among land-use systems. Tukey post-host tests were performed on the best-fit linear mixed effects models which determined the effect of land-use change on (a) ant, (b) leaf-litter invertebrate and (c) bird overall diversity (both species richness and functional diversity) (Table S3.1). Significant $P$-values are indicated in bold (Tukey's HSD, $P=\leq 0.05$ ). F=forest, $\mathrm{J}=$ jungle rubber, $\mathrm{R}=$ rubber, $\mathrm{O}=$ oil palm.

\begin{tabular}{cccc}
\hline Response variable & Estimate & Z-value & P-value \\
\hline (a) Ant diversity & & & \\
J - F & 0.043 & 0.132 & 1.000 \\
O-F & 0.933 & 2.867 & $\mathbf{0 . 0 2 5}$ \\
R - F & 0.170 & 0.522 & 1.000 \\
O- J & 0.889 & 2.734 & $\mathbf{0 . 0 3 8}$ \\
R - J & 0.127 & 0.390 & 1.000 \\
R - O & -0.763 & -2.344 & 0.114 \\
(b) Leaf-litter invertebrate diversity & & & \\
J - F & -0.774 & -2.619 & 0.053 \\
O - F & -0.158 & -5.345 & $<\mathbf{0 . 0 0 1}$ \\
R - F & -0.702 & -2.374 & 0.106 \\
O- J & -0.806 & -2.726 & $\mathbf{0 . 0 3 8}$ \\
R - J & 0.072 & 0.245 & 1.000 \\
R - O & 0.878 & 2.971 & 0.018 \\
(c) Bird diversity & & & \\
J - F & -0.698 & -2.345 & 0.114 \\
O - F & -1.446 & -4.688 & $<\mathbf{0 . 0 0 1}$ \\
R - F & -0.707 & -2.375 & 0.105 \\
O- J & -0.748 & -2.425 & 0.092 \\
R - J & -0.030 & 1.000 \\
R - O & & 2.396 & 0.099 \\
\hline
\end{tabular}


Table S3.4. Linear mixed effect model ANOVA outputs testing for a significant effect of land-use system on trait-space based functional indices. The linear mixed effects models determined the effect of land-use change on (a) arboreal ant, (b) leaf-litter invertebrate and (c) bird functional evenness, functional evenness and functional dispersion. Significant $P$-values are indicated in bold $(P=\leq 0.05)$.

\begin{tabular}{|c|c|c|c|c|c|c|c|c|c|c|}
\hline \multirow[b]{2}{*}{ Response variable } & \multirow[b]{2}{*}{ Effect } & \multicolumn{3}{|c|}{ functional evenness } & \multicolumn{3}{|c|}{ functional divergence } & \multicolumn{3}{|c|}{ functional dispersion } \\
\hline & & $\mathrm{df}$ & F-value & P-value & $\mathrm{df}$ & F-value & P-value & $\mathrm{df}$ & F-value & P-value \\
\hline (a) Ant & Land-use system & 27 & 0.504 & 0.683 & 27 & 5.433 & 0.005 & 27 & 3.882 & 0.020 \\
\hline (b) Invertebrate & Land-use system & 27 & 0.307 & 0.820 & 27 & 1.841 & 0.164 & 27 & 1.656 & 0.200 \\
\hline (c) Bird & Land-use system & 26 & 7.254 & 0.001 & 26 & 1.988 & 0.141 & 26 & 0.231 & 0.874 \\
\hline
\end{tabular}


Table S3.5. Summary statistics of Tukey post-hoc tests testing for significant differences in trait-space based functional indices among land-use systems. Tukey post-host tests were performed on linear mixed effects models determining the effect of land-use change on (a) arboreal ant and (b) bird functional evenness, functional evenness and functional dispersion. Only values from response variables with significant responses to land-use system (Table S3.4) are shown here. Significant $P$-values are indicated in bold (Tukey's HSD, $P=\leq 0.05$ ). $\mathrm{F}=$ forest, $\mathrm{J}=$ jungle rubber, $\mathrm{R}=$ rubber, $\mathrm{O}=$ oil palm.

\begin{tabular}{|c|c|c|c|c|c|c|c|c|c|c|}
\hline \multirow{2}{*}{\multicolumn{2}{|c|}{ Response variable }} & \multicolumn{3}{|c|}{ functional evenness } & \multicolumn{3}{|c|}{ functional divergence } & \multicolumn{3}{|c|}{ functional dispersion } \\
\hline & & estimate & z-value & P-value & estimate & z-value & P-value & estimate & z-value & P-value \\
\hline \multicolumn{11}{|c|}{ (a) Ant } \\
\hline & $\mathrm{J}-\mathrm{F}$ & & & & 0.210 & 3.221 & 0.008 & 0.542 & 2.243 & 0.194 \\
\hline & $\mathrm{O}-\mathrm{F}$ & & & & 0.220 & 3.370 & 0.005 & 0.796 & 3.292 & 0.006 \\
\hline & $\mathrm{R}-\mathrm{F}$ & & & & 0.072 & 1.103 & 1.000 & 0.560 & 2.314 & 0.124 \\
\hline & $\mathrm{O}-\mathrm{J}$ & & & & 0.010 & 0.149 & 1.000 & 0.254 & 1.049 & 1.000 \\
\hline & $\mathrm{R}-\mathrm{J}$ & & & & -0.139 & -2.118 & 0.205 & 0.017 & 0.071 & 1.000 \\
\hline & $\mathrm{R}-\mathrm{O}$ & & & & -0.148 & -2.267 & 0.140 & -0.237 & -0.978 & 1.000 \\
\hline \multicolumn{11}{|c|}{ (b) Bird } \\
\hline & $J-F$ & -0.010 & -0.368 & 1.000 & & & & & & \\
\hline & $\mathrm{O}-\mathrm{F}$ & -0.113 & -4.163 & $<0.001$ & & & & & & \\
\hline & $\mathrm{R}-\mathrm{F}$ & -0.017 & -0.647 & 1.000 & & & & & & \\
\hline & $\mathrm{O}-\mathrm{J}$ & -0.103 & -3.807 & $<0.001$ & & & & & & \\
\hline & $\mathrm{R}-\mathrm{J}$ & -0.007 & -0.279 & 1.000 & & & & & & \\
\hline & $\mathrm{R}-\mathrm{O}$ & 0.096 & 3.538 & 0.002 & & & & & & \\
\hline
\end{tabular}


Table S3.6. Linear mixed effect model ANOVA outputs testing for a significant effect of land-use system on single-trait (biomass) functional indices. The linear mixed effects models determined the effect of land-use change on the community weighted mean (CWM) and community weighted variance (CWV) (a) arboreal ant, (b) leaf-litter invertebrate and (c) bird biomass traits. v.

\begin{tabular}{|c|c|c|c|c|c|c|c|}
\hline \multirow[b]{2}{*}{ Response variable } & \multirow[b]{2}{*}{ Effect } & \multicolumn{3}{|c|}{ CWM } & \multicolumn{3}{|c|}{ CWV } \\
\hline & & $\mathrm{df}$ & F-value & $\mathrm{P}$-value & $\mathrm{df}$ & F-value & $\mathrm{P}$-value \\
\hline (a) Ant (head length) & Land-use system & 27 & 2.028 & 1.336 & 27 & 1.265 & 0.306 \\
\hline (b) Invertebrate (body mass) & Land-use system & 27 & 4.146 & 0.015 & 27 & 7.424 & $<0.001$ \\
\hline (c) Bird (body mass) & Land-use system & 26 & 2.333 & 0.097 & 26 & 2.031 & 0.134 \\
\hline
\end{tabular}

Table S3.7. Summary statistics of Tukey post-hoc tests testing for significant differences in single-trait (biomass) functional indices among land-use systems. Tukey post-host tests were performed on linear-mixed effect models testing the response of the community weighted mean (CWM) and community weighted variance $(\mathrm{CWV})$ of leaf-litter invertebrate to land-use system. Only values from response variables with significant responses to land-use system (Table S3.6) are shown here. Significant $P$-values are indicated in bold (Tukey's HSD, $P=\leq 0.05$ ).

\begin{tabular}{|c|c|c|c|c|c|c|}
\hline \multirow[b]{2}{*}{ Response variable } & \multicolumn{3}{|c|}{ CWM-biomass } & \multicolumn{3}{|c|}{ CWV-biomass } \\
\hline & estimate & z-value & $\mathrm{p}$-value & estimate & z-value & $\mathrm{p}$-value \\
\hline \multicolumn{7}{|c|}{ Invertebrate (body mass) } \\
\hline$J-F$ & -0.780 & -1.477 & 0.838 & -1.371 & -2.667 & 0.046 \\
\hline $\mathrm{O}-\mathrm{F}$ & -1.428 & -2.706 & 0.041 & -2.211 & -4.301 & 0.001 \\
\hline $\mathrm{R}-\mathrm{F}$ & 0.237 & 0.448 & 1.000 & -0.418 & -0.813 & 1.000 \\
\hline $\mathrm{O}-\mathrm{J}$ & -0.649 & -1.229 & 1.000 & -0.840 & -1.634 & 0.614 \\
\hline $\mathrm{R}-\mathrm{J}$ & 1.016 & 1.925 & 0.325 & 0.953 & 1.854 & 0.382 \\
\hline $\mathrm{R}-\mathrm{O}$ & 1.665 & 3.154 & 0.010 & 1.793 & 3.488 & 0.003 \\
\hline
\end{tabular}


Table S3.8. Linear mixed effect model ANOVA outputs testing for a significant effect of land-use system on single-trait (feeding guild) functional indices. The linear mixed effects models determined the effect of land-use change on the community weighted mean (CWM) and community weighted variance (CWV) (a) arboreal ant, (b) leaf-litter invertebrate and (c) bird feeding traits. Significant $P$-values are indicated in bold $(P=\leq 0.05)$.

\begin{tabular}{|c|c|c|c|c|c|c|c|}
\hline \multirow[b]{2}{*}{ Response variable } & \multirow[b]{2}{*}{ Effect } & \multicolumn{3}{|c|}{ CWM } & \multicolumn{3}{|c|}{ CWV } \\
\hline & & $\mathrm{df}$ & F-value & P-value & $\mathrm{df}$ & F-value & P-value \\
\hline (a) Ant (protein/carbohydrate ratio) & Land-use system & 27 & 5.437 & 0.005 & 27 & 0.669 & 0.578 \\
\hline (b) Invertebrate (feeding guild) & Land-use system & 27 & 3.047 & 0.046 & 27 & 2.401 & 0.090 \\
\hline (c) Bird (feeding guild) & Land-use system & 26 & 6.737 & 0.002 & 26 & 2.054 & 0.131 \\
\hline
\end{tabular}


Table S3.9. Summary statistics of Tukey post-hoc tests testing for significant differences in singletrait (feeding guild) functional indices among land-use systems. Tukey post-host tests determined the response of the community weighted mean (CWM) of (a) arboreal ant, (b) leaf-litter invertebrate and (c) bird feeding guild traits to land-use system. Only values from response variables with significant responses to land-use system (Table S3.8) are shown here. Significant $P$-values are indicated in bold (Tukey's HSD, $P=\leq 0.05$ ).

\begin{tabular}{llcr}
\hline & \multicolumn{3}{c}{ CWM-feeding guild } \\
\cline { 2 - 4 } Response variable & estimate & Z-value & P-value \\
\hline (a) $\quad$ Ant (protein/carbohydrate ratio) & -0.047 & -1.447 & 0.887 \\
J - F & -0.122 & -3.763 & $\mathbf{0 . 0 0 1}$ \\
O - F & -0.020 & -0.611 & 1.000 \\
R - F & -0.075 & -2.316 & 0.123 \\
O - J & 0.027 & 0.836 & 1.000 \\
R - J & 0.102 & 3.151 & $\mathbf{0 . 0 1 0}$ \\
R - O & & & \\
(b) Invertebrate (feeding guild) & -0.032 & -0.830 & 1.000 \\
J - F & -0.112 & -2.919 & $\mathbf{0 . 0 2 1}$ \\
O - F & -0.057 & -1.494 & 0.811 \\
R - F & -0.080 & -2.090 & 0.220 \\
O - J & -0.025 & -0.664 & 1.000 \\
R - J & 0.055 & 1.425 & 0.925 \\
R - O & & & \\
(c) Bird (feeding guild) & & & 1.000 \\
J - F & -0.043 & -0.599 & $<0.001$ \\
O - F & -0.313 & -4.185 & 0.510 \\
R - F & -0.124 & -1.722 & 0.002 \\
O - J & -0.270 & -3.606 & 1.000 \\
R - J & -0.081 & -1.123 & 0.070 \\
R - O & 0.189 & 2.521 &
\end{tabular}


Table S3.10. Linear mixed effect model ANOVA outputs testing for a significant effect of land-use system on single-trait (mobility) functional indices. The linear mixed effects models determined the effect of land-use change on the community weighted mean (CWM) and community weighted variance (CWV) of (a) arboreal ant, (b) leaf-litter invertebrate, and (c) bird mobility traits. Significant $P$-values are indicated in bold $(P=\leq 0.05)$.

\begin{tabular}{|c|c|c|c|c|c|c|c|}
\hline \multirow[b]{2}{*}{ Response variable } & \multirow[b]{2}{*}{ Effect } & \multicolumn{3}{|c|}{ CWM } & \multicolumn{3}{|c|}{ CWV } \\
\hline & & $\mathrm{df}$ & F-value & P-value & $\mathrm{df}$ & F-value & P-value \\
\hline (a) Ant (relative leg length) & Land-use system & 27 & 7.451 & $<0.001$ & 27 & 12.637 & $<0.001$ \\
\hline (b) Invertebrate (dispersal capacity) & Land-use system & 27 & 0.684 & 0.569 & 27 & 0.641 & 0.595 \\
\hline (c) Bird (relative wing length) & Land-use system & 26 & 3.417 & 0.032 & 26 & 0.425 & 0.736 \\
\hline
\end{tabular}


Table S3.11. Summary statistics of Tukey post-hoc tests testing for significant differences in single-trait (mobility) functional indices among land-use systems. Tukey post-host tests determined the response of the community weighted mean (CWM) and community weighted variance (CWV) of (a) arboreal ant and (b) bird dispersal traits to land-use system. Only values from response variables with significant responses to land-use system (Table S3.10) are shown here. Significant $P$-values are indicated in bold (Tukey's HSD, $P=\leq 0.05$ ).

\begin{tabular}{|c|c|c|c|c|c|c|c|}
\hline \multirow{2}{*}{\multicolumn{2}{|c|}{ Response variable }} & \multicolumn{3}{|c|}{ CWM-mobility/dispersal } & \multicolumn{3}{|c|}{ CWV- mobility/dispersal } \\
\hline & & \multirow[t]{2}{*}{ estimate } & \multirow[t]{2}{*}{ z-value } & \multirow[t]{2}{*}{ P-value } & \multirow[t]{2}{*}{ estimate } & \multirow[t]{2}{*}{ z-value } & \multirow[t]{2}{*}{ P-value } \\
\hline (a) & Ant (relative leg length) & & & & & & \\
\hline & $\mathrm{J}-\mathrm{F}$ & 0.651 & 2.652 & 0.048 & 2.320 & 5.056 & $<0.001$ \\
\hline & $\mathrm{O}-\mathrm{F}$ & 1.053 & 4.289 & $<0.001$ & 2.546 & 5.550 & $<0.001$ \\
\hline & $\mathrm{R}-\mathrm{F}$ & 0.197 & 0.762 & 1.000 & 1.468 & 3.200 & 0.008 \\
\hline & $\mathrm{O}-\mathrm{J}$ & 0.402 & 1.637 & 0.610 & 0.227 & 0.494 & 1.000 \\
\hline & $\mathrm{R}-\mathrm{J}$ & -0.464 & -1.890 & 0.352 & -0.851 & -1.856 & 0.381 \\
\hline & $\mathrm{R}-\mathrm{O}$ & -0.866 & -3.527 & 0.003 & -1.078 & 2.350 & 0.113 \\
\hline \multirow[t]{7}{*}{ (b) } & Bird (relative wing length) & & & & & & \\
\hline & $\mathrm{J}-\mathrm{F}$ & 0.863 & 2.570 & 0.061 & & & \\
\hline & $\mathrm{O}-\mathrm{F}$ & 0.870 & 2.501 & 0.074 & & & \\
\hline & $\mathrm{R}-\mathrm{F}$ & 0.912 & 2.713 & 0.040 & & & \\
\hline & $\mathrm{O}-\mathrm{J}$ & 0.007 & 0.019 & 1.000 & & & \\
\hline & $\mathrm{R}-\mathrm{J}$ & 0.048 & 0.143 & 1.000 & & & \\
\hline & $\mathrm{R}-\mathrm{O}$ & 0.042 & 0.120 & 1.000 & & & \\
\hline
\end{tabular}




\title{
Chapter 4
}

\section{Local and landscape drivers of arthropod diversity and decomposition processes in oil palm leaf axils}

\author{
Dominik Ganser, Lisa H. Denmead, Yann Clough, Damayanti Buchori, Teja Tscharntke
}

In review, Agricultural and Forest Entomology, submitted: $26^{\text {th }}$ February 2016

\begin{abstract}
Oil palm expansion results in a loss of biodiversity and associated ecosystem services.

However, there are factors which influence the severity of these impacts and enhancing biodiversity within plantations is important. Here, we examine the role of epiphytes for supporting arthropod communities in oil palm plantations in Sumatra, Indonesia. We considered the effects of landscape context and local characteristics (epiphyte cover, herbicide use, and local microclimate) on arthropod communities and litter decomposition in oil palm leaf axils. We surveyed arthropods and measured decomposition rates at two different heights on eighty oil palm trees located at the centre and the edge of eight plantations. We found that oil palm trees at the edge of plantations hosted a higher abundance and more arthropod taxa than oil palms in the centre of plantations. Moreover, organic matter mass and height of the leaf axil were important for arthropod communities, and decomposition rate negatively related to ant abundance. However, epiphyte cover did not influence arthropod communities. Our results show that leaf axils with more organic matter and at a higher location on the oil palm promote arthropod biodiversity. Furthermore, oil palm plantations adjacent to different land-use systems have enhanced biodiversity.
\end{abstract}




\subsection{Introduction}

The intensification and expansion of agriculture is the greatest global threat to biodiversity (Donald 2004; Fitzherbert et al. 2008; Danielsen et al. 2009) and associated ecosystem services (Cardinale et al. 2012). The global demand for agricultural products is increasing (Hansen et al. 2009; FAO 2016), in particular for vegetable oils to be used as food, cosmetics and biofuel (Basiron 2007; Danielsen et al. 2009). Oil palm (Elaeis guineensis) is the highest yielding vegetable oil crop per unit area (Donald 2004) and its production increased by 75\% between 2004 and 2014, mostly due to the expansion of area cultivated (FAO 2016). Indonesia and Malaysia, which are located in one of the most biodiverse regions of the world (Sodhi et al. 2010), produce over $80 \%$ of the world's palm oil (Koh and Wilcove 2007). Oil palm plantations have considerably lower tree diversity, more uniform tree structure, a hotter, drier and more variable climate, and higher human disturbance than primary forests (Peh et al. 2006; Danielsen et al. 2009; Luskin and Potts 2011; Hardwick et al. 2015). These changes lead to a much lower species richness and significant changes in trophic structure and ecosystem functioning (Barnes et al. 2014).

Epiphytes, which are commonly associated with oil palms, may increase biodiversity in otherwise sparse plantations (Koh 2008b). As epiphyte species provide resources, increase habitat heterogeneity and buffer temperature and evaporative fluctuations, they represent a microhabitat for organisms such as arthropods in otherwise hot and dry plantations (Freiberg 2001; Stuntz et al. 2002; Fayle et al. 2010). Nevertheless, for many farmers epiphytes in oil palm plantation are seen as obstacles for harvesting (Koh 2008b), although there is no evidence of a potential negative effect on yield (Prescott et al. 2015). Most farmers remove epiphytes manually or with herbicides (pers. obs.) and removal is mentioned in several management practice guides for the industry (e.g. Rankine and Fairhurst 1999; Turner and Gillbanks 2003).

In addition to these plot specific factors, the landscape surrounding the oil palm plantations can be of importance. Studies have shown that the heterogeneity of commodity landscapes can highly enhance biodiversity (Bennett et al. 2006; Karp et al. 2012; Steckel et al. 2014). A mosaic landscape with different land-use types could add new resources for arthropods enabling spillover of individuals into oil palm plantations from neighbouring land-use systems (De Vries et al. 1997; Koh 2008b; Lucey and Hill 2012; Tscharntke et al. 2012a; Lucey et al. 2014). For example, Lucey and Hill (2012) found increased butterfly diversity in oil palm plantations with increasing proximity to forest. Moreover, species whose individuals can disperse between habitat patches usually face less fluctuation in metapopulation size than isolated populations (Burel and Baudry 2003).

Little is known about the interaction between arthropod communities, decomposition processes and epiphyte cover in oil palm plantations. Previous studies have either focused only on the epiphyte species bird's nest fern Asplenium nidus (Turner and Foster 2009; Fayle et al. 2010), or rather have concentrated on ground dwelling (Brühl 2001; Lucey and Hill 2012) or canopy arthropods (Philpott et al. 2006; Prescott et al. 2015), but not on epiphyte or leaf axil dwelling arthropods (a substantial amount of organic matter accumulates in the leaf-axils, potential habitat for a wide range of animals, pers. obs.). 
Quantification of litter decomposition can provide a direct relationship between biodiversity and ecosystem services (Huhta 2007). Ants (Hymenoptera: Formicidae) can affect other organisms and decomposition directly or indirectly, which may lead to complex interactions (Frouz and Jilková 2008). Here, we examine (i) the role of epiphytes inhabiting oil palm leaf axils and their possible influence on arthropod and, more specifically, ant (Hymenoptera: Formicidae) communities, and (ii) the effects of the neighbouring non-oil palm land use on epiphytes and associated arthropod communities. We also assess litter decomposition in the leaf axils of the oil palm trees and its relationship to the arthropod community. We conclude with suggestions how management strategies may counteract negative aspects of highly simplified ecosystems such as oil palm plantations.

\subsection{Materials and methods}

\section{Study area}

The research was conducted in two regions, one adjacent to Bukit Duabelas National Park and the other adjacent to Harapan rainforest (PT. REKI) in Jambi province, Sumatra, Indonesia (Fig. S4.1). Located in central Sumatra, Jambi Province has a tropical climate with originally covered by lowland tropical rainforest, which is said to be one of the most diverse and complex ecosystems on earth (Whitten et al. 2000). However, due to large amounts of land-use change in the past decades, Sumatra has lost 2.6 million hectares of its lowland rainforest in the last 20 years (Hansen et al. 2009). Oil palm monoculture is now among the most dominant agricultural systems in Sumatra.

\section{Study design}

In each of the two regions, four replicate oil palm plantations were investigated (eight plantations in total) (Fig. S4.1). The plantations were similarly aged (12-15 years) and situated in lowland areas (below $400 \mathrm{~m}$ a.s.l). The climate can be characterised as tropical humid, with an average rainfall of over $2000 \mathrm{~mm}$ per year (Allen et al. 2015). All plantations were owned by smallholders, who continued business-as-usual management practices during the research. Management practices usually consist of manual removal of epiphytes, harvesting of the fruits every two weeks and the application of herbicides, insecticides and fertiliser. Herbicides and insecticides are applied to the ground and oil palm trunks. The timing and quantity of applications differed between plantations, however, herbicide use was the main vegetation clearance method used in the study plantations (not manual clearance).

In each plantation ten oil palm trees were chosen, five at the centre of a $50 \mathrm{~m}$ x $50 \mathrm{~m}$ established research plot and five at the edge of the plantation $(n=80)$. Each plantation was surrounded by different landscapes. To be selected, an oil palm had to fulfil three characteristics: (1) trunk height of at least six metres, (2) distance to another selected oil palm of at least ten metres and (3) no visible damage to the trunk (e.g. leaf axils fallen off). Moreover to be chosen as a centre oil palm, it had to be at least twenty metres from the edge of the plantation. Although, edge effects can easily extend past twenty metres, in smallholder plantations often the furthest point from the edge is of similar distance (or less), therefore the distance is appropriate in the context of small holder plantations. For each plot the neighbouring land use 
and habitat structure were documented. Most common neighbour habitat types were jungle rubber, described as rubber agroforestry, where secondary forest understorey is allowed to regrow as the rubber trees mature (Wilcove et al. 2013) and shrub, which was most often abandoned agricultural land.

\section{Measurement of vegetation variables}

We measured two vegetation variables for each tree studied, (i) epiphyte cover and (ii) ground cover. Epiphyte cover was defined as the estimated proportion of the trunk overlain by vascular plants on a scale of one (low) to six (high); (1) $0-15 \%$, (2) $16-30 \%$, (3) $31-50 \%$, (4) $51-65 \%$, (5) 66-80\%, and (6) = 81-100\% trunk cover (Fig. 4.1). The majority of epiphytes were ferns, and were generally rooted in the oil palm leaf axils. Ground cover was defined as the estimated proportion of ground within a two metre radius of the oil palm trunk covered in vegetation on a scale of one (low) to three (high); (1) $0-35 \%$, , (2) 36-65\%, (3) 66-100\% ground cover (Fig. S4.2). This is the area most heavily sprayed with herbicides to allow plantation workers access and easy sighting of the fruits. Ground cover was therefore used as an indicator for herbicide use.

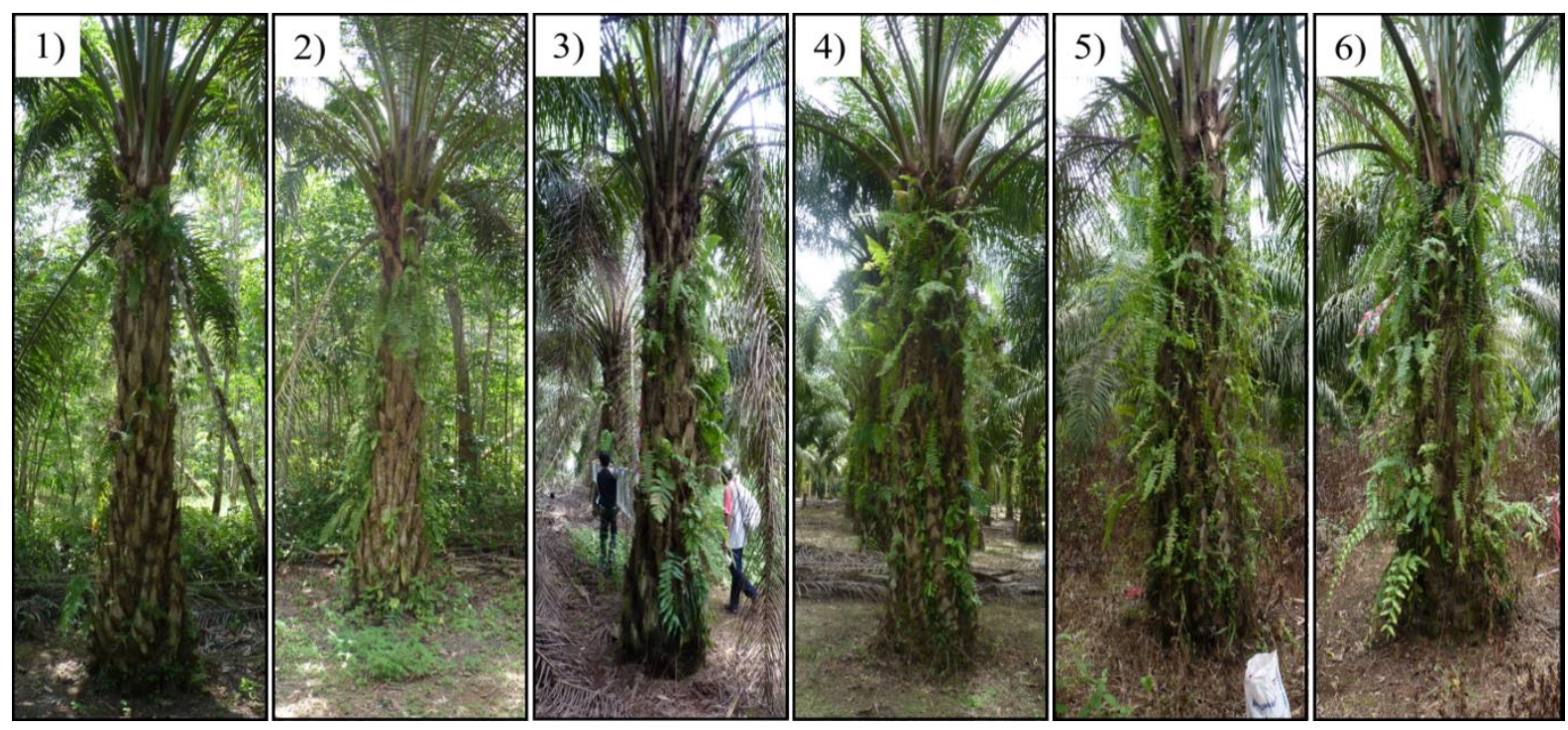

Figure 4.1. Epiphyte cover, the proportion of vascular plants covering the oil palm trunk assessed on a scale of 1-6: (1) $0-15 \%$, (2) $16-30 \%$, (3) $31-50 \%$, (4) $51-65 \%$, (5) 66-80\%, and (6) $81-100 \%$ trunk cover.

\section{Arthropod sampling}

One litre of organic matter was collected from the inside of a randomly chosen leaf axil (independent of epiphyte presence) on each selected oil palm tree at two heights ( $2 \mathrm{~m}$ and $4 \mathrm{~m}, \mathrm{n}=160$ ). If there was not one litre of organic matter in the first leaf axil, we chose another at random (still at the same height) until one litre was collected. The organic matter was transported to the laboratory in cotton bags, where the samples were sieved over a $10 \mathrm{~mm}$ mesh and the top fraction discarded. Sampling was conducted between 11:00 and 13:00 during the dry season, from May to June 2014. Samples were immediately weighed to obtain wet mass. Following this, arthropods were extracted from the samples using Winkler extractors (Agosti and Alonso 2000). The organic matter was placed into elastic 6-mm 
mesh bags, which were suspended inside the Winkler sack, fitted at the bottom with a falcon tube containing $75 \%$ ethanol to preserve the fauna extracted.

The organic matter was removed after 72 hours, which is sufficient for Winkler extraction (Krell et al., 2005). The organic matter was then oven-dried for 48 hours at $80^{\circ} \mathrm{C}$ and weighed again to obtain the dry mass. The moisture content of the organic material collected was calculated as a percentage of dry organic matter:

$M C \%=\left(W_{W}-W_{D}\right) / W_{D} \times 100$

where: $W_{W}=$ Mass wet organic matter; $W_{D}=$ Mass dry organic matter

All arthropods extracted were then identified to higher taxonomic groups in the laboratory. The ants (Hymenoptera: Formicidae) were further identified to genus level (Fayle et al. 2014).

\section{Measurement of decomposition rate}

To determine decomposition rate in the oil palm leaf axils, litter bags (Falconer et al. 1933) were placed in each of the five centre oil palm study trees (described above) at each plantation. Edge oil palms were not included because they were not within the core research plot and it could not be guaranteed that litter bags placed there would be left undisturbed for the required time period. In each oil palm we placed six litter bags at $2 \mathrm{~m}$ and $4 \mathrm{~m}$ (12 per tree): a total of 480 litter bags. Three were removed from each location after two months, and the other three after four months.

The litter bags were $10 \times 10 \mathrm{~cm}$, with a $2 \mathrm{~mm}$ mesh and contained $3 \mathrm{~g}$ of dried epiphyte leaves. The fern species Nephrolepisa cutifolia was used for the reason that it was the most common epiphytic species found in all sampled plantations. The leaves were dried for 48 hours at $60^{\circ} \mathrm{C}$ and then being put into the litter bags, which were then weighed and pinned into the leaf axils. After removal from the palms the leaves from the litter bags were dried to a constant weight in the laboratory at room temperature and weighed again. Decomposition rates were calculated using exponential decay function (Olson 1963):

$W=W_{0} \exp (-k t)$

where: $W=$ amount dry matter $(g)$ remaining at time $t$ (60 days, 120 days);

$W_{0}=I$ initial amount

dry matter $(g) ; k=$ decomposition rate

\section{Statistical analyses}

The completeness of ant and overall arthropod sampling was evaluated with species and higher taxa accumulation curves (Magurran 2013) using the R package vegan, version 2.0-9 (Oksanen et al. 2015).

We tested oil palm parameters (epiphyte cover, ground vegetation cover, location (centre/edge), height, dry organic matter mass, moisture content) on arthropod community variables: (i) arthropod abundance (ants excluded), (ii) ant abundance, (iii) arthropod taxon richness, and (iv) ant genus richness $(n=160)$ using linear mixed effect models (LME). First, we created an initial full model for each response 
variable with all explanatory variables with their pairwise interaction included. Significant interactions as well as all main effects were included in the final models. Analyses of decomposition rates were as follows. We included all explanatory variables used above (without location, as only non-edge palms were assessed for decomposition rates) and the arthropod community parameters on (i) decomposition rate after 60 days and (ii) 120 days using LMEs ( $n=80)$. To allow consideration of interactions but avoid over parameterisation for the decomposition rate, interactions were first evaluated in a block-wise manner. For each main term we computed one model with all the interactions involving that main term. We then composed the full model with all the main terms, plus the interactions that were significant at the alpha level of 0.05 in one of the models in the approach just described. Plantation and oil palm tree were included in the models for all predictors as random effects. Response variables were log transformed ( +1 due to some zero abundance) before analysis to meet assumptions of normality. Ground and epiphyte cover were positively correlated ( $P=0.0001, r=0.41)$, but not strongly enough to preclude including them jointly as explanatory variables in the models. LMEs were implemented within the nlme package in R (Pinheiro et al. 2015; R Core Team 2015) and were refitted with maximum likelihood (ML).

\subsection{Results}

\section{Arthropod communities}

In total 6638 arthropod individuals were found over all plots $(n=160)$. The individuals were identified to 28 taxonomic groups (Table S4.1). The most abundant group was Hymenoptera (4405, 65\% of total arthropod abundance), 99\% of which were ants (Formicidae). The mean abundance of arthropods excluding ants was $14.23 \pm 18.12$ (mean \pm SE) per sample and a taxon richness of $4.62 \pm 2.07$ per sample. A total of 4366 ant individuals were found in the collected samples, representing seven subfamilies and 41 genera (Table S2). The subfamily with the highest representation was Myrmicinae (73\%), followed by Dolichoderinae (10\%) and Ponerinae (7\%). The average number of ant individuals per sample was $28.23 \pm 44.4$ with an average genus richness of $3.21 \pm 1.99$ per sampled plot. The taxon accumulation curve for arthropods and the genus accumulation curve for ants pass into saturation phase suggesting the sampling effort almost fully captured the richness of arthropod and ant communities (Fig. S4.3).

\section{The effect of epiphytes and neighbouring non-oil palm habitats on arthropod communities}

Epiphyte cover did not explain variation in abundance of arthropods excluding ants (hereafter, “arthropod abundance") $(P=0.27)$, arthropod taxon richness $(P=0.33)$, ant abundance or genus richness $(P=0.94 ; P=0.77$ ) (Fig. S4.4, Table S4.3). Increased ground cover had a significantly negative influence on abundance $(P=0.04)$ and taxon richness of arthropods $(P=<0.01)$. However, ant abundance $(P=0.83)$ and genus richness $(P=0.45)$ were not dependent on ground cover (Fig. 4.4, Table S4.3). Arthropod and ant abundance was higher at the edge compared with the centre of the plantation $(P=0.01 ; P=0.04)$. Taxon richness was also marginally $(P=0.09)$ higher at the edge but 
this only equated to an average of 0.7 more taxon at the edge compared with the centre (Fig. 4.2a, d, g, Table S4.3) and there was no difference for ant genus richness $(P=0.31)$ (Fig. 4.2j, Table S4.3). Height was significantly positively correlated with arthropod abundance $(P=<0.01)$, ant abundance $(P=$ $<0.01)$ and arthropod taxon richness $(P=<0.01)$, but not for ant genus richness $(P=0.07)$ (Fig. 4.2b, e, $\mathrm{h}, \mathrm{k}$, Table S4.3). Furthermore, the interaction between height and moisture content was significant for arthropod abundance $(P=<0.01)$ and taxon richness $(P=<0.01)$. The direction of the relationship between moisture content and abundance of arthropods was dependent on height (positive at $4 \mathrm{~m}$ and negative at $2 \mathrm{~m}$ ). Additionally, there is a significant interaction between height and organic matter on arthropod taxon richness $(P=0.04)$. Dry organic matter mass had a positive effect on arthropod abundance, arthropod taxon richness and ant genus richness, but not ant abundance (Fig. 4.2c, f, i, l, Table S4.3). Finally, moisture content had a significant positive effect on ant genus richness $(P=0.04)$. 


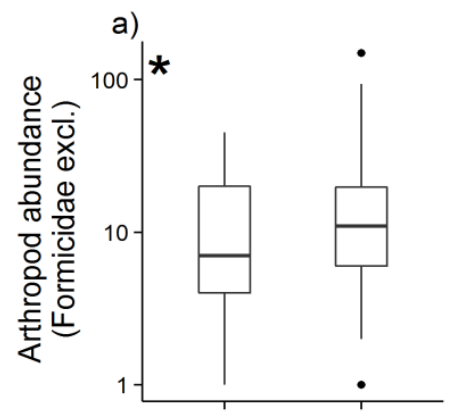

d)

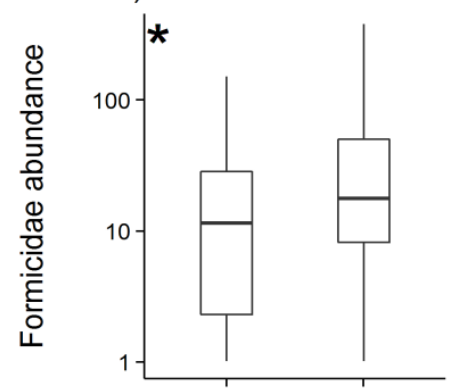

g)
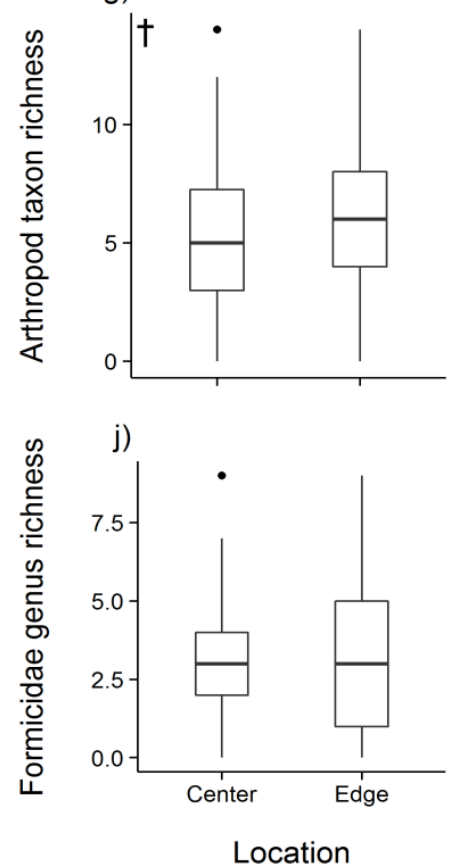

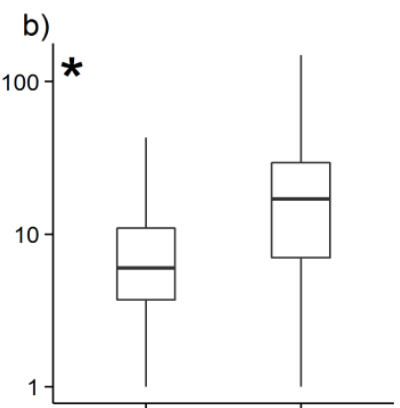

e)

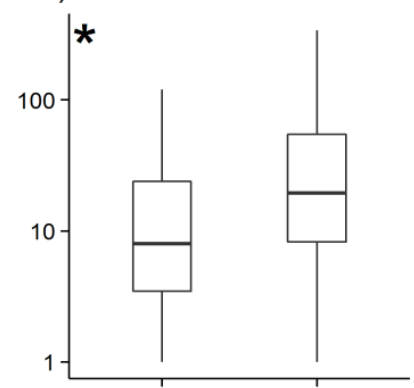

h)
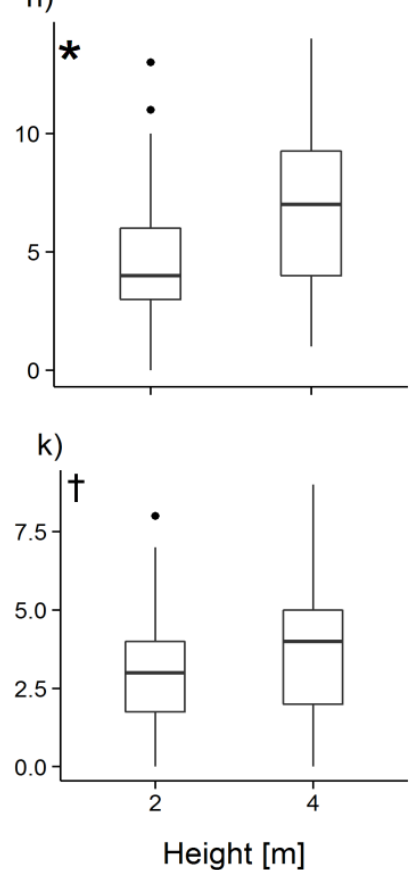

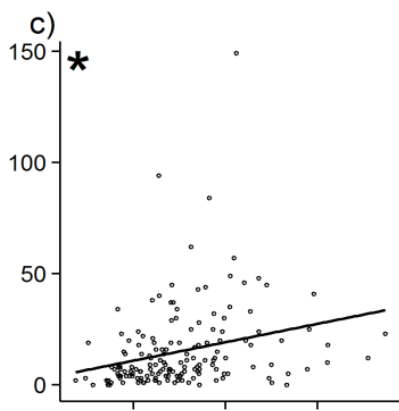

f)

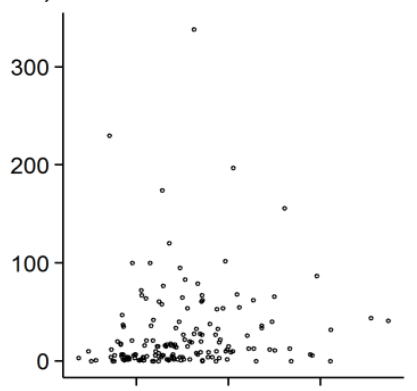

i)

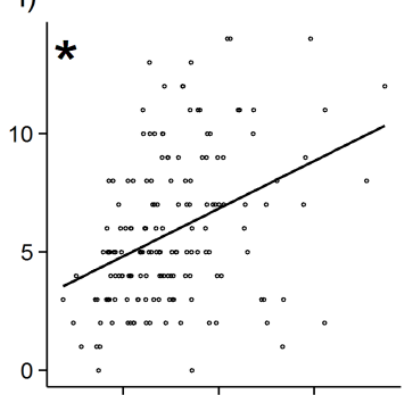

l)



Figure 4.2. The response of (a-c) arthropod abundance (ants excluded), (d-f) ant abundance, (g-i) arthropod taxon richness and $(\mathrm{j}-1)$ ant genus richness to location (centre, edge) of oil palm trees, height on the trunk $(2 \mathrm{~m}, 4 \mathrm{~m})$ and amount of dry organic matter $(\mathrm{n}=160)$. The error bars indicate the standard errors. Significant results $(P=\leq 0.05)$ are indicated with a star. Marginally significant $(P=\leq 0.10)$ are indicated with "†".

\section{The effect of plantation characteristics and arthropod and ant communities on decomposition}

The mean loss of organic material from the litter bags was $1.55 \pm 0.51$ grams $(52 \%)$ and $1.88 \pm$ 0.47 grams (61\%) after 60 and 120 days, respectively. Of the oil palm characteristics tested, moisture content had a significantly positive relationship with decomposition rate after both $60(P=0.03)$ and 120 days $(P=<0.01)$ (Fig. $4.3 \mathrm{~b}$, Table S4.4), whereas, height $(P=0.01)$ and ground cover $(P=0.01)$ only 
had a significant positive relationship with decomposition rate after 60 and 120 days, respectively (Fig. 4.3a, Fig. S4.5b, Table S4.4). Only one out of the four arthropod variables significantly explained variation in decomposition rates after both 60 and 120 days (Table S4.4). Arthropod abundance had a significant positive relationship with decomposition rate after 60 days $(P=0.04)$ (Fig. 4.4a, Table S4.4a), and conversely, ant abundance had a significant negative relationship with decomposition rate after 120 days $(P=0.01)$ (Fig. 4.4c, Table S4.4b). Also, there was a significant interaction between height and epiphyte cover $(P=<0.01)$ and between organic matter mass and ant abundance $(P=0.05)$ on decomposition rate after 60 days. Epiphyte cover had a negative effect on decomposition rates at $4 \mathrm{~m}$ but not at $2 \mathrm{~m}$. Ant abundance was more positively correlated with decomposition when organic matter mass was increase.
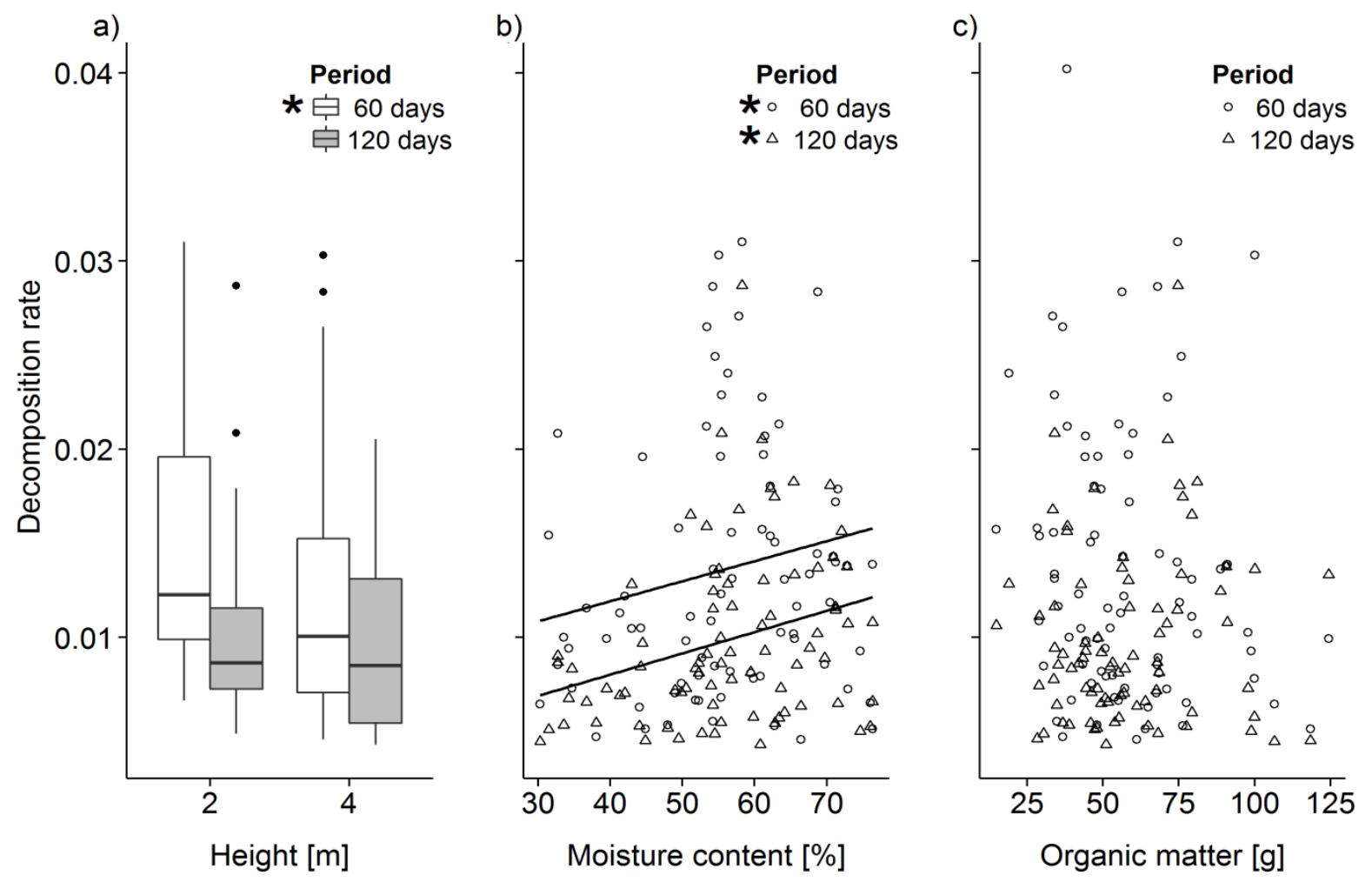

Figure 4.3.The relationship between decomposition rate after 60 and 120 days and (a) height $(2 \mathrm{~m}, 4 \mathrm{~m})$, (b) moisture content $(\%)$ and (c) dry organic matter of central oil palm trees $(\mathrm{n}=80)$. Significant results $(P$ $=\leq 0.05)$ are indicated with a star. 

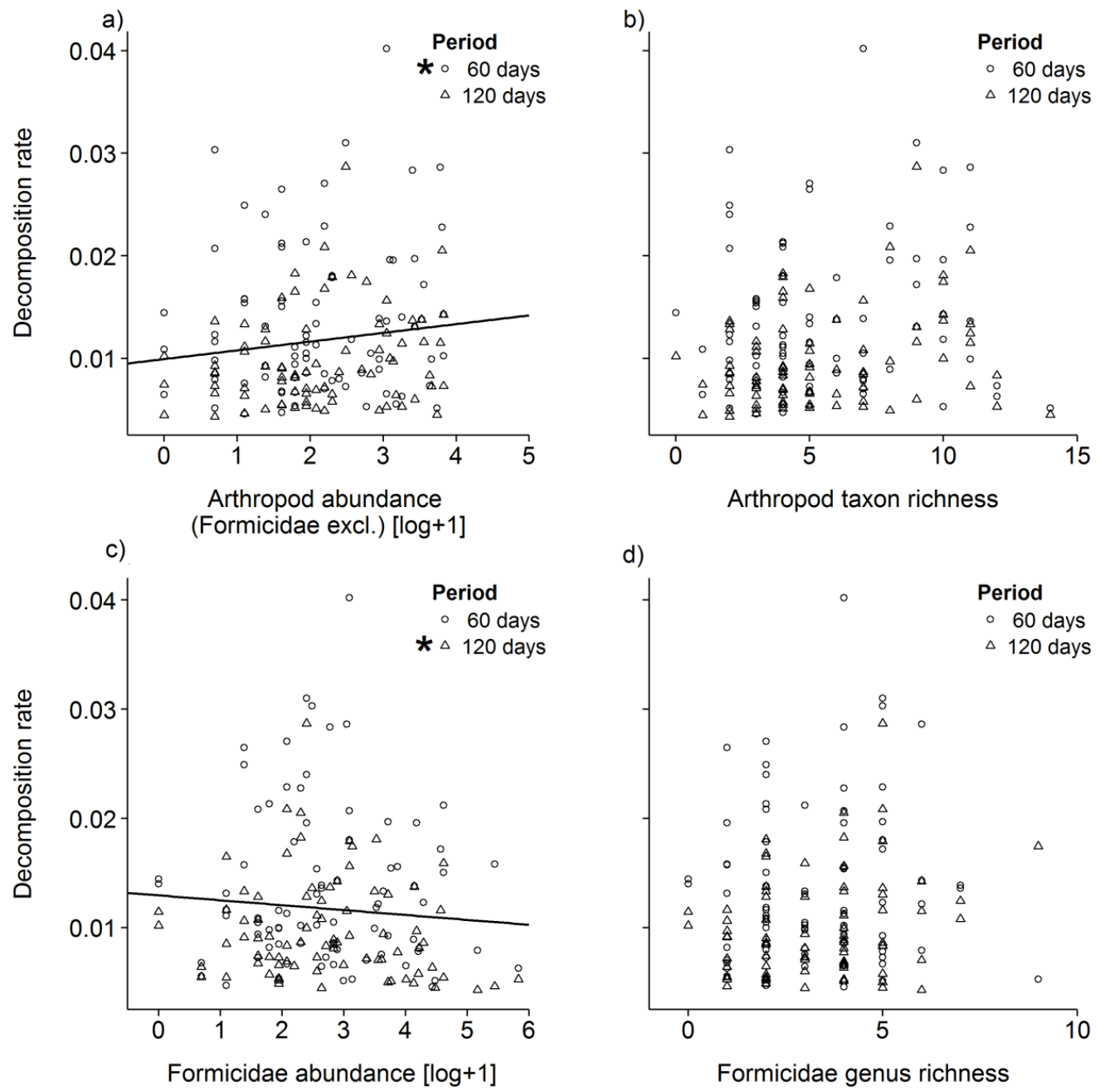

Figure 4.4. The relationship between decomposition rate after 60 and 120 days and (a) arthropod abundance (Formicidae excluded, log+1 transformed), (b) arthropod taxon richness, (c) Formicidae abundance (log+1 transformed) and (d) Formicidae genus richness of central oil palm trees $(\mathrm{n}=80)$. Significant results $(P=\leq 0.05)$ are indicated with a star.

\subsection{Discussion}

\section{The effect of edge habitats on arthropod and ant communities}

We found that oil palm trees at the edge of plantations host more arthropod and ant individuals and slightly higher arthropod taxa richness than oil palms in the centre of plantations. The most common habitats neighbouring the study sites were jungle rubber and shrub land, which have higher habitat diversity than oil palm plantations and may act as source habitats for arthropods spilling over into the oil palm plantations (Tscharntke et al. 2012b). Moreover Rubiana et al. (2015) showed that there is a different ant assemblage structure in jungle rubber, compared with oil palm plantation. Although there was no control in which two adjacent plantations were sampled, previous studies have found that more diverse habitat surrounding plantations can encourage spill over of non-plantation species, supporting the positive effects of more diverse habitats surrounding the plantations found in this study (Koh 2008b; Lucey et al. 2014). For example, Lucey et al (2014) found that adjacent habitats may act as 'stepping stones' for some species normally absent in oil palm plantations, whereas monocultures of oil palm 
enhance the number of mostly generalist species. Also, in monocultures local extinction is a common process and immigration is of major importance (Tscharntke et al. 2012b). Our results provide a strong argument in support of having more patches of different habitats in the surrounding landscape to enhance arthropods in the plantations and to maintain higher landscape diversity as a result.

\section{The impact of oil palm characteristics on arthropod and ant communities}

Organic matter within the oil palm leaf axils plays an important role in both arthropod and ant community structure. We found that the abundance of arthropods and ants as well as the genus and taxon richness showed a positive correlation with total organic matter mass. This is due to the organic matter in leaf axils being important for arthropods as a nesting substrate, food source and shelter in the hot and dry plantations. Furthermore, there was increased ant and overall arthropod abundance and genus and taxon richness higher on the oil palm tree ( $4 \mathrm{~m}$ compared with $2 \mathrm{~m}$ ), indicating a more suitable habitat for arthropod communities. A possible explanation for this could be the interaction between organic matter and height, as there is higher organic matter accumulation at $4 \mathrm{~m}$ compared with $2 \mathrm{~m}$. Finally, there may be a less intensive use of chemicals higher on the oil palm (pers. obs.), because spraying chemicals at a height above two metres is impractical for the plantation workers. Therefore, the higher position might be less disturbed than the lower parts where a frequent use of herbicides and insecticides is common.

The response of arthropods to ground cover was surprising, because the abundance of arthropods was highest when the ground cover was lowest. The amount of ground cover investigated in this study was included as a proxy for the last application of herbicide use, and we expected that arthropod abundance would be higher with ground cover present, but the opposite was the case. These results could indicate that oil palm trees may become habitat islands for arthropods when ground cover plants are absent due to the use of herbicides, with leaf axils, especially those harbouring epiphytes, providing refugia for them. The higher abundance may be diluted again when ground cover plants grow back and can be used by the arthropods. Research is needed investigating the differences in arthropod communities between the different habitats in oil palm plantations.

\section{The influence of arthropod and ant communities and oil palm characteristics on decomposition rates}

Ant abundance had a significantly negative effect on decomposition rate after 120 days. This could be due to predatory ants negatively influencing the decomposer community. Ants can have significant top down effects on the arthropod fauna (Philpott et al. 2004) due to certain species becoming ecologically dominant, which leads to a reduction of species richness and evenness of arthropod communities (Hölldobler and Wilson 1994). Certain dominant ant species may exclude other species from their territory and food sources (Gibb and Hochuli 2003), which in this case could be the detritivorous species influencing decomposition rate. Conversely, high overall arthropod abundance (excluding ants) had a significantly positive effect on decomposition rate after 60 days. Moreover, we found that high moisture content in the organic matter positively influenced decomposition. A certain amount of water in the organic matter is necessary for the survival of detritivorous organisms affecting decomposition rate (Kowalenko et al. 1978). 


\section{The impact of epiphytic plants on arthropod and ant communities}

The extent of epiphyte establishment on palms did not influence associated ant or overall arthropod communities. Although this is initially surprising, it is supported by similar results in a study by Prescott et al (2015) which found total removal of epiphytes in oil palm plantations does not affect ant species richness. The lack of relationships in our study may be due to the absence of certain epiphyte species (in particular, Asplenium nidus) or because of the age structure of the investigated oil palms. The epiphyte species and community structure change between middle aged (like in this study) and old oil palms (Altenhövel 2013; Krobbach 2014). Leaf-axils fall off older oil palms and epiphytic plants may become more important in the absence of leaf axils due to the epiphytes providing a structure for habitats unavailable when leaf axils are absent. Also, it is important to consider that although ants and broad measures of the arthropod community are not influenced by epiphyte cover, the community composition or richness of other taxa may be affected (Prescott et al. 2015). Additionally, a possibility for future research would be to investigate the influence of epiphyte presence at the exact sample site, rather than just total epiphyte cover.

\section{Conclusions and management recommendations}

This study indicates that higher species richness in oil palm plantations can be achieved with adjacent fields of different agricultural land use or other systems. A mosaic of patch types of agricultural and semi-natural systems may act as a reservoir for beneficial species spilling over to the oil palms. Even a plantation design of different aged small fields of oil palms would increase heterogeneity within a plantation (Luskin and Potts 2011) having possible positive implications for arthropod biodiversity. Furthermore, we found that height on the tree and amount of organic matter were more important for arthropod communities than epiphyte cover. Epiphyte cover did not positively influence arthropod communities, however, this should not provide a justification for removal of epiphytes in the plantations as other animal groups and functions not studied could still be negatively influenced and they retain plant diversity in often depauperate plantations. Also, a recent study found no effect of epiphytes on yield (Prescott et al. 2015) which, along with the fact that epiphytes are by name non-parasitic, eliminates one of the main arguments for removal.

\section{Acknowledgments}

We thank Derly Hartika, Bagus Putra Hamonangan Hutajulu and Rico Fardiansah for all their help in the lab and the field. We thank the village leaders and local plot owners for granting us the use of their properties. This study was financed by the Deutsche Forschungsgemeinschaft (DFG) in the framework of the collaborative German - Indonesian research project CRC990: EFForTS (Ecological and Socioeconomic Functions of Tropical Lowland Rainforest Transformation Systems in Sumatra, Indonesia). 


\subsection{Supplementary material}

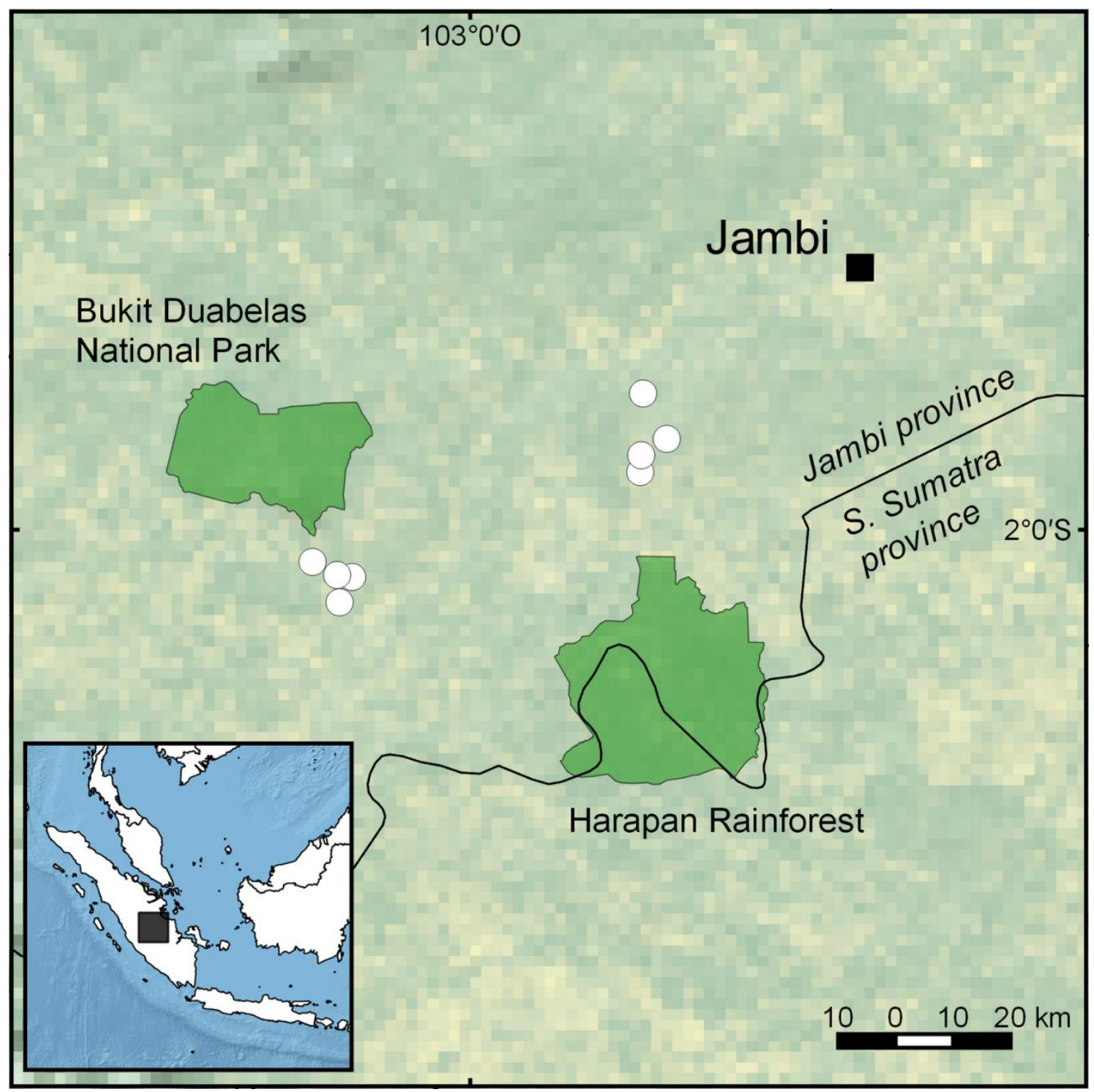

Figure S4.1. Map of study area located in Jambi, Sumatra, Indonesia. Four oil palm plantations were located in each of the two study regions. Study plantations are indicated with a white point. The regions were adjacent to two protected areas, the Bukit Duabelas National Park and the Harapan rainforest. 


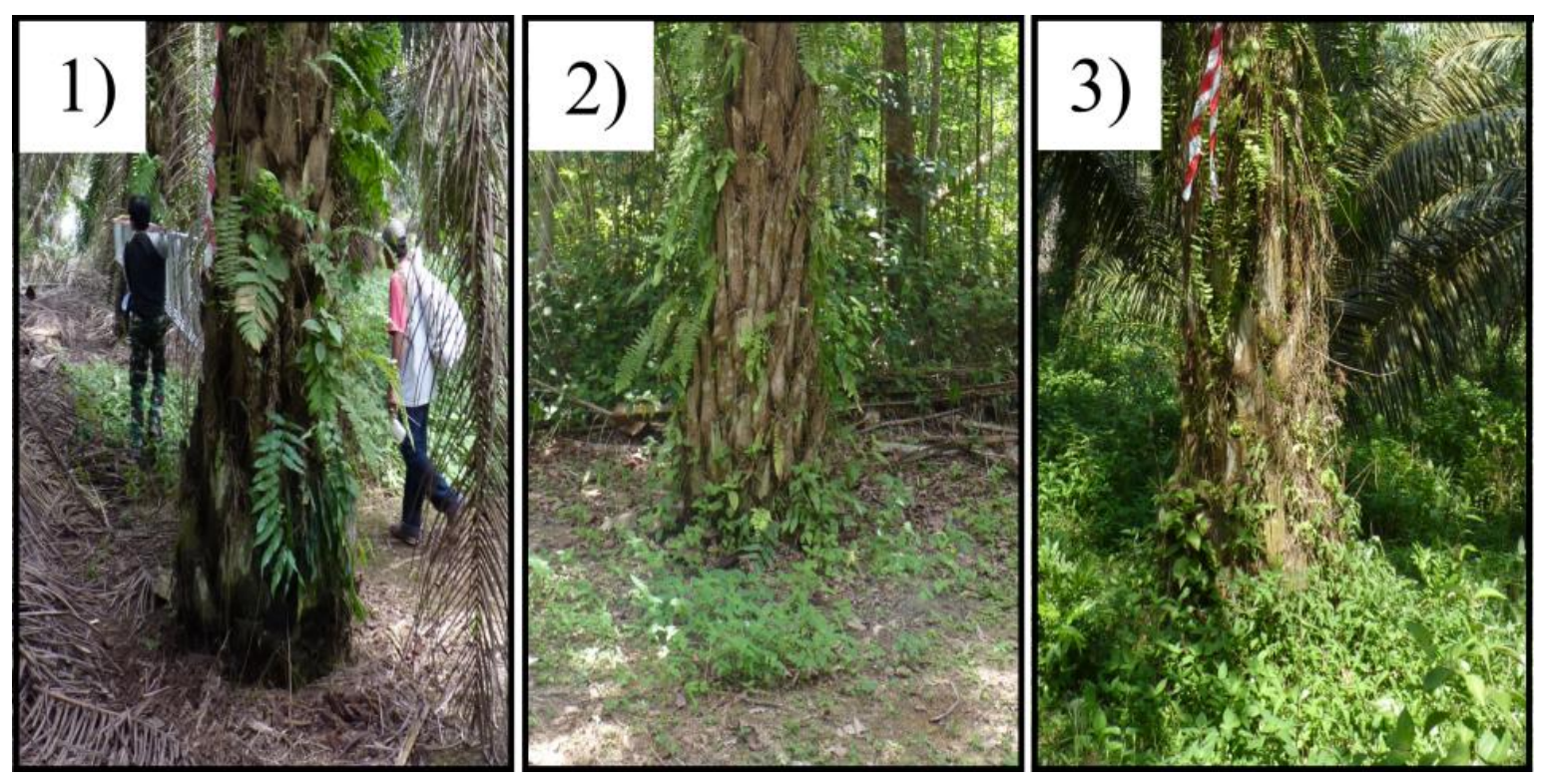

Figure S4.2. Ground cover, proportion of ground next to the oil palm within a two metre radius covered by other vegetation assessed on a scale of 1-3: (1) $0-35 \%$, (2) $36-65 \%$, (3) $66-100 \%$ ground cover.

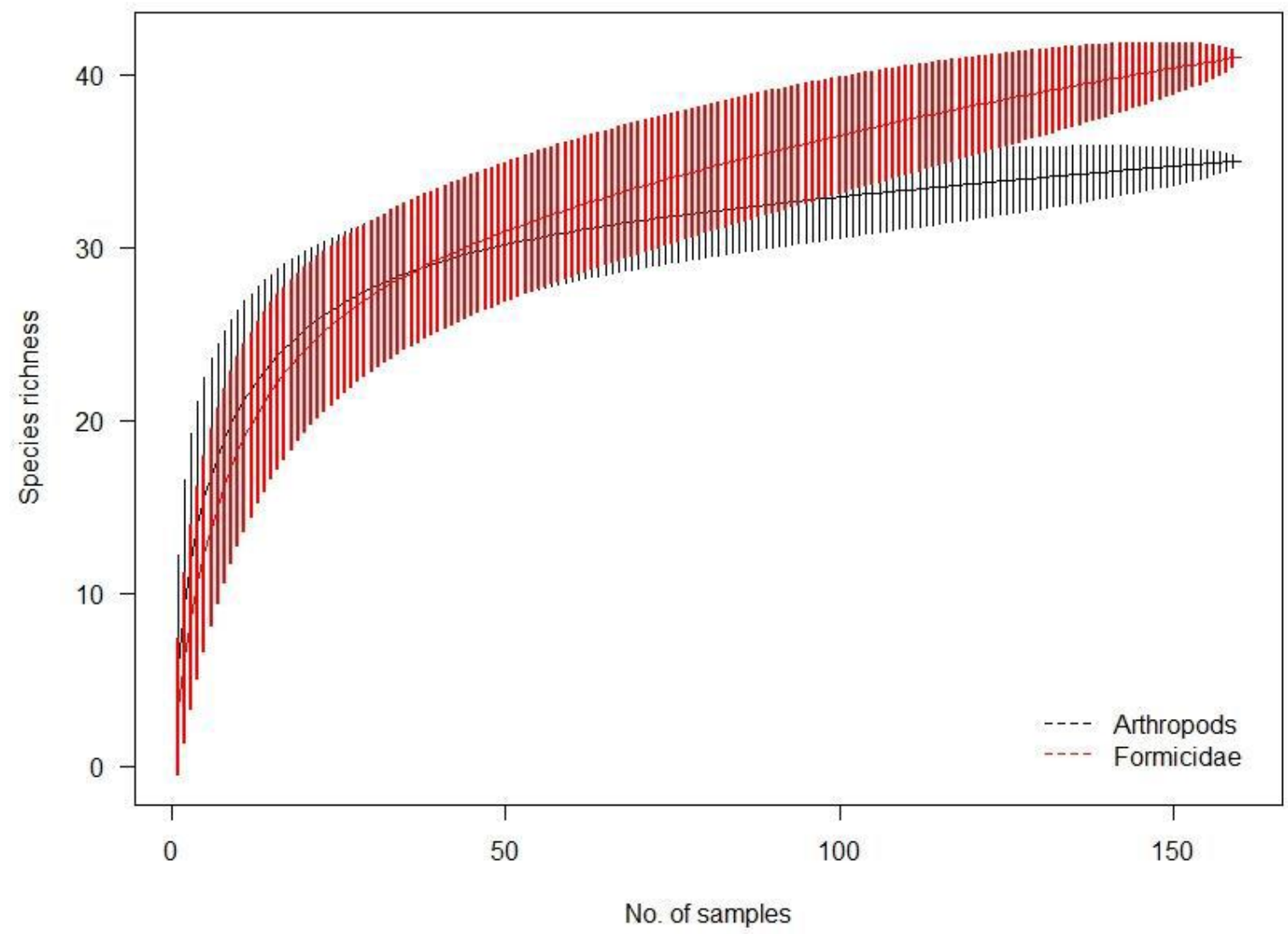

Figure S4.3. Formicidae genus and higher-ranked taxon accumulation curve for all samples ( $n=160)$. 100 permutations. The error bars indicate the standard errors. 

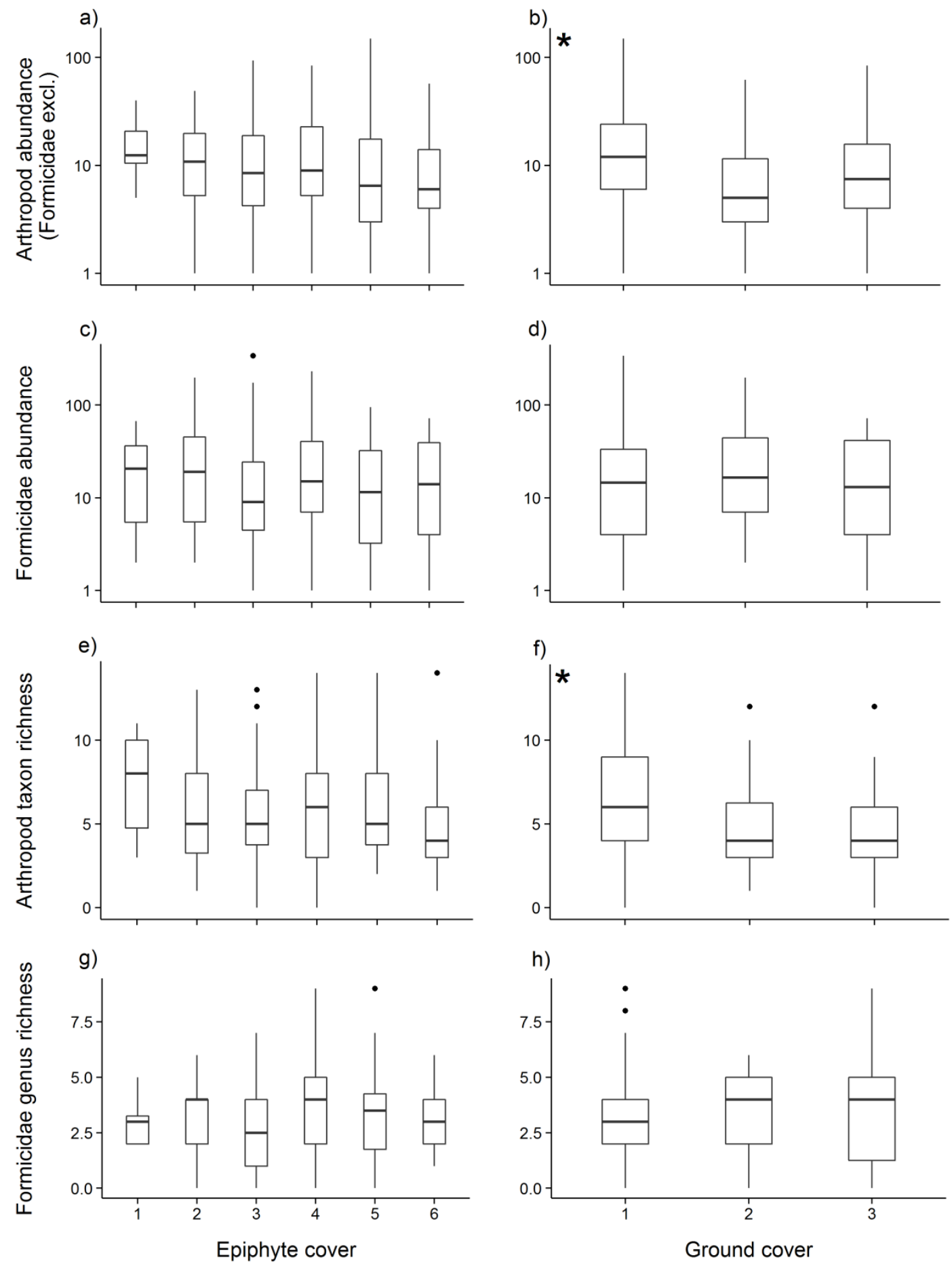

Figure S4.4. The response of (a-b) arthropod abundance (Formicidae excluded), (c-d) Formicidae abundance, (e-f) arthropod taxon richness and (g-h) Formicidae genus richness to epiphyte cover (categorical: $1=$ very low, $6=$ very high) and ground cover (categorical: $1=$ low, $3=$ high) in oil palm plantation $(\mathrm{n}=160)$. Significant results $(P=\leq 0.05)$ are indicated with a star. 

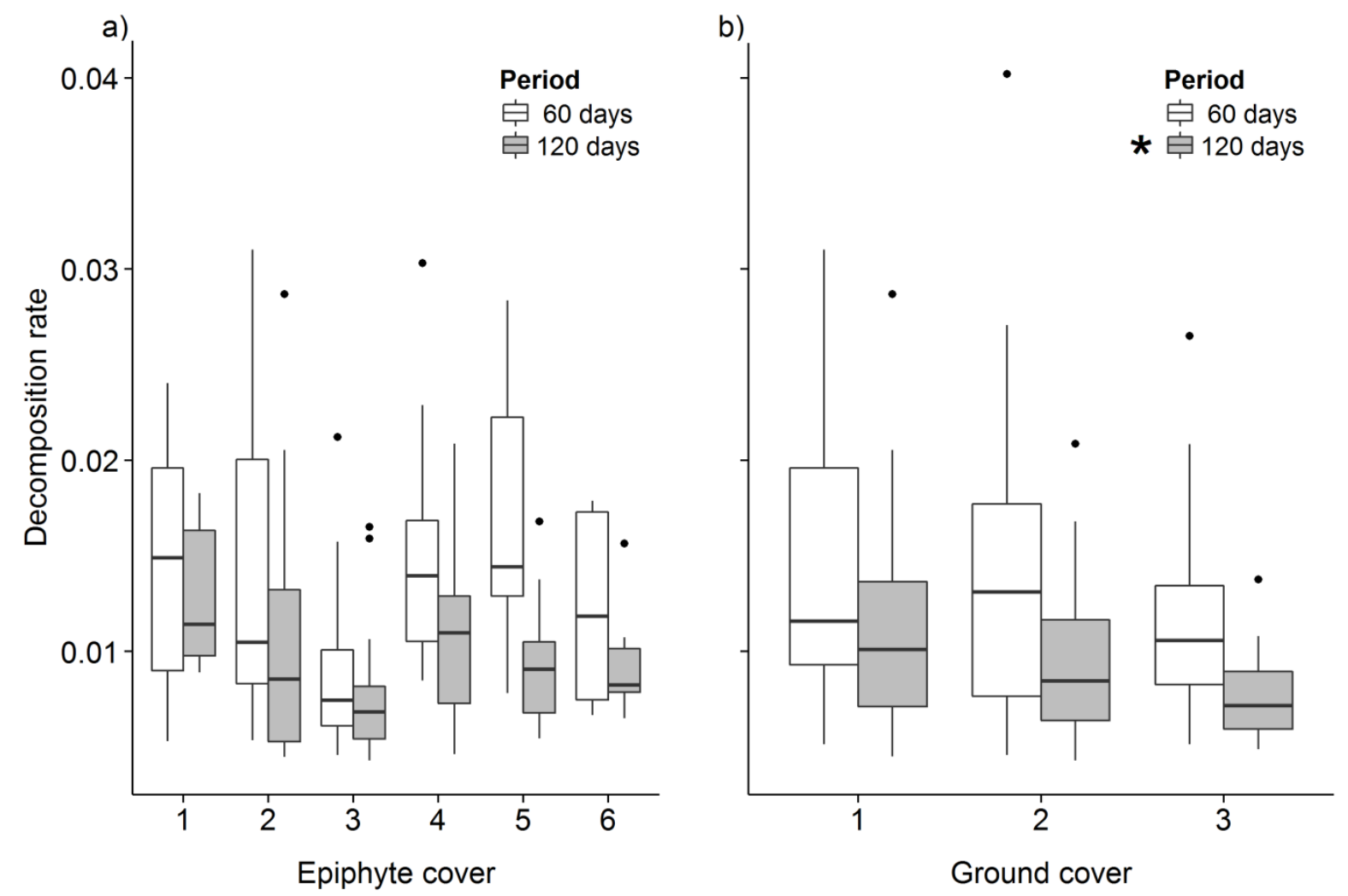

Figure S4.5.The relationship between decomposition rate after 60 and 120 days and (a) epiphyte cover (categorical: $1=$ very low, $6=$ very high) and (b) ground cover (categorical: $1=$ low, $3=$ high) of central oil palm trees $(\mathrm{n}=80)$. Significant results $(P=\leq 0.05)$ are indicated with a star. 
Table S4.1. Total abundance of each higher taxonomic group in the studied oil palm plantations $(n=8)$, separated into the two study regions (a) Harapan and (b) Bukit12.

\begin{tabular}{|c|c|c|c|}
\hline \multirow[b]{2}{*}{ Taxon } & \multicolumn{3}{|c|}{ Number of individuals } \\
\hline & a) Harapan & b) Bukit12 & Total \\
\hline Araneae & 116 & 124 & 240 \\
\hline Arcari & 144 & 39 & 183 \\
\hline Amphipoda & 5 & 0 & 5 \\
\hline Archaeognatha & 4 & 1 & 5 \\
\hline Blattodea & 47 & 50 & 97 \\
\hline Chilopoda & 27 & 34 & 61 \\
\hline Coleoptera & 83 & 123 & 206 \\
\hline Collembola & 139 & 187 & 326 \\
\hline Dermaptera & 103 & 101 & 204 \\
\hline Diplopoda & 11 & 65 & 76 \\
\hline Diplura & 17 & 15 & 32 \\
\hline Diptera & 51 & 103 & 154 \\
\hline Formicidae & 1521 & 2845 & 4366 \\
\hline Hemiptera & 3 & 21 & 24 \\
\hline Hymenoptera (non Formicidae) & 16 & 23 & 39 \\
\hline Isoptera & 12 & 0 & 12 \\
\hline Isopoda & 184 & 219 & 403 \\
\hline Lepidoptera & 10 & 11 & 21 \\
\hline Opiliones & 5 & 7 & 12 \\
\hline Orthoptera & 8 & 8 & 16 \\
\hline Pauropoda & 0 & 1 & 1 \\
\hline Protura & 1 & 0 & 1 \\
\hline Pseudoscorpions & 7 & 3 & 10 \\
\hline Psocoptera & 17 & 9 & 26 \\
\hline Scorpiones & 0 & 1 & 1 \\
\hline Symphyla & 37 & 38 & 75 \\
\hline Thysanoptera & 1 & 2 & 3 \\
\hline Total & 2587 & 4511 & 6638 \\
\hline
\end{tabular}


Table S4.2. Total abundance of each Formicidae genus in the studied oil palm plantations $(n=8)$, separated into the two different study regions (a) Harapan and (b) Bukit12.

\begin{tabular}{|c|c|c|c|}
\hline \multirow[b]{2}{*}{ Genus } & \multicolumn{3}{|c|}{ Number of individuals } \\
\hline & a) Harapan & b) Bukit12 & Total \\
\hline Proatta & 445 & 289 & 734 \\
\hline Pheidologeton & 9 & 531 & 540 \\
\hline Paratopula & 100 & 403 & 503 \\
\hline Pheidole & 176 & 276 & 452 \\
\hline Monomorium & 229 & 211 & 440 \\
\hline Tapinoma & 137 & 266 & 403 \\
\hline Hypoponera & 85 & 123 & 208 \\
\hline Cardiocondyla & 28 & 154 & 182 \\
\hline Aphaenogaster & 36 & 84 & 120 \\
\hline Tetramorium & 67 & 34 & 101 \\
\hline Prionopelta & 1 & 90 & 91 \\
\hline Pyramica & 64 & 0 & 64 \\
\hline Strumigenys & 36 & 27 & 63 \\
\hline Anochetus & 43 & 17 & 60 \\
\hline Euprenolepis & 0 & 56 & 56 \\
\hline Prenolepis & 1 & 53 & 54 \\
\hline Anoplolepis & 17 & 35 & 52 \\
\hline Crematogaster & 1 & 49 & 50 \\
\hline Technomyrmex & 16 & 22 & 38 \\
\hline Ponera & 6 & 24 & 30 \\
\hline Odontomachus & 5 & 15 & 20 \\
\hline Rotastruma & 0 & 17 & 17 \\
\hline Camponotus & 1 & 15 & 16 \\
\hline Rhoptromyrmex & 14 & 0 & 14 \\
\hline Philidris & 0 & 10 & 10 \\
\hline Tetraponera & 0 & 9 & 9 \\
\hline Lordomryma & 0 & 8 & 8 \\
\hline Plagiolepis & 0 & 7 & 7 \\
\hline Pseudolasius & 1 & 6 & 7 \\
\hline Pachycondyla & 0 & 5 & 5 \\
\hline Lasiomyrma & 0 & 2 & 2 \\
\hline
\end{tabular}




\begin{tabular}{lccc}
\hline Calyptomyrmex & 2 & 0 & 2 \\
Myrmecina & 0 & 2 & 2 \\
Leptogenys & 0 & 2 & 2 \\
Myrmicaria & 0 & 1 & 1 \\
Meranoplus & 1 & 0 & 1 \\
Paratrechina & 0 & 1 & 1 \\
Proceratium & 0 & 1 & 1 \\
\hline Total & $\mathbf{1 5 2 1}$ & $\mathbf{2 8 4 5}$ & $\mathbf{4 3 6 6}$ \\
\hline
\end{tabular}


Table S4.3. Summary of statistics (model output tables) of linear mixed effects analyses of oil palm components: dry organic matter, height ( 2 metres, 4 metres), location (centre, edge), moisture content (\%), epiphyte cover (1=low, $6=$ high), and ground cover ( $1=$ low, $3=$ high) on (a) arthropod abundance with Formicidae excluded $(\log +1)$,(b) Formicidae abundance $(\log +1)$,(c) arthropod taxon richness and (d) Formicidae genus richness. Random effects: $1 \mid$ plantation/tree. Significant $P$-values $(P=\leq 0.05)$ are indicated in bold.

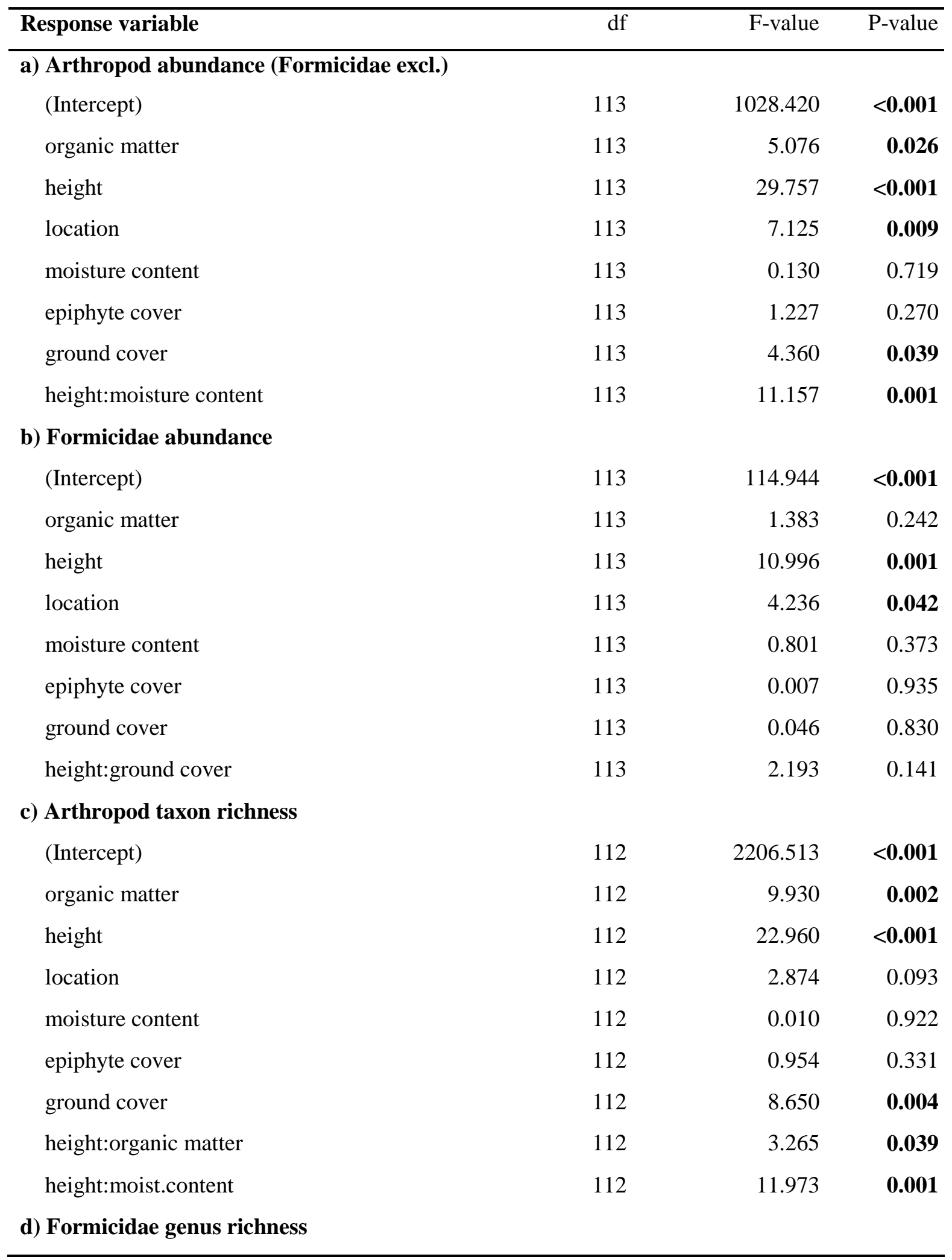




\begin{tabular}{lrrr}
\hline Intercept $)$ & 112 & 200.237 & $<\mathbf{0 . 0 0 1}$ \\
Formicidae abund. $(\log +1)$ & 112 & 83.678 & $<\mathbf{0 . 0 0 1}$ \\
organic matter & 112 & 6.833 & $\mathbf{0 . 0 1 0}$ \\
height & 112 & 3.358 & 0.070 \\
location & 112 & 1.040 & 0.310 \\
moisture content & 112 & 4.176 & $\mathbf{0 . 0 4 3}$ \\
epiphyte cover & 112 & 0.086 & 0.770 \\
ground cover & 112 & 0.565 & 0.454 \\
height:ground cover & 112 & 3.664 & 0.051 \\
epiphyte cover:organic matter & 112 & 2.900 & 0.091 \\
\hline
\end{tabular}


Table S4.4. Summary of statistics (model output tables) of linear mixed effects analyses of oil palm components: dry organic matter, height ( 2 metres, 4 metres), moisture content (\%), epiphyte cover (1=low $-6=$ high), ground cover ( $1=$ low $-3=$ high), epiphyte species richness, arthropod abundance (Formicidae excluded), Formicidae abundance, arthropod taxon richness and Formicidae genus richness on (a) decomposition rate after 60 days (log), and (b) decomposition rate after 120 days (log) in the centre plots. Random effects: $1 \mid$ plantation/tree. Significant $P$-values $(P=\leq 0.05)$ are indicated in bold.

\begin{tabular}{lrrr}
\hline Response variable & df & F-value & P-value \\
\hline a) Decomposition rate after 60 days & 30 & 4453.096 & $<\mathbf{0 . 0 0 1}$ \\
(Intercept) & 23 & 8.338 & $\mathbf{0 . 0 0 8}$ \\
height & 30 & 4.047 & 0.063 \\
epiphyte cover & 30 & 2.406 & 0.131 \\
ground cover & 23 & 0.985 & 0.331 \\
organic matter & 23 & 5.713 & $\mathbf{0 . 0 2 5}$ \\
moisture content & 23 & 3.263 & $\mathbf{0 . 0 4 4}$ \\
arthropod abundance (Form. excl.) & 23 & 0.151 & 0.879 \\
arthropod taxon richness & 23 & 0.546 & 0.468 \\
Formicidae abundance & 23 & 0.024 & 0.879 \\
Formicidae genus richness & 23 & 29.664 & $<\mathbf{0 . 0 0 1}$ \\
height : epiphyte cover & 23 & 2.361 & $\mathbf{0 . 0 4 7}$
\end{tabular}

a) Decomposition rate after 120 days

$\begin{array}{lrrr}\text { (Intercept) } & 30 & 12714.091 & <\mathbf{0 . 0 0 1} \\ \text { height } & 29 & 2.249 & 0.152 \\ \text { epiphyte cover } & 30 & 0.167 & 0.679 \\ \text { ground cover } & 30 & 8.498 & \mathbf{0 . 0 0 6} \\ \text { organic matter } & 29 & 0.364 & 0.518 \\ \text { moisture content } & 29 & 20.814 & <\mathbf{0 . 0 0 1} \\ \text { arthropod abund. (Form. excl.) } & 29 & 2.602 & 0.120 \\ \text { arthropod taxon richness } & 29 & 1.374 & 0.134 \\ \text { Formicidae abund. } & 29 & 9.523 & \mathbf{0 . 0 0 4} \\ \text { Formicidae genus richness } & 29 & 1.577 & 0.200 \\ \text { organic matter } \text { : Formicidae abund. } & 29 & 3.010 & \mathbf{0 . 0 4 5}\end{array}$




\title{
Chapter 5
}

\section{Biological control in oil palm is enhanced by landscape context}

Fuad Nurdiansyah, Lisa H. Denmead, Yann Clough, Kerstin Wiegand, and Teja Tscharntke

In review, Agriculture, Ecosystems and Environment, submitted: $23^{\text {rd }}$ March 2016

\begin{abstract}
Oil palm plantation expansion is occurring at a rapid pace. However, substantial yield losses from pest attacks are becoming major threats to the oil palm industry, while the potential role of conservation biological control, a sustainable and environmentally friendly solution for pest control, is still largely unknown. The type of vegetation surrounding oil palm plantations can be hypothesized to influence pest predation, and we tested this in Indonesia (Sumatra), the worldwide largest palm oil producer. We studied six different vegetation types adjacent to oil palm plantations: another oil palm plantation (control), weedy oil palm, weedy rubber, scrub, jungle rubber, and secondary forest. Each border type was replicated eight times. We quantified predation rates and predator occurrences using dummy caterpillars and mealworms $20 \mathrm{~m}$ inside of the adjacent vegetation and $20 \mathrm{~m}$ as well as $50 \mathrm{~m}$ inside the oil palm plantation. Ants and bush crickets were the most prominent predators in the plantations, whereas birds, bats, monkeys, beetles, and molluscs played a minor role. Predation rates were $\sim 70 \%$ higher in non-oil palm habitat. This effect spilled over into the focal plantations, where predations were increased by $55-100 \%$ at a distance of $20 \mathrm{~m}$ from the border and $40-55 \%$ at a distance of $50 \mathrm{~m}$ from the border, indicating the need for improved vegetation diversification inside plantations. Overall predation rates in oil palm decreased slightly but significantly with distance to the border. Our results suggest that oil palm management maintaining non-oil palm vegetation in the area and weedy plant strips inside the plantation may be most promising for effective conservation biological control in the future.
\end{abstract}




\subsection{Introduction}

Oil palm plantation expansion is occurring at a rapid pace (Foster et al. 2011), particularly due to it being the highest yielding vegetable oil crop per unit area (Murphy 2009). However, substantial yield losses from pest attacks are becoming major threats to the oil palm industry (Kamarudin and Wahid 2010; Constantin et al. 2013; Woruba et al. 2014). Pests can be potentially controlled through two main methods, chemical inputs (pesticides) or biocontrol (Wood 2002). Compared to pesticide applications, biocontrol is known as a sustainable and ecofriendly solution, to reduce pest numbers below economic level by using natural enemies (Norris et al. 2003; Hajek 2004). However, research on factors influencing biocontrol agents in oil palm plantations, such as landscape context or local management, is lacking but urgently needed to understand the potential for biocontrol methods to stop yield losses from pest attacks.

Oil palms are attacked by a large number of insect pests (e.g. trunk borers and defoliators) and diseases (e.g. Ganoderma, Fusarium, and Phytomonas) (Corley and Tinker 2003). Both of which occur often in oil palm plantations and have a high impact on oil palm production (Wood 2002; Corley and Tinker 2003; Foster et al. 2011). However, defoliating pests, in particular bagworms (Psychidae) and nettle caterpillars (Limacodidae), play one of the most important roles in reducing crop yield due to their high reproduction and mobility (Wood 2002). For example, bagworms can cause up to 50\% yield loss at high infestation levels (Basri et al. 1995; Kamarudin and Wahid 2010), while nettle caterpillars can cause $29 \%$ and $31 \%$ yield reduction after the first and second year of infestation respectively (Potineni and Saravanan 2013). Significant pest attacks can be related to an imbalance between pests and their natural enemies (Igbinosa 1992; Wood 2002). In the past, pest resurgence after insecticide application was assumed to be a major cause of the imbalance (Wood 1971). However, despite the decline in use of broad spectrum-long residual contact-insecticides (bslrcs), pest numbers have still continued to reach detrimental numbers in many locations (Wood 2002; Kamarudin and Wahid 2010). Investigation of methods for promoting biocontrol agents in plantations is therefore crucial for decreasing pest outbreaks and maintaining or increasing production levels (Corley and Tinker 2003; Foster et al. 2011).

Fostering native biocontrol in oil palm plantations through local or landscape management may be an important approach to decreasing pest populations. Conversion to oil palm plantations results in highly simplified landscapes leading to huge biodiversity losses for a wide range of organisms, including biocontrol agents (Fitzherbert et al. 2008; Barnes et al. 2014; Dislich et al. in revision). Of particular concern is a decline in predatory species (Denmead et al. in review), which are the main cause of defoliator pest mortality in the field (Wood 2002). For example, Aratrakorn et al. (2006), and Koh (2008b) found that insectivorous birds have difficulty adapting to oil palm plantations and therefore, have a reduced capacity for top-down control of crop pests. Ant community composition is also largely changed, with many forest species lost and a decline in predatory species (Denmead et al. in review; Rubiana et al. 2015). Dejean et al (1997) reported that when two predatory 
ants, Crematogaster gabonensis and Tetramorium aculeatum, occupied oil palm plantations in Cameroon, there were lower attack rates by a leaf-mining beetle (Coleoptera: Chrysomelidae). However, studies on the biocontrol of oil palm pests in the past have mostly focused on the introduction of exotic biocontrol agents to the field or assessments of potential agents (Zeddam et al. 2003; Bakeri et al. 2009; Kamarudin and Wahid 2010), rather than evaluating factors influencing the native enemy population. There has been no comprehensive study that links pests to native biocontrol agents (Foster et al. 2011; Savilaakso et al. 2014). A potential method for increasing biodiversity, and in particular native biocontrol agents, in the plantations are the increase of landscape heterogeneity through such approaches as protecting riparian buffers (Gray and Lewis 2014), leaving patches of natural forest and agroforestry within the landscape, and enhancing the understorey vegetation (Koh 2008a; Koh et al. 2009). Thus, increasing landscape complexity and connectivity among habitats may provide a way to manipulate biological control in agroecosystem (Tscharntke et al. 2007; Tscharntke et al. 2012b).

Developing ecologically sound integrated pest management strategies in such a rapidly expanding agricultural system will be extremely important for the sustainability of the crop and the wider ecosystems in the long term. However, these concerns have only received little attention in the past. Here, we investigated if the surrounding landscape and the distance from border influence predator predation rates in oil palm plantations in Sumatra, Indonesia. We measured predation rates and predator occurrences using dummy caterpillars and mealworms in oil palm plantations bordered by important vegetation types such as another oil palm plantation (control), weedy oil palm, weedy rubber, scrub, jungle rubber, and secondary forest to determine if the border type can influence the potential for biocontrol in the plantations. We also surveyed a key predator group (ants) in different vegetation types to link predation rates with probable predators. Understanding how the landscape context and management can influence biocontrol agents in oil palm plantations is a crucial factor to allow farmers to promote biocontrol of crop pests.

\subsection{Materials and methods}

\section{Study area}

The study was conducted within two regions in the Batanghari and Sarolangun Regencies in Jambi Province, Sumatra, Indonesia. Both study regions were located in the lowland area of the province with potential vegetation of tropical lowland rainforest. However, there has been considerable land-use change in the province over the past 50 years as result of the expansion of agricultural land. In particular, more recently, the area cultivated as oil palm plantations increased from 150,000 ha to 550,000 ha in the period from 1996 to 2011 (Gatto et al. 2015) making oil palm one of the most dominant crops in the province.

Four important vegetation types in the study area include degraded lowland rainforest, jungle rubber (agroforestry system consisting of degraded forest with rubber trees between native 
vegetation), rubber plantations, and oil palm plantations. A major arthropod predator group across all these vegetation types is ants, which maintains dominance across all systems, with even slightly higher abundances and richness in oil palm plantations compared to other systems (Table 5.1, Appendix S5.1, Denmead et al. in review) and predatory ants lowest in the oil palm plantations (Table 5.1, Denmead et al. in review).

Table 5.1. Ant community composition measures (mean $\pm S E, n=8$ ) for each land-use system. Ant community responses to vegetation type were also tested using LMEs with region specified as a random effect (Appendix S5.1, Table S5.1). Means (within rows) with different letters are significantly different (Tukey's HSD, $P=\leq 0.05$ ) (Table S5.2). CWM preference ratio = community weighted mean (abundance-weighted mean trait values for a community) for the protein/carbohydrate preference ratio, a higher ratio indicates increased predator abundance (Appendix S5.1).

\begin{tabular}{lrrrr}
\hline & Forest & Jungle rubber & Rubber & Oil palm \\
\hline Ant species richness & $9.25 \pm 0.62 \mathrm{ab}$ & $8.75 \pm 0.92 \mathrm{a}$ & $12.50 \pm 0.68 \mathrm{bc}$ & $14.50 \pm 1.35 \mathrm{c}$ \\
Ant abundance & $15.72 \pm 3.93 \mathrm{a}$ & $14.57 \pm 4.15 \mathrm{a}$ & $17.15 \pm 2.85 \mathrm{a}$ & $26.13 \pm 5.19 \mathrm{~b}$ \\
& & & & \\
CWM preference ratio & $0.77 \pm 0.02 \mathrm{a}$ & $0.72 \pm 0.03 \mathrm{ab}$ & $0.75 \pm 0.02 \mathrm{a}$ & $0.65 \pm 0.01 \mathrm{~b}$
\end{tabular}

\section{Experimental design}

Sample and data collection were completed from October 2012 to June 2014 at the border of oil palm plantations that were surrounded by six different vegetation types: another oil palm plantation (control), weedy oil palm, weedy rubber, scrub, jungle rubber, and secondary forest (Fig. 5.1). In each of the two study regions each border type was replicated four times ( $\mathrm{n}=48$ sites). The minimum distance from a selected border to another was one kilometre. The age of the oil palm plantations was from five to 15-years-old.

At each of these 48 sites, we conducted our research at three locations: $20 \mathrm{~m}$ from border into the adjacent vegetation (OUT 20) and $20 \mathrm{~m}$ and $50 \mathrm{~m}$ into the focal oil palm plantation (IN 20 and IN 50) (Fig. S5.1). Each location consisted of two stations. Inside the plantation, each pair of stations was separated by one oil palm ( $\sim 20 \mathrm{~m})$. Inside the bordering vegetation, due to the high variance in vegetation the stations were not centred on particular trees, rather, at each station we marked a five metre long transect perpendicular to the border beginning at $20 \mathrm{~m}$ from the border (OUT 20) (Fig. 5.2). The distance between these stations (i.e. transects) was $20 \mathrm{~m}$. 

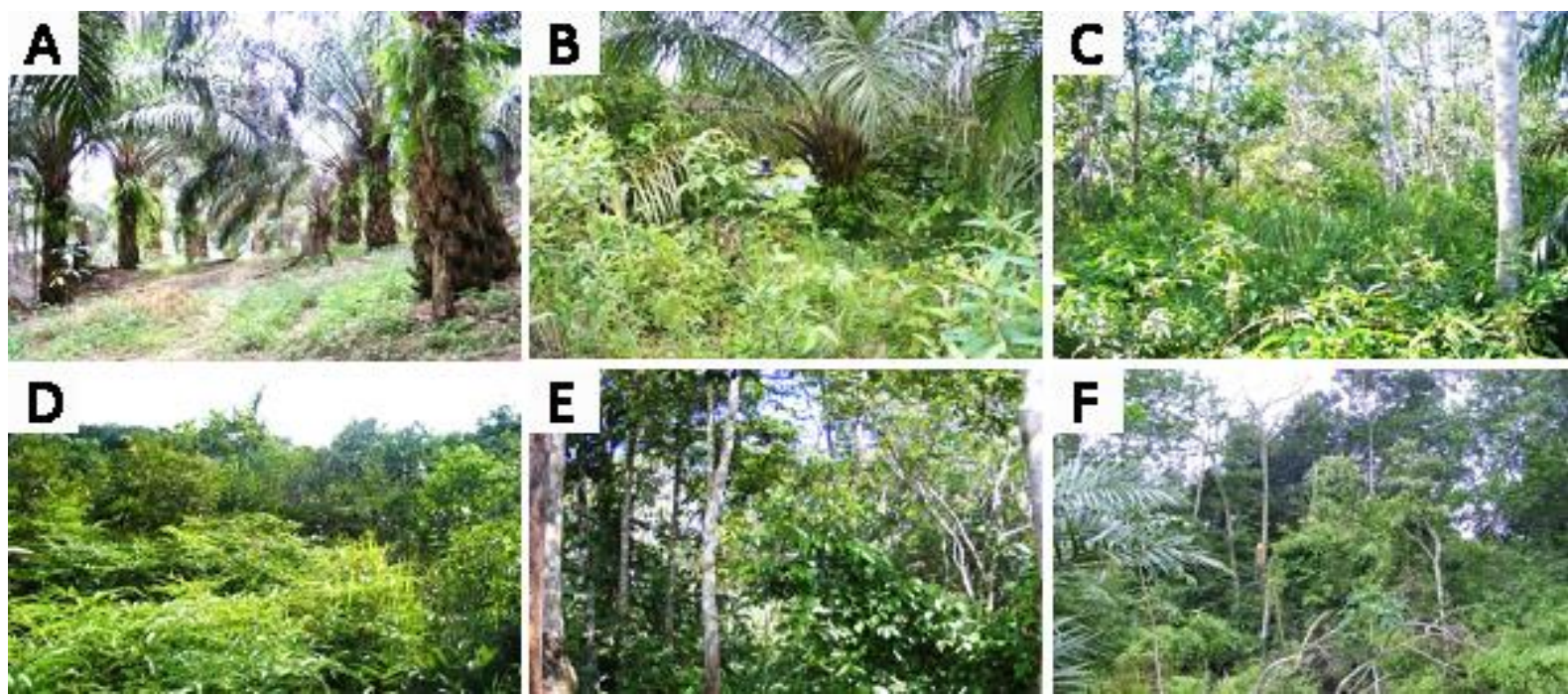

Figure 5.1. The types of vegetation bordering the oil palm plantations included in this study. A) Control (oil palm plantation), B) weedy oil palm plantation, C) weedy rubber plantation, D) scrub, E) jungle rubber, and F) secondary forest.

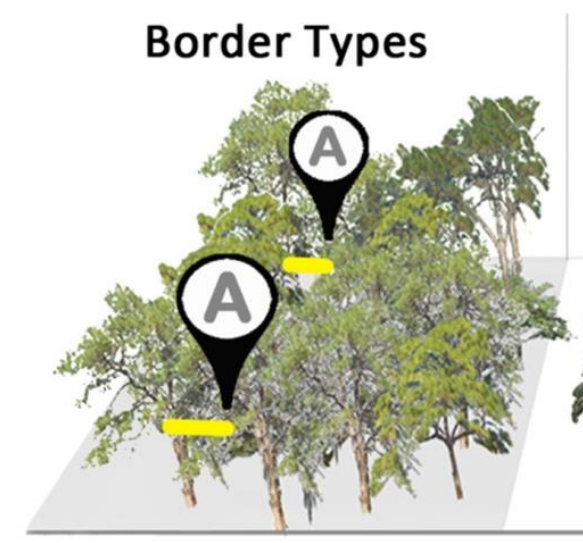

OUT 20

Border

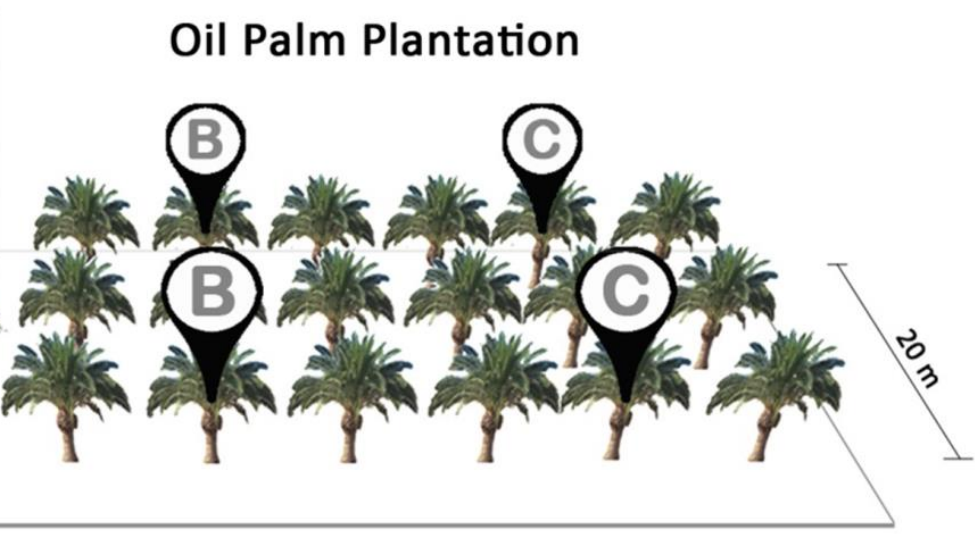

IN 20

IN 50

Figure 5.2. The experimental design at each border included in the study. All research was conducted at three paired locations at each border: (A) two $5 \mathrm{~m}$ transects within the bordering vegetation at $20 \mathrm{~m}$ from the border and two oil palms within the oil palm plantation at (B) $20 \mathrm{~m}$ from the border and (C) $50 \mathrm{~m}$ from the border.

\section{Measuring Predation Rates and Predator Occurrences}

We measured predation rates at the sites using dummy caterpillars (Howe et al. 2009) and predator occurrences using mealworms as exposed prey. The dummy caterpillars were modelled on the nettle caterpillar (Setothosea asigna), which is an important pest of oil palm. The caterpillars were made from a 50/50 mixture of brown and green plasticine and the size was similar to a ninth instar nettle caterpillar ( $3.6 \mathrm{~cm}$ long, $1.1 \mathrm{~cm}$ diameter). The mealworms (yellow mealworm, Tenebrio molitor) were collected from local bird traders, which sold them as bird food.

Ten dummy caterpillars and ten mealworms were exposed at each station (i.e., 60 of each prey type per border site, $\mathrm{n}=2880$ ). Inside the plantation (IN 20 and IN 50), the caterpillars and 
mealworms were glued to four fronds on each selected oil palm with a minimum distance of $30 \mathrm{~cm}$ between each prey item (Fig. S5.2). Inside the bordering vegetation (OUT 20), the dummy caterpillars and mealworms were glued to leaves between $1.5 \mathrm{~m}$ and $2 \mathrm{~m}$ high either side of the transect (Fig. S5.2). The exposure time for the dummy caterpillars and exposed preys was four days and one day respectively. Preliminary experiments determined the chosen exposure time to be optimal for detecting differences in predation rates and predator occurrences. After exposure, dummy caterpillars were transported to the laboratory where they were examined for signs of predation using either a magnifying glass or a stereomicroscope. Mealworm damage was assessed directly in the field.

Camera traps were utilised inside the plantation nearby border types to observe predator type and activities on dummy caterpillar and mealworm. Ten caterpillars or mealworms were glued on leaves about $30 \mathrm{~cm}$ in front of a camera lens. The camera took a picture every 2 minutes between $9 \mathrm{am}$ until $5 \mathrm{pm}$ two times a week for two months. The use of camera traps allowed us to distinguish the types of damage produced by two major insect predator groups, ants and Orthoptera and therefore assign damage on mealworms to a particular predator (Fig. 5.3). We observed the surface of dummy caterpillar can record multiple successive predators in the field and therefore the more marks left on the caterpillar can be representative as a proxy of higher predators abundances.

On the dummy caterpillars all marks caused by a predator's mandibles, teeth, beak, or ovipositor were recorded (Fig. 5.3). Predation rate was expressed as percentage of dummy caterpillar surface area marked by predators (Appendix S5.1, Fig. S5.2) and assigned to a predator group where possible. Missing dummy caterpillars were excluded from analysis. Damage recorded on the mealworms was classified into four categories of predator occurrence based on camera trap observations: 1) $0 \%$ damage $=$ no predator occurrence, 2) $20 \%$ damage $=$ a single foraging ant, 3) 40 $80 \%$ predatory Orthoptera or Mantodea, 4) $100 \%$ = group of predatory ants. 




Figure 5.3. Observations of predation by the main predators. A) Camera trap photos of the main predators. Ants and crickets attacking $(1,2)$ a dummy caterpillar and $(3,4)$ a mealworm. B). Marks of predator bites on dummy caterpillars made by some predator groups.

\section{Statistical analysis}

We used linear mixed effect models (LMEs) (fitted by maximum likelihood (ML)) to investigate the effect of border type, location (OUT 20, IN 20, and IN 50), and their interaction on species-specific predation rates and predator occurrences (separately for the four predation damage categories), with site specified as a random effect. For both response variables we fitted four models with all combinations of explanatory variables (only border type, only location, both border type, and location with and without an interaction term) and ranked them by AIC score (Burnham and Anderson 2002). The model with the lowest AIC score was considered the best-fit model and used for analysis. If the best-fit model included only location, then the model was re-analysed excluding predation rates at the control border type. If the best-fit model included an interaction term, we created a new "interaction" variable and only included that in the final model for post-hoc analysis. When the final model contained a significant term we determined contrasts of interest post-hoc with the generalised linear hypothesis test (glht). To meet assumptions of normality, predation rate and predator occurrence were $\log$ transformed ( +1 due to some zero abundances) before analysis.

LMEs and post-hoc tests were carried out in R 2.13.0 environment ( $R$ Core Team 2015) using the nlme (Pinheiro et al. 2015) and multcomp (Hothorn et al. 2008) packages respectively.

\subsection{Results}

Predators of dummy caterpillar and exposed prey 
There were several predators which bit into the dummy caterpillars, including arthropods (Hymenoptera (ants), Orthoptera, and Coleoptera), birds and mammals (bats and monkeys) (Fig. 3). Ants and Orthoptera dominated the predation recorded with mean predation rates of $24.28 \%$ and $10.87 \%$ respectively. The other predators totalled less than $3 \%$ : bats $0.28 \%$, coleoptera $0.43 \%$, birds $0.04 \%$, monkeys $1.39 \%$, and molluscs $0.38 \%$ and were therefore left out of further analysis.

Similarly to the dummy caterpillars, ants and Orthoptera were also the main predators of the exposed prey (mealworms), with a total occurrence of 1660 and 728 out of 2880 prey, respectively. Pictures taken using camera traps and direct observation in the field during data collection also revealed that the majority of Orthoptera predating on dummy caterpillars and mealworms were the bush cricket, Nisitrus vittatus (Orthoptera: Gryllidae).

\section{Border type and location effects on predation rates}

At the control border, mean percentages of ant and Orthoptera predation rates at OUT 20 were $16.39 \%$ and $7.16 \%$ respectively, and $16.03 \%$ and $6.1 \%$ at IN 20 , and $14.47 \%$ and $7.48 \%$ at IN 50 . Averaged across all other borders except control, mean percentages for ant and Orthoptera were $28.90 \%$ and $12.26 \%$, respectively, at OUT $20,26.61 \%$ and $12.40 \%$ at IN 20 , and $22.93 \%$ and $10.58 \%$ IN 50. Comparison of AIC scores determined that the best-fit model for both ant and orthoptera predation rates included border type, location, and their interaction (Table S5.3).

The interaction term in the final model testing the influence of border types and locations on ant predation rate on dummy caterpillars was significant (Table S5.4). Post-hoc analysis of the influence of border type on ant predation rates inside the border vegetation (OUT 20) showed there were significantly higher ant predation rates in jungle rubber, weedy oil palm, and weedy rubber than in the control (oil palm plantation), and intermediate rates in the scrub (Fig. 5.4a, Table S5.5). Within the oil palm (IN 20 and IN 50) both jungle rubber and weedy oil palm had significantly higher ant predation rates than the control (Fig. 5.4a, Table S5.5). Weedy rubber and secondary forest also had significantly higher rates than the control at IN 20 and IN 50, respectively. For all but one border type (secondary forest) there was also a decline in predation rate with distance, from outside the plantation (OUT 20) to the furthest inside (IN 50) (Fig. 5.4a).

Orthoptera predation rates on dummy caterpillars were significantly influenced by border type, location, and their interaction (Table S5.4). Comparison of orthopteran predation rates within the border vegetation (OUT 20) showed a significantly higher predation rate in jungle rubber and weedy rubber compared with the control, and intermediate rates in secondary forest (Fig. 5.4b, Table S5.5). Twenty metres within the oil palm plantation (IN 20), orthopteran predation rates were significantly higher in weedy rubber and secondary forest than in the control. However, $50 \mathrm{~m}$ within the plantation there was no significant difference in the predation rate between border types, indicating a decline in the effect of border type with distance to the border (Fig. 5.4b, Table S5.5). 
A)

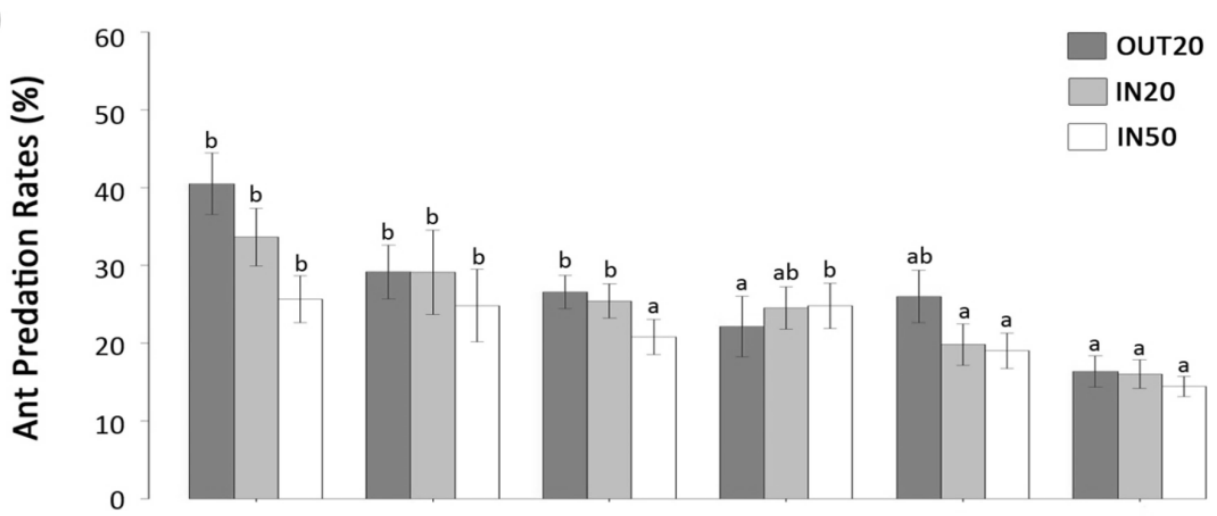

B)

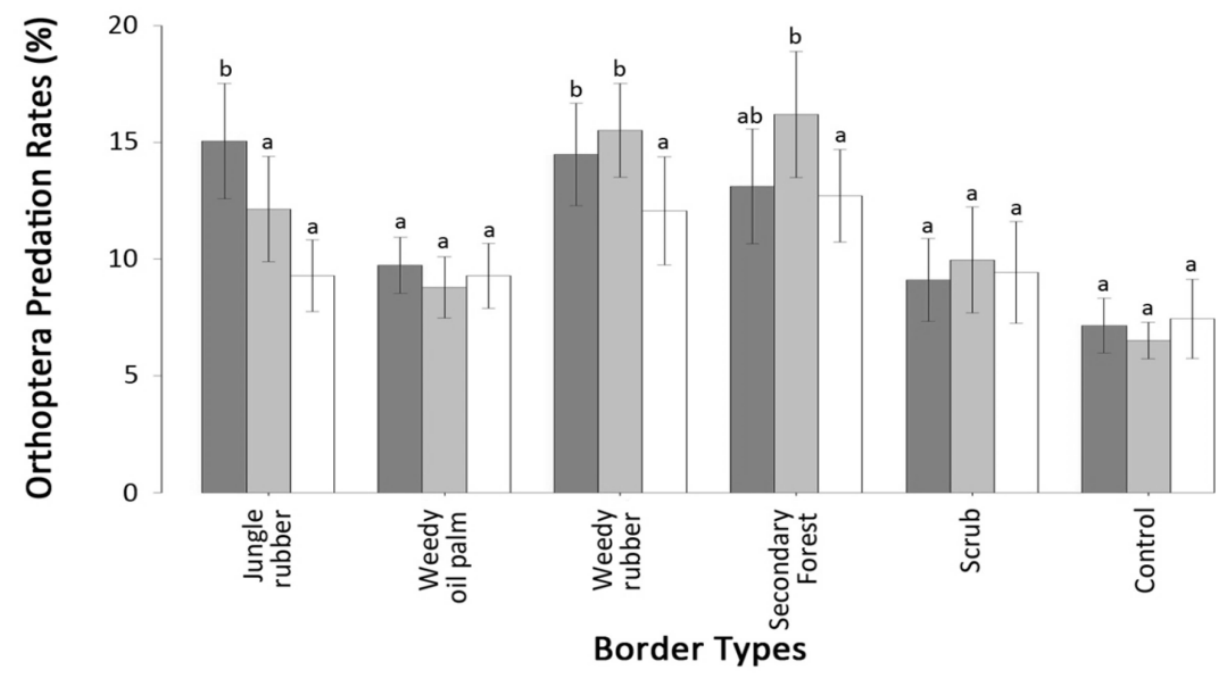

Figure 5.4. The effects of border type on (A) ant and (B) Orthoptera predation rates of the dummy caterpillars at three different locations. Means with different letters within location are significantly different (glht, $P=\leq 0.05$ ).

\section{Border type and location effects on predator occurrences}

The average of the ant group predator occurrences was by 53.63 occurrences inside the border, while 36.63 and 32.38 occurrences in the plantation interior, IN 20 and IN 50 respectively. Predatory Orthoptera occurrences OUT 20, IN 20 and IN 50 were 18.25, 28.75 and 24.50 occurrences respectively and single ant occurrences were $13.00,16.63$ and 21.38 occurrences for the locations of OUT 20, IN 20 and IN 50 respectively. Incidences without predator occurrences were almost similar between the locations with the average all of the three locations was 18.29 occurrences. For predator occurrences, the best-fit model for all four predation damage categories (no damage, single ant, Orthoptera, and group of ants) included only location. Thus, the control values were excluded from the data and it was re-analysed, with the best-fit model still only including location (Table S5.6).

Location, the only variable in the final models testing influences on predator occurrences, had a significant effect on all four categories of predator occurrence on mealworms (Table S5.7). More specifically, for all predation damage categories except groups of ants (100\% damage), there was lower predator occurrence outside the border (OUT 20) than $20 \mathrm{~m}$ inside (IN 20) (Fig. S5.3, Table S5.8). Single ants had similar occurrences $50 \mathrm{~m}$ inside (IN 50) as outside the plantation, but the 
orthopteran occurrence at $50 \mathrm{~m}$ inside was similar to $20 \mathrm{~m}$ inside (IN 20). The opposite was observed for group of ants, there were higher occurrences outside the plantation than inside (both IN 20 and IN 50) (Fig. S5.3, Table S5.8).

\subsection{Discussion}

We found that the vegetation surrounding oil palm plantations and the distance from the border of the plantation affected both predation rates and predator occurrences. Predatory ants and Orthoptera were the dominant predators for the prey items tested and other animal groups only played minor role. Overall, predation rates were higher in plantations bordered by vegetation types other than another oil palm plantation. The distance from the plantation border also played a role in determining both predation rates and predator occurrences, with predation rates almost always lowest further into the plantation.

The most dominant predators were ants and Orthoptera, whereas very low predation rates were recorded for the other predators recorded, i.e., bats, Coleopterans, birds, monkeys, and molluscs. Until now there have been no direct tests of potential predator groups on predation rates of defoliating insects in oil palm plantations except for one study by Basri et al. (1995) which focused on the predatory beetle, Callimerus arcufer (Coleoptera: Cleridae), as potential predator of the bagworm, Metisa plana Walker (Lepidoptera: Psychidae). Other studies have shown the potential for birds to be important biocontrol agents in oil palm (Koh 2008a), and that the abundance of insectivorous birds can increase in plantations when the non-crop vegetation is enhanced (Nájera and Simonetti 2010). However, none of these studies directly tested predation of oil palm pests. Although birds are very important for controlling herbivorous pests in many crops, their contribution to predation was very low in oil palm plantations. Surprisingly, $N$. vittatus was the most common Orthoptera predating on our prey, although $N$. vittatus is often identified as a pest of many trees and crops (e.g. Acacia mangium seedlings, Hamid 1987). Furthermore, species of Orthoptera from the family Tettigoniidae are one of the most important pests of oil palm in certain areas (e.g. Papua New Guinea, Howard et al. 2001). Due to their significant contribution to predation however on both dummy caterpillars and mealworms, as well as their high occurrences in oil palm plantations, $N$. vittatus appeared to have the potential to act as insect biocontrol agent in oil palm, especially for caterpillar pests.

The majority of previous studies on the transformation of forest to oil palm plantation and its management intensification have reported extensive losses in biodiversity, in particular of higher tropic levels (Chung et al. 2000; Senior et al. 2013; Barnes et al. 2014). For example, Chung et al. (2000) found that forest conversion to oil palm reduces predatory beetles. Our results show that ants, although following the same pattern of predatory species loss, still remain one of the most dominant predators. This may be little surprising, as ants are still the dominant insect group in the plantation (Pfeiffer et al. 2008), and ant community composition can influence oil palm herbivory rates (Dejean et al. 1997). The higher ant predation rate on the caterpillars indicates higher predatory ant activity 
(Human and Gordon 1999; Peters et al. 2009; Klimes et al. 2011). We found some of the most dominant ant species in the plantations, such as Anoplolepis gracilipes, the yellow crazy ant (Pfeiffer et al. 2008), which predated on the dummy caterpillars and the exposed prey. Although they are known as exotic tramp ants, which might displace other species, A. gracilipes, could be important for biocontrol in oil palm and in fact has been used to control herbivore populations in cocoa and coconut plantations (Way and Khoo 1992).

Oil palm plantations surrounded by non-oil palm vegetation enhanced insect predation, possibly due to additional resources (Foster et al. 2011; Lucey and Hill 2012; Mitchell et al. 2013). Landscape context is known to influence functional biodiversity in agricultural systems, although most studies have been conducted in temperate systems (Tscharntke et al. 2007; but see Poveda et al. 2012). In oil palm, so far only four studies investigated how to promote biocontrol in these plantations (Basri et al. 1995; Koh 2008b; Kamarudin and Wahid 2010; Gitau et al. 2011). In addition, Koh (2008b) found that increasing epiphyte and leguminous crop cover in the oil palm plantation can enhance insectivorous bird populations and Kamarudin \& Wahid (2010) observed that planting Cassia cobanensis within the vicinity of oil palm plantations can promote parasitoids of bagworms, a major oil palm pest (Kamarudin and Wahid 2010). None of these studies however, investigated the effect of surrounding habitats on predation rates in the oil palm plantation. Nevertheless, retaining natural habitat, surrounding the plantation as a source for beneficial organisms, has been widely advocated by many authors (Koh et al. 2009; Foster et al. 2011). Our results suggest that different land uses such as jungle rubber, weedy oil palm, and weedy rubber can support predatory arthropods to deliver strong top-down effects on crop pests inside the plantation. Due to increases in predation pressure, maintaining natural habitat surroundings agricultural landscapes can support specifically beneficial species. Maintaining diverse habitats inside and surrounding oil palm plantations supports the movement of predatory insects and the potential for predators to control crop pests bridging biodiversity conservation and function (Tscharntke et al. 2007; Senior et al. 2013; Lucey et al. 2014). We therefore recommend improving predation rates by keeping alternative vegetation types such as jungle rubber, weedy oil palm, weedy rubber, and secondary forest near oil palm plantations.

The majority of the effects of border type tended to decline along the distance gradients, with (aside from a few exception) the lowest predation rates and predator occurrences the furthest into the plantation. An interesting exception occurred in the plantation nearby secondary forest borders where the predation rates were still similarly enhanced even at the furthest distance measured, $50 \mathrm{~m}$ inside the plantation. The general decline in insect predation rates towards the centre of the plantation needs further assessment, however, in order to quantify overall biological control effectiveness across the whole plantation area. Our results suggest that both ants and Orthoptera are major insect predators in oil palm plantation and might complement each other in pest suppression.

\section{Conclusions}


The present study suggests that ant and Orthoptera are the main predators of defoliating pests in oil palm plantations and their predation pressure are influenced by border types and edge effects. The higher attack pressure in plantations surrounded by jungle rubber, weedy oil palm, weedy rubber, and secondary forest suggests that diverse vegetation surrounding oil palm plantations could be useful for conserving predators and controlling oil palm pests, especially caterpillars. However, the border effect quickly declines with distance from the border so that management inside the plantation is necessary, for example through restoring or maintaining weedy understory or flowering plant strips. Better understanding of the ecological management of oil palm plantations including biological pest control needs more experimental studies testing the optimum plantation size and shape and the type and size of adjacent vegetation as well as the kind of ecological improvements inside the plantations with weedy strips .

\section{Acknowledgments}

We thank David Warisman, Deslian Permana, Febrina Herawani, Rico Fardiansa, Derly Hartika, and Tutty for all their help in the lab and the field. We thank the village leaders and local homegarden owners for granting us the use of their properties. This study was financed by the Deutsche Forschungsgemeinschaft (DFG) in the framework of the collaborative German - Indonesian research project Collaborative Research Centre 990 EFForTS: Ecological and Socioeconomic Functions of Tropical Lowland Rainforest Transformation Systems (Sumatra, Indonesia). FN was supported by the German Academic Exchange Service (DAAD). 


\subsection{Supplementary material}

Appendix S5.1. Supplementary methods.

\section{Ant sampling in different vegetation types}

Ant sampling was conducted across four different vegetation types: degraded lowland rainforest, jungle rubber, rubber plantation and oil palm plantation. In the two study regions, each vegetation type was replicated four times $(n=32)$. At each of the 32 study sites, a $50 \mathrm{~m} \times 50 \mathrm{~m}$ sampling plot was defined, which included five randomly assigned $5 \mathrm{~m}$ x $5 \mathrm{~m}$ subplots. All sites were on little or no slope and there was a minimum distance of $120 \mathrm{~m}$ between each site (mean distance between sites was $14.9 \mathrm{~km}$ ). The rainforest sites were within Bukit Duabelas National Park and Harapan Rainforest and, although protected, have been selectively logged in the past. The rubber and oil palm plantations, were intensively managed monoculture systems, with the oil palm plantations resembling the "control" border vegetation type described above.

We used plastic observation plates with two baits of $2 \mathrm{~cm}^{3}$ of tuna in oil and two sponges saturated with $70 \%$ sucrose solution attached to sample ant species (Wielgoss et al. 2010). One plate was tied at breast height on each of two randomly selected trees in all five subplots at each site. If there were not two trees in a subplot (often the case in oil palm plantations), the closest trees to the subplot were chosen. At 15, 30, 45, and 60 minutes after placing the plates on the trees, the abundance of each ant species present on the plate (separately for ants feeding on sugar or tuna) was recorded. Specimens were collected from each ant species present where possible without disrupting recruitment. Surveys were conducted at each site four times during the study period (first: October 2012, second: February-March 2013, third: September-October 2013, fourth: February 2014), between 9:00 am, and 11:00 am. No sampling was conducted during or immediately after rain due to a reduction in ant activity under wet conditions. All ants collected were identified to genus level (Fayle et al. 2014). We identified specimens to species level where possible and assigned the remainder to morphospecies. Ant abundance per species at a given site was defined as the mean of the maximum number of each species on each plate (at any time measurement) used at a site (over the whole survey). By taking the mean abundance from the maximum at any given time during the surveys we took into account the possibility of competition that could disadvantage subdominant species if only looking at the abundance after 60 minutes. A protein/carbohydrate preference ratio was defined for each ant species by dividing the total abundance of the species counted at the protein baits (tuna) by the total abundance of the species at both baits (higher ratio indicates increased predator abundance). A community-weighted mean (CWM) of the preference ratio was then determined for each site as an indicator of predator abundance at the site.

\section{Statistical analysis}

We used LMEs to determine the effect of vegetation type on ant species richness, ant abundance and the community-weighted mean (CWM) of the protein/carbohydrate preference ratio, 
with region specified as a random effect. When the LME contained a significant effect of land-use system on the response variable, we performed a Tukey post-hoc test (with Bonferroni correction) to test for significant pair-wise differences among land-use systems. To meet assumptions of normality all ant abundance was log transformed prior to analysis. LMEs and post-hoc tests were conducted using the nlme (Pinheiro et al. 2015) and multcomp (Hothorn et al. 2008) packages in R 3.2.0 (R Core Team 2015).

\section{Assessing dummy caterpillar predation rate}

Initially the caterpillar was divided into five sections, (excluding the part of the caterpillar which was glued to the leaf), three rectangular with an area of $3.96 \mathrm{~cm}^{2}(25.7 \%)$ and two circular with an area of $1.77 \mathrm{~cm}^{2}(11.5 \%$ ) (Fig. 5.2a). Percentage marked by each predator type was estimated by overlaying marked transparent plastic over each section (Fig. 5.2b). Total predation rate for each predator type was calculated for each dummy caterpillar by adding together all sections. 

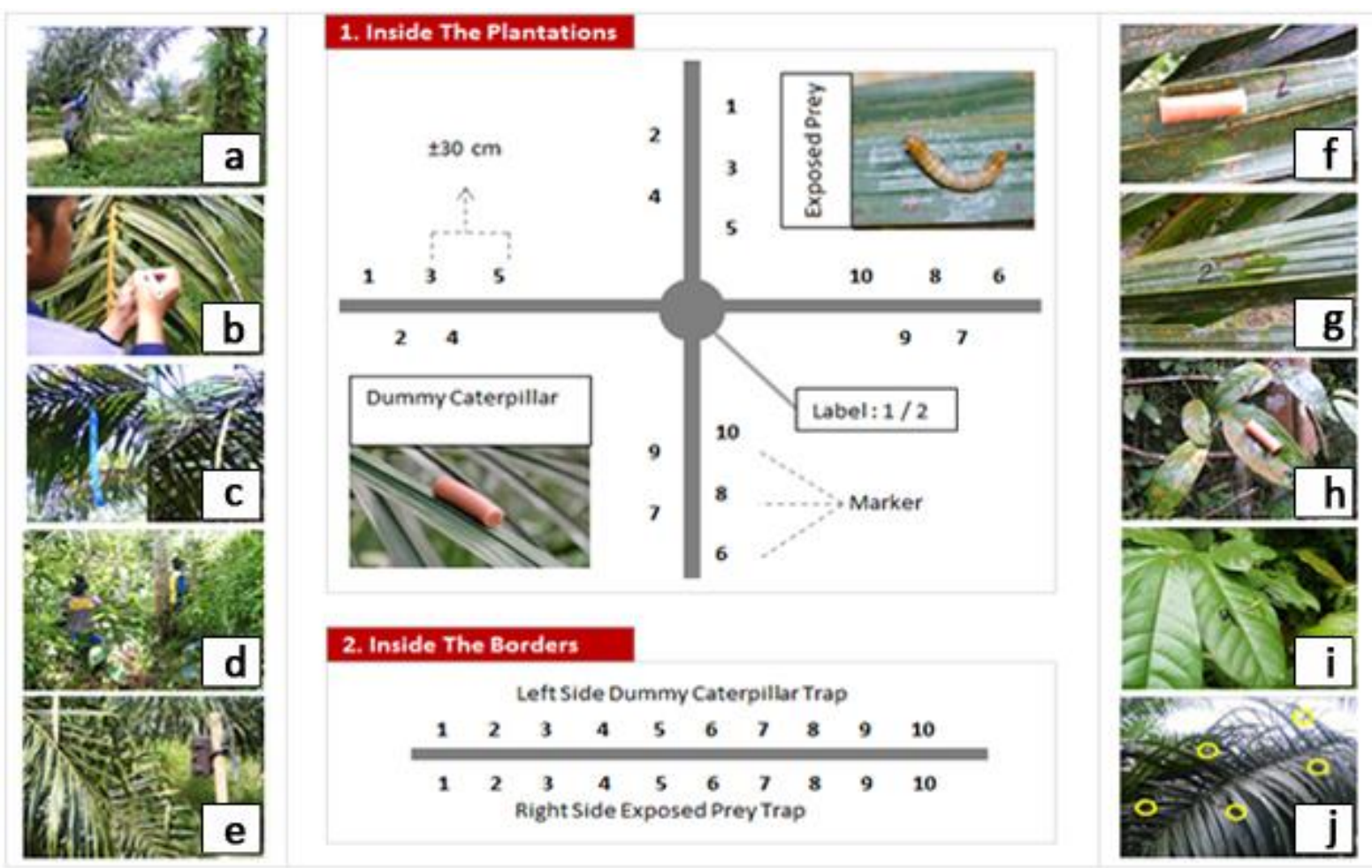

Figure S5.2. Experimental design. a) dummy caterpillar and exposed prey were attached on the frond; b) each location of the caterpillars were labeled using waterproof marker; c) Every frond with the caterpillar on them was marked with color tape in order to find them easily; d) Inside the border, right side was used for artificial caterpillar and left side was used for exposed prey; e) the arrangement of camera trap in some study sites; f \& g) a dummy caterpillar and a mealworm larvae with labels inside the plantation; h \& i) a dummy caterpillar and a mealworm larvae with labels inside the border; and j) the location of dummy caterpillar and exposed prey on a frond .

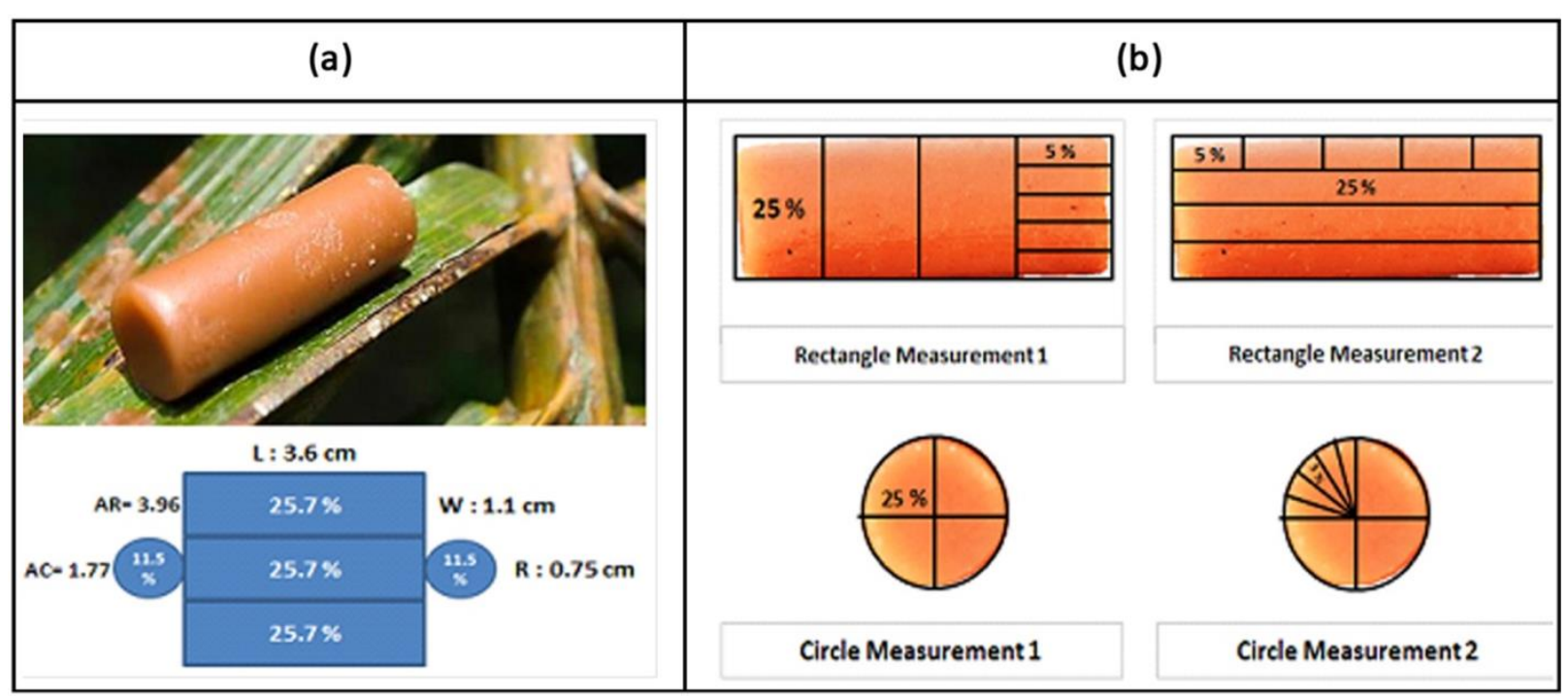

Figure S5.2. Method for quantifying predation rate on dummy caterpillars. (a) Each caterpillar was divided into five sections for assessment. (b) Marked transparent plastic was overlayed on each section to help assess percentage marked by predators. 




Figure S5.3. The effect of location on predator occurrences on the exposed prey. Means with different letters within locations are significantly different (glht, $P=\leq 0.05$ ).

\section{Table S5.1. Linear mixed effect model ANOVA outputs testing for a significant effect of} vegetation type on ant communities. The linear mixed effects models determined the effect of vegetation type on (a) ant species richness, (b) ant abundance, and (c) community-weighted mean $(\mathrm{CWM})$ of the protein/carbohydrate preference ratio (Ant P/C ratio). Significant $\mathrm{P}$-values are indicated in bold $(P=\leq 0.05)$.

\begin{tabular}{llrrr}
\hline Response variable & Effect & df & F-value & P-value \\
\hline (a) Ant species richness & Vegetation type & 27 & 8.73 & $<\mathbf{0 . 0 1}$ \\
(b) Ant abundance & Vegetation type & 27 & 14.24 & $<\mathbf{0 . 0 1}$ \\
(c) Ant P/C ratio & Vegetation type & 27 & 5.44 & $<\mathbf{0 . 0 1}$ \\
\hline
\end{tabular}


Table S5.2. Summary statistics of Tukey post-hoc tests testing for significant differences in ant communities among vegetation types. Tukey post-host tests determined the response of ant species richness, ant abundance and community-weighted mean (CWM) of the protein/carbohydrate preference ratio (Ant P/C ratio) to vegetation type. Significant $\mathrm{P}$-values are indicated in bold (Tukey's HSD, $P=\leq 0.05)$.

\begin{tabular}{lrrr}
\hline Response variable & Estimate & Z-value & P-value \\
\hline Ant species richness & & & \\
J - F & -0.50 & -0.38 & 1.00 \\
O-F & 5.25 & 4.02 & $<\mathbf{0 . 0 1}$ \\
R - F & 3.25 & 2.49 & 0.08 \\
O- J & 5.75 & 4.40 & $<\mathbf{0 . 0 1}$ \\
R - J & 3.75 & 2.87 & $\mathbf{0 . 0 3}$ \\
R - O & -2.00 & -1.53 & 0.76 \\
Ant abundance & & & \\
J - F & 0.44 & 1.77 & 0.46 \\
O-F & 1.55 & 6.25 & $<\mathbf{0 . 0 1}$ \\
R - F & 0.44 & 1.76 & 0.47 \\
O- J & 1.11 & 4.48 & $<\mathbf{0 . 0 1}$ \\
R - J & -0.00 & -0.00 & 1.00 \\
R - O & -1.11 & -4.48 & $<\mathbf{0 . 0 1}$ \\
Ant P/C ratio & & & \\
J - F & -0.05 & -1.45 & 0.89 \\
O - F & -0.12 & -3.76 & $<\mathbf{0 . 0 1}$ \\
R - F & -0.02 & -0.61 & 1.00 \\
O- J & -0.07 & -2.32 & $\mathbf{0 . 0 1}$ \\
R - J & 0.03 & 0.84 & 1.00 \\
R - O & 0.10 & 3.15 & $\mathbf{0 . 0 1}$ \\
\hline
\end{tabular}


Table S5.3. AIC table for comparison of fit of LMEs testing the influence of border type and location on predation rate. For both (a) ant and (b) Orthoptera predation rate and we fitted four models with all combinations of explanatory variables, with df (degrees of freedom) in the model), AIC and $\triangle \mathrm{AIC}$. The best supported models are indicated in bold.

\begin{tabular}{lrrr}
\hline Response variable & df & AIC & $\Delta$ AIC \\
\hline (a) Ant predation rate & $\mathbf{2 0}$ & $\mathbf{- 1 7 4 . 6 3}$ & $\mathbf{0 . 0 0}$ \\
Border type*Location & 10 & -173.82 & 0.81 \\
Border type+location & 8 & -161.42 & 13.20 \\
$\quad$ Border type & 5 & -159.27 & 15.36 \\
Location & & & \\
(b) Orthoptera predation rate & $\mathbf{2 0}$ & $\mathbf{- 1 4 2 . 9 1}$ & $\mathbf{0 . 0 0}$ \\
Border type*Location & 10 & -140.91 & 2.00 \\
Border type+location & 8 & -136.12 & 6.79 \\
Border type & 5 & -135.95 & 6.96 \\
Location & &
\end{tabular}

Table S5.4. Linear mixed effect model ANOVA outputs testing for a significant effect of border type, location and their interaction on predation rates. The best-fit linear mixed effect models which determined the effect of border type, location and their interaction on (a) ant and (b) Orthoptera predation rates on dummy caterpillars (Tables S5.3). Significant P-values $(P=\leq 0.05)$ are also indicated in bold.

\begin{tabular}{llrrr}
\hline Response variable & Effect & df & F-value & P-value \\
\hline (a) Ant predation rate & Border type & 5 & 5.61 & $<\mathbf{0 . 0 1}$ \\
& Location & 2 & 9.71 & $<\mathbf{0 . 0 1}$ \\
& Border type*location & 10 & 2.03 & $\mathbf{0 . 0 4}$ \\
(b) Orthoptera predation rate & Border type & 5 & 3.07 & $\mathbf{0 . 0 2}$ \\
& Location & 2 & 5.06 & $\mathbf{0 . 0 1}$ \\
& Border type*location & 10 & 2.16 & $\mathbf{0 . 0 3}$ \\
\hline
\end{tabular}


Table S5.5. Summary statistics of glht post-hoc tests testing for significant differences in predation rates between border types within a location. Glht post-host tests determined the response of (a) ant and (b) Orthoptera predation rate on dummy caterpillars to border type at each location. Significant $\mathrm{P}$-values are indicated in bold $(P=\leq 0.05)$. JR $=$ Jungle rubber, WOP $=$ Weedy oil palm, WR=Weedy Rubber, SF=Secondary Forest, $\mathrm{SC}=\mathrm{Scrub}$, and Control=Oil Palm Border.

\begin{tabular}{|c|c|c|c|c|}
\hline \multicolumn{2}{|c|}{ Response variable } & \multirow[t]{2}{*}{ Estimate } & \multirow[t]{2}{*}{ z-value } & \multirow[t]{2}{*}{ P-value } \\
\hline & Ant predation rate & & & \\
\hline & JR.IN50 - Control.IN50 & 0.23 & 3.37 & 0.01 \\
\hline & WOP.IN50 - Control.IN50 & 0.19 & 2.89 & 0.04 \\
\hline & WR.IN50 - Control.IN50 & 0.15 & 2.20 & 0.25 \\
\hline & SF.IN50 - Control.IN50 & 0.21 & 3.14 & 0.02 \\
\hline & SC.IN50 - Control.IN50 & 0.10 & 1.56 & 0.69 \\
\hline & JR.IN20 - Control.IN20 & 0.31 & 4.61 & $<0.01$ \\
\hline & WOP.IN20 - Control.IN20 & 0.23 & 3.41 & $<0.01$ \\
\hline & WR.IN20 - Control.IN20 & 0.20 & 2.97 & $\mathbf{0 . 0 3}$ \\
\hline & SF.IN20 - Control.IN20 & 0.17 & 2.59 & 0.10 \\
\hline & SC.IN20 - Control.IN20 & 0.08 & 1.23 & 0.90 \\
\hline & JR.OUT20 - Control.OUT20 & 0.38 & 5.66 & $<0.01$ \\
\hline & WOP.OUT20 - Control.OUT20 & 0.24 & 3.52 & $<0.01$ \\
\hline & WR.OUT20 - Control.OUT20 & 0.21 & 3.11 & 0.02 \\
\hline & SF.OUT20 - Control.OUT20 & 0.11 & 1.59 & 0.67 \\
\hline & SC.OUT20 - Control.OUT20 & 0.19 & 2.79 & 0.06 \\
\hline \multirow[t]{16}{*}{ (b) } & Orthoptera predation rate & & & \\
\hline & JR.IN50 - Control.IN50 & 0.09 & 1.09 & 0.92 \\
\hline & WOP.IN50 - Control.IN50 & 0.10 & 1.19 & 0.87 \\
\hline & WR.IN50 - Control.IN50 & 0.19 & 2.16 & 0.24 \\
\hline & SF.IN50 - Control.IN50 & 0.21 & 2.45 & 0.12 \\
\hline & SC.IN50 - Control.IN50 & 0.07 & 0.81 & 0.99 \\
\hline & JR.IN50 - Control.IN20 & 0.12 & 1.36 & 0.77 \\
\hline & WOP.IN20 - Control.IN20 & 0.10 & 1.16 & 0.89 \\
\hline & WR.IN20 - Control.IN20 & 0.33 & 3.80 & $<0.01$ \\
\hline & SF.IN20 - Control.IN20 & 0.35 & 3.94 & $<0.01$ \\
\hline & SC.IN20 - Control.IN20 & 0.12 & 1.42 & 0.72 \\
\hline & JR.OUT20 - Control.OUT20 & 0.29 & 3.26 & 0.01 \\
\hline & WOP.OUT20 - Control.OUT20 & 0.13 & 1.44 & 0.70 \\
\hline & WR.OUT20 - Control.OUT20 & 0.28 & 3.15 & 0.01 \\
\hline & SF.OUT20 - Control.OUT20 & 0.23 & 2.66 & 0.07 \\
\hline & SC.OUT20 - Control.OUT20 & 0.08 & 0.90 & 0.97 \\
\hline
\end{tabular}


Table S5.6. AIC table for comparison of fit of LMEs testing the influence of border type and location on predator occurrences. For (a) no damage and damage by (b) single ants, (c) Orthoptera, and (d) group of ants, we fitted four models with all combinations of explanatory variables, with $\mathrm{df}$ (degrees of freedom) in the model, AIC and $\triangle$ AIC. The best supported models are indicated in bold. Predator occurrences were assigned based on percent damage of mealworm prey items.

\begin{tabular}{lrrr}
\hline Response variable & df & AIC & $\Delta$ AIC \\
\hline (a) No damage (0\% damage) & 17 & 108.00 & 7.49 \\
Border type * Location & 9 & 103.74 & 3.23 \\
Border type + Location & 7 & 105.37 & 4.86 \\
Border type & $\mathbf{5}$ & $\mathbf{1 0 0 . 5 1}$ & $\mathbf{0 . 0 0}$ \\
Location & & & \\
(b) Single ant (20\% damage) & 17 & 67.71 & 10.65 \\
Border type * Location & 9 & 62.87 & 5.81 \\
Border type + Location & 7 & 68.93 & 11.88 \\
Border type & $\mathbf{5}$ & $\mathbf{5 7 . 0 6}$ & $\mathbf{0 . 0 0}$ \\
Location & & & \\
(c) Orthoptera (40 - 80\% damage) & 17 & 75.96 & 16.30 \\
Border type * Location & 9 & 67.03 & 7.38 \\
Border type + Location & 7 & 78.36 & 18.71 \\
Border type & $\mathbf{5}$ & $\mathbf{5 9 . 6 5}$ & $\mathbf{0 . 0 0}$ \\
Location & & & \\
(d) Group of ants (100\% damage) & & & \\
Border type * Location & $\mathbf{5}$ & $\mathbf{6 4 . 5 4}$ & $\mathbf{0 . 0 0}$ \\
Border type + Location & 9 & 69.19 & 4.65 \\
Border type & & & 14.85 \\
Location & & & \\
\hline
\end{tabular}


Table S5.7. Linear mixed effect model ANOVA outputs testing for a significant effect of location on predator occurrence. The best-fit linear mixed effect models which determined the effect of location on (a) no predator occurrence and predation by (b) sinlge ants, (c) Mantodea and Orthoptera, and (d) group of ants. Significant P-values $(P=\leq 0.05)$ are also indicated in bold. Predator occurrences were assigned based on percent damage of mealworm prey items.

\begin{tabular}{llrrr}
\hline Response variable & Effects & df & F-value & P-value \\
\hline (a) No predator (0\% damage) & Location & 2 & 2.84 & 0.06 \\
(b) Single ants (20\% damage) & Location & 2 & 5.23 & $<\mathbf{0 . 0 1}$ \\
(c) Orthoptera (40 - 80\% damage) & Location & 2 & 8.23 & $<\mathbf{0 . 0 1}$ \\
(d) Groups of ants (100\% damage) & Location & 2 & 8.19 & $<\mathbf{0 . 0 1}$ \\
\hline
\end{tabular}


Table S5.8. Summary statistics of glht post-hoc tests testing for significant differences in predator occurrences between locations. Glht post-host tests determined the response of (a) no predator occurrence, (b) single ants, (c) Mantodea and Orthoptera, and (d) groups of ants. Significant P-values are indicated in bold $(P=\leq 0.05)$. Predator occurrences were assigned based on percent damage of mealworm prey items.

\begin{tabular}{|c|c|c|c|c|}
\hline \multicolumn{2}{|c|}{ Response variable } & \multirow[t]{2}{*}{ Estimate } & \multirow[t]{2}{*}{ z-value } & \multirow[t]{2}{*}{ P-value } \\
\hline (a) & No predators ( $0 \%$ damage) & & & \\
\hline & OUT20 - IN20 & -0.17 & -2.34 & 0.05 \\
\hline & OUT20 - IN50 & -0.12 & -1.68 & 0.21 \\
\hline & IN20 - IN50 & 0.05 & 0.66 & 0.79 \\
\hline \multirow[t]{4}{*}{ (b) } & Single ants (20\% damage) & & & \\
\hline & OUT20 - IN20 & -0.20 & -3.27 & $<0.01$ \\
\hline & OUT20 - IN50 & -0.09 & -1.50 & 0.29 \\
\hline & IN20 - IN50 & 0.11 & 1.77 & 0.18 \\
\hline \multirow[t]{4}{*}{ (c) } & Orthoptera (40 - 80\% damage) & & & \\
\hline & OUT20 - IN20 & -0.15 & -2.66 & 0.02 \\
\hline & OUT20 - IN50 & -0.22 & -4.04 & $<0.01$ \\
\hline & IN20 - IN50 & -0.08 & -1.38 & 0.35 \\
\hline \multirow[t]{4}{*}{ (d) } & Groups of ants (100\% damage) & & & \\
\hline & OUT20 - IN20 & 0.23 & 3.94 & $<0.01$ \\
\hline & OUT20 - IN50 & 0.17 & 2.95 & $<0.01$ \\
\hline & IN20 - IN50 & -0.06 & -1.00 & 0.58 \\
\hline
\end{tabular}




\title{
Chapter 6
}

\section{Ants affect belowground invertebrate communities and associated ecosystem processes across tropical land-use systems}

Lisa H. Denmead, Bernhard Klarner, Yann Clough, Ingo Grass, Valentyna Krashevska, Widria Liza, Akhmad Rizali, Stefan Scheu, Rahayu Widyastuti, Teja Tscharntke

In prep, to be submitted to, Ecological Entomology, May 2016

\begin{abstract}
Ants make up an estimated $15 \%$ of the total terrestrial animal biomass. Furthermore, ants carry out and influence a wide range of important ecosystem processes such as predation, seed dispersal, soil aeration and pollination, varying across land-use systems. Ant exclusion experiments can help us understand the role of ants in shaping above- and belowground invertebrate communities and associated processes, but have up until now mostly focused on aboveground communities and herbivory only. We created paired ant suppression and control plots in 16 lowland forest, jungle rubber, rubber and oil palm sites in Sumatra, Indonesia. We assessed above- and below-ground invertebrates as well as soil and litter variables. Ant suppression was linked to a decline in the aboveground herbivores, detritivores and predators, but not omnivores likely as an artefact of the suppression treatments. Furthermore, all aboveground feeding guilds negatively responded to land-use change. Although, unexpectedly, herbivore and predator abundance was lowest in rubber not oil palm. Belowground invertebrates, i.e. Collembola, were strongly influenced in ant suppression plots. However, soil and litter $\mathrm{C}: \mathrm{N}$ ratio, moisture and microbial biomass were mostly unaffected by ant suppression. Most notably, effects on decomposition rates were dependent on the land-use system, whereby ant suppression reduced decomposition in the forest sites only. In conclusion, differences in ant communities between land-use systems alter their relationship to decomposition processes; however, the underlying drivers of these effects require further investigation.
\end{abstract}




\subsection{Introduction}

Ants make up an estimated $15 \%$ of terrestrial animal biomass globally, and in the tropics this estimate is even higher, at approximately $25 \%$ (Schultz 2000). They also exhibit a wide range of important ecosystem functions such as seed dispersal, soil aeration and pollination (Folgarait 1998; Vandermeer et al. 2002; Lach et al. 2010). Ants can be omnivores, herbivores and opportunistic feeders, while they also include specialist and generalist predators (Hölldobler and Wilson 1994). Ants play an important role in the shaping of animal food webs through predation, symbiosis and as a prolific food source (Folgarait 1998; Gaume et al. 1998; Lach et al. 2010). Due to the important role ants play in ecosystems, it is likely that ecosystem functioning will be altered when ant communities are affected by disturbances such as land-use change.

In the tropics, unlike for many other taxa, ant diversity and biomass can be retained in agricultural systems (Folgarait 1998; Rubiana et al. 2015). However, these communities can still be highly impacted by land-use change through changes in taxonomic and functional composition. For example, Rubiana et al. (2015) found no difference in ant species richness between forest, jungle rubber, rubber plantation and oil palm sites in Sumatra, Indonesia; however, community composition was very different between each land-use type and species from higher trophic guilds declined from forest to oil palm (Denmead et al. in review). It is particularly important to understand how such a dominant animal group's role is altered in different land-use systems if we are to understand the longterm consequences of land-use change.

Decomposition rates can be an important indicator of how land-use change is affecting a key ecosystem process in agricultural systems (Hättenschwiler et al. 2005). The process of leaf litter decomposition is a vital ecosystem process that is carried out by invertebrates, fungi and microbes (Swift et al. 1979). It is crucial for soil formation and the cycling of nutrients (Swift et al. 1979; Throop and Archer 2007). Decomposition is a particularly important service to increase soil fertility and microbial activity (Bardgett 2005; Moradi et al. 2014) and therefore in crop systems it is related to the sustainability of agriculture. Decomposition is influenced by above- and below ground biotic communities (e.g. arthropods and microbes) as well as abiotic conditions (e.g. moisture availability, soil structure and temperature) (Swift et al. 1979). Whereas abundance of invertebrate individuals or their species richness describe a community in numbers and their diversity, quantification of decomposition rates can provide a direct relation between biodiversity and ecosystem services (Huhta 2007).

Ant exclusion experiments can help us understand the role of ants in ecosystem processes, but have up until now mostly focused on above-ground communities and herbivory (e.g. Sanders and van Veen 2011; Mestre et al. 2012; Gras et al. 2016), whereas research on below-ground communities and associated ecosystem processes, such as decomposition is lacking (but see Wardle et al. 2011). In this study we implemented paired ant suppression and control plots for one year across four different land uses in Sumatra, Indonesia: 1) tropical lowland rainforest; 2) jungle rubber, an agroforestry systems 
closely resembling secondary rainforest; 3) rubber monoculture plantation and 4) oil palm monoculture plantation. To investigate the relative effect of ants on species communities and associated ecosystem processes across these land-uses, we conducted comprehensive sampling at all study sites including above- and belowground invertebrate communities, soil, litter and vegetation, and measurements of decomposition rates.

\subsection{Materials and methods}

\section{Study Area}

Our study was carried out within the Batanghari Regency of Jambi Province, Sumatra, Indonesia (Figure S6.1). Located in central Sumatra, the area has potential vegetation of tropical lowland rainforest, however Sumatra has lost 2.6 million ha of its lowland rainforest in the last 20 years (Hansen et al. 2009) as a result of the increasing expansion of agricultural land. Currently the most dominant crop in the province is rubber, however oil palm is becoming increasingly dominant with an almost 4-fold increase in land-cover over the past 20 years (Gatto et al. 2015).

\section{Experimental Design}

Sampling was conducted across four land-use systems: lowland disturbed rainforest, jungle rubber, rubber plantation and oil palm plantation. Each land-use system was replicated four times (16 sites, Figure S6.1). At each of the 16 study sites six $1.5 \mathrm{~m} \mathrm{x} 1 \mathrm{~m}$ experimental plots were defined, consisting of three pairs of one ant suppression plot and one control plot (six plots/site, $n=96$ ). Paired plots had similar vegetation cover at the beginning of the experiment. All sites were on little or no slope, the plantations were of similar age and the mean pair-wise distance between sites was $18.2 \mathrm{~km}$ $( \pm$ SE, $9.6 \mathrm{~km})$, respectively. The lowland rainforest sites were within a protected area, Harapan Rainforest. Jungle rubber sites selected occurred in secondary forest with rubber trees between the native vegetation and minimal management. The rubber and oil palm plantations, in contrast, were intensively managed monoculture systems. For a detailed description of the study site management practices see Allen et al. (2015).

Two methods were used to suppress ants in the ant exclusion plots. A $50 \mathrm{~cm}$ high aluminium barrier was established surrounding the plot, buried $20 \mathrm{~cm}$ beneath the soil and the top of the barrier was cover in insect glue (Tanglefoot, Contech Enterprises Inc., British Columbia). The glue was replaced as needed. The control plots also had a similar aluminium barrier without glue and regular small holes were cut into the aluminium (below- and aboveground) to facilitate invertebrate movement (Figure S6.2). We also carried out regular toxic baiting for the duration of the experiment. The toxic baiting consisted of placing two types of attractants, sugar and tuna, mixed with the insecticide chlorpyrifos (Dursban ${ }^{\mathrm{TM}}$ 200EC, Dow AgriSciences, Jakarta, Indonesia) in two random locations in the exclusion plots for one hour once per week. Preliminary experiments and a previous study (Klimes et al. 2011) determined these two baits were attractive to the majority of ant species present but no other 
invertebrates. Exclusion was continuous for one year from February 2014 to February 2015. No management practices (e.g. herbicide spraying) were carried out in the plots for the duration of the experiment.

Ants were surveyed monthly in every plot to monitor the effectiveness of the ant suppression methods. We used plastic observation plates with two baits of $2 \mathrm{~cm}^{3}$ of tuna in oil and two sponges saturated with $70 \%$ sugar solution attached to sample ant species (Wielgoss et al. 2010). One plate was put on the ground in each experimental plot at each site. At 15, 30, 45 and 60 minutes after placing the plates on the ground the abundance of each ant species present on the plate was recorded. Specimens were collected from each ant species present where possible without disrupting recruitment. All ants collected were identified to genus level (Fayle et al. 2014). We identified specimens to species level where possible and assigned the remainder to morphospecies. Ant species abundance at a given plot each month was defined as the maximum number of each species on the plate over the hour sampling period (Denmead et al. in review).

\section{Sampling methods}

\section{Aboveground invertebrates}

We combined insecticide spraying with vacuum sampling to sample aboveground invertebrates in the experimental plots at the end of the experiment (February 2015). First, the plot was covered with a cloth tent and we sprayed insecticide (Decis ${ }^{\circledR}$ 2,5 EC, Bayer CropScience, Jakarta, Indonesia) within the tent. The amount of insecticide sprayed into each plot was consistent between plots. After 15 minutes the tent was removed and the vegetation was removed (see below, vegetation surveys). Vegetation was shaken over the plot before removal to drop any invertebrates from the vegetation onto the ground. We then vacuumed and hand-collected over the entire area of the plot to collect all invertebrates within the plot.

All invertebrates (excluding ants) collected by the three sampling methods were identified to higher taxonomic groups, counted and assigned to four feeding guilds; herbivores, predators, detritivores and omnivores based on information from literature (Table S6.1).

\section{Belowground invertebrates}

Below-ground invertebrates were sampled at the end of the experiment by taking one $16 \times 16$ $\mathrm{cm}$ soil core per plot and extracting the invertebrates using the high gradient canister method in modified Kempson extractors (Kempson et al. 1963).

All Collembola extracted were counted and identified to genus. The biomass of Collembola was determined by length-mass regressions from Petersen (1975). Body length was measured on 1015 individuals (or all available if less abundant) from each genus. Regressions values for each genus were determined from morphologically similar species based on morphotype (Poduromorpha, Entomobryomorpha and Symphypleona) and size class (small or medium, determined from mean body length) (Petersen 1975). 


\section{Soil, litter and vegetation}

We collected one soil and litter sample in February 2015 to a depth of $10 \mathrm{~cm}$ at each experimental plot using a $5 \mathrm{~cm}$ diameter soil corer to measure carbon $(\mathrm{C})$, nitrogen $(\mathrm{N})$, moisture content and microbial biomass in the plots. Half of the sample was dried at $65^{\circ} \mathrm{C}$ for $72 \mathrm{~h}$, milled and analysed for total $\mathrm{C}$ and $\mathrm{N}$ concentrations using an elemental analyser (Carlo Erba, Milan, Italy) and the moisture content was determined gravimetrically. Microbial biomass was determined from the other half of the sample by measuring $\mathrm{O}_{2}$ consumption using an automated respirometer system (Scheu 1992). We collected all vegetation (cutting at ground level) from the plots three times to gain an estimate of plant biomass. The collected vegetation was dried in an oven at $60^{\circ} \mathrm{C}$ for 48 hours, then weighed. Vegetation samples were taken in June 2014, October 2014 and when the experiment ended in January 2015 (at the same time as above-ground invertebrate sampling, see above). We collected the samples three times during the experiment due to the presence of fast growing species in the plantations compromising the effectiveness of the exclusion by growing over the sides of the plot barriers. Plant biomass is the total dry weight of all three samples at each plot.

\section{Litter decomposition}

Litter decomposition rates were measured using litter bags (Falconer et al. 1933) placed in the plot between March and September 2014. A total of 96 litterbags $(20 \mathrm{~cm} \times 20 \mathrm{~cm})$ were made from polyester mesh with a $4 \mathrm{~mm} \times 4 \mathrm{~mm}$ mesh size. Each litterbag contained $10.0 \pm 0.05 \mathrm{~g}$ of the dominant litter type in each land-use system. For forest plots the litter was a mixture of three species: $4 \mathrm{~g}$ from cf. Garcinia sp., $3 \mathrm{~g}$ from Gironniera nervosa, $3 \mathrm{~g}$ from cf. Santiria lavigata, while in jungle rubber and rubber plantations the litter was rubber (Hevea brasiliensis) leaves and in the oil palm plantations, oil palm (Elaeis guineensis) leaves. Fresh fallen (fresh cut for the oil palm) leaves were collected from one plot for each land-use system and dried at $25^{\circ} \mathrm{C}$ for 72 hour and put into the bags. Litter decomposition was calculated as the difference between the initial litter dry mass and litter dry mass remaining after six months and expressed as percentage of the initial leaf litter mass.

\section{Statistical analysis}

\section{Ant suppression effectiveness}

We used linear mixed effect models (LMEs) to determine the effect of ant suppression on average ant abundance and species richness over the whole year of monthly sampling (lme() function in package nlme, Pinheiro et al. 2015). Site was included as a random effect. To meet assumptions of normality ant abundance was log-transformed prior to analysis. Linear mixed-effect models with transformation (log or square root) were used for non-normal data because they had better fit and convergence than generalised linear mixed-effect models based on untransformed data with Poisson or negative-binomial error distributions. 
Above- and belowground invertebrate, soil and litter variables, vegetation and decomposition responses to ant exclusion and other measured variables

We used LMEs to determine the relative effect of treatment on all response variables: aboveground invertebrate feeding guild (predator, omnivore, herbivore, detritivore) abundances excluding ants, collembola genus richness and biomass, soil and litter C:N ratio, soil and litter microbial biomass, soil moisture, plant biomass and decomposition (percentage of the initial leaf litter mass lost after six months). Treatment (exclusion or control), land-use system and their interaction were included in all models. The interaction term was included to detect if treatment effects were dependent on land use. Also included in each model were all other theoretically possible measured predictors (Table S6.2), however, both litter and soil measures of the same variable (microbial biomass and C:N ratio) were never included in the same model due to significant correlations between the two. Similarly, collembola richness was never included as a predictor because of a correlation with collembola biomass. Pair was nested within sites as a random effect. To meet assumptions of normality, invertebrate abundances, collembola biomass and richness, microbial biomasses were logtransformed $(+1$ in the case of some zero abundance) and plant biomass square root transformed prior to analysis.

We then used an information-theoretic approach to identify the most important variables in explaining each response variable. First, we constructed model sets of all possible combinations of variables included in an initial full model (dredge() function in package MuMIn, Bartoń 2013). Second, we ranked models best on Akaike's Information Criterion for small sample sizes (AICc), and selected the best models as those with $\triangle \mathrm{AICc}<2$ (Burnham and Anderson 2002). Third, we used model averaging on the best models (model.avg() function in package MuMIn) for each response variable (Grueber et al. 2011). P-values, coefficients and relative variable importance values (equivalent to summing up the predicted variables weights, Burnham \& Anderson, 2002) were derived from the average best models.

When there was at least one significant $(P=\leq 0.05)$ land-use effect in the average best model Tukey post-hoc tests with Bonferroni correction (glht() function in package multcomp, Hothorn et al. 2008) were used on the best fit model including land-use system (lowest AICc score) to test for significant differences among the land-use systems. When there was a significant treatment and landuse interaction term in the average best model, the response variable was also assessed for each landuse separately using the same process as when considering all land-uses together, though without landuse in the initial full model. All analyses were conducted in R 3.2.0 (R Core Team 2015).

\subsection{Results}

\section{Ant suppression effectiveness}

Average ant abundance was $48 \%$ lower and species richness was 0.5 species less on average over the year of the experiment in ant suppression plots compared with the control plots (Table S6.3). 


\section{Above-ground invertebrates}

Herbivore abundance was on average $40 \%$ lower in suppression plots than control (Table 6.1, Figure 6.1a). Furthermore, herbivore abundance responded significantly to land-use change (Table 6.1), with a 76\% and 69\% decline from forest to rubber and jungle rubber (though it was nonsignificant for jungle rubber) respectively, but no difference between forest and oil palm (Figure 6.1b, Table S6.4). Herbivore abundance was also positively related to plant biomass (Table 6.1). Detritivore abundance had only a marginally significant negative response to ant suppression (55\% decline), but did respond to land-use system (Table 6.1, Figure 6.1c). More specifically, detritivore abundance was $88 \%, 79 \%$ and $95 \%$ lower on average in jungle rubber, rubber and oil palm sites than forest (though for rubber this difference was only marginally significant). (Figure 6.1d, Table S6.4). Detritivores also responded positively to $\mathrm{C}: \mathrm{N}$ ratio but the relationship was only marginally significant (Table 6.1). Predator abundance was on average 70\% lower in suppression plots than control plots (Table 6.1, Figure 6.1e). Predator abundance also had a significant land-use effect, however, the relative importance value was only 0.50 , and the post-hoc test on the best-fit model only contained a marginally significant decrease from forest to rubber (72\% decline, Figure 6.1f, Table S6.4). Omnivore abundance did not response to treatment (Table 6.1, Figure 6.1g), however, was 67\% and $84 \%$ lower in rubber and oil palm than in forest and 55\% and $78 \%$ lower than in jungle rubber (Figure 6.1h, Table S6.4). 
Table 6.1. The coefficients (coeff), p-values (p-val) and relative variable importance values (Imp) for each predictor in the average of the best models ( $\Delta$ AICc $<2$ ) for invertebrate feeding guild abundances and collembola biomass and genus richness. LUS=land-use system. T=Treatment. Control is the intercept for treatment, and forest is the intercept for land-use system. Predictors marked with "---" were included in the full but not the average best model. Significant $(P=\leq 0.05)$ predictors are indicated in bold. Marginally significant $(P=\leq 0.10)$ are indicated with a $\uparrow$.

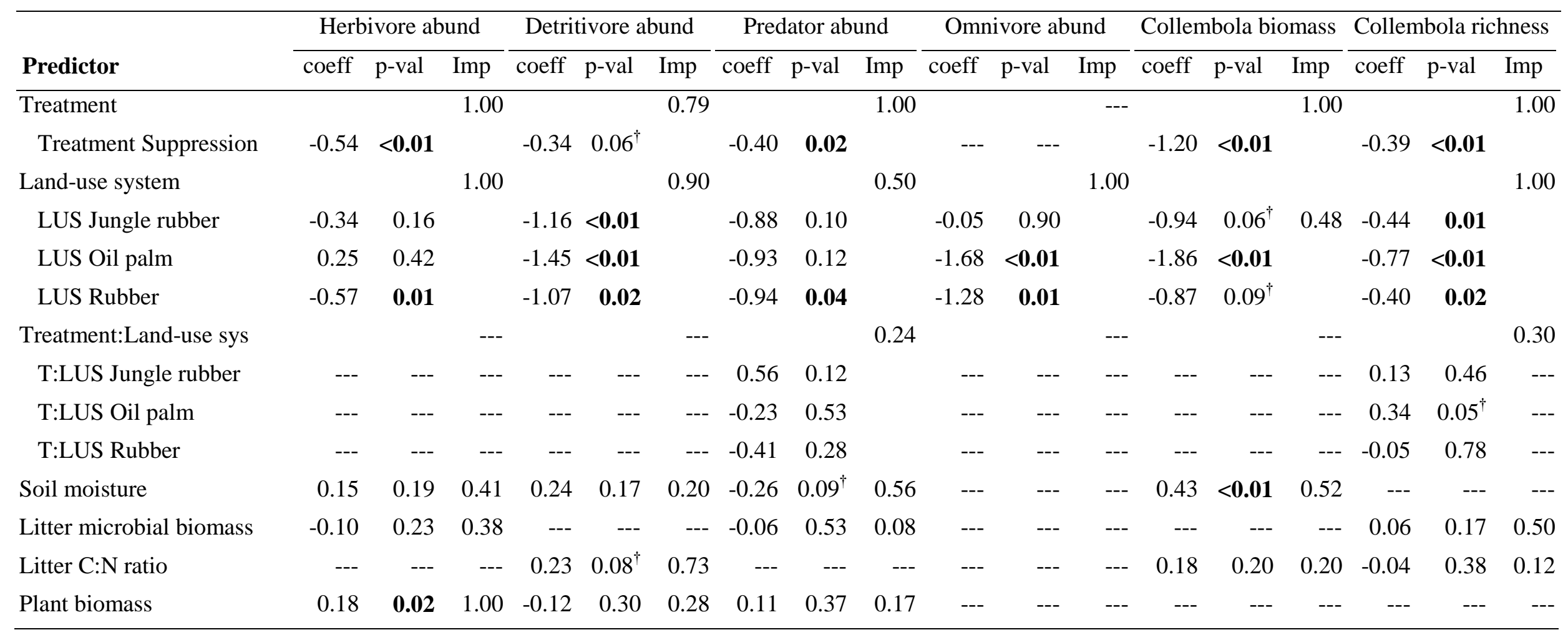


a)

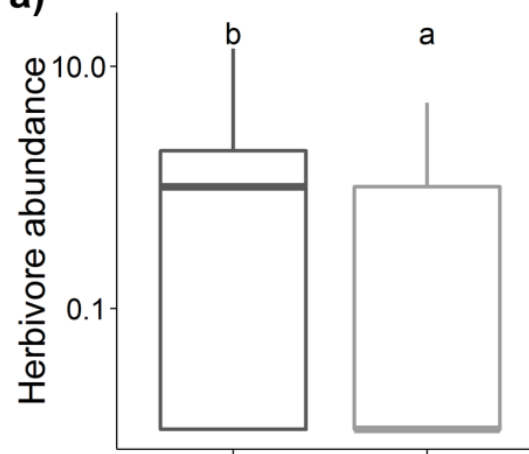

c)



e)

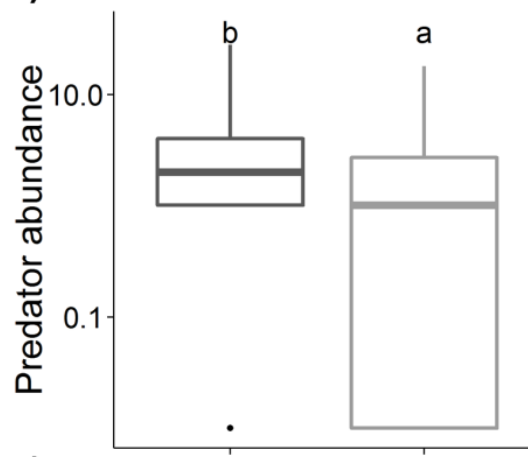

g)

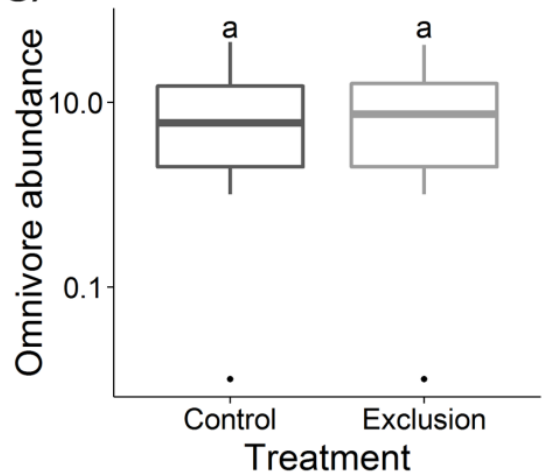

b)

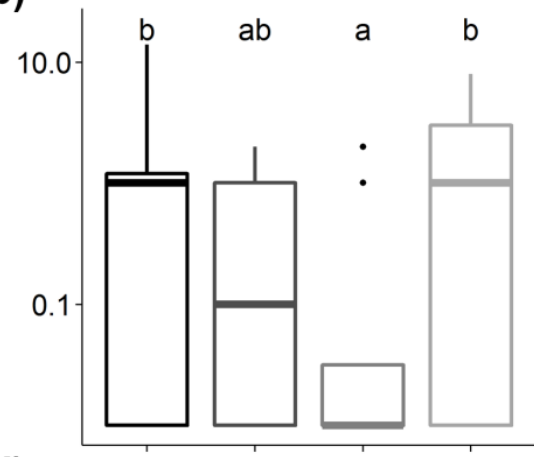

d)

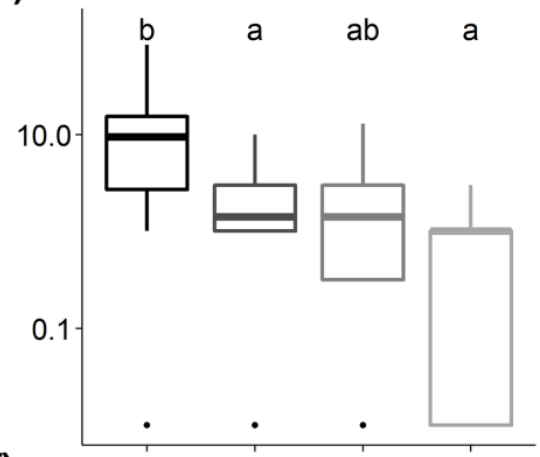

f)

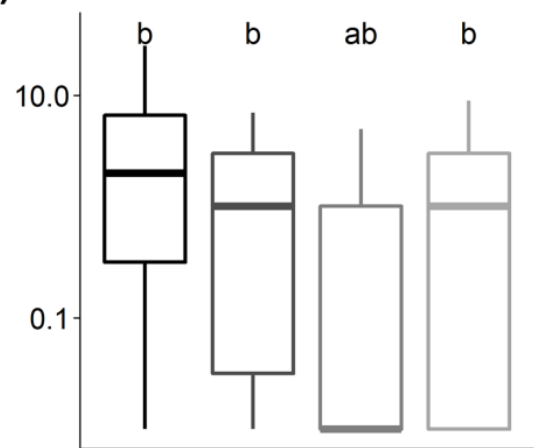

h)

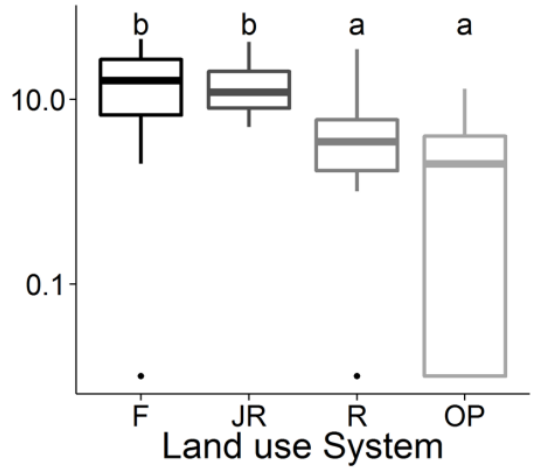

Figure 6.1. Response of (a-b) herbivore abundance, (c-d) detritivore abundance, (e-f) predator abundance and ( $\mathrm{g}-\mathrm{h})$ omnivore abundance to treatment and land-use system. Treatment or land-use system means with different letters are significantly different (Tukey's HSD, $P=\leq 0.05$ ).

\section{Below-ground invertebrates}

Collembola biomass and genus richness were $68 \%$ and $16 \%$ lower in ant suppression plots than control (Figure 6.2a, c, Table 6.1). Collembola also negatively responded to land-use change (Table 6.1). Biomass declined by $81 \%$ from forest to oil palm, however the decline from forest to 
jungle rubber and rubber was non-significant (Figure 6.2b, Table S6.4). Genus richness declined 33\%, $35 \%$ and $58 \%$ from forest to jungle rubber, rubber (only marginally significant) and oil palm respectively. (Figure 6.2d, Table S6.4). Collembola biomass also responded positively to soil moisture content (Table 6.1).
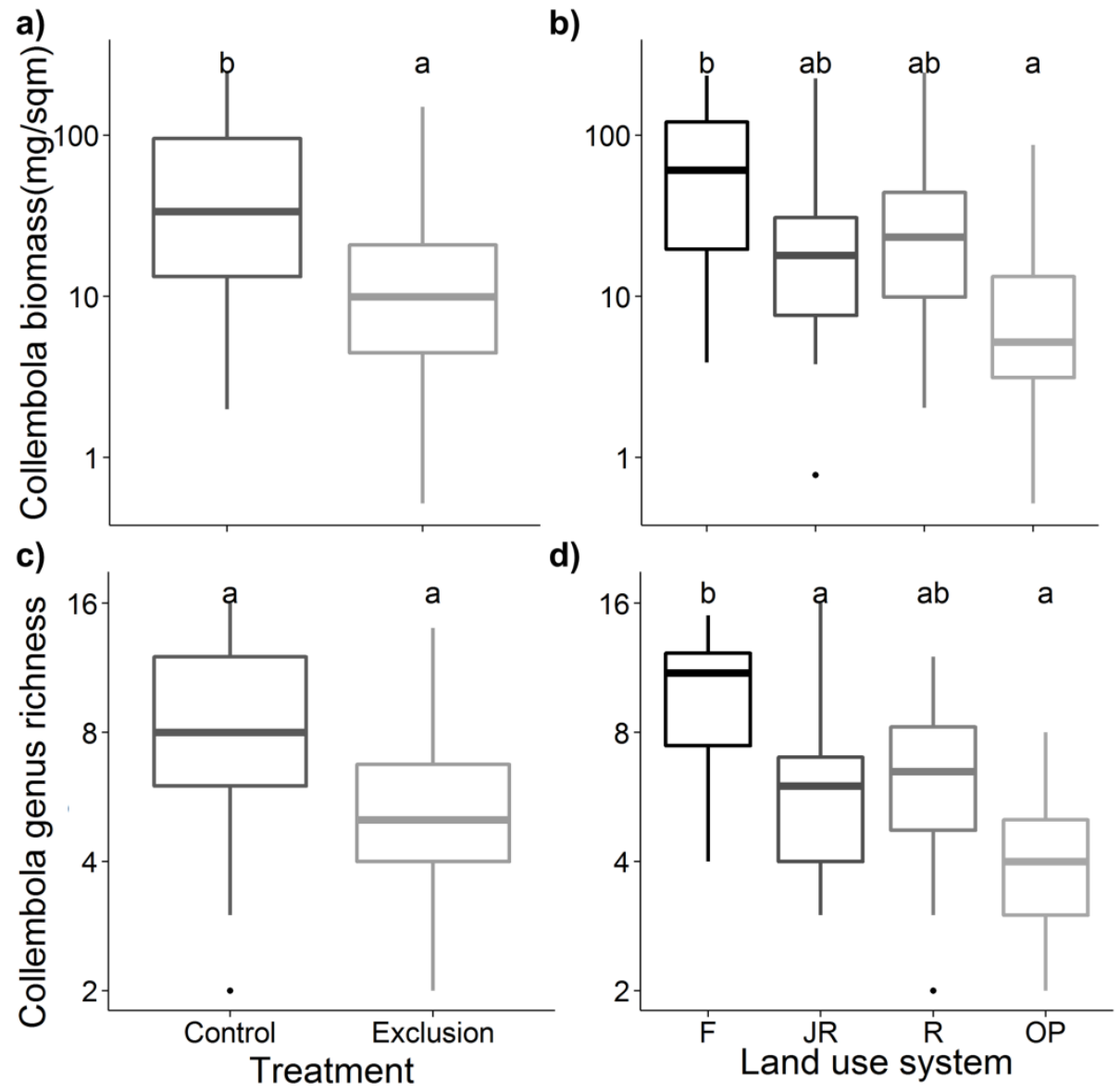

Figure 6.2. Response of (a-b) Collembola biomass (mg/sqm) and (b) Collembola genus richness to treatment and land-use system. Treatment or land-use system means with different letters are significantly different (Tukey's HSD, $\mathrm{P}=\leq 0.05$ ).

\section{Soil, litter and vegetation}

Soil microbial biomass did not respond to treatment or land-use system, rather only had a positive relationship with soil moisture content (Table 6.2, Figure 6.3a). Litter microbial biomass however, did respond to ant suppression though was only $2.9 \%$ lower in the suppression than control plots and relative importance value of treatment was only 0.53 (Table 6.2, Figure 6.3b). Litter microbial biomass was also significantly lower in oil palm than the other three land-uses and was positively related to detritivore abundance (though only marginally significant), soil moisture and plant biomass (Table 6.2, Table S6.5). Soil and litter C:N ratio was not affected by ant suppression, but both responded significantly to land use (Table 6.2, Figure 6.3d, e). However, for soil C:N ratio the post-hoc test on the best-fit model did not show any significant differences between land uses (Table S6.5). Litter C:N ratio was higher in forest than rubber and oil palm, and higher in jungle 
rubber than oil palm but the rubber systems were only marginally significantly different from each other (Table S6.5). Soil moisture was 7\% higher in the ant suppression than the control plots and responded to land-use change (Table 6.2, Figure 6.3e.) More specifically, soil moisture was highest in forest, lowest in oil palm and had intermediate values in the rubber sites (Table S6.5). Plant biomass did not respond to any predictors included in the model (Table 6.2, Figure 6.3f). 
Table 6.2. The coefficients (coeff), p-values (p-val) and relative variable importance values (Imp) for each predictor in the average of the best models ( $\Delta$ AICc $<2$ ) for soil and litter variables, plant biomass and decomposition. LUS=land-use system, T=Treatment. Control is the intercept for treatment, and forest for land-use system. Predictors marked with "X" were not included in the full model, predictors marked with "---."were included in the full but not average best model. Significant $(P=\leq 0.05)$ predictors are indicated in bold, and marginally significant $(P=\leq 0.10)$ with $\uparrow$.

\begin{tabular}{|c|c|c|c|c|c|c|c|c|c|c|c|c|c|c|c|c|c|c|c|c|c|}
\hline \multirow[b]{2}{*}{ Predictor } & \multicolumn{3}{|c|}{ Soil microbial B } & \multicolumn{3}{|c|}{ Litter microbial B } & \multicolumn{3}{|c|}{ Soil C:N ratio } & \multicolumn{3}{|c|}{ Litter C:N ratio } & \multicolumn{3}{|c|}{ Soil moisture } & \multicolumn{3}{|c|}{ Plant biomass } & \multicolumn{3}{|c|}{ Decomposition } \\
\hline & coeff & $\mathrm{p}$-val & $\operatorname{Imp}$ & coeff & p-val & $\operatorname{Imp}$ & coeff & p-val & Imp & coeff & p-val & Imp & coeff & p-val & $\operatorname{Imp}$ & coeff & p-val & $\operatorname{Imp}$ & coeff & $\mathrm{p}$-val & Imp \\
\hline Treatment & & & 0.48 & & & 0.53 & & & 0.11 & -- & 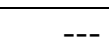 & --- & & & 0.86 & & & 0.41 & & & 1.00 \\
\hline Treatment Suppression & -0.13 & 0.11 & & -0.35 & 0.04 & & 0.16 & 0.55 & & & & & 2.60 & 0.05 & & 1.27 & 0.14 & & -28.92 & $<0.01$ & \\
\hline Land-use system & & & --- & & & 0.47 & & & 0.19 & & & 1.00 & & & 1.00 & & & --- & & & 1.00 \\
\hline LUS Jungle rubber & --- & --- & --- & -0.11 & 0.68 & & -0.58 & 0.47 & & -1.68 & 0.36 & & -12.17 & $<0.01$ & & --- & --- & --- & -16.10 & 0.02 & \\
\hline LUS Oil palm & --- & --- & --- & -0.87 & 0.01 & & -1.15 & 0.15 & & -8.34 & $<0.01$ & & -22.17 & $<0.01$ & & --- & --- & --- & -22.87 & $<0.01$ & \\
\hline LUS Rubber & --- & --- & --- & 0.31 & 0.25 & & -1.86 & 0.02 & & -5.73 & $<0.01$ & & -6.43 & 0.05 & & --- & --- & -- & -20.14 & 0.01 & \\
\hline Treatment:Land-use sys & & & --- & & & --- & & & --- & & & --- & & & --- & & & --- & & & 1.00 \\
\hline T:LUS Jungle rubber & --- & --- & --- & --- & --- & --- & --- & --- & --- & --- & --- & --- & -- & --- & --- & --- & --- & --- & 26.89 & $<0.01$ & \\
\hline T:LUS Oil palm & --- & --- & --- & --- & --- & --- & --- & --- & --- & --- & --- & --- & -- & --- & --- & --- & --- & --- & 30.36 & $<0.01$ & \\
\hline T:LUS Rubber & --- & --- & --- & --- & --- & --- & --- & --- & --- & --- & --- & --- & -- & --- & --- & --- & --- & -- & 30.14 & $<0.01$ & \\
\hline Herbivore abundance & $\mathrm{X}$ & $\mathrm{X}$ & $\mathrm{X}$ & -0.24 & 0.20 & 0.53 & $\mathrm{X}$ & $\mathrm{X}$ & $\mathrm{X}$ & --- & --- & --- & $X$ & $\mathrm{X}$ & $\mathrm{X}$ & -0.50 & 0.33 & 0.08 & 1.70 & 0.16 & 0.29 \\
\hline Detritivore abundance & $\mathrm{X}$ & $\mathrm{X}$ & $\mathrm{X}$ & 0.20 & $0.06^{\dagger}$ & 0.32 & $\mathrm{X}$ & $\mathrm{X}$ & $\mathrm{X}$ & 1.25 & 0.04 & 0.82 & $\mathrm{X}$ & $\mathrm{X}$ & $\mathrm{X}$ & $\mathrm{X}$ & $\mathrm{X}$ & $\mathrm{X}$ & 1.63 & 0.22 & 0.14 \\
\hline Predator abundance & $\mathrm{X}$ & $\mathrm{X}$ & $X$ & -0.08 & 0.43 & $0.09^{\dagger}$ & $\mathrm{X}$ & $\mathrm{X}$ & $\mathrm{X}$ & --- & --- & --- & $X$ & $\mathrm{X}$ & $X$ & $\mathrm{X}$ & $\mathrm{X}$ & $\mathrm{X}$ & -- & --- & --- \\
\hline Omnivore abundance & $\mathrm{X}$ & $\mathrm{X}$ & $\mathrm{X}$ & --- & --- & --- & $\mathrm{X}$ & $\mathrm{X}$ & $\mathrm{X}$ & -0.93 & 0.15 & 0.27 & $\mathrm{X}$ & $\mathrm{X}$ & $\mathrm{X}$ & -0.76 & 0.27 & 0.28 & 2.17 & 0.15 & 0.19 \\
\hline Collembola biomass & 0.04 & 0.46 & 0.11 & --- & --- & --- & --- & --- & --- & -0.42 & 0.46 & 0.07 & 0.80 & 0.43 & 0.25 & -0.65 & 0.27 & 0.10 & 2.02 & 0.22 & 0.24 \\
\hline Soil moisture & 0.13 & 0.03 & 1.00 & 0.26 & 0.03 & 0.62 & 0.16 & 0.46 & 0.12 & -1.06 & 0.17 & 0.33 & $\mathrm{X}$ & $\mathrm{X}$ & $\mathrm{X}$ & --- & --- & --- & --- & --- & --- \\
\hline Soil microbial biomass & $\mathrm{X}$ & $\mathrm{X}$ & $X$ & $\mathrm{X}$ & $\mathrm{X}$ & $X$ & 0.20 & 0.22 & 0.20 & $X$ & $\mathrm{X}$ & $\mathrm{X}$ & 1.16 & 0.14 & 0.45 & -0.64 & 0.27 & 0.31 & $\mathrm{X}$ & $\mathrm{X}$ & $\mathrm{X}$ \\
\hline Litter microbial biomass & $\mathrm{X}$ & $\mathrm{X}$ & $\mathrm{X}$ & $\mathrm{X}$ & $\mathrm{X}$ & $\mathrm{X}$ & $\mathrm{X}$ & $\mathrm{X}$ & $\mathrm{X}$ & 0.62 & 0.28 & 0.24 & -- & --- & --- & $\mathrm{X}$ & $\mathrm{X}$ & $\mathrm{X}$ & --- & --- & --- \\
\hline Soil C:N ratio & 0.05 & 0.30 & 0.32 & $\mathrm{X}$ & $\mathrm{X}$ & $\mathrm{X}$ & $\mathrm{X}$ & $\mathrm{X}$ & $\mathrm{X}$ & $\mathrm{X}$ & $\mathrm{X}$ & $\mathrm{X}$ & -- & --- & --- & -0.83 & 0.19 & 0.37 & $\mathrm{X}$ & $\mathrm{X}$ & $\mathrm{X}$ \\
\hline Litter C: $\mathrm{N}$ ratio & $\mathrm{X}$ & $\mathrm{X}$ & $\mathrm{X}$ & 0.12 & 0.23 & 0.19 & $\mathrm{X}$ & $\mathrm{X}$ & $\mathrm{X}$ & $\mathrm{X}$ & $\mathrm{X}$ & $\mathrm{X}$ & -- & --- & --- & $\mathrm{X}$ & $\mathrm{X}$ & $\mathrm{X}$ & --- & --- & -- \\
\hline Plant biomass & --- & --- & --- & 0.22 & 0.03 & 0.64 & -0.16 & 0.43 & 0.12 & --- & --- & --- & -- & --- & --- & $\mathrm{X}$ & $\mathrm{X}$ & $\mathrm{X}$ & --- & --- & --- \\
\hline
\end{tabular}



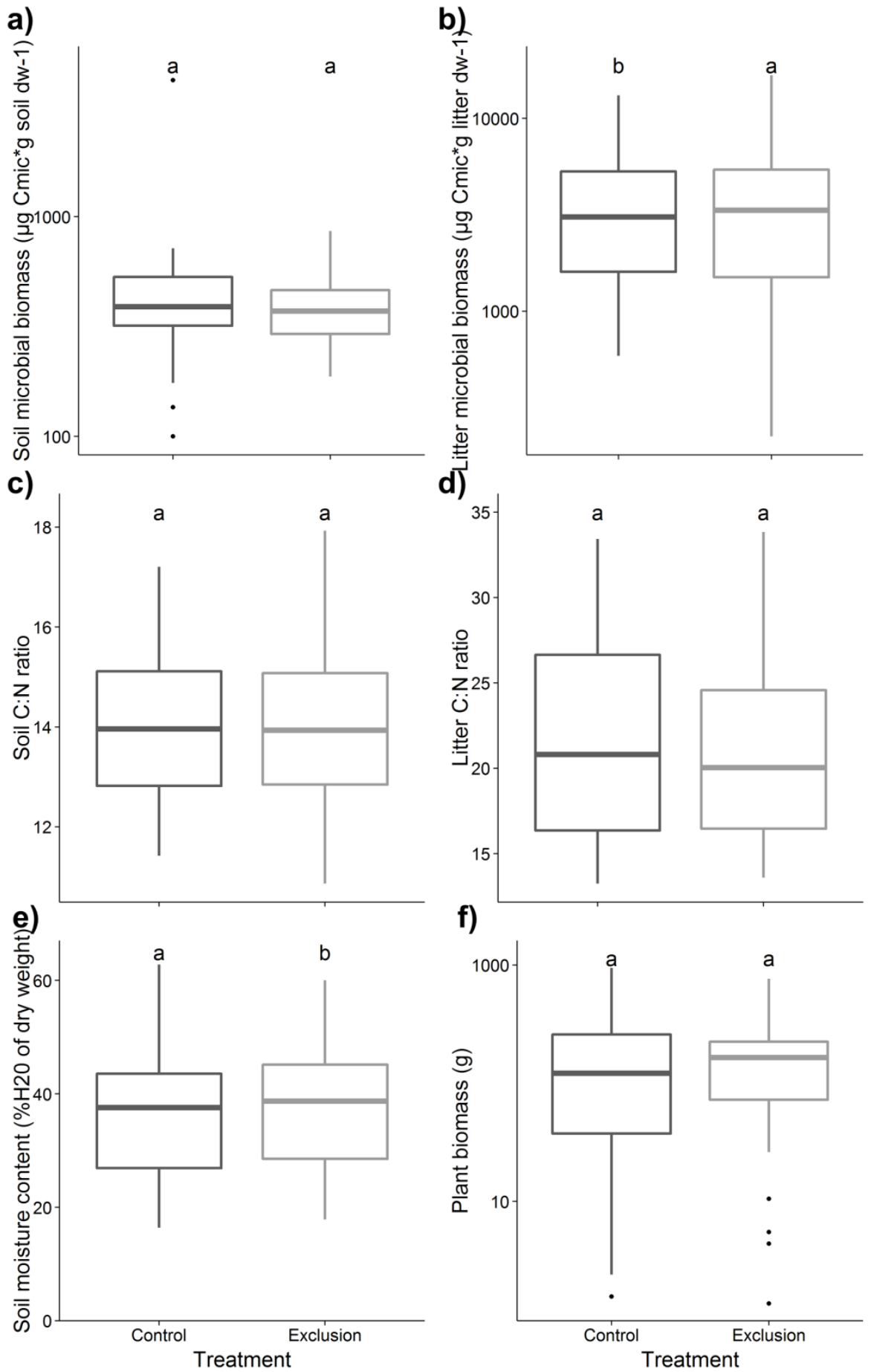

Figure 6.3. Response of (a) soil microbial biomass, (b) litter microbial biomass, (c) soil C:N ratio, (d) litter $\mathrm{C}: \mathrm{N}$ ratio, (e) soil moisture and (f) plant biomass to measured predictors. Treatment means with different letters are significantly different (Tukey's HSD, $P=\leq 0.05$ ).

\section{Litter decomposition}

Land-use system, treatment and interaction had a significant effect on decomposition (Table 6.2). Overall decomposition was significantly lower in ant suppression plots than control, however, when assessing decomposition rate in each land-use separately, decomposition was only significantly 
different between treatments in the forest, where it was $47 \%$ lower in suppression rather than control plots (Figure 6.4, Table S6.6).

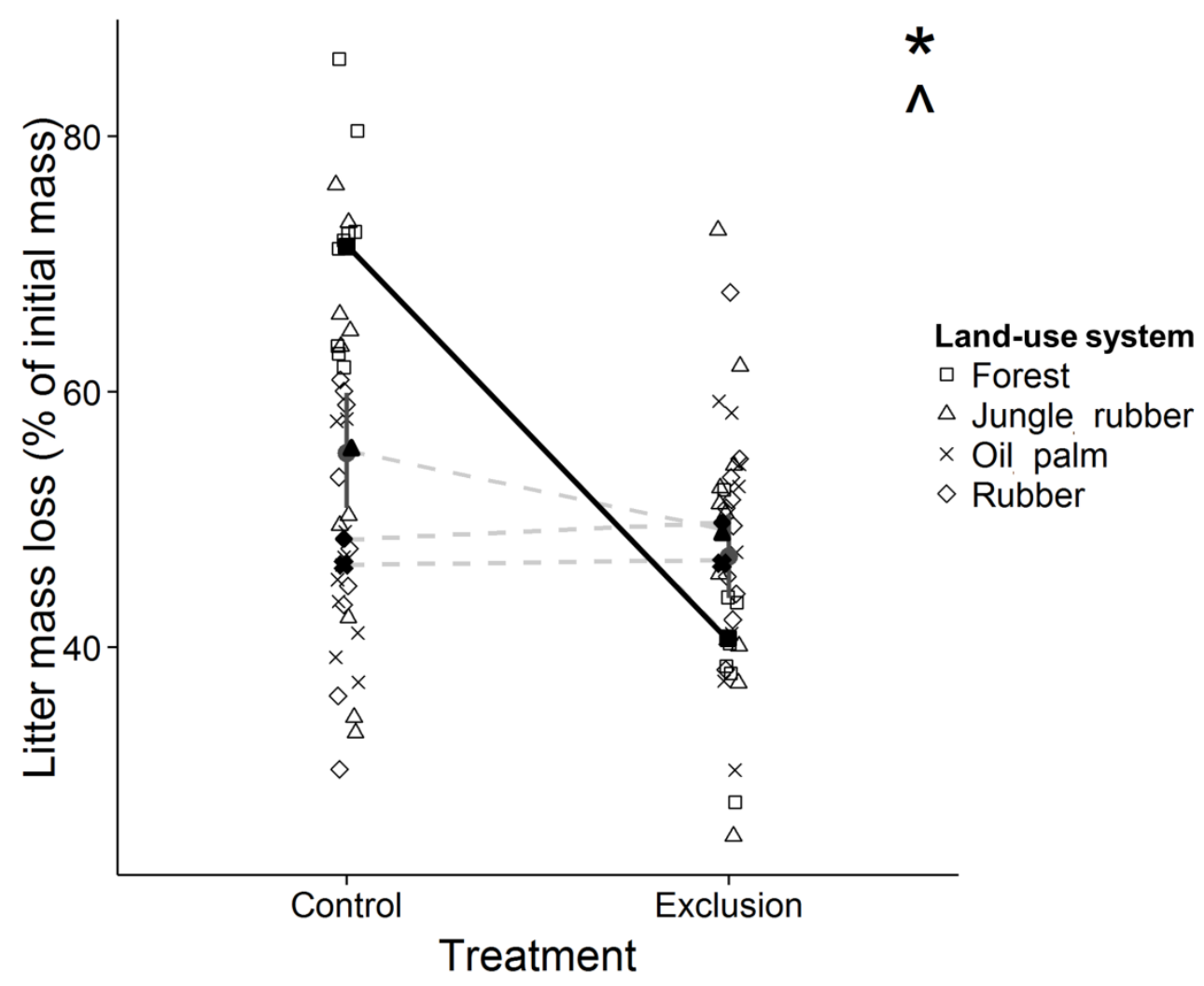

Figure 6.4. Response of decomposition rate to ant exclusion treatment and treatment: land-use system interaction. Significant treatment main effects are denoted with "*” (LME, $P=\leq 0.05$ ). The presence of a significant interaction between treatment and land-use system included in final model is denoted with "^". Treatment mean and standard error across all land-uses are marked with a grey circle and line. Treatment mean within land-use are marked with solid shapes. Significant differences between treatments for a land-use type are indicated with a solid line between treatment means.

\subsection{Discussion}

Our results show that ants influence above- and belowground invertebrate communities, soil and litter variables and decomposition. Experimental ant suppression was linked to a decline in three out of four aboveground invertebrate feeding guilds (herbivores, detritivores, predators, but not omnivores). Also, belowground invertebrates, i.e. collembola, were strongly influenced with lower biomass and genus richness in ant suppression plots. Soil and litter variables were mostly unaffected by ant suppression. Differences in local conditions within and between the four studies land-use systems were generally foremost predictors of our response variables. Most notably, ant suppression reduced decomposition in the forest sites only.

\section{Aboveground invertebrates}


Predators, herbivores and to a lesser extent detritivores declined with ant suppression, however, omnivores did not change. This is likely due to the ant suppression treatment not only having a negative effect on ants but also other invertebrates. All four feeding guilds also had strong responses to land-use change with all groups severely declining from forest to one or more of the agricultural systems. Interestingly, although detritivores and omnivores were lowest in oil palm, herbivores and predators were lowest in rubber even though oil palm is usually presumed to be more intensive and therefore have less biodiversity than rubber. Jungle rubber abundance values, although lower than forest, were generally intermediate between the plantations and forest sites. These results support previous studies suggesting forest conversion and the intensification of agriculture are two of the main threats to global biodiversity (Sala et al. 2000; Danielsen et al. 2009; Laurance et al. 2014)

Furthermore, the effects of land use change were dependent on functional feeding guild, which in turn infers differing functional impacts of land use change, though these effects are less well studied. Finally, herbivore abundance was positively related to plant biomass, although this is unsurprising it has implications for management in the plantations were the understory biomass is almost entirely dependent on management practices.

\section{Belowground invertebrates}

Collembola are heavily influenced by ant suppression, in particular in terms of biomass, with suppression plots only having $30 \%$ of the collembola biomass of control plots. Due to the small size of Collembola we expect effects of the barriers to be of low importance unlike the large aboveground community. Altered ant densities may indirectly influence Collembola populations, due to ants reducing other predator groups, especially spiders, which are known to affect Collembola populations (Moya-Laraño and Wise 2007; Sanders and Platner 2007; Sanders and van Veen 2011). Abundances of spiders and other aboveground predators in general also decreased with ant suppression here, but it is possible a belowground predator group such as predatory mites (Acari, Gamasida) were oppositely affected. In the aboveground invertebrate samples, number of mites did increase with ant suppression; however, we did not look at predatory mites specifically.

In contrast to our expectations, ant suppression decreased Collembola biomass and genus richness in a similar manner across land use systems, including structurally complex forests and structure-poor oil palm plantations. This is surprising considering that the presence of complex structure, e.g., dense undergrowth vegetation, may strongly dampen antagonistic interactions among predators and enhance prey suppression (Finke and Denno 2002). However, we measured moderate but significant increases of soil moisture in ant suppression plots, which may be closely connected to the decreases of Collembola. Ants have been linked to increases in soil aeration and therefore greater water infiltration and drainage (Majer et al. 1987; Folgarait 1998). Few studies investigated the effect of soil moisture and seasonal rainfall on Collembola populations in tropical forests in detail, the available data show that decreases in Collembola populations are mainly caused by prolonged drought events (Holt 1985; Frith and Frith 1990; Wiwatwitaya and Takeda 2005). However, Collembola 
numbers may also decrease when soil conditions are very wet (Holt 1985; Frith and Frith 1990; Bardgett et al. 1993). For our study Collembola have been sampled once around the end of the rainy season, when the soil on the study sites is frequently highly humid or even water logged. Additional soil moisture and decreased drainage may have negatively affected Collembola populations by increasing the frequency and duration of periods in which the soil is water logged.

\section{Soil, litter and vegetation}

A previous long term (13 years) ant exclusion experiment also found increases in soil moisture, though they linked moisture changes to changes in vegetation composition and cover (Wardle et al. 2011). We did not find any changes in plant biomass with ant suppression; however we did not look at compositional differences in the plant community. Plant biomass could be expected to change with ant suppression, due to their role as seed dispersers and predators (Carlson and Whitford 1991; Levey and Byrne 1993; Wardle et al. 2011); however, this was not the case here. The plants also did not respond to our measured soil variables (moisture, $\mathrm{C}: \mathrm{N}$ ratio and microbial biomass). The plant biomass and the species present in the three agricultural systems in particular was very variable within land use and could have been affected by past management and light conditions. For example, herbicide use is quite variable within the plantation systems and there is variation in light availability between jungle rubber sites.

Soil and litter C:N ratio and microbial biomass were not (or only slightly) influenced by ant suppression, which was against expectation due to many other studies showing effects of ants on soil properties (though not litter) (e.g. Folgarait 1998; Cammeraat and Risch 2008; Frouz and Jilková 2008). A possible reason for the lack of differences seen in this experiment is the scale of the experiment, both in regards to size and time. Changes in soil properties at this scale may have only been detected if the plots were of a scale that could include ant nests (which there weren't in any our experimental plots) or if the experiment was longer term (e.g. Wardle et al. 2011 found increases in microbial biomass with ant exclusion after 6 years). Most commonly, ant effects on soil properties are found due to nest construction (Jouquet et al. 2006) and although not often studied it is important to understand nest patterns in the landscape when studying the impacts of ants (Folgarait 1998; Cammeraat and Risch 2008).

\section{Decomposition}

Almost all responses to treatment were independent of land-use system, however there was a significant interaction between treatment and land-use system in the final model for decomposition. Treatment only influenced decomposition in forest sites where it was significantly lower in suppression rather than control plots. This could be due to different plant material used, or just as likely due to the large differences in ant communities between the land-uses included in this study (Denmead et al. in review; Rubiana et al. 2015). Although ants are still dominant in jungle rubber, rubber and oil palm, there are large changes in the functional composition of ant communities between 
the land-use systems (Denmead et al. in review). Certain species of ant that are forest specialists could be directly influencing decomposition or rather, indirectly through effects such as predation and competition altering the decomposer community.

\section{Conclusions}

In this study we found that ant suppression at small scales can cause suppression of other aboveground invertebrates, and have severe negative effects on belowground invertebrates, i.e. Collembola. The substantial effects on Collembola need further investigation, particularly in regards to their relationship with predatory mites and seasonal variation. Ant suppression effects on vegetation and soil and litter variables were minimal, nevertheless, effects on decomposition rates were dependent on land use, whereby ant suppression reduced decomposition in the forest sites only. It is likely that ant community changes from forest, which supports more forest specialists and predators, to agricultural systems have altered their influence on decomposition, however, the underlying drivers of these effects require further investigation. Knowledge of changes in the functional role of animal groups in response to land-use change is important to understand the long-term consequences of landuse change.

\section{Acknowledgements}

We thank Rico Fardiansah, Derly Hartika, Patrick Diaz, Arie Perdana, Ozy Borland and Ilham for all their help in the lab and the field. We thank village leaders, local plot owners, and PT REKI for granting us the use of their properties. This study was financed by the Deutsche Forschungsgemeinschaft (DFG) in the framework of the collaborative German - Indonesian research project Collaborative Research Centre 990: Ecological and Socioeconomic Functions of Tropical Lowland Rainforest Transformation Systems (Sumatra, Indonesia). 


\subsection{Supplementary material}

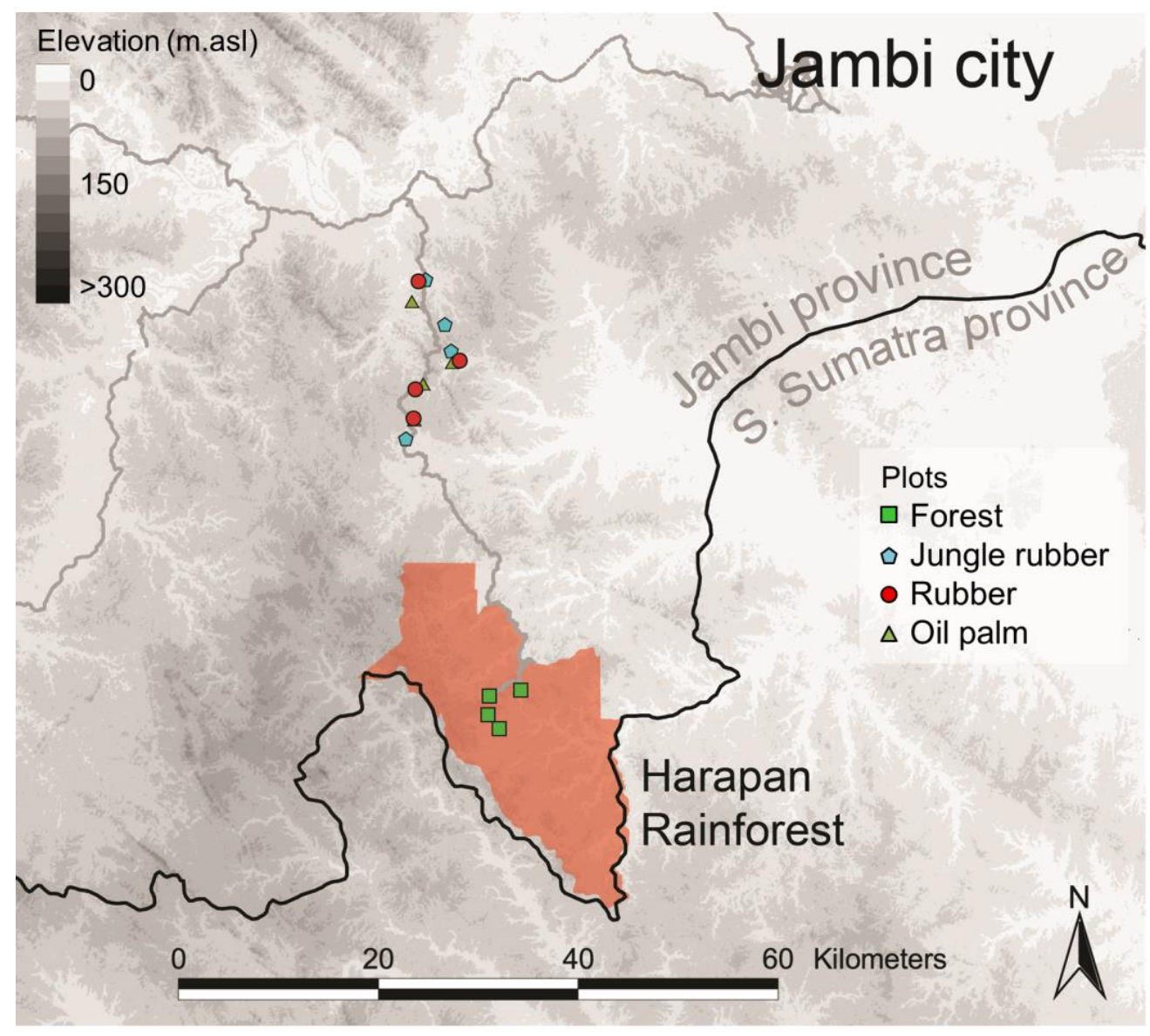

Figure S6.1. Study site location and study design. Map of study area located in Jambi, Sumatra, Indonesia. Each land-use system was replicated four times in the Batanghari regency. The study area was adjacent to a protected area which also contained the forest sites, the Harapan rainforest (area shaded in orange). Figure modified from Allen et al (2015). 


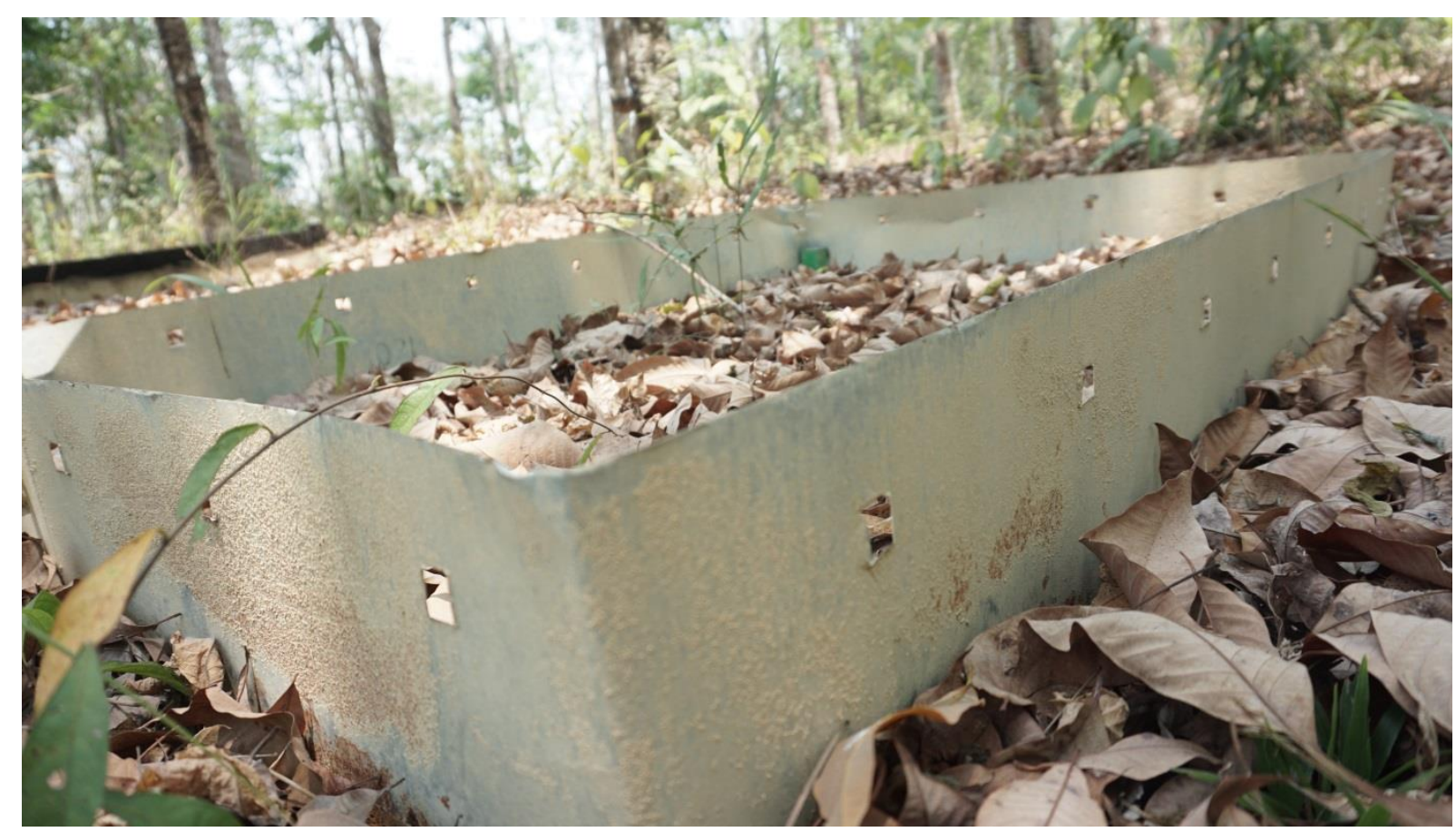

Figure S6.2. Photo of a control plot. One control plot from a rubber site showing the regular holes cut into the aluminium 
Table S6.1. Invertebrate higher taxonomic groups, assigned to feeding guilds.

\begin{tabular}{ll}
\hline Higher taxonomic group & Feeding guild \\
\hline Acari & omnivore \\
Araneae & predator \\
Blattodea & detritivore \\
Chilopoda & predator \\
Coleoptera & omnivore \\
Collembola & omnivore \\
Dermaptera & omnivore \\
Diplopoda & detritivore \\
Diptera & omnivore \\
Gastropoda & detritivore \\
Haplotaxida & detritivore \\
Hemiptera & omnivore \\
Hymenoptera (non formicidae) & omnivore \\
Isopoda & detritivore \\
Isoptera & detritivore \\
Lepidoptera & herbivore \\
Mantodea & predator \\
Neuroptera & predator \\
Opiliones & omnivore \\
Orthoptera & herbivore \\
Pseudoscorpionida & predator \\
Psocoptera & detritivore \\
Symphyla & \\
\hline
\end{tabular}


Table S6.2. Variables included in full models for each response variable. Variables marked with an " $\mathrm{X}$ " are included as predictors within the corresponding response variables initial full model. Pred $=, \mathrm{Herb}=$ herbivore, Det $=$ detritivore, Omni $=$ omnivore, $\mathrm{A}=$ abundance, $\mathrm{R}=$ richness, Col $=$ collembola, $\mathrm{B}=$ biomass, $\mathrm{S}=$ soil, $\mathrm{L}=$ litter, moisture $=$ moist content, microB $=$ microbial biomass, $\mathrm{CN}=\mathrm{C}: \mathrm{N}$ ratio.

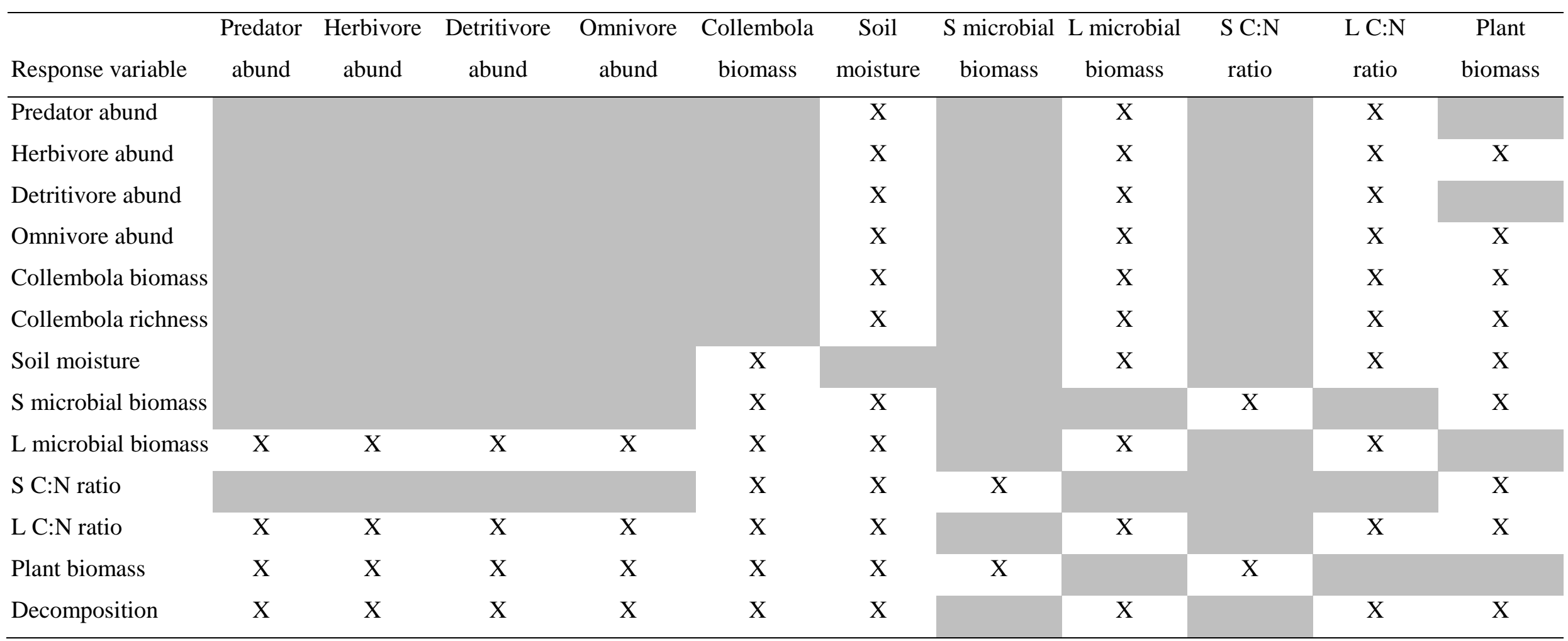


Table S6.3. Linear mixed effect model ANOVA outputs testing for a significant effect of ant suppression on ant abundance and richness. The linear mixed effects models which determined the effect of the ant suppression treatment on (a) average ant abundance and (b) average ant species richness. Significant $p$-values are indicated in bold $(p \leq 0.05)$.

\begin{tabular}{|c|c|c|c|c|c|}
\hline & ponse variable & Effect & $\mathrm{df}$ & F-value & p-value \\
\hline a) & Ant abundance & Ant suppression treatment & 79 & 63.968 & $<0.001$ \\
\hline b) & Ant species richness & Ant suppression treatment & 79 & 86.547 & $<0.001$ \\
\hline
\end{tabular}


Table S6.4. Summary statistics of Tukey post-hoc tests testing for significant differences in invertebrate response variables among land-use systems. Tukey post-host tests were performed on the best-fit linear mixed effects models which determined the effect of land-use change a) herbivore abundance, b) detritivore abundance, c) predator abundance, d) omnivore abundance, e) collembola biomass, f) collembola richness. Significant p-values are indicated in bold (Tukey's HSD, $P=\leq 0.05$ ). Marginally significant $(P=<0.10)$ are indicated with $\mathrm{a} \uparrow . \mathrm{F}=$ forest, $\mathrm{J}=$ jungle rubber, $\mathrm{R}=$ rubber, $\mathrm{O}$ $=$ oil palm.

Response variable

a) Herbivore abundance

$$
\begin{aligned}
& J-F \\
& O-F \\
& R-F \\
& O-J \\
& R-J \\
& R-O
\end{aligned}
$$

b) Detritivore abundance

$$
\begin{aligned}
& J-F \\
& O-F \\
& R-F \\
& O-J \\
& R-J \\
& R-O
\end{aligned}
$$

c) Predator abundance

$$
\begin{aligned}
& \mathrm{J}-\mathrm{F} \\
& \mathrm{O}-\mathrm{F} \\
& \mathrm{R}-\mathrm{F} \\
& \mathrm{O}-\mathrm{J} \\
& \mathrm{R}-\mathrm{J} \\
& \mathrm{R}-\mathrm{O}
\end{aligned}
$$

$-1.18$

$-1.07$

$-0.35$

$-0.24$

0.11

$-1.18$

$-2.98$

0.02

$-1.40$

$-3.16$

$-2.51$

$-0.52$

0.30

0.85

0.83

0.34

$-1.79$

0.28

$-2.21$

$-2.38$

0.12

$0.08^{\dagger}$

$-0.75$

0.87

$-0.53$

0.95

0.23

1.00

d) Omnivore abundance

$$
\begin{aligned}
& \mathrm{J}-\mathrm{F} \\
& \mathrm{O}-\mathrm{F} \\
& \mathrm{R}-\mathrm{F} \\
& \mathrm{O}-\mathrm{J} \\
& \mathrm{R}-\mathrm{J} \\
& \mathrm{R}-\mathrm{O}
\end{aligned}
$$

$-0.05$

$-0.13$

1.00

$-1.68$

4.02

$<0.01$

$-1.28$

$-3.04$

0.01

$-1.63$

$-3.86$

$<0.01$

$-1.22$

$-2.90$

0.02

0.41

0.95

0.78

e) Collembola biomass

$$
\begin{aligned}
& \mathrm{J}-\mathrm{F} \\
& \mathrm{O}-\mathrm{F}
\end{aligned}
$$$$
-0.98
$$$$
-1.82
$$$$
0.26
$$ 


$\begin{array}{lrrr}\mathrm{R}-\mathrm{F} & -0.83 & -1.53 & 0.42 \\ \mathrm{O}-\mathrm{J} & -0.96 & -1.76 & 0.29 \\ \mathrm{R}-\mathrm{J} & 0.15 & 0.27 & 0.99 \\ \mathrm{R}-\mathrm{O} & 1.10 & 2.02 & 0.18\end{array}$

f) Collembola richness

$\begin{array}{lccc}\text { J }- \text { F } & -0.49 & -2.69 & \mathbf{0 . 0 4} \\ \text { O-F } & -0.88 & -4.78 & <\mathbf{0 . 0 1} \\ \text { R - F } & -0.45 & -2.47 & 0.06^{\dagger} \\ \text { O- J } & -0.39 & -2.10 & 0.15 \\ \text { R - J } & 0.04 & 0.19 & 1.00 \\ \text { R - O } & 0.42 & 2.27 & 0.11\end{array}$


Table S5. Summary statistics of Tukey post-hoc tests testing for significant differences in soil, litter and vegetation response variables among land-use systems. Tukey post-host tests were performed on the best-fit linear mixed effects models which determined the effect of land-use change on a) litter microbial biomass, b) soil $\mathrm{C}: \mathrm{N}$ ratio, c) litter $\mathrm{C}: \mathrm{N}$ ratio and d) soil moisture. Only response variables with significant responses to land-use system (Table 2) are shown here. Significant p-values are indicated in bold (Tukey's HSD, $P=\leq 0.05)$. Marginally significant $(P=<0.10)$ are indicated with a $\dagger$. $\mathrm{F}=$ forest, $\mathrm{J}=$ jungle rubber, $\mathrm{R}=$ rubber, $\mathrm{O}=$ oil palm.

Response variable

Estimate

z-value

p-value

a) Litter microbial biomass

$\mathrm{J}-\mathrm{F}$
$\mathrm{O}-\mathrm{F}$
$\mathrm{R}-\mathrm{F}$
$\mathrm{O}-\mathrm{J}$
$\mathrm{R}-\mathrm{J}$
$\mathrm{R}-\mathrm{O}$

$-0.14$

$-0.57$

0.94

$-0.98$

3.93

$<0.01$

0.28

1.09

0.69

$-0.84$

$-3.31$

$<\mathbf{0 . 0 1}$

0.42

1.63

0.36

1.26

4.87

$<0.01$

b) Soil C:N ratio

$\begin{array}{lrrl}\mathrm{J}-\mathrm{F} & -0.58 & -0.71 & 0.89 \\ \mathrm{O}-\mathrm{F} & -0.16 & -1.42 & 0.48 \\ \mathrm{R}-\mathrm{F} & -1.86 & -2.27 & 0.11 \\ \mathrm{O}-\mathrm{J} & -0.58 & -0.71 & 0.89 \\ \mathrm{R}-\mathrm{J} & -1.28 & -1.56 & 0.40 \\ \mathrm{R}-\mathrm{O} & 0.70 & -0.85 & 0.83\end{array}$

c) Litter $\mathrm{C}: \mathrm{N}$ ratio

$\begin{array}{lrrr}\text { J }- \text { F } & -1.30 & -0.76 & 0.87 \\ \text { O-F } & -7.31 & -4.00 & <\mathbf{0 . 0 1} \\ \text { R - F } & -5.14 & -2.96 & \mathbf{0 . 0 2} \\ \text { O- J } & -6.01 & -3.66 & <\mathbf{0 . 0 1} \\ \text { R - J } & -3.84 & -2.35 & 0.09^{\dagger} \\ \text { R }- \text { O } & 2.16 & 1.30 & 0.56\end{array}$

d) Soil moisture

\begin{tabular}{lrrr} 
J - F & -12.50 & -3.74 & $<\mathbf{0 . 0 1}$ \\
O - F & -23.38 & -6.96 & $<\mathbf{0 . 0 1}$ \\
R - F & -6.76 & -2.01 & 0.18 \\
O - J & -10.88 & -3.22 & $<\mathbf{0 . 0 1}$ \\
R - J & 5.74 & 1.98 & 0.33 \\
R - O & 16.62 & 4.89 & $<\mathbf{0 . 0 1}$ \\
\hline
\end{tabular}


Table S6. The coefficients (coeff), p-values (p-val) and relative variable importance values (Imp) for each predictor in the average of the best models $(\triangle \mathrm{AICc}<2)$ for decomposition rate in each land-use. Predictors marked with a --- were included in the full but not the average best model. Control is the intercept for treatment. Significant $(P=\leq 0.05)$ predictors are indicated in bold. Marginally significant $(P=<0.10)$ are indicated with a $\uparrow$.

Land-use system

Predictor

coeff $\quad$-val Imp

a) Forest

Treatment

Treatment Suppression

$-32.27$

$<0.01$

Herbivore abundance

$-2.67$

0.02

1.00

Detritivore abundance

Predator abundance

Omnivore abundance

Collembola biomass

Soil moisture

Litter microbial biomass

Litter C:N ratio

Plant biomass

b) Jungle rubber

Treatment

Treatment Suppression

Herbivore abundance

Detritivore abundance

Predator abundance

Omnivore abundance

Collembola biomass

Soil moisture

Litter microbial biomass

Litter C:N ratio

Plant biomass

c) Rubber

Treatment

Treatment Suppression

Herbivore abundance

Detritivore abundance

Predator abundance

Omnivore abundance 
Collembola biomass

Soil moisture

Litter microbial biomass

Litter C:N ratio

Plant biomass

d) Oil palm

Treatment

Treatment Suppression

Herbivore abundance

2.89

Detritivore abundance

$-4.54$

$0.06^{\dagger}$

0.68

Predator abundance

Omnivore abundance

Collembola biomass

Soil moisture

Litter microbial biomass

Litter C:N ratio

$\begin{array}{ll}0.22 & 0.19\end{array}$

Plant biomass 


\title{
Chapter 7
}

\section{The role of ants, birds and bats for ecosystem functions and services in oil palm plantations}

Lisa H. Denmead, Kevin Darras, Yann Clough, Patrick Diaz, Ingo Grass, Munir Hoffmann, Fuad Nurdiansyah, Teja Tscharntke

In review, Ecology, submitted: $14^{\text {th }}$ March 2016

\begin{abstract}
One of the world's most important and rapidly expanding crops, oil palm, is associated with low levels of biodiversity. Large changes in communities at higher trophic levels might alter ecosystem services and subsequently sustainable management but these links have received little attention to date. Here, we manipulated ant and flying vertebrate (birds and bats) access for the first time, using six smallholder oil palm plantations in Sumatra (Indonesia), and measured effects on arthropod communities, related ecosystem functions (herbivory, predation, decomposition and pollination) and crop yield. Spiders increased in response to reductions in ant and bird access, but the overall effect of experimental manipulations on ecosystem functions was minimal. Similarly, effects on yield were not significant. We conclude that ecosystem functions and productivity in oil palm are, under current levels of pest pressure and pollinator populations, robust to large changes in the communities of major predator groups.
\end{abstract}




\subsection{Introduction}

Conversion of natural forests to agricultural systems results in considerable losses in biodiversity (Newbold et al. 2015), yet the remaining biodiversity can play an important role through supporting ecosystem functions and services, alongside inputs such as fertilisers and labour (Fischer et al. 2006). In tropical agricultural systems, species groups such as ants, birds and bats contribute to a number of ecosystem services, such as predation (biocontrol), soil aeration and nutrient cycling (Folgarait 1998; Vandermeer et al. 2002; Evans et al. 2011), and have been shown to positively affect yield (Evans et al. 2011; Wielgoss et al. 2014; Maas et al. 2015; Maine and Boyles 2015). Currently the most rapidly expanding tropical perennial crop is oil palm, the world's most important oilseed commodity (Phalan et al. 2013). Despite the importance of oil palm, there have been few studies linking biodiversity and function (e.g. Dejean et al. 1997; Koh 2008a; Slade et al. 2014) and the majority of these have only looked at only one function or service (but see, Gray and Lewis 2014) and no studies as yet have looked at the relationship between biodiversity, functions and yield.

Almost all organisms studied thus far show a decrease in species diversity from forest to oil palm (Fitzherbert et al. 2008; Foster et al. 2011; Barnes et al. 2014). More importantly, this biodiversity loss is often non-random, endangering ecosystem functioning (Fitzherbert et al. 2008; Senior et al. 2013). However, certain management practices can promote biodiversity in oil palm plantations (Chung et al. 2000; Nájera and Simonetti 2010; Teuscher et al. 2015). Yet, plantation owners are unlikely to adopt new management practices to increase biodiversity alone. Nevertheless, if there is any relationship between biodiversity and yield and/or any beneficial ecosystem service this might alter a plantation owner's willingness to change.

While ant species richness and abundance in Indonesian oil palm can equal or exceed that in lowland rainforest, species and functional composition is drastically altered (Denmead et al. in review; Rubiana et al. 2015). Therefore, although ants remain dominant and likely play an important part in oil palm plantations, their influence on the community and certain ecosystem functions may be altered. Furthermore, birds and bats reduce the abundance of arthropod communities in agricultural systems which results into lower herbivory and higher yields (Maas et al. 2015). For instance, birds may lower leaf damage by pests in young, unproductive oil palms (Koh 2008a). However, null and negative effects on herbivory and yield have also been reported for other systems (e.g. Gras et al. 2016).

Exclusion studies including ants, birds and bats can exhibit important intra-guild interactions that lead to non-additive effects (Maas et al. 2015), but such studies are scarce (Gras et al. 2016). In the present study, we established a one year long, large scale full factorial combination of bird/bat and ant exclosures in young, productive oil palm plantations in Sumatra, Indonesia. We comprehensively assess the influence of ants, birds and bats on arthropod communities and associated ecosystem functions and services, investigating changes in arthropod communities and four key ecosystem functions: herbivory, predation, pollination and decomposition. Furthermore, this is the first study to assess the impact of predator exclusions on oil palm yield. 


\subsection{Materials and methods}

\section{Study area}

The experiment was carried out in the Batanghari Regency of Jambi Province, Sumatra, Indonesia. The climate of the region can be characterised as tropical humid, with more than $2000 \mathrm{~mm}$ rainfall per year (Allen et al. 2015) and a long sunshine duration of an average 6h/day. Thus, it is classified as suitable for oil palm production (Corley and Tinker 2003), and attainable yields are above $30,000 \mathrm{~kg} \mathrm{FFB} / \mathrm{ha} /$ year $(\mathrm{FFB}=$ fresh fruit bunch) during the most productive phase in the life cycle of the oil palm (Hoffmann et al. 2014). Over the past 20 years oil palm has become one of the most dominant crops in the Province, increasing almost 4-fold from 150,000 ha to 550,000 in the period from 1996 to 2011 (Gatto et al. 2015).

\section{Experimental design}

Six smallholder oil palm plantations were selected in the study area for inclusion in this study with a minimum distance between the sites of $1.0 \mathrm{~km}$ (mean distance to closest site: $2.4 \mathrm{~km}$; Fig. S7.1). We selected oil palm sites with trees that were 2-3 years old (earliest age to begin harvesting) due to height limitations of establishing the bird and bat exclusion cages. The plantation management was consistent with plantations in the study area and site conditions were relatively similar (Supplementary methods, Appendix 7.1). Within each plantation we created a full factorial combination of ant and flying vertebrate (bird and bat) exclusion plots, and each plot's location was randomly assigned (Fig. 7.1). This resulted in four experimental plots per site: control, ant exclusion only, flying vertebrate exclusion only and both ant and flying vertebrate exclusion. Each plot was approximately $16 \mathrm{~m} \times 16 \mathrm{~m}$, encompassing four oil palm trees. 
a)
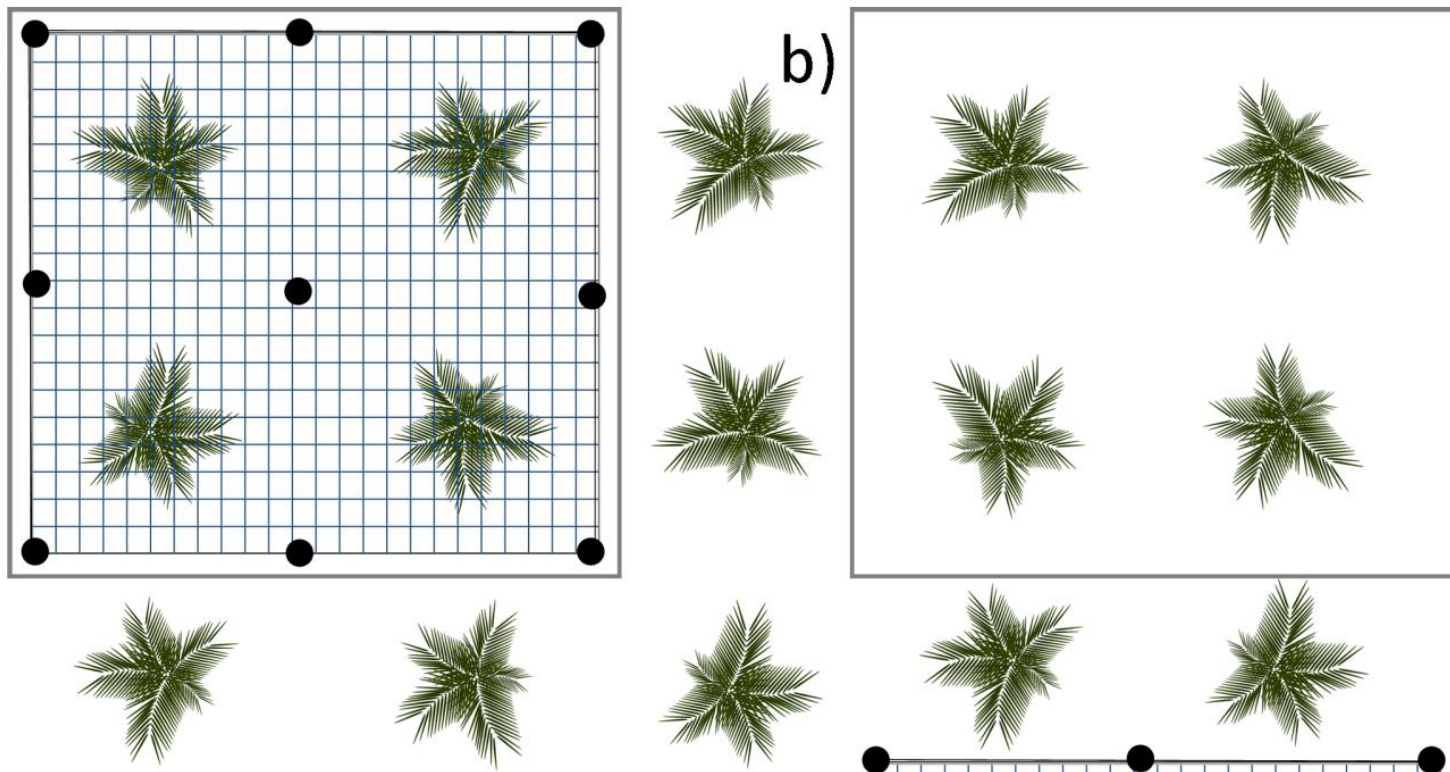

c)
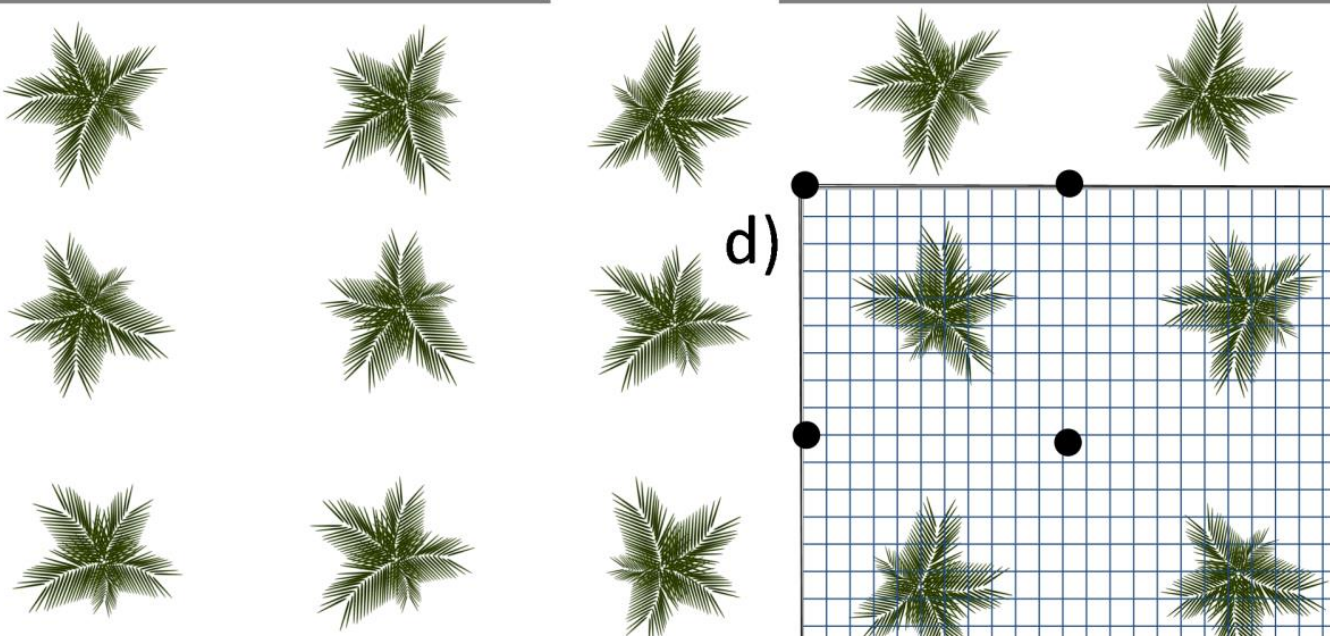

d)


e)

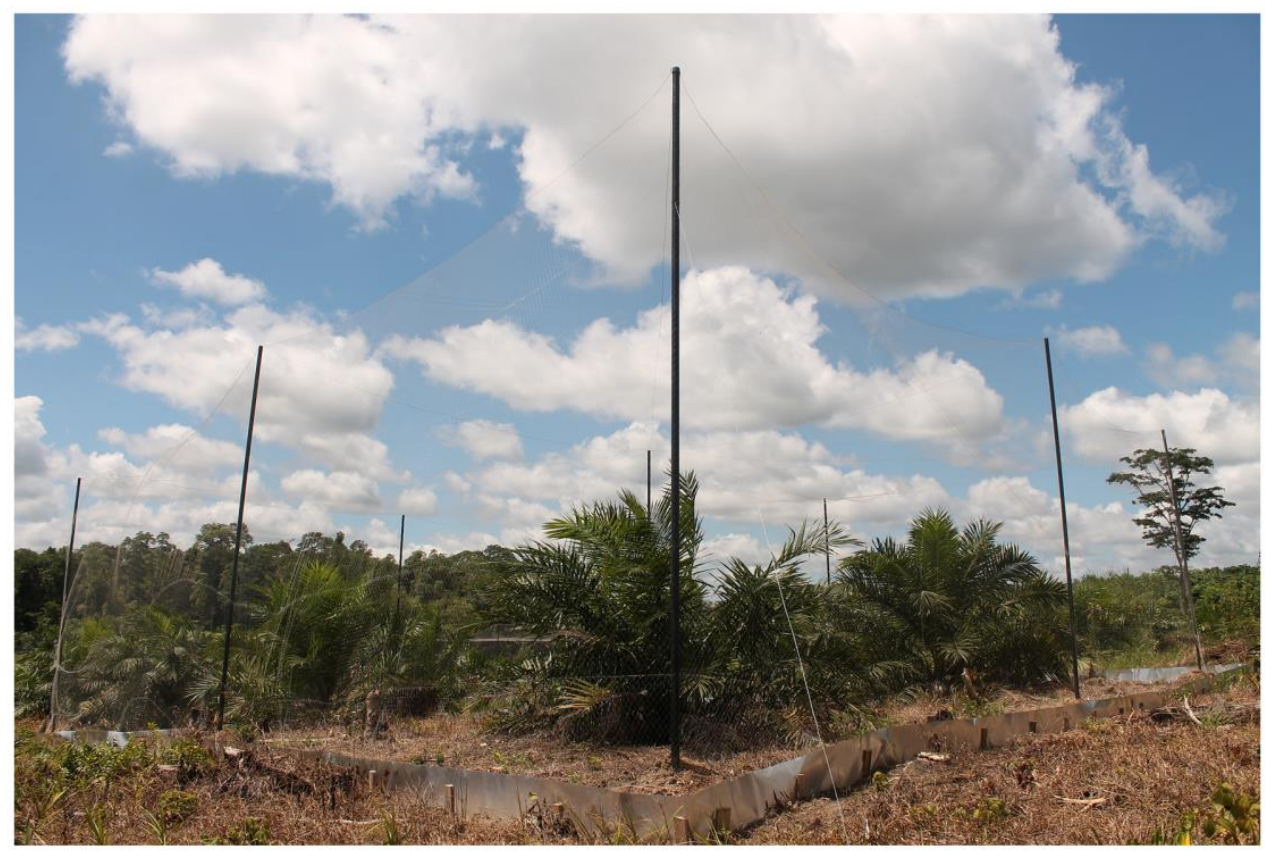

Figure 1. Experimental design. Full factorial combination of ant and bird and bat exclusion plots at each study site. (a) Both bird, bat and ant exclusion, (b) ant exclusion only, (c) control (no exclusion), (d) bird and bat exclusion only. (e) Example of a bird, bat and ant exclusion plot. 


\section{Exclusion methodology}

Two methods were used to suppress ants in the exclusion plots. A $50 \mathrm{~cm}$ high aluminium barrier was established surrounding the plot, buried $20 \mathrm{~cm}$ beneath the soil and the top of the barrier was covered in insect glue (Tanglefoot, Contech Enterprises Inc., British Columbia). The glue was regularly checked and replaced when needed. We also carried out toxic baiting five days per week and targeted poisoning of ant nests during the first month of the experiment and then toxic baiting three times per week for the duration of the experiment. The toxic baiting consisted of placing sugar and tuna as attractants, mixed with the insecticide chlorpyrifos (Dursban ${ }^{\mathrm{TM}} 200 \mathrm{EC}$, Dow AgriSciences, Jakarta, Indonesia) in nine random locations (one in each tree, five on the ground) in each ant suppression plot for a minimum of one hour. Preliminary experiments determined these two attractants to be attractive to the majority of ant species present, but not to other arthropods.

Flying vertebrate (birds and bats) exclusion cages were constructed using a metal structure consisting of nine 5.0-5.5 m high iron poles (2.5 inches diameter). The poles were embedded in concrete foundations, lined with plastic bags to prevent leaching of carbonate to the soil. Fish nets (35 $\mathrm{mm}$ mesh size transparent, nylon) were pulled over the structure and fastened to the ground. Due to the size of the exclosure and the length of the experiment it was not possible to use removable nets that could be manipulated to differentiate between the effects of vertebrates with day or night activity (i.e., birds and bats; Maas et al. 2013). Ant suppression and bird and bat exclusion was continuous for one year, from August 2013 until August 2014 in four out of six plots, and from May 2014 to May 2015 for the other two.

Ant abundance, bird and bat activity monitoring

Ants were surveyed monthly in every plot to monitor the effectiveness of the ant suppression methods. We used two plastic observation plates per plot with two baits of $2 \mathrm{~cm}^{3}$ of tuna in oil and two sponges saturated with 70\% sugar solution attached (Wielgoss et al. 2010). At 15, 30, 45 and 60 minutes after placing the plates on the ground the abundance of each ant species present on the plate was recorded. Specimens were collected from each ant species present and were identified at species or morpho-species level (Fayle et al. 2014). Ant species abundance at a given plot each month was defined as the mean of the maximum number of each species on each plate used at an exclusion plot and the sum of all these values at each plot determined the total ant abundance each month (Denmead et al. in review).

Bird and bat calls were recorded in January (4 sites) and July (6 sites) 2014, and January 2015 (remaining two sites) with automated sound recorders attached to the central oil palm, and fitted with one acoustic and one ultrasound microphone (SM2Bat+ recorder, SMX-II and SMXUS microphones, Wildlife Acoustics Inc., Massachusetts, USA). We recorded sound for 48 hours starting at sunset, and programmed a sampling rate of $44.1 \mathrm{kHz}$ during the day and a sampling rate of $192 \mathrm{kHz}$ at night. Bird and bat recordings were processed on an online sound platform (http://soundefforts.uni-goettingen.de/). An ornithologist identified bird species in one morning 
recording per plot for each month (20 min starting after sunrise). We classified them into feeding guilds based on Thiollay et al. (1995); missing data were retrieved from del Hoyo et al. (2015). The distance to bird calls (including songs) was estimated by ear by both the ornithologist and an additional listener. We computed the mean distance for each call and excluded calls beyond $35 \mathrm{~m}$. For bats, night recordings of $20 \mathrm{~min}$ per plot for each month (starting from 18:30) were time-expanded by a factor of 4 (from 192 to $48 \mathrm{kHz}$ ) to make bat ultrasound calls audible. For insectivorous and omnivorous birds as well as insectivorous (echolocating) bats, we used the total duration of their calls in each plot to measure their activity. The activity of birds and bats inside cages was assumed to be null.

\section{Sampling methods}

\section{Environmental and tree variables}

In each plot we measured four variables which could potentially vary between and within sites and influence our experiment's response variables to be included in our analysis: $\operatorname{Soil} \mathrm{pH}\left(\mathrm{H}_{2} \mathrm{O}\right)$, soil texture (clay content), initial oil palm height and oil palm red/green leaf colour ratios (Appendix 7.1). Soil $\mathrm{pH}$ and texture reflected soil conditions at our plots, initial oil palm height accounts for oil palm developmental stage and red/green leaf colour ratios were used to gauge the proportion of the leaves that had photosynthetic activity.

\section{Arthropod collection and identification}

The arthropod communities present in the oil palms were sampled intensively after one year of exclusion through three survey methods: insecticide spraying, beating and vacuuming. All methods were completed at one plot before moving to the next. First we laid four $0.9 \mathrm{~m}$ x $2.9 \mathrm{~m}$ white sheets on the ground at right angles from four points at the base of the trunk of each oil palm. One person then walked around the palms twice spraying an insecticide with knock-down effect (deltamethrin, Decis ${ }^{\circledR}$ 2,5 EC, Bayer CropScience, Jakarta, Indonesia) over each palm using a knapsack sprayer. After 15 min all arthropods on the sheets were collected. Next, the beating method was completed by holding a $5 \mathrm{~m} \times 3 \mathrm{~m}$ sheet under four different fronds per palm and shaking the frond up and down so arthropods dropped onto the sheet. All arthropods that had dropped onto the sheet were collected. Finally, arthropods in the oil palm leaf axils and flowers were collected by vacuuming the axils for four minutes per palm using a modified vacuum cleaner.

Arthropods - other than ants and the introduced oil palm pollinator Elaeidobius kamerunicus, which were identified to species/morpho-species level - were identified to higher taxonomic groups, counted and assigned to four feeding guilds: herbivores, predators, detritivores and omnivores based on literature (Table S7.1).

\section{Ecosystem functions}

In each of the plots, data on four important ecosystem functions were collected: herbivory, decomposition, predation and pollination. 
Herbivory was quantified using photos of two leaflets (pinnae) from four fronds per palm (eight leaflets per palm). Percentage leaf loss per photo was calculated using ImageJ software and converted to an average leaf loss per palm. These photos were taken at nine months after exclusion.

Leaf-litter decomposition was measured using litter bags (Falconer et al. 1933). Litter bags were $20 \mathrm{~cm} \times 20 \mathrm{~cm}$ and made from mesh with a $4 \mathrm{~mm} \times 4 \mathrm{~mm}$ mesh size. Each litter bag contained a known dry weight $(10.0 \mathrm{~g} \pm 0.05 \mathrm{~g})$ of oil palm leaves. Four litter bags were placed at random points within each plot. After approximately four and a half months the litter bags were collected and the remaining contents were air dried and weighed. Initial weight minus weight at collection divided by days exposed determined the decomposition rate.

Predation rates were estimated using three different prey sizes. To represent the large prey size we used dummy caterpillars modelled on (similar size and colour) a common species of nettle caterpillar that is known to attack oil palm (Setothosea asigna). Four dummy caterpillars were glued to a leaflet on four different fronds on each oil palm (four caterpillars/palm) and collected 48 hours later. Each caterpillar was defined as predated (visible marks present in the clay) or not (no marks present) and missing caterpillars were excluded from analysis. This method was carried out four and eight months after exclusion start. To represent a medium and small prey size we used dead crickets (Acheta domesticus) and aphids (Aphidoidea sp.) respectively. Four individuals were glued onto a piece of card and then one card was glued to four different fronds on each oil palm (16 individuals/palm for both prey). Cards were checked after two hours for crickets and four hours for aphids, and each individual was defined as predated (visible marks present, or individual missing) or not (no marks present). The cricket predation method was carried out at eight (last two sites) and 12 months (first four sites), and the aphids at five and eight (last two sites), and 11 and 12 months (first four sites) after exclusion.

We used the abundance of Elaeidobius kamerunicus collected at final arthropod sampling as a proxy for pollination in our ecosystem functions analysis. Elaeidobius kamerunicus was introduced to South East Asia in the 1980s and is now the main pollinator of oil palm in the area (Foster et al. 2011). The introduction resulted in an approximate $20 \%$ increase in yield and removed the need for hand pollination (Greathead 1983; Foster et al. 2011).

\section{Yield}

Yield measurements continued throughout the experiment and six months after exclusion ended (total = 18 months), except for one plot where the manager decided to terminate their partnership with the experiment at exclusion end (site two, Fig. S7.2). Plantation owners harvested fruit bunches following their normal schedule (twice per month). Yield as fresh fruit bunch weight (FFB) was recorded as $\mathrm{kg} / \mathrm{palm}$. Oil palm takes 5-6 months between flowering and yield (Verheye 2010), therefore we discarded the first six months of data and used the following 12 months' data in order to reduce carry-over effects from the pre-study period. Also, a few palms had not developed mature bunches by the experiment start, therefore, we computed yield by time by dividing yield by the number of days since the first harvest (FFB (kg/palm)/day) (Fig. S7.2). Two palms (out of 96) that 
were never harvested were excluded from the overall analysis. Three supplementary measures of yield were analysed and included in the supporting information to confirm the robustness of the yield measurement used here (Appendix 7.1).

\section{Statistical analysis}

Treatment effects on arthropods, ecological functions, growth and yield

We used linear-mixed effect models (LMEs) to determine the effect of experimental treatment on the arthropod feeding guild abundances (predator, herbivore, detritivore and omnivore), weevil abundances, oil palm herbivory (\% leaf loss), decomposition rate, predation rates and oil palm yield (FFB $(\mathrm{kg} / \mathrm{palm}) /$ time $)$. In the LMEs a Poisson distribution was specified for modelling arthropod abundances and a binomial distribution was specified for modelling predation rates, where we used the counts of predated and unpredated prey items (aphids, crickets and dummy caterpillars). An observation-level random effect was included in the case of over-dispersion with the Poisson distributions (Harrison 2014). Experimental treatment consisted of three variables: average ant abundance, bird activity and bat activity (bird and bat activity in caged plots was set to zero). To account for the different combinations of exclusion we included an interaction term for ants and birds and ants and bats. We used these three continuous variables instead of the factorial treatment to account for the variation in the effectiveness of ant suppression and the known variation in bird and bat activity between sites (Appendix 7.1, Table S7.2, Fig. S7.3+S7.4). In each model all other theoretically possible measured predictors were also included (Table S7.3) and treatment was nested within site (plantation) as a random effect. Oil palm initial height, soil $\mathrm{pH}$ and soil clay content were included as predictors in all the models where is was theoretically relevant due to preliminary analyses determining there were significant differences between treatments within sites (Appendix 7.1, Table S7.4). Due to highly skewed distributions, we log-transformed bat activity and weevil abundance when they were included in models as predictors. All numeric predictors were z-transformed to facilitate comparisons of effect sizes.

We then used a model selection approach to assess which of the variables included were most important in explaining each response variable (i.e., maximized the likelihood of the model). For each response, we constructed a model set based on the initial full model -which included all possible combinations of predictors up to a model including only the intercept - and ranked models within each set using Akaike's Information Criterion for small sample sizes (AICc) (dredge() function in R-package MuMIn, Bartoń 2013). We then identified the best models as those with $\Delta \mathrm{AICc}<2$ (Burnham and Anderson 2002). We used model averaging to combine the best models, which were equivalently likely (Grueber et al. 2011), and derived relative variable importance by summing up the predicted variables weights (model.avg() function in package MuMIn) (Burnham and Anderson 2002). We also determined conditional $\mathrm{R}^{2}$ values for all of the best models (Table S7.5). All analyses were conducted in R 3.2.2 (R Core Team 2015). 


\subsection{Results}

The following results from LMEs are displayed in Fig. 7.2, 7.3 and 7.4 and listed in detail in the supplement (see Table S7.6 (arthropods), S7.7 (functions) and S7.8 (yield)). If not specified, discussed relationships are significant at least at a $P$-value of $<0.05$.

\section{Arthropod responses to ant, bird and bat treatments.}

Average ant abundance and bird activity had negative effects on predator abundance, however, bat activity did not significantly influence predators (Fig. 7.2). Predator abundance decreased by $53 \%$ and $42 \%$ from the lowest to the highest ant abundance and bird activity respectively. Ant abundance had a marginally significant negative relationship with herbivore $(P=$ $0.087)$ and omnivore $(P=0.076)$ abundance (both also had a relative importance value of one) but not bird or bat activity (Fig 7.2). Also, for omnivores, ant abundance had a significant and a marginally significant $(P=0.070)$ interaction with bat activity and bird activity respectively. Detritivore abundance was not affected by ant abundance or bird and bat activity. Soil clay content had a positive relationship with predator, herbivore and detritivore abundance.

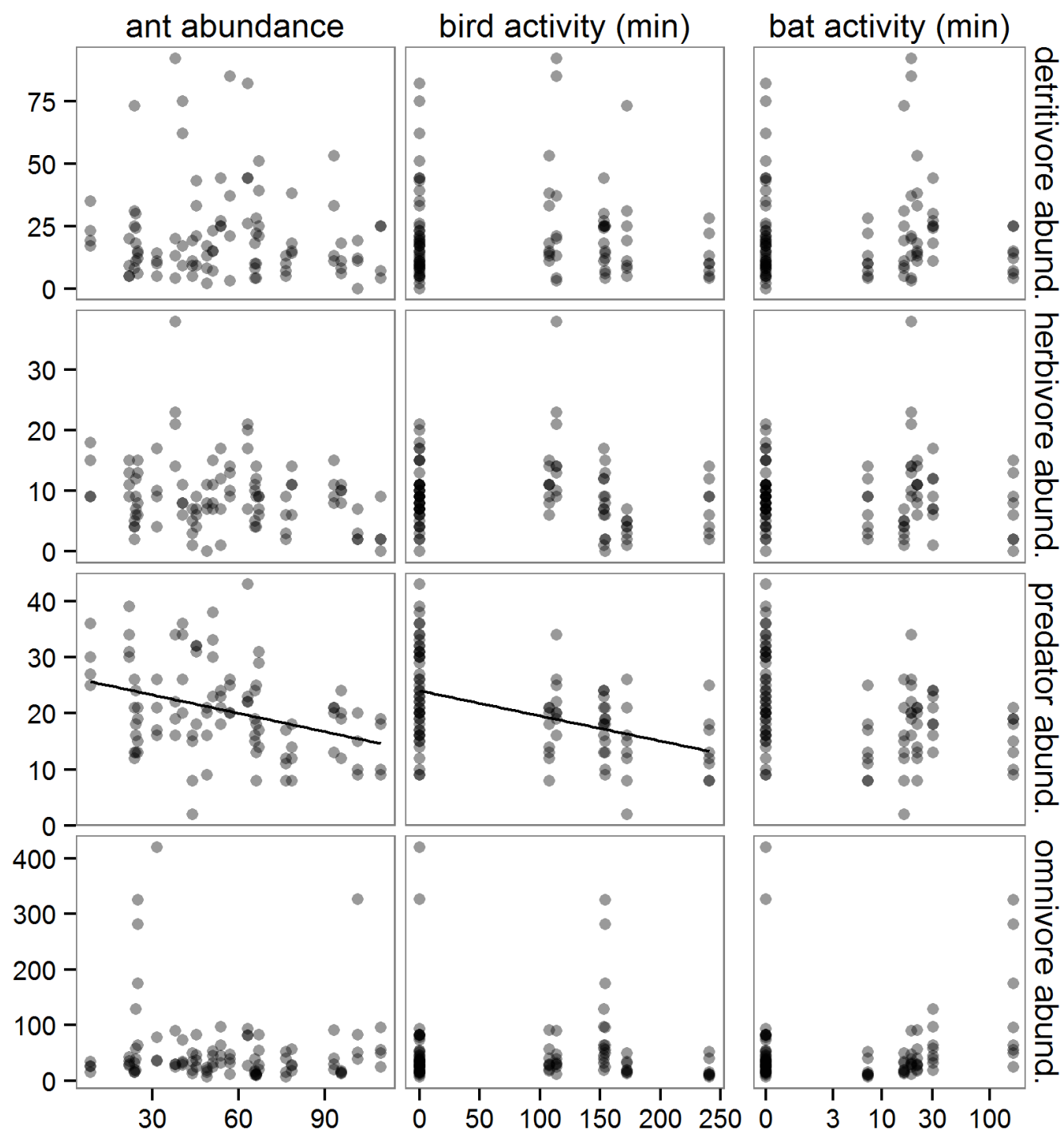


Figure 7.2. The response of arthropod feeding guilds to average ant abundance, bird activity and bat activity. Significant $(P=<0.05)$ relationships are indicated with a solid line. Darker shading of points indicates multiple overlapping points.

\section{Ecosystem function responses to ant, bird and bat treatments and arthropod communities}

Our ant, bird and bat manipulations had no effects on herbivory, rather only oil palm initial height and soil $\mathrm{pH}$ had (marginally significant for height) positive and negative effects respectively (Fig. 7.3). Decomposition was not affected by any of our treatments (Fig. 7.3) or measured variables. Bird and bat activity respectively had a negative and positive marginally significant relationship $(P=$ 0.070 and 0.081 ) with cricket predation rate, but were not related to the predation rate for aphids and dummy caterpillars (Fig. 7.3). Ant abundance did not affect predation rate for any of the prey types. Arthropod predator abundance (99\% of which were spiders) however had a positive effect on predation rate of all three prey types (though only marginally significant for dummy caterpillars, $P=$ 0.090). Furthermore, herbivore abundance had a positive relationship with aphid predation and omnivore abundance had a negative relationship with cricket predation. Pollinator weevil abundance was not affected by ant abundance and bird and bat activity (Fig. 7.3). However, weevil abundance was positively related to omnivore abundance and soil clay content and negatively to oil palm initial height. 


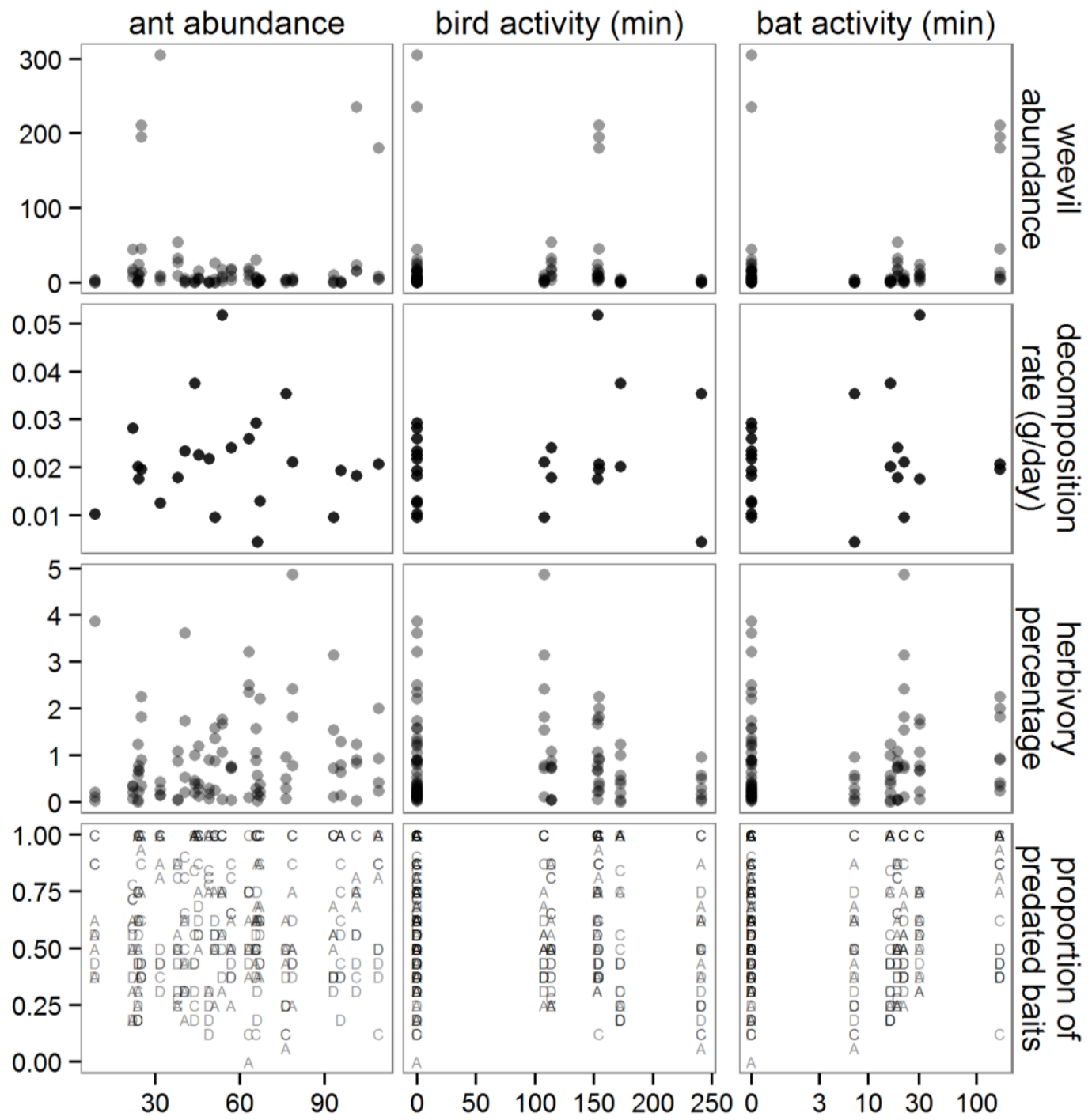

Figure 7.3. The response of ecosystem functions to average ant abundance, bird activity and bat activity. Predation of aphids is indicated by "A", crickets " $C$ " and dummy caterpillars "D". Significant $(\mathrm{P}=<0.05)$ relationships are indicated with a solid line. Darker shading of points indicates multiple overlapping points 


\section{Oil palm yield responses to ant, bird and bat treatments and ecosystem functions}

Total oil palm yields for the year averaged $37 \mathrm{~kg}$ FFB/tree $( \pm 28 \mathrm{~kg} \mathrm{SD})$. The variables included in our models had no effects on yield (FFB $(\mathrm{kg} / \mathrm{palm}) / \mathrm{time})$ (Fig. 4) and the three supplementary yield measurements showed similar results (Table S9.7).

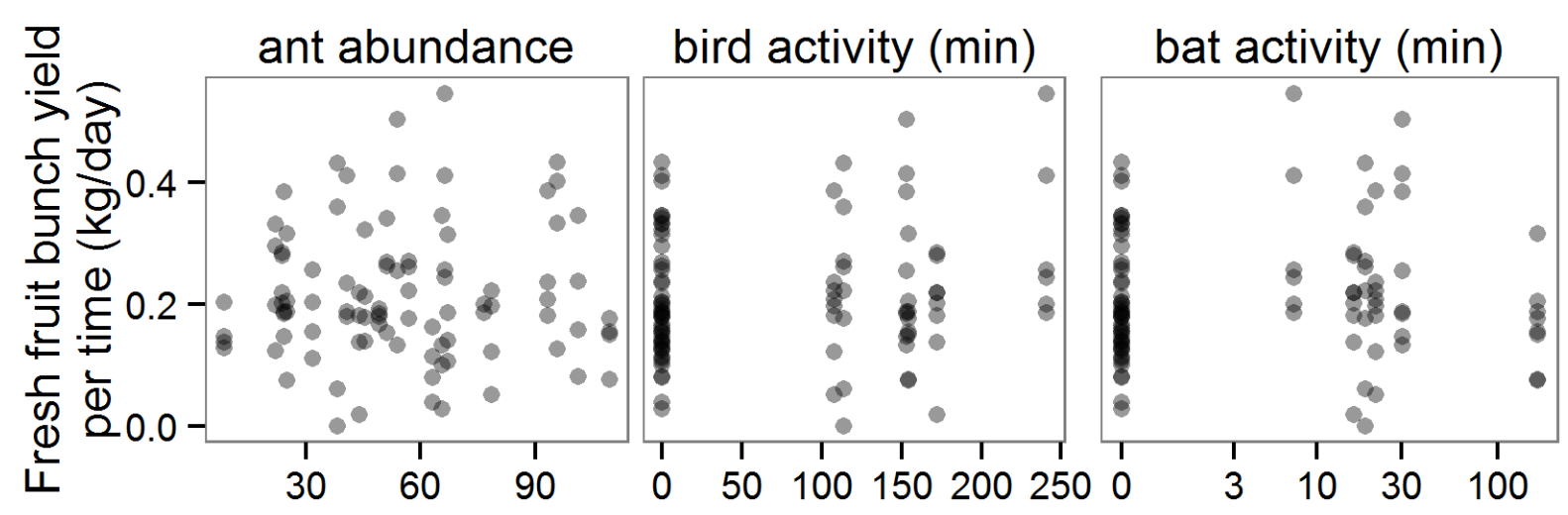

Figure 7.4. The response of yield ( $\mathrm{FFB}(\mathrm{kg} / \mathrm{palm}) /$ time $)$ to average ant abundance, bird activity and bat activity. Significant $(P=<0.05)$ relationships are indicated with a solid line. Darker shading of points indicates multiple overlapping points.

\subsection{Discussion}

Our results detail the role of ants, birds and bats for arthropod communities, ecosystem functions and yield in oil palm plantations using an exclusion experiment. We found a strong negative effect of manipulated ant abundance and bird activity on arthropod predators, but only minimal effects if any on the other arthropod feeding guilds. The measured ecosystem functions, including herbivory, predation, decomposition and pollination, did not respond to variation in ant, bird and bat abundance. Rather, local soil variables, tree height and arthropod abundances (other than ants) were, although generally weakly related, the most important predictors for ecosystem functions in our oil palm plantations. The economically most important ecosystem service, yield, however, did not respond to our measured predictors.

\section{Birds and ants have strong effects on arthropod predators but not on other arthropods groups}

Our study showed that ants and birds both have a strong negative influence on arthropod predators. However, except for a weak negative influence of ants on herbivores, all other feeding guilds were not influenced by our experimental exclusion. It is likely that the predators (ants, birds, and other arthropod predators) of our disturbed sites are generalists (Fitzherbert et al. 2008) and therefore can exert similar predation pressures on the other arthropod communities. The predators could be complementary through processes such as mesopredator release or similar in the sense that the absence of one predator group is compensated by the increase of the other, resulting in a constant predation pressure. Indeed, the most dominant birds were middle-sized omnivorous bulbuls 
(Pycnonotus sp.). True insectivorous birds (such as Orthotomus sp. and Prinia sp.) were less active than omnivores, and overall, insectivorous birds accounted for only one quarter of the measured bird calling activity. The lack of bat effects on arthropods could be due to bats mostly feeding on aerial nocturnal insects, which would not have been optimally sampled with our methods and can disperse freely between experimental cages, diluting the effect of bat predation.

\section{No net effects of ants, birds and bats on ecosystem functions in oil palm plantations}

Our manipulations of ants, birds and bats had no significant effects on any of the ecosystem functions measured. Local environmental variables and arthropods other than ants were generally more important.

Although ants, birds and bats manipulation did not influence predation rates, we found a positive correlation between arthropod predator abundance and predation rate for all three prey types. This suggests that ants, birds and bats may not successfully suppress phytophagous insects, or at least the species we investigated, in oil palm plantations. Also, other predators could play an important role (e.g. spiders and spiders and Orthoptera (Nurdiansyah et al. unpublished data)).

Contrary to previous research (Koh 2008a), exclusion of birds and bats did not affect oil palm herbivory. However, the previous research looked at very young (one year old) palms, which are likely more susceptible to damage (Coley 1980). Furthermore, these plants were situated in a relatively old (more than one crop generation) and large oil palm complex (pers. comm. Lian Pin Koh), where pest pressure may be higher. The herbivory we measured on our palms was overall quite low $(0-4.8 \%$, mean \pm standard error of $0.9 \pm 0.1 \%$, versus $0-21 \%$ herbivory in Koh (2008)). Overall, our findings suggest that defoliating pests are not a major problem in the small holder oil palm plantations of Jambi Province, where the crop has been introduced only one crop cycle ago. In particular, two of the most important defoliating pests of oil palm, the nettle caterpillar (Setothosea asigna) and bagworm (Metisa plana) are relatively uncommon in the study area (Nurdiansyah et al. unpublished data) and tend to have non-cyclic outbreaks. We only observed a single pest outbreak in our experimental sites, which was controlled immediately and aside from that outbreak, insecticide application was very low. However with time, if pest numbers increase and outbreaks become cyclic the role of predators for pest control may become more important.

Ant, bird and bat manipulation did not affect decomposition rates directly or indirectly through changes in detritivore abundance. This could suggest that other unmeasured variables are more important for the decomposition rate of oil palm leaves than the variables we measured. Many other factors can contribute to decomposition and are often more important than the variables we measured, such as local climatic variables, microbial activity and soil nutrients (Vossbrinck et al. 1979; Dyer et al. 1990).

The pollination of oil palm in Indonesia relies to a large extent on the weevil E. kamerunicus (Foster et al. 2011). While birds can consume E. kamerunicus in oil palm plantations (Amit et al. 2015), the lack of predator effects on E. kamerunicus found in our study is reassuring, and suggests 
that measures taken to increase the abundance and diversity of predators of arthropods are unlikely to be accompanied by reduced pollination. However, in the long-term the reliance on a single pollinator species may be a risky strategy given the significant fluctuations of wild and managed pollinators in other agricultural systems (Potts et al. 2010).

\section{Ants, birds and bats and other measured variables do not influence oil palm yield}

Oil palm yield was not affected by the variables studied in this research, indicating that our comprehensive manipulations of biodiversity or even variation in arthropods and ecosystem functions do not affect oil palm productivity. Most interestingly we found no link between herbivory and yield. However, as mentioned, herbivory was low at the sites, and in the past other studies have shown leaf herbivory is not always important for yield, rather other types of herbivory can be more important (e.g. flower herbivory, Maas et al. 2013). Also, yield responses to herbivory may only be observed in the case of pest outbreaks (Kamarudin and Wahid 2010), which are rare and non-cyclic in oil palm in Indonesia. However, there is evidence from other crops that as the area cultivated increases there is an increase in pest and disease problems (Clough et al. 2009). Lack of any effects on yield at these sites suggests that other limiting factors play a more important role in yield variation, such as nutrient availability, rainfall and efficiency of light uptake from the canopy (Rafflegeau et al. 2010; Breure 2010). For example, the very low soil $\mathrm{pH}$ across sites could indicate a potential phosphorous deficiency. Furthermore, the absence of a biodiversity and yield relationship suggests there is an opportunity for a win-win situation for high biodiversity and yield in oil palm plantations as seen in cacao agroforestry (Clough et al. 2011).

\section{Conclusions}

We conclude that ecosystem functions and productivity in oil palm are, under current levels of pest pressure and pollinator populations, robust to large changes in the communities of major predator groups. Although, it is widely presumed that biocontrol plays a major role in crop production everywhere, the lack of relationship we observed between predators and yield proves that expectation to be wrong. However biodiversity conservation should not be compromised if it is not coupled with economically meaningful services; its intrinsic value alone is also important.

\section{Acknowledgements}

We thank Rico Fardiansah, Derly Hartika, Marisi Italiansia, Leonarda Situmorang, Ilham, Fahrurozi and Arie Perdana for all their help in the lab and the field. We thank local plot owners and village leaders for granting us the use of the study sites. This study was financed by the Deutsche Forschungsgemeinschaft (DFG) in the framework of the collaborative German - Indonesian research project Collaborative Research Centre 990: Ecological and Socioeconomic Functions of Tropical Lowland Rainforest Transformation Systems (Sumatra, Indonesia). 


\subsection{Supplementary material}

\section{Appendix S7.1. Supplementary Methods}

\section{Site conditions}

The plantation management was consistent with plantations in the study area; herbicides were used 2-3 times per year and both chemical and organic fertilisers were used, however exact quantification of nutrient input was not possible. Soils of the region are fine textured but there was some variation between sites (Table A1.1). The $\mathrm{pH}\left(\mathrm{H}_{2} 0\right)$ ranged from 4.03 (site four) to 4.45 (site five) (Table A1.1). Plantation area was between 2 and 10 ha and planting density was between 25 and 47 palms/ha (Table A1.1).Tree density at each site was determined by measuring the area of a block containing 49 oil palms (a 7x7 block) with a GPS device (Garmin GPSmap 63s), centred around the experiment.

Table A7.1.1. Conditions for each plantation.

\begin{tabular}{lllllll}
\hline Site Plant source & Size (ha) & $\begin{array}{l}\text { Planting density Planting date } \\
\text { (palms/ha) }\end{array}$ & $\begin{array}{l}\text { Average } \mathrm{pH} \\
\left(\mathrm{H}_{2} \mathrm{O}\right)^{1}\end{array}$ & Soil type $^{1}$ \\
\hline 1 & Marihat & 7 & 188 & January 2011 & 4.15 & Clay \\
2 & Supindo & 2 & 170 & August 2010 & 4.17 & Sandy clay \\
3 & Marihat & 10 & 100 & August 2010 & 4.12 & Sandy clay \\
4 & Marihat & 4 & 116 & September 2009 & 4.03 & Clay \\
5 & Private nursery & 2.5 & 153 & March 2008 & 4.45 & Sandy clay loam \\
6 & AHOK & 4 & 150 & August 2011 & 4.37 & Clay
\end{tabular}

${ }^{1}$ Methods for determination of soil $\mathrm{pH}$ and texture (type) are included in the following section

Environmental and tree variable measurements and analysis

We took soil cores in each experimental plot at a depth of $50 \mathrm{~cm}$ eight months after experiment start. Eight samples were taken in caged plots, and four samples in plots without cage. All soil samples were taken between bordering oil palms $200 \mathrm{~cm}$ away the foundation at the border middle. The additional four samples were taken at $20 \mathrm{~cm}$ from the foundation concrete border to test for possible effects of carbonate leaching into the soil from the concrete foundations of the bird/bat cages. The soil samples were air dried and sieved $(2 \mathrm{~mm})$ then analysed for $\mathrm{pH}$ and texture at the University of Jambi, Indonesia. Soil $\mathrm{pH}\left(\mathrm{H}_{2} \mathrm{O}\right)$ was analysed in a 1:2.5 soil-to-water ratio and soil texture (clay content) was measured using the pipette method (Gee \& Bauder 1986). The height of each oil palm included in the experimental plots was recorded at the beginning (initial height) and the end of the experiment (final height). We measured height from the palm base to the tip of the meristem (Kotowska et al. 2015). We 
used linear mixed effect models (LMEs) to determine the differences in initial palm height, soil $\mathrm{pH}$ and soil texture between treatments with plantation (experiment site) included as a random effect. We used Wilcoxon rank sum tests to compare mean $\mathrm{pH}$ values between samples collected near $(20 \mathrm{~cm})$ and far $(200 \mathrm{~cm})$ from the concrete foundation border $(\mathrm{n}=48)$. Mean $\mathrm{pH}$ values far from the concrete foundation (mean $=4.27 \pm 0.21 \mathrm{sd}$ ) were higher than $\mathrm{pH}$ values near to it (mean $=4.20 \pm 0.17$ ), confirming that the concrete foundations were not leaking carbonates into the soil. The Wilcoxon mean comparison was not significant $(\mathrm{p}=0.288)$. The occurrence of red and brown spots on the oil palm leaves was determined by analysis of the red and green components of leaf JPEG photographs taken for herbivory measurements to estimate a red/green leaf area ratio. Brownish spots on oil palm leaflets, typical of wet conditions, are due to algal infestation, and orange-coloured spots are caused by K-deficiency (Turner 1981). One photograph from each of four fronds was chosen randomly per tree and the white balance was adjusted with the underlying white cardboard. The crops were twice longer than wide and taken from the greatest leaf portion without holes. The mean of its scaled red and green values were used to compute the red/green leaf area ratio, indicating the proportion of the leaf surface that is red and thus photosynthetically not active.

\section{Supplementary yield variables and analysis}

In addition to total yield divided by time harvested with a six month delay in the data $(\mathrm{FFB}(\mathrm{kg}) / \mathrm{time})$, three other yield measurements were analysed to confirm the robustness of the variable. We also used total yield without delay (18 months of data) divided by time harvested (18m $\mathrm{FFB}(\mathrm{kg}) / \mathrm{time})$, total yield without delay $(18 \mathrm{~m} \mathrm{FFB}(\mathrm{kg}))$ and total yield with six month delay $(12 \mathrm{~m}$ $\mathrm{FFB}(\mathrm{kg}))$. Data were analysed as with the analysis of $12 \mathrm{~m} \mathrm{FFB/time} \mathrm{in} \mathrm{the} \mathrm{main} \mathrm{text.}$

\section{Effectiveness of ant suppression analysis}

We used linear mixed effect models (LMEs) to determine the effect of ant suppression (independent of bird/bat exclusion) on ant abundance and species richness in the experimental plots with plantation (experiment site) included as a random effect. To meet assumptions of normality ant abundance was log transformed prior to analysis. LMEs were conducted using the nlme (Pinheiro et al. 2015) package in R 3.2.0 (R Core Team 2015).

\section{Supplementary references}

Gee GW, Bauder JW (1986) Particle-size analysis. Methods of soil analysis. Part 1. Physical and mineralogical methods. American Society of Agronomy, Inc., Madison, Wisconsin, pp. 383411.

Kotowska MM, Leuschner C, Triadiati T, Meriem S, Hertel D (2015) Quantifying above-and belowground biomass carbon loss with forest conversion in tropical lowlands of Sumatra (Indonesia). Glob change biol, doi: 10.1111/gcb.12979.

Pinheiro J, Bates D, DebRoy S, Sarkar D, R Core Team. (2015) Nlme: Linear and Nonlinear Mixed Effects Models. R package version 3.1-120.

Turner PD (1981) Oil Palm Diseases and Disorders. Oxford University Press, Kuala Lumpur, Malaysia. 


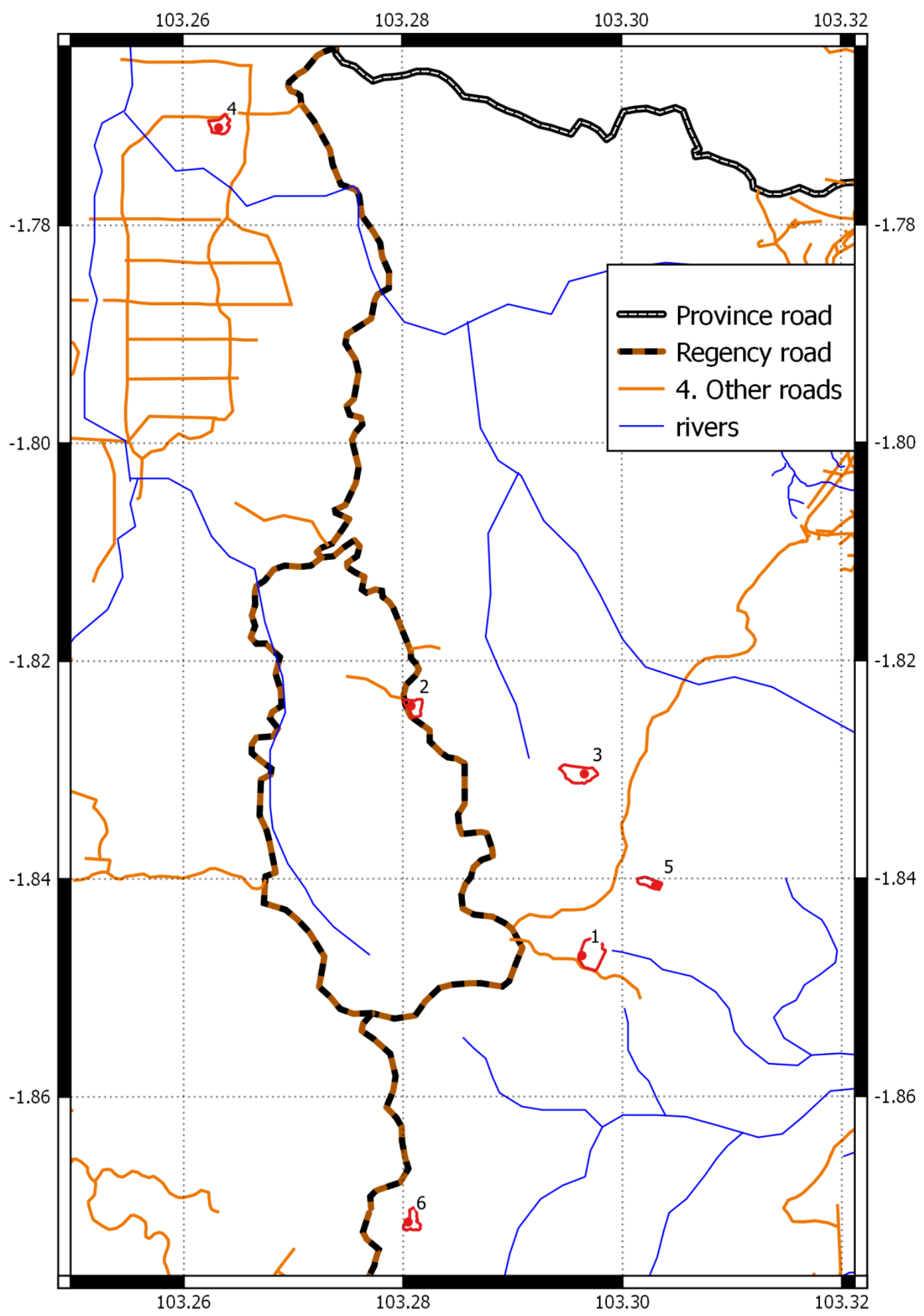

Figure S7.1. Study site location. Map of study area located in Batanghari Regency, Jambi Province, Sumatra, Indonesia. Experimental sites were located in six oil palm plantations. Plantation borders are indicated in red, Site centres marked with red dots. 


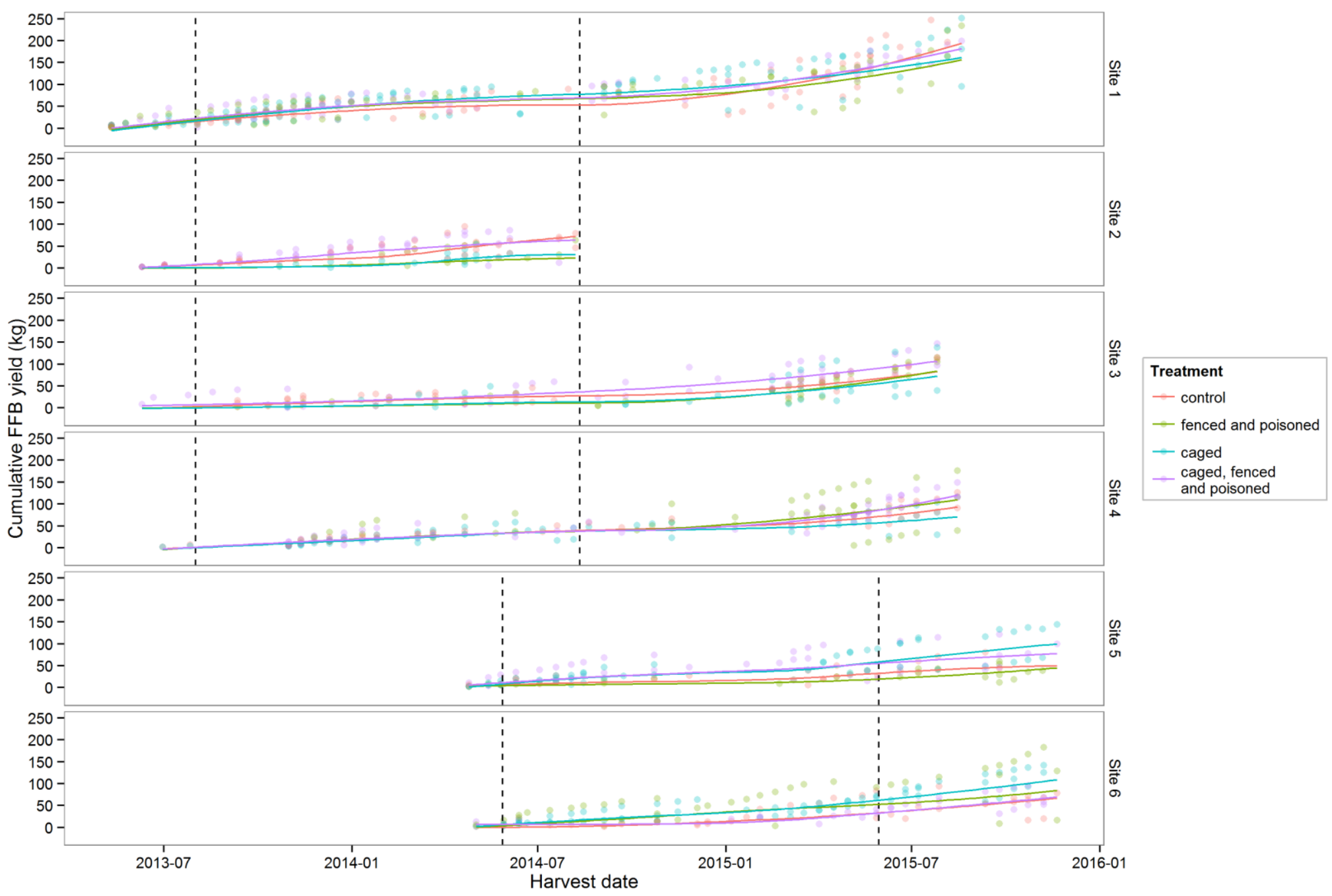

Figure S7.2. Cumulative oil palm yield (FFB (kg)) across sites and treatments. Dashed lines indicate the beginning and end of the experiment. 


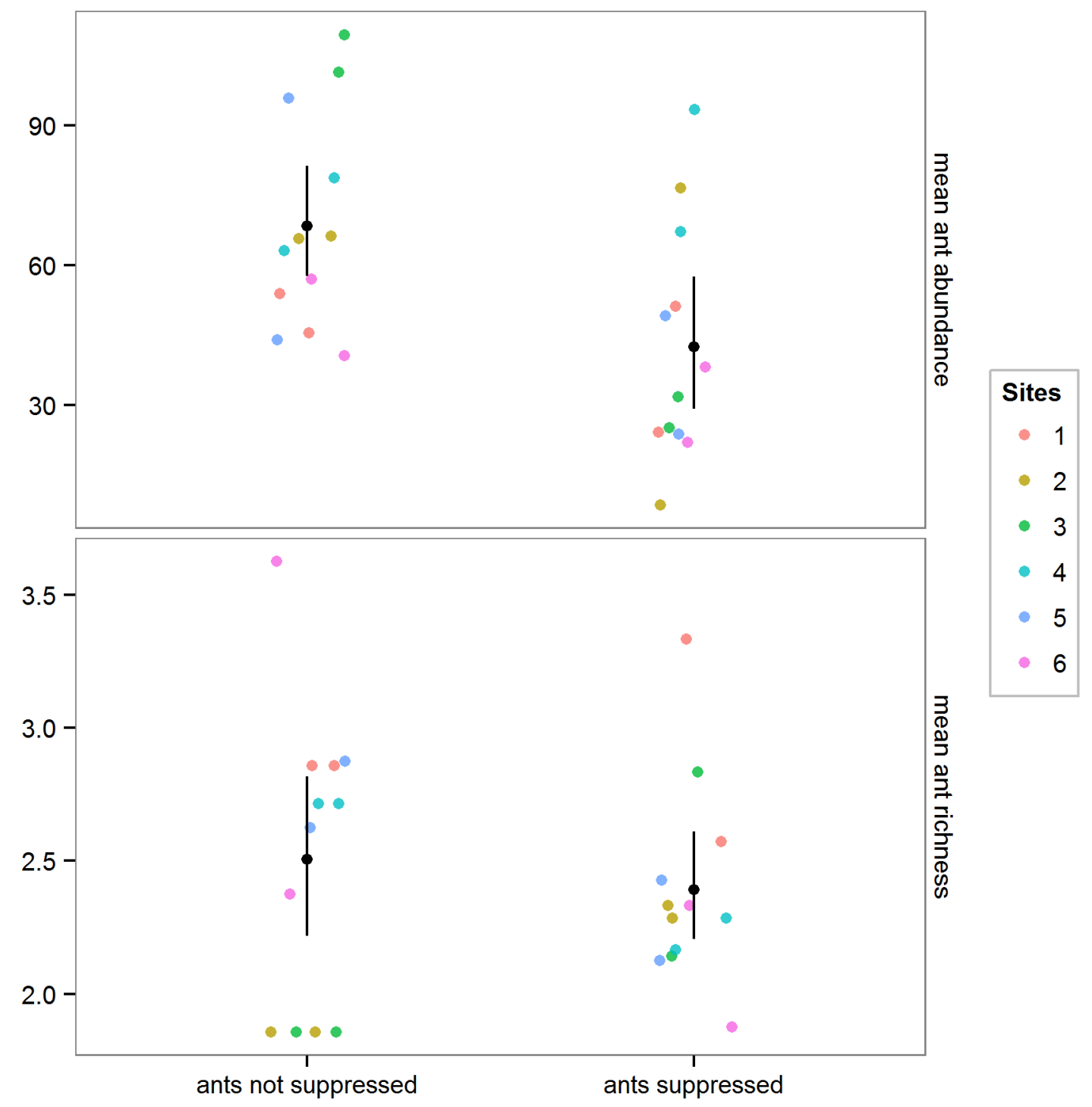

Figure S7.3. Ant suppression effectiveness. Means indicated by black dots, error bars represent standard error of the mean. 


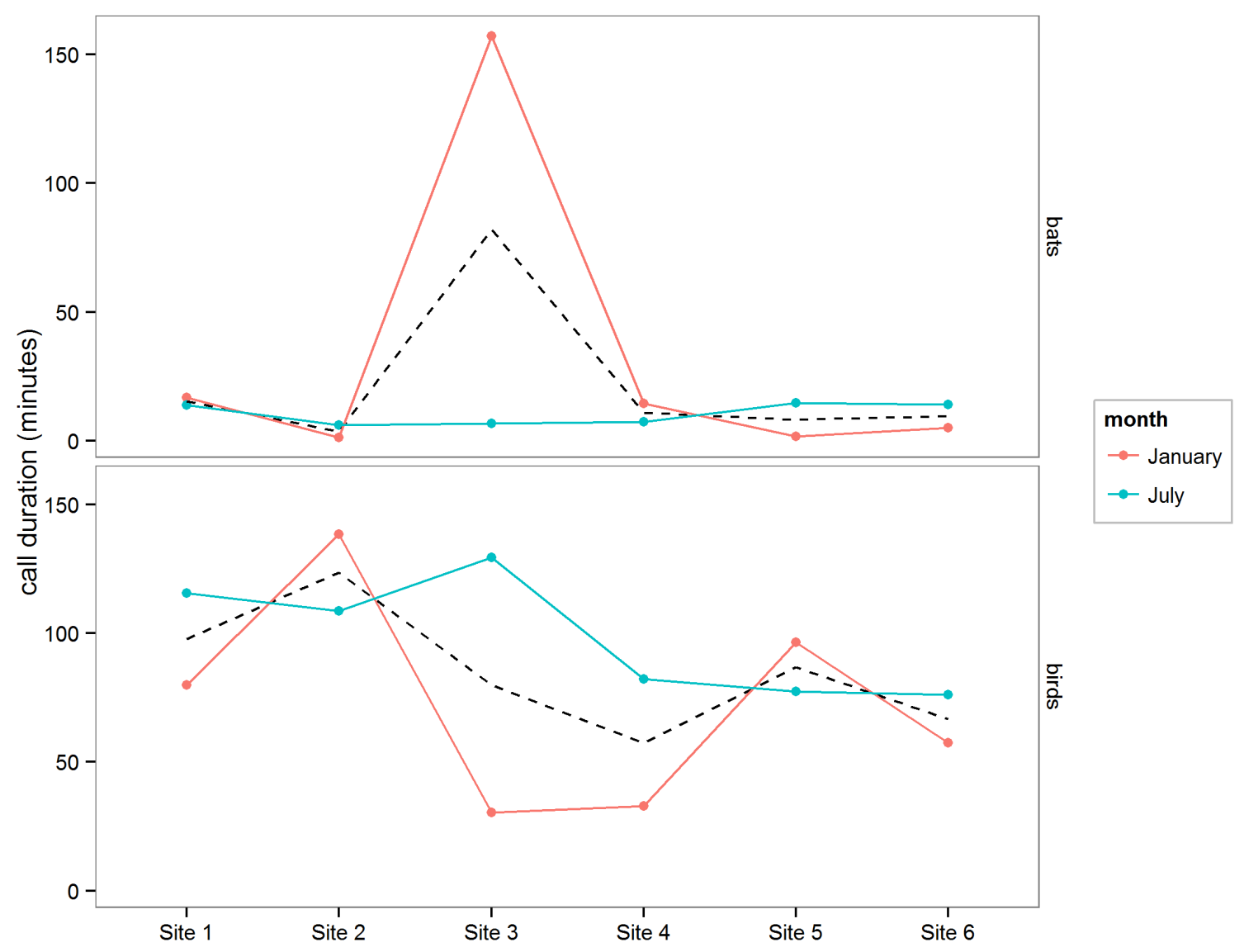

Figure S7.4. Variation in bat and bird calling activity between sites. The mean between the two values is indicated by the dashed line. 
Table S7.1. Invertebrate higher taxonomic groups, assigned to feeding guilds.

\begin{tabular}{|c|c|}
\hline Higher taxonomic group & Feeding guild \\
\hline Acari & omnivore \\
\hline Annelida & detritivore \\
\hline Araneae & predator \\
\hline Blattodea & detritivore \\
\hline Chilopoda & predator \\
\hline Coleoptera & omnivore \\
\hline Collembola & omnivore \\
\hline Dermaptera & omnivore \\
\hline Diplopoda & detritivore \\
\hline Diptera & omnivore \\
\hline Gastropoda & detritivore \\
\hline Haplotaxida & detritivore \\
\hline Hemiptera & omnivore \\
\hline Hymenoptera: Formicidae & omnivore \\
\hline Hymenoptera: other & omnivore \\
\hline Isopoda & detritivore \\
\hline Isoptera & detritivore \\
\hline Lepidoptera & herbivore \\
\hline Mantodea & predator \\
\hline Neuroptera & predator \\
\hline Opiliones & omnivore \\
\hline Orthoptera & herbivore \\
\hline Pseudoscorpionida & predator \\
\hline Psocoptera & detritivore \\
\hline Symphyla & detritivore \\
\hline Thysanoptera & herbivore \\
\hline Thysanura & omnivore \\
\hline
\end{tabular}


Table S7.2. Linear mixed effect model ANOVA outputs testing for a significant effect of ant suppression on ant abundance and richness. The linear mixed effects models which determined the effect of the ant suppression treatment on (a) average ant abundance and (b) average ant species richness. Significant $\mathrm{p}$-values are indicated in bold $(P=\leq 0.05)$.

\begin{tabular}{llccc}
\hline Response variable & Effect & df & F-value & p-value \\
\hline (a) Ant abundance & Ant suppression treatment & 17 & 8.003 & $\mathbf{0 . 0 1 2}$ \\
(b) Ant species richness & Ant suppression treatment & 17 & 0.395 & 0.538 \\
\hline
\end{tabular}


Table S7.3. Variables included in full models for each response variable. PredA = predator abundance, HerbA = herbivore abundance, DetA = detritivore abundance, OmniA = omnivore abundance, herb = herbivory, Decomp = decomposition, Pred = predation rate, $\mathrm{WvilA}=$ weevil abundance, Ant $\mathrm{A}=$ average ant abundance, BirdA = bird activity, BatA = bat activity, height = initial oil palm height and $\mathrm{RG}=$ leaf red/green ratio.

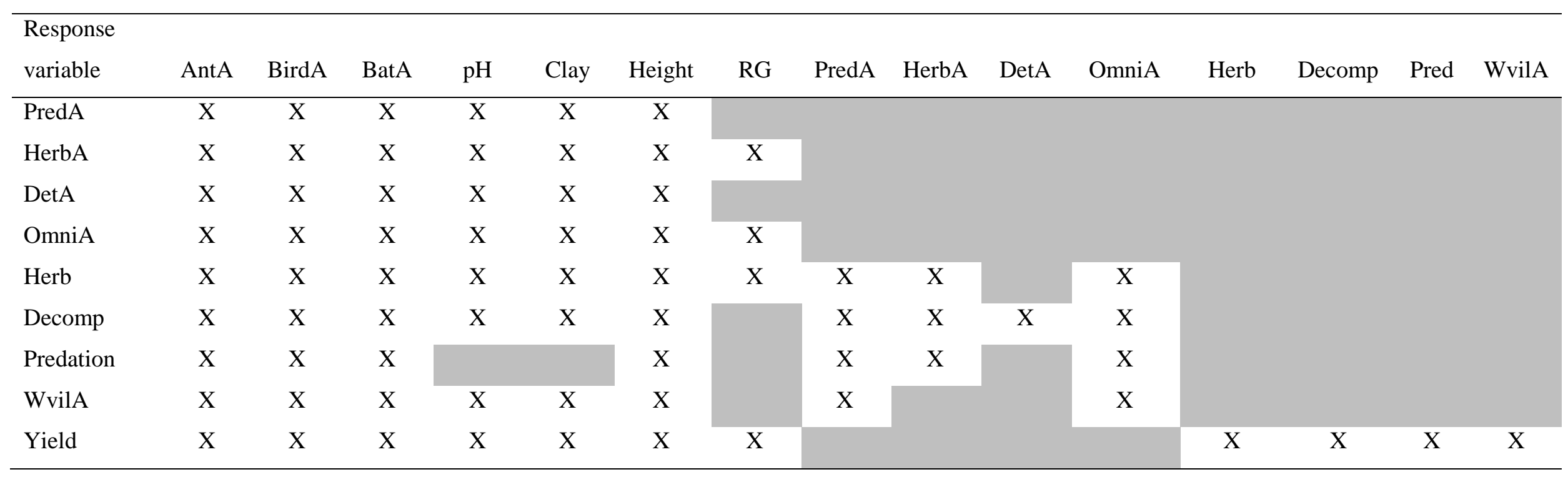


Table S7.4. Linear mixed effect model ANOVA outputs testing for significant difference in environmental variables between treatments. The linear mixed effects models which determined the effect of treatment on (a) soil $\mathrm{pH}$, (b) soil texture and (c) initial palm height. Significant $\mathrm{P}$-values are indicated in bold $(P=\leq 0.05)$.

\begin{tabular}{|c|c|c|c|c|c|}
\hline \multicolumn{2}{|c|}{ Response variable } & \multirow{2}{*}{$\begin{array}{l}\text { Effect } \\
\text { Treatment }\end{array}$} & \multirow{2}{*}{$\frac{\mathrm{df}}{85}$} & \multirow{2}{*}{$\begin{array}{r}\text { F-value } \\
7.395\end{array}$} & \multirow{2}{*}{$\begin{array}{r}\text { p-value } \\
<0.001\end{array}$} \\
\hline (a) & Soil pH & & & & \\
\hline (b) & Soil texture & Treatment & 81 & 9.525 & $<0.001$ \\
\hline (c) & Initial palm height & Treatment & 85 & 4.995 & 0.003 \\
\hline
\end{tabular}

Table S7.5. The range of conditional $R^{2}$ values for all best models $(\triangle \mathrm{AICc}<2)$ for each response variable.

\begin{tabular}{lr}
\hline Response variable & $\mathrm{R}^{2}$ range \\
\hline Predator abundance & $0.466-0.473$ \\
Herbivore abundance & $0.445-0.450$ \\
Detritivore abundance & $0.267-0.304$ \\
Omnivore abundance & $0.413-0.487$ \\
Decomposition & $<0.001-0.060$ \\
Herbivory & $0.121-0.137$ \\
Predation: aphids & $0.280-0.393$ \\
Predation: crickets & $0.213-0.221$ \\
Predation: dummy caterpillars & $0.026-0.033$ \\
Weevil abundance & $0.705-0.725$ \\
\hline
\end{tabular}


Table S7.6. Linear mixed effect model ANOVA outputs and relative variable importance (RVI) for the average of the best models $(\triangle \mathrm{AICc}<2)$ for arthropod feeding guild abundances. Pred $\mathrm{A}=$ predator abundance, $\mathrm{Herb} \mathrm{A}=$ herbivore abundance, Det $\mathrm{A}=\operatorname{detritivore}$ abundance, OmniA = omnivore abundance, Ant A = average ant abundance, BirdA = bird activity, BatA = bat activity, height = initial oil palm height and RG = leaf red/green ratio. Predictors marked with an "X" were not included in the full model, predictors marked with a "---" were included in the full but not the average best model. Significant $(P=\leq 0.05)$ predictors are indicated in bold.

\begin{tabular}{|c|c|c|c|c|c|c|c|c|c|c|c|c|}
\hline \multirow[b]{2}{*}{ Predictor } & \multicolumn{3}{|c|}{ HerbA } & \multicolumn{3}{|c|}{ DetA } & \multicolumn{3}{|c|}{ PredA } & \multicolumn{3}{|c|}{ OmniA } \\
\hline & coeff & P-val & RVI & coeff & P-val & RVI & coeff & p-val & RVI & coeff & P-val & RVI \\
\hline AntA & -0.13 & 0.087 & 1.00 & -0.10 & 0.268 & 0.25 & -0.11 & 0.005 & 1.00 & -0.11 & 0.076 & 1.00 \\
\hline BirdA & --- & --- & --- & --- & --- & --- & -0.16 & $<0.001$ & 1.00 & --- & 0.948 & 0.10 \\
\hline BatA & --- & --- & --- & --- & --- & --- & --- & --- & --- & 0.13 & 0.400 & 0.50 \\
\hline AntA:BirdA & --- & --- & --- & --- & --- & --- & 0.07 & 0.099 & 0.59 & --- & 0.071 & 0.06 \\
\hline AntA:BatA & --- & --- & --- & --- & --- & --- & --- & --- & --- & -0.10 & 0.042 & 0.40 \\
\hline Clay & 0.29 & $<0.001$ & 0.64 & 0.24 & 0.011 & 1.00 & 0.11 & 0.007 & 1.00 & --- & --- & --- \\
\hline $\mathrm{pH}$ & -0.06 & 0.395 & 0.20 & -0.12 & 0.192 & 0.29 & 0.04 & 0.451 & 0.17 & -0.17 & 0.190 & 0.33 \\
\hline Height & --- & --- & --- & 0.17 & 0.068 & 0.82 & --- & --- & --- & -0.17 & 0.178 & 0.34 \\
\hline RG & --- & --- & --- & $\mathrm{X}$ & $\mathrm{X}$ & --- & $\mathrm{X}$ & $\mathrm{X}$ & --- & -0.07 & 0.425 & 0.15 \\
\hline
\end{tabular}


Table S7.7. Linear mixed effect model ANOVA outputs and relative variable importance (RVI) for the average of the best models $(\triangle A I C c<2)$ for ecosystem functions. Abbreviations are as in Table 1, except for, Dcat = dummy caterpillar. Predictors marked with an "X" were not included in the full model, predictors marked with a "---" were included in the full but not the average best model. Significant $(P=\leq 0.05)$ predictors are indicated in bold. Interaction terms are not included in the table because although included in all full models they were not included in any average best models.

\begin{tabular}{|c|c|c|c|c|c|c|c|c|c|c|c|c|c|c|c|c|c|c|}
\hline \multirow[b]{2}{*}{ Predictor } & \multicolumn{3}{|c|}{ Decomposition } & \multicolumn{3}{|c|}{ Herbivory } & \multicolumn{3}{|c|}{ Predation:aphids } & \multicolumn{3}{|c|}{ Predation:crickets } & \multicolumn{3}{|c|}{ Predation:Dcat } & \multicolumn{3}{|c|}{ Weevil abund } \\
\hline & coeff & P-val & $\mathrm{RVI}$ & coeff & P-val & $\overline{\mathrm{RVI}}$ & coeff & P-val & $\mathrm{RVI}$ & coeff & P-val & $\mathrm{RVI}$ & coeff & P-val & $\overline{\mathrm{RVI}}$ & coeff & P-val & RVI \\
\hline$\overline{\text { AntA }}$ & --- & --- & --- & 0.08 & 0.475 & 0.10 & 0.26 & 0.151 & 0.37 & --- & --- & --- & 0.05 & 0.403 & 0.18 & --- & --- & --- \\
\hline BirdA & --- & --- & --- & -0.34 & 0.107 & 0.12 & -0.11 & 0.483 & 0.05 & -0.82 & 0.070 & 0.28 & -0.05 & 0.348 & 0.08 & -0.46 & 0.158 & 0.20 \\
\hline BatA & --- & --- & --- & 0.28 & 0.217 & 0.17 & 0.31 & 0.339 & 0.20 & 0.80 & 0.081 & 0.28 & --- & --- & --- & 0.34 & 0.237 & 0.44 \\
\hline Clay & --- & --- & --- & 0.10 & 0.396 & 0.11 & --- & --- & --- & --- & --- & --- & --- & --- & --- & 0.44 & 0.013 & 1.00 \\
\hline $\mathrm{pH}$ & 0.01 & 0.295 & 0.31 & -0.25 & 0.032 & 0.63 & $X$ & $X$ & $X$ & $X$ & $X$ & $\mathrm{X}$ & $X$ & $X$ & $X$ & --- & --- & --- \\
\hline Height & --- & --- & --- & 0.19 & 0.092 & 0.83 & 0.24 & 0.115 & 0.85 & --- & --- & --- & --- & --- & --- & -0.67 & $<0.001$ & 1.00 \\
\hline $\mathrm{RG}$ & $X$ & $\mathrm{X}$ & $X$ & -0.16 & 0.255 & 0.11 & $X$ & $X$ & $X$ & $X$ & $X$ & $X$ & $X$ & $X$ & $\mathrm{X}$ & $X$ & $\mathrm{X}$ & $X$ \\
\hline PredA & --- & --- & --- & --- & --- & --- & 0.18 & 0.046 & 0.51 & 0.31 & 0.002 & 1.00 & 0.11 & 0.090 & 0.64 & -0.12 & 0.417 & 0.17 \\
\hline HerbA & --- & --- & --- & 0.09 & 0.379 & 0.11 & 0.18 & 0.050 & 0.86 & -0.05 & 0.596 & 0.19 & 0.09 & 0.156 & 0.48 & --- & --- & --- \\
\hline DetA & --- & --- & --- & $X$ & $X$ & $X$ & $X$ & $X$ & $X$ & $X$ & $X$ & $X$ & $X$ & $X$ & $X$ & $X$ & $\mathrm{X}$ & $X$ \\
\hline OmniA & --- & --- & --- & 0.17 & 0.142 & 0.18 & -0.15 & 0.119 & 0.55 & -0.68 & $<0.001$ & 1.00 & -0.05 & 0.563 & 0.08 & 1.03 & $<0.001$ & 1.00 \\
\hline
\end{tabular}


Table S7.8. Linear mixed effect model ANOVA outputs and relative variable importance (RVI) for the average best model $(\triangle \mathrm{AICc}<2)$ for yield $(\mathrm{FFB}(\mathrm{kg} / \mathrm{palm}) / \mathrm{time})$. Abbreviations are as in Table 1 and 2. Predictors marked with an "X" were not included in the full model, predictors marked with a "---" were included in the full but not the average best model. Significant $(P=\leq 0.05)$ predictors are indicated in bold.

\begin{tabular}{lrrr}
\hline & \multicolumn{3}{c}{ FFB $(\mathrm{kg}) / \mathrm{time}$} \\
\cline { 2 - 4 } Predictor & coeff & P-val & \multicolumn{1}{c}{ RVI } \\
\hline AntA & --- & --- & --- \\
BirdA & ---- & --- & --- \\
BatA & --- & --- & --- \\
AntA:BirdA & --- & --- & --- \\
AntA:BatA & --- & --- & --- \\
Clay & 0.02 & 0.130 & 0.53 \\
pH & --- & --- & --- \\
Height & 0.01 & 0.389 & 0.10 \\
RG & -0.01 & 0.512 & 0.18 \\
Herbivory & --- & --- & --- \\
Decomposition & --- & --- & --- \\
Predation:aphids & --- & --- & --- \\
Predation:crickets & --- & --- & --- \\
Predation:Dcat & -0.01 & 0.486 & 0.09 \\
Weevil abundance & & &
\end{tabular}


Table S7.9. Linear mixed effect model ANOVA outputs for the average of the best models

$(\triangle \mathrm{AICc}<2)$ for supplementary yield measures. Abbreviations are as in Table S6. Predictors marked with an "X" were not included in the full model, predictors marked with a "---." were included in the full but not the average best model. Significant $(P=\leq 0.05)$ predictors are indicated in bold. Interaction terms are not included in the table because although included in all full models they were not included in any average best models.

\begin{tabular}{|c|c|c|c|c|c|c|}
\hline & \multicolumn{2}{|c|}{$18 \mathrm{~m} \mathrm{FFB}(\mathrm{kg}) /$ time } & \multicolumn{2}{|c|}{$18 \mathrm{~m} \mathrm{FFB}(\mathrm{kg})$} & \multicolumn{2}{|c|}{$12 \mathrm{~m} \mathrm{FFB}(\mathrm{kg})$} \\
\hline Predictor & coeff & p-val & coeff & p-val & coeff & p-val \\
\hline AntA & --- & -- & 4.624 & 0.411 & --- & --- \\
\hline Bird activity & --- & --- & --- & --- & --- & --- \\
\hline Bat activity & --- & --- & --- & --- & --- & --- \\
\hline Clay & --- & --- & --- & --- & --- & --- \\
\hline $\mathrm{pH}$ & --- & --- & -14.153 & 0.193 & -9.172 & 0.302 \\
\hline Height & --- & --- & 15.310 & 0.088 & 14.171 & 0.053 \\
\hline RG & --- & --- & -5.913 & 0.416 & -5.906 & 0.321 \\
\hline Decomposition & --- & --- & --- & --- & --- & --- \\
\hline Herbivory & 0.007 & 0.478 & --- & --- & --- & --- \\
\hline Predation:aphids & --- & --- & 5.647 & 0.334 & 5.488 & 0.255 \\
\hline Predation:cricket & 0.007 & 0.471 & --- & --- & --- & --- \\
\hline Predation:Dcat & --- & --- & --- & --- & --- & --- \\
\hline Weevil abund & --- & --- & -8.744 & 0.136 & -3.131 & 0.520 \\
\hline
\end{tabular}




\section{Chapter 8}

\section{Synthesis}

\subsection{Objective 1: Understand ant taxonomic and functional diversity responses to land-use change}

In Chapter 2 and Chapter 3 I investigated the taxonomic (Chapter 2, Rubiana et al. 2015) and functional diversity (Chapter 3 ) responses of ants to land-use change from forest to jungle rubber, rubber monoculture and oil palm plantations. I show that ant species richness responded contrary to expected to land-use change, either increasing (Chapter 3) or not changing (Chapter 2, Rubiana et al. 2015) from forest to the agricultural systems studied depending on the sampling methods used.

However, the results from Chapter 2 show there are distinct changes in the ant species community composition (Rubiana et al. 2015). Few ant species were shared among all the different land-uses, and the ones that were (e.g. from the genera Crematogaster and Pheidole) are known as generalist species. The species that were dominant in the plantations are general tramp and/or invasive species (e.g. species of the genus Pheidole and Tetromorium and Anoplolepis gracilipes). A. gracilipes in particular, a well-known invasive species was present in all three agricultural systems but not in any of the forest plots. The lack of A. gracilipes in the forest sites has positive implications for the integrity of our study forests even though they are not undisturbed primary forest. These results suggest that although species numbers may increase or stay the same with land-use change, overall with increased conversion of forest to agricultural systems there will be a net loss in regional species diversity.

Further to species composition, in Chapter 3 I show that ant functional community composition changed considerably between forest, jungle rubber, rubber and oil palm, across a wide range of functional measures. For example, functional dispersion and functional divergence was lowest in forest compared with the three agricultural systems, suggesting, increased levels of community heterogeneity and higher abundance of species with extreme traits from forest to the managed systems, particularly oil palm plantations. Furthermore, species from higher trophic guilds (predators) and with lower mobility were more common in forest than oil palm, with intermediate numbers in the rubber systems. The loss of predators in agricultural systems is particularly worrying, as it could be linked to a loss of biocontrol services. The strong negative responses of ant community composition to land-use change both in regards to species and function along with the minimal or positive response of species richness, show how important it is to not only look at simple measures of communities such as species richness if we want to fully understand the consequences of land-use change. 


\subsection{Objective 2: Investigate the response of ant communities and associated functions to landscape context and local management in oil palm plantations}

\section{Local management}

In Chapter 4 I investigated the effect of epiphytes and ground cover, two vegetation variables that are influenced by management, on ant communities and associated functions living in the oil palm leaf axils. The results showed that epiphyte cover and ground cover (around the trees) did not influence ant communities or decomposition rates in oil palm leaf-axils. In the middle aged trees (10-15 years) investigated it seems that the leaf-axil habitat (e.g. amount of organic matter, moisture and height on the tree) is more important than the vegetation growing on and around the tree for ant community structure or decomposition. As the leaf axils fall off the tree with age, the epiphytes themselves could become more important for harbouring ants on the oil palms. Particularly, due to the higher likelihood of large epiphyte species (e.g. bird's nest ferns, Asplenium nidus) being present on older palms (pers. obs). The lack of effect of epiphytes on ants and associated functions should not provide a justification for removal of epiphytes in the plantations however, as other animal groups and functions not studied could still be negatively influenced and they retain plant diversity in often depauperate plantations. Furthermore, a recent study found no effect of epiphytes on yield (Prescott et al. 2015) which, along with the fact that epiphytes are by name non-parasitic, eliminates one of the main arguments for removal.

Ground cover did not influence ants living on the oil palms, however it did influence the overall arthropod community and it is still likely that ground cover can enhance litter and soil dwelling ants and associated functions in oil palm plantations. For instance, in Chapter 5 when investigating predation rates in oil palm plantations and the surrounding vegetation types I found that predation rates by ants were higher in weedy oil palm plantations than in non-weedy oil palm plantations. Also, other studies have found positive effects of understory vegetation on other animal groups (Chung et al. 2000; Koh 2008c; Nájera and Simonetti 2010). For example, Chung et al. (2000) found understory vegetation was correlated with species richness and abundance of beetles in oil palm plantations in Malaysia and Nájera and Simonetti (2010) found that bird species richness and abundance was highest in Guatemalan oil palm plantations with understory vegetation than without. Therefore, clearing of understory vegetation in plantations should be discouraged. Understory and epiphyte management are only two aspects of local management in oil palm plantations however, and it is essential that comprehensive experiments looking at the response of biodiversity and ecosystem functions to these and other management options (e.g. fertiliser and pesticide use) together are carried out. Identifying and investigating trade-offs between the positive effects of different management regimes on yield and their potential negative effects on the environment is needed to make informed decisions on best 
practice management for both oil palm production and the retention of biodiversity and ecosystem function in the landscape.

\section{Landscape context}

In Chapters 4 and 5 I also investigated the effect of landscape context on ant communities and their associated functions in oil palm plantations. Specifically, Chapter 4 considered the differences in ant communities dwelling in oil palm leaf-axils dependent on the location of the oil palm within the plantation, comparing the edge to 20 metres inside and Chapter 5 looked at if predation rates in the plantations were dependent on the surrounding land-use type and the distance from the edge of the plantation. I found that the abundance and genus richness of ants dwelling in oil palm leaf-axils was highest on oil palms that were at the edge of the plantations (Chapter 4) and predation by ants declined with distance from the edge of plantations (Chapter 5). Also, oil palm plantations bordered by a different land-use had higher predation rates than when bordered by similar oil palm plantations.

Taken together these results indicate a strong landscape context effect on ant communities and one of their key functions. Increased ant abundance and richness and predation by ants closer to the edge of plantations bordered by other land-uses is likely due to spill-over from the neighbouring land-uses. Ant community composition is different in oil palm plantations that in other common land-uses in the study area, with different species composition and lower predator abundances in oil palm compared with forest, jungle rubber and oil palm (Chapter 2, Rubiana et al. 2015; Chapter 3). There is extensive research showing positive effects of landscape heterogeneity on biodiversity and ecosystem function in a range of agricultural systems (e.g. Weibull et al. 2003; Rundlöf and Smith 2006; Tscharntke et al. 2007; Steckel et al. 2014) and the results presented here along with a growing amount of comparable studies (e.g. Koh 2008c; Azhar et al. 2013; Lucey et al. 2014) are showing similar results in oil palm. Maintaining a heterogeneous landscape of different agricultural, natural and semi-natural systems is key to sustaining biodiversity and ecosystem functions in agricultural landscapes. For example, the spill-over of species not commonly associated with oil palm plantations from the surrounding landuses can helps mitigate local extinction events (Tscharntke et al. 2012b). Furthermore, less intensive land-uses and natural habitat near to the oil palm plantations could act as a source for beneficial organisms (Tscharntke et al. 2007). In particular, increased predation pressure from surrounding landuses could be important for maintaining biocontrol services within oil palm plantations (Chapter 3; Chapter 5; Tscharntke et al. 2007; Lucey et al. 2014).

\subsection{Objective 3: Examine the role of ant communities in shaping arthropod communities and associated ecosystem functions and services}

In Chapters 6 and 7 I used exclusion experiments to investigate the role of ant communities in shaping invertebrate communities and ecosystem functions and services. In chapter 6 I studied the relative effects on ants on above- and belowground invertebrates, soil and litter, vegetation and 
decomposition rates across forest, jungle rubber, rubber and oil palm sites with small scale (1.5 $\mathrm{m} \mathrm{x} 1$ m) ant suppression and control plots. From Chapter 2 and 3 we know that the ant communities are different between these systems, therefore our aim was to determine if these changes can influence their role in the ecosystem. Experimental ant suppression was linked to a decline in three out of four aboveground invertebrate feeding guilds though, this was likely an artefact of the suppression treatments. Belowground invertebrates, i.e. Collembola severely declined in both biomass and richness with ant suppression across all land-use systems. Collembola changes may have been caused by predator release when ants were suppressed (Moya-Laraño and Wise 2007; Sanders and van Veen 2011) or by slight changes in the soil moisture which can have strong influences on Collembola populations (Holt 1985; Frith and Frith 1990). Surprisingly, soil and litter C:N ratio and microbial biomass and vegetation were mostly unaffected by ant suppression though this is likely due to no ant nests being present in the experimental plots. Ant effects on soil properties are most commonly found due to nest construction (Jouquet et al. 2006) and although not often studied it is important to understand nest patterns in the landscape when studying the impacts of ants (Folgarait 1998; Cammeraat and Risch 2008). Most notably, effects on decomposition rates were dependent on the land-use system, whereby ant suppression reduced decomposition in the forest sites only. It is likely that ant community changes from forest, which supports more forest specialists and predators, to agricultural systems (Chapter 2, Rubiana et al. 2015; Chapter 3) have altered their relationship with decomposition processes, however, the underlying drivers of these effects require further investigation.

In chapter 7 I focused on oil palm, and studied the effect of ant and fly vertebrate (bird and bat) exclusion on arthropods, four ecosystem functions (herbivory, predation, decomposition and pollination) and yield in oil palm plantations using large-scale (four trees within one plot) exclusion and control plots. Birds and bats were included in this experiment because as well as ants they are two important predator groups. I found a strong negative effect of manipulated ant abundance and bird activity on arthropod predators, but only minimal effects on the other arthropod feeding guilds. Differing patterns in invertebrate responses from chapter 6 are likely due to the differing scale of the experiments. The measured ecosystem functions, herbivory, predation, decomposition (similar to chapter 6) and pollination, did not respond to variation in ant, bird and bat abundance. Rather, local soil variables, tree height and arthropod abundances (other than ants) were, although generally weakly related, the most important predictors for ecosystem functions in our oil palm plantations. The economically most important ecosystem service, yield, however, did not respond to our measured predictors. The results show that ecosystem functions and productivity in oil palm are, under current levels of pest pressure and pollinator populations, robust to large changes in the communities of major predator groups.

\subsection{Overall conclusions}


This thesis shows that ant species richness may not decrease with land-use change from forest to jungle rubber, rubber monoculture and oil palm plantations however there are severe changes to the species and functional composition of ant communities, particularly in oil palm plantations. These community changes are non-random, with forest specialists and species from higher trophic guilds (predators) and with lower mobility particularly threatened. The results also demonstrate that landscape context and local management can influence the severity of land-use impacts on ant communities and associated ecosystem functions in oil palm plantations. In particular, increased landscape heterogeneity can enhance oil palm ant populations and their functions. Encouragingly, the positive influence of the surrounding landscape is strong not only when surrounded by complex natural and agroforestry systems but also when surrounded by less intensively managed oil palm plantations (dense and high understory vegetation present) and other monocultures (i.e. rubber). Local management effects on biodiversity and ecosystem functioning however are less clear; more comprehensive research investigating many aspects of management, biodiversity, and functioning, and most importantly their links to yield is urgently needed. Particularly in large-scale plantations, local management will be a more important tool for enhancing biodiversity rather than landscape management due to the positive effects of surrounding land-use declining rapidly with distance from edge. Finally, I show that although changes in ant communities between land-uses can alter their relationship to ecosystem functions, within oil palm plantations ecosystem functions and productivity are not altered by large changes in ant communities and the communities of other major predator groups. Nevertheless, the lack of a relationship between biodiversity and yield should not discourage enhancement of biodiversity in oil palm plantations through local and landscape management for three main reasons. Firstly, maintaining biodiversity in agriculture allows for insurance against future disturbances. In the oil palm Indonesia for example, pest outbreaks are uncommon and non-cyclic, however, pest and disease outbreaks are known to increase with time and area under cultivation. Therefore, in the future, pest problems could become more severe and in that case predators may play a more important role. Secondly, a lack of relationship between biodiversity and yield allows for a win-win situation for biodiversity and yield in oil palm plantations. There is no trade-off between biodiversity and yield as is commonly found in agricultural systems. Therefore management practices that do not compromise yield themselves but could possibly promote biodiversity (e.g. not removing epiphytes) can be encouraged. Lastly, intrinsic values alone should be a sufficient reason for biodiversity conservation. Conservation need not be compromised just because it does not lead to an increase in one or more economically meaningful ecosystem services.

In conclusion, although forest conversion to oil palm and other agricultural systems in Indonesia has wide-ranging negative influences on biodiversity and function, there is the opportunity to enrich biodiversity in these systems. In oil palm plantations in particular this should be encouraged as changes in biodiversity do not compromise production. 


\section{Bibliography}

Abood SA, Lee JSH, Burivalova Z, et al (2015) Relative Contributions of the Logging, Fiber, Oil Palm, and Mining Industries to Forest Loss in Indonesia. Conserv Lett 8:58-67. doi: 10.1111/conl.12103.

Agosti D, Alonso LE (2000) The ALL protocol. In: Ants: Standard methods for measuring and monitoring biodiversity. Smithsonian Institution Press, Washington, DC, pp 204-206.

Alberti M (2005) The effects of urban patterns on ecosystem function. Int Reg Sci Rev 28:168-192.

Allen K, Corre MD, Tjoa A, Veldkamp E (2015) Soil nitrogen-cycling responses to conversion of lowland forests to oil palm and rubber plantations in Sumatra, Indonesia. PLoS ONE 10:e0133325.

Altenhövel C (2013) Diversity of vascular epiphytes in lowland rainforest and oil palm plantations in Sumatra (Indonesia). BSc Thesis, Georg-August-Universität Göttingen.

Amit B, Tuen AA, Haron K, et al (2015) The diet of Yellow-vented Bulbul (Pycnonotus goiavier) in oil palm agroecosystems. J Oil Palm Res 27:417-424.

Andersen AN (2000) A global ecology of rainforest ants: functional groups in relation to environmental stress and disturbance. In: Ants: Standard methods for measuring and monitoring biodiversity. Smithsonian Institution Press, Washington, DC, pp 25-34.

Aratrakorn S, Thunhikorn S, Donald PF (2006) Changes in bird communities following conversion of lowland forest to oil palm and rubber plantations in southern Thailand. Bird Conserv Int $16: 71-82$.

Azhar B, Lindenmayer DB, Wood J, et al (2013) The influence of agricultural system, stand structural complexity and landscape context on foraging birds in oil palm landscapes. Ibis 155:297-312.

Bakeri SA, Siti Ramlah AA, Tajuddin NS, Kamaruzzaman NE (2009) Efficacy of entomopathogenic fungi, Paecilomyces spp., in controlling the oil palm bag worm, Pteroma pendula (Joannis). J Oil Palm Res 21:693-699.

Bardgett RD (2005) The biology of soil: a community and ecosystem approach. Oxford University Press, Oxford, UK.

Bardgett RD, Frankland JC, Whittaker JB (1993) The effects of agricultural management on the soil biota of some upland grasslands. Agric Ecosyst Environ 45:25-45.

Barnes AD, Jochum M, Mumme S, et al (2014) Consequences of tropical land use for multitrophic biodiversity and ecosystem functioning. Nat Commun. doi: 10.1038/ncomms6351.

Bartoń K (2013) MuMIn: multi-model inference. R package version 1.9.5.

Basiron Y (2007) Palm oil production through sustainable plantations. Eur J Lipid Sci Technol 109:289-295.

Basri MW, Norman K, Hamdan AB (1995) Natural enemies of the bagworm, Metisa plana Walker (Lepidoptera: Psychidae) and their impact on host population regulation. Crop Prot 14:637645. doi: 10.1016/0261-2194(95)00053-4.

Bennett AF, Radford JQ, Haslem A (2006) Properties of land mosaics: implications for nature conservation in agricultural environments. Biol Conserv 133:250-264. 
Bestelmeyer BT, Agosti D, Alonso LE, et al (2000) Field techniques for the study of ground-dwelling ants: an overview, description and evaluation. In: Ants: Standard methods for measuring and monitoring biodiversity. Smithsonian Institution Press, Washington, DC, pp 122-144 .

Bharti H, Silla S (2011) Notes on life history of Oecophylla smaragdina (Fabricius) and its potential as biological control agent. Halteres 3:57-64.

Bianchi FJJA, Booij CJH, Tscharntke T (2006) Sustainable pest regulation in agricultural landscapes: a review on landscape composition, biodiversity and natural pest control. Proc R Soc Lond B Biol Sci 273:1715-1727. doi: 10.1098/rspb.2006.3530.

Bihn JH, Gebauer G, Brandl R (2010) Loss of functional diversity of ant assemblages in secondary tropical forests. Ecology 91:782-792.

BirdLife International (2015) Birdlife Data Zone. http://www.birdlife.org/datazone/home. Accessed 2 Oct 2015.

Bos MM, Tylianakis JM, Steffan-Dewenter I, Tscharntke T (2008) The invasive Yellow Crazy Ant and the decline of forest ant diversity in Indonesian cacao agroforests. Biol Invasions 10:1399-1409.

Breure CJ (2010) Rate of leaf expansion: A criterion for identifying oil palm (Elaeis guineensis Jacq.) types suitable for planting at high densities. NJAS - Wagening J Life Sci 57:141-147. doi: 10.1016/j.njas.2010.03.001.

Brown KA, Flynn DF, Abram NK, et al (2011) Assessing natural resource use by forest-reliant communities in Madagascar using functional diversity and functional redundancy metrics. PLoS ONE 6:e24107.

Brühl CA (2001) Leaf litter ant communities in tropical lowland rain forests in Sabah, Malaysia: effects of forest disturbance and fragmentation. PhD Thesis, Julius-Maximilians-Universität Würzburg.

Brühl CA, Eltz T (2010) Fuelling the biodiversity crisis: species loss of ground-dwelling forest ants in oil palm plantations in Sabah, Malaysia (Borneo). Biodivers Conserv 19:519-529.

Burel F, Baudry J (2003) Landscape ecology: concepts, methods, and applications. Science Publishers, Inc, Enfield, USA.

Burnham KP, Anderson DR (2002) Model selection and multimodel inference: a practical information-theoretic approach. Springer Science \& Business Media, New York, New York.

Butterfield BJ, Suding KN (2013) Single-trait functional indices outperform multi-trait indices in linking environmental gradients and ecosystem services in a complex landscape. J Ecol 101:9-17.

Cagnolo L, Valladares G, Salvo A, et al (2009) Habitat Fragmentation and Species Loss across Three Interacting Trophic Levels: Effects of Life-History and Food-Web Traits. Conserv Biol 23:1167-1175.

Cammeraat ELH, Risch AC (2008) The impact of ants on mineral soil properties and processes at different spatial scales. J Appl Entomol 132:285-294.

Capinera JL, Weissling TJ, Schweizer EE (1985) Compatibility of intercropping with mechanized agriculture: effects of strip intercropping of pinto beans and sweet corn on insect abundance in Colorado. J Econ Entomol 78:354-357. 
Cardinale BJ, Duffy JE, Gonzalez A, et al (2012) Biodiversity loss and its impact on humanity. Nature 486:59-67.

Carlson SR, Whitford WG (1991) Ant mound influence on vegetation and soils in a semiarid mountain ecosystem. Am Midl Nat 126:125-139.

Chaplin-Kramer R, O'Rourke ME, Blitzer EJ, Kremen C (2011) A meta-analysis of crop pest and natural enemy response to landscape complexity. Ecol Lett 14:922-932.

Chung AYC, Eggleton P, Speight MR, et al (2000) The diversity of beetle assemblages in different habitat types in Sabah, Malaysia. Bull Entomol Res 90:475-496.

Clarke KR (1993) Non-parametric multivariate analyses of changes in community structure. Aust J Ecol 18:117-117.

Clough Y, Barkmann J, Juhrbandt J, et al (2011) Combining high biodiversity with high yields in tropical agroforests. Proc Natl Acad Sci 108:8311-8316.

Clough Y, Faust H, Tscharntke T (2009) Cacao boom and bust: sustainability of agroforests and opportunities for biodiversity conservation. Conserv Lett 2:197-205. doi: 10.1111/j.1755263X.2009.00072.x.

Clough Y, Krishna VV, Corre MD, et al Land-use choices, profitability, and consequences for biodiversity and ecological functions in Indonesian smallholder landscapes. Nat Commun In review.

Coley PD (1980) Effects of leaf age and plant life history patterns on herbivory. Nature 284:545-546.

Constantin M, Ntsefong GN, Frank NEG, et al (2013) Spatio-temporal distribution of Coelaenomenodera minuta Uhmann (Coleoptera: Chrysomelidae), a serious insect pest of oil palm (Elaeis guineensis Jacq.) in the south-west region of Cameroon. Albanian J Agric Sci 12:479-483.

Corley RHV, Tinker PBH (2003) The oil palm. Blackwell Publishing Ltd, Oxford, UK.

Danielsen F, Beukema H, Burgess ND, et al (2009) Biofuel plantations on forested lands: double jeopardy for biodiversity and climate. Conserv Biol 23:348-358.

Dejean A, Djieto-Lordon C, Durand JL (1997) Ant mosaic in oil palm plantations of the southwest province of Cameroon: impact on leaf miner beetle (Coleoptera: Chrysomelidae). J Econ Entomol 90:1092-1096.

del Hoyo J, Elliot A, Sargatal J, et al (2015) Handbook of the Birds of the World Alive. Lynx Edicions, Barcelona, Spain.

Denmead LH, Darras K, Clough Y, et al. Single- and multi-trait measures reveal widespread functional diversity loss in human-modified tropical landscapes. Ecosphere In review.

De Vries PJ, Murray D, Lande R (1997) Species diversity in vertical, horizontal, and temporal dimensions of a fruit-feeding butterfly community in an Ecuadorian rainforest. Biol J Linn Soc 62:343-364.

Dislich C, Keyel A, Salecker J, et al Ecosystem functions of oil palm plantations: a review. Biol Rev In revision.

Donald PF (2004) Biodiversity impacts of some agricultural commodity production systems. Conserv Biol 18:17-38. 
Driscoll DA, Weir TOM (2005) Beetle responses to habitat fragmentation depend on ecological traits, habitat condition, and remnant size. Conserv Biol 19:182-194.

Dyer ML, Meentemeyer V, Berg B (1990) Apparent controls of mass loss rate of leaf litter on a regional scale: litter quality vs. climate. Scand J For Res 5:311-323.

Edwards FA, Edwards DP, Larsen TH, et al (2014a) Does logging and forest conversion to oil palm agriculture alter functional diversity in a biodiversity hotspot? Anim Conserv 17:163-173. doi: 10.1111/acv.12074.

Edwards FA, Edwards DP, Sloan S, Hamer KC (2014b) Sustainable management in crop monocultures: the impact of retaining forest on oil palm yield. PLoS ONE 9:e91695.

Eguchi K, Hashimoto Y, Malsch AK (2006) Pheidole schoedli sp. n.(Hymenoptera: Formicidae), a subterranean species found from North Borneo. Myrmecol Nachrichten 8:31-34.

Ekadinata A, Vincent G (2011) Rubber agroforests in a changing landscape: analysis of land use/cover trajectories in Bungo district, Indonesia. For Trees Livelihoods 20:3-14.

Euler M, Schwarze S, Siregar H, Qaim M (2015) Oil palm expansion among smallholder farmers in Sumatra, Indonesia. Georg-August-Universität Göttingen, Göttingen.

Evans TA, Dawes TZ, Ward PR, Lo N (2011) Ants and termites increase crop yield in a dry climate. Nat Commun 2:262. doi: 10.1038/ncomms1257.

Fahrig L, Baudry J, Brotons L, et al (2011) Functional landscape heterogeneity and animal biodiversity in agricultural landscapes. Ecol Lett 14:101-112.

Falconer JG, Wright JW, Beall HW (1933) The decomposition of certain types of forest litter under field conditions. Am J Bot 20:196-203.

FAO (2015) FAOSTAT Online Statistical Service. http://faostat.fao.org. Accessed 19 Aug 2015.

FAO (2016) FAOSTAT Online Statistical Service. http://faostat3.fao.org/. Accessed 21 Jan 2016.

Fayle TM, Turner EC, Snaddon JL, et al (2010) Oil palm expansion into rain forest greatly reduces ant biodiversity in canopy, epiphytes and leaf-litter. Basic Appl Ecol 11:337-345.

Fayle TM, Yusah KM, Hashimoto Y (2014) Key to the ant genera of Borneo in English and Malay. http://www.tomfayle.com/Ant\%20key.htm. Accessed 2 Jan 2013.

Fearnside PM (2000) Global warming and tropical land-use change: greenhouse gas emissions from biomass burning, decomposition and soils in forest conversion, shifting cultivation and secondary vegetation. Clim Change 46:115-158.

Feintrenie L, Levang P (2009) Sumatra's rubber agroforests: advent, rise and fall of a sustainable cropping system. Small-Scale For 8:323-335.

Finke DL, Denno RF (2002) Intraguild predation diminished in complex-structured vegetation: implications for prey suppression. Ecology 83:643-652.

Fischer J, Lindenmayer DB, Manning AD (2006) Biodiversity, ecosystem function, and resilience: ten guiding principles for commodity production landscapes. Front Ecol Environ 4:80-86.

Fitzherbert EB, Struebig MJ, Morel A, et al (2008) How will oil palm expansion affect biodiversity? Trends Ecol Evol 23:538-545.

Flynn DF, Gogol-Prokurat M, Nogeire T, et al (2009) Loss of functional diversity under land use intensification across multiple taxa. Ecol Lett 12:22-33. 
Foley JA, Asner GP, Costa MH, et al (2007) Amazonia revealed: forest degradation and loss of ecosystem goods and services in the Amazon Basin. Front Ecol Environ 5:25-32.

Foley JA, DeFries R, Asner GP, et al (2005) Global Consequences of Land Use. Science 309:570574. doi: 10.1126/science. 1111772 .

Folgarait PJ (1998) Ant biodiversity and its relationship to ecosystem functioning: a review. Biodivers Conserv 7:1221-1244.

Foster WA, Snaddon JL, Turner EC, et al (2011) Establishing the evidence base for maintaining biodiversity and ecosystem function in the oil palm landscapes of South East Asia. Philos Trans R Soc Lond B Biol Sci 366:3277-3291. doi: 10.1098/rstb.2011.0041.

Fraterrigo JM, Pearson SM, Turner MG (2009) Joint effects of habitat configuration and temporal stochasticity on population dynamics. Landsc Ecol 24:863-877.

Freiberg M (2001) The influence of epiphyte cover on branch temperature in a tropical tree. Plant Ecol 153:241-250.

Frith D, Frith C (1990) Seasonality of litter invertebrate populations in an Australian upland tropical rain forest. Biotropica 22:181-190.

Frouz J, Jilková V (2008) The effect of ants on soil properties and processes (Hymenoptera: Formicidae). Myrmecol News 11:191-199.

Gagic V, Bartomeus I, Jonsson T, et al (2015) Functional identity and diversity of animals predict ecosystem functioning better than species-based indices. Proc R Soc Lond B Biol Sci 282:20142620. doi: 10.1098/rspb.2014.2620.

Gammans N, Bullock JM, Schönrogge K (2005) Ant benefits in a seed dispersal mutualism. Oecologia 146:43-49.

Gardner TA, Barlow J, Chazdon R, et al (2009) Prospects for tropical forest biodiversity in a humanmodified world. Ecol Lett 12:561-582.

Gatto M, Wollni M, Qaim M (2015) Oil palm boom and land-use dynamics in Indonesia: the role of policies and socioeconomic factors. Land Use Policy 46:292-303.

Gaume L, McKey D, Terrin S (1998) Ant-plant-homopteran mutualism: how the third partner affects the interaction between a plant-specialist ant and its myrmecophyte host. Proc R Soc Lond B Biol Sci 265:569-575.

Gibb H, Hochuli DF (2003) Colonisation by a dominant ant facilitated by anthropogenic disturbance: effects on ant assemblage composition, biomass and resource use. Oikos 103:469-478.

Gibbs HK, Ruesch AS, Achard F, et al (2010) Tropical forests were the primary sources of new agricultural land in the 1980s and 1990s. Proc Natl Acad Sci 107:16732-16737.

Gibson L, Lee TM, Koh LP, et al (2011) Primary forests are irreplaceable for sustaining tropical biodiversity. Nature 478:378-381.

Gitau CW, Gurr GM, Dewhurst CF, et al (2011) Potential for biological control of Zophiuma butawengi (Heller)(Hemiptera: Lophopidae) in coconut and oil palms using the hymenopterans Ooencyrtus sp.(Encyrtidae) and Parastethynium maxwelli (Girault)(Mymaridae). Biol Control 59:187-191.

Gouyon A, de Foresta H, Levang P (1993) Does "jungle rubber"deserve its name? An analysis of rubber agroforestry systems in southeast Sumatra. Agrofor Syst 22:181-206. 
Gras P, Tscharntke T, Maas B, et al (2016) How ants, birds and bats affect crop yield along shade gradients in tropical cacao agroforestry. J Appl Ecol In press.

Grass I, Berens DG, Farwig N (2014a) Natural habitat loss and exotic plants reduce the functional diversity of flower visitors in a heterogeneous subtropical landscape. Funct Ecol 28:11171126.

Grass I, Berens DG, Farwig N (2014b) Guild-specific shifts in visitation rates of frugivores with habitat loss and plant invasion. Oikos 123:575-582.

Gray CL, Lewis OT (2014) Do riparian forest fragments provide ecosystem services or disservices in surrounding oil palm plantations? Basic Appl Ecol 15:693-700.

Gray CL, Slade EM, Mann DJ, Lewis OT (2014) Do riparian reserves support dung beetle biodiversity and ecosystem services in oil palm-dominated tropical landscapes? Ecol Evol 4:1049-1060.

Greathead DJ (1983) The multi-million dollar weevil that pollinates oil palms. Antenna 7:105-107.

Grimes A, Loomis S, Jahnige P, et al (1994) Valuing the rain forest: the economic value of nontimber forest products in Ecuador. Ambio 405-410.

Grueber CE, Nakagawa S, Laws RJ, Jamieson IG (2011) Multimodel inference in ecology and evolution: challenges and solutions. J Evol Biol 24:699-711.

Hajek AE (2004) Natural enemies: an introduction to biological control. Cambridge University Press, Cambridge, UK.

Hamid AA (1987) Insect pests of Acacia mangium Willd. in Sarawak. Forest Entomology Unit, Forest Department, Sarawak.

Hansen MC, Stehman SV, Potapov PV, et al (2009) Quantifying changes in the rates of forest clearing in Indonesia from 1990 to 2005 using remotely sensed data sets. Environ Res Lett 4:034001.

Hardwick SR, Toumi R, Pfeifer M, et al (2015) The relationship between leaf area index and microclimate in tropical forest and oil palm plantation: forest disturbance drives changes in microclimate. Agric For Meteorol 201:187-195.

Harrison XA (2014) Using observation-level random effects to model overdispersion in count data in ecology and evolution. PeerJ 2:e616.

Hashimoto Y (2003) Identification guide to the ant genera of Borneo. In: Inventory and Collection. Total protocol for understanding of biodiversity. Research and Education Component, BBEC Programme (Universiti Malaysia Sabah), Kota Kinabalu, Malaysia, pp 89-162.

Hättenschwiler S, Tiunov AV, Scheu S (2005) Biodiversity and litter decomposition in terrestrial ecosystems. Annu Rev Ecol Evol Syst 3:191-218.

Henle K, Davies KF, Kleyer M, et al (2004) Predictors of species sensitivity to fragmentation. Biodivers Conserv 13:207-251.

Hill SL, Hoy MA (2003) Interactions between the red imported fire ant Solenopsis invicta and the parasitoid Lipolexis scutellaris potentially affect classical biological control of the aphid Toxoptera citricida. Biol Control 27:11-19.

Hölldobler B, Wilson EO (1994) Journey to the Ants. Belknap Press, Cambridge, Massachusetts

Holt JA (1985) Acari and Collembola in the litter and soil of three north Queensland rainforests. Aust J Ecol 10:57-65. 
Holt RD (2009) Toward a trophic island biogeography. In: The Theory of Island Biogeography Revisted. Princeton University Press, Princeton, USA, pp 143-185.

Hothorn T, Bretz F, Westfall P (2008) Simultaneous inference in general parametric models. Biom J 50:346-363.

Howard FW, Giblin-Davis R, Moore D, Abad R (2001) Insects on palms. CABI publishing, New York, New York.

Howe A, Lövei GL, Nachman G (2009) Dummy caterpillars as a simple method to assess predation rates on invertebrates in a tropical agroecosystem. Entomol Exp Appl 131:325-329.

Huhta V (2007) The role of soil fauna in ecosystems: a historical review. Pedobiologia 50:489-495.

Human KG, Gordon DM (1999) Behavioral interactions of the invasive Argentine ant with native ant species. Insectes Sociaux 46:159-163.

Igbinosa IB (1992) Field and laboratory techniques for assessing infestations of the nettle caterpillar, Latoia viridissima Holland (Lepidoptera: Limacodidae). Int J Trop Insect Sci 13:389-398.

Isaacs R, Tuell J, Fiedler A, et al (2008) Maximizing arthropod-mediated ecosystem services in agricultural landscapes: the role of native plants. Front Ecol Environ 7:196-203.

Jepson P, Jarvie JK, MacKinnon K, Monk KA (2001) The End for Indonesia's Lowland Forests? Science 292:859-861. doi: 10.1126/science.1061727.

Jouquet P, Dauber J, Lagerlöf J, et al (2006) Soil invertebrates as ecosystem engineers: intended and accidental effects on soil and feedback loops. Appl Soil Ecol 32:153-164.

Kamarudin N, Wahid MB (2010) Interactions of the bagworm, Pteroma pendula (Lepidoptera: Psychidae), and its natural enemies in an oil palm plantation in Perak. J Oil Palm Res 22:758764.

Karp DS, Rominger AJ, Zook J, et al (2012) Intensive agriculture erodes $\beta$-diversity at large scales. Ecol Lett 15:963-970.

Kaspari M, Yuan M, Alonso L (2003) Spatial grain and the causes of regional diversity gradients in ants. Am Nat 161:459-477.

Kempson D, Lloyd M, Ghelardi R (1963) A new extractor for woodland litter. Pedobiologia 3:1-21.

Klein A-M, Steffan-Dewenter I, Tscharntke T (2002) Predator-prey ratios on cocoa along a land-use gradient in Indonesia. Biodivers Conserv 11:683-693.

Klein A-M, Vaissière BE, Cane JH, et al (2007) Importance of pollinators in changing landscapes for world crops. Proc R Soc Lond B Biol Sci 274:303-313. doi: 10.1098/rspb.2006.3721.

Klimes P, Janda M, Ibalim S, et al (2011) Experimental suppression of ants foraging on rainforest vegetation in New Guinea: testing methods for a whole-forest manipulation of insect communities. Ecol Entomol 36:94-103.

Koh LP (2008a) Birds defend oil palms from herbivorous insects. Ecol Appl 18:821-825.

Koh LP (2008b) Can oil palm plantations be made more hospitable for forest butterflies and birds? J Appl Ecol 45:1002-1009. doi: 10.1111/j.1365-2664.2007.0

Koh LP (2008c) Can oil palm plantations be made more hospitable for forest butterflies and birds? J Appl Ecol 45:1002-1009. 
Koh LP, Ghazoul J (2010) Spatially explicit scenario analysis for reconciling agricultural expansion, forest protection, and carbon conservation in Indonesia. Proc Natl Acad Sci 107:1114011144.

Koh LP, Levang P, Ghazoul J (2009) Designer landscapes for sustainable biofuels. Trends Ecol Evol $24: 431-438$.

Koh LP, Wilcove DS (2008) Is oil palm agriculture really destroying tropical biodiversity? Conserv Lett 1:60-64.

Koh LP, Wilcove DS (2007) Cashing in palm oil for conservation. Nature 448:993-994.

Kowalenko CG, Ivarson KC, others (1978) Effect of moisture content, temperature and nitrogen fertilization on carbon dioxide evolution from field soils. Soil Biol Biochem 10:417-423.

Kremen C, Williams NM, Thorp RW (2002) Crop pollination from native bees at risk from agricultural intensification. Proc Natl Acad Sci 99:16812-16816. doi: $10.1073 /$ pnas. 262413599

Krobbach JA (2014) Diversity and dynamics of vascular epiphytes and arthropods in oil palm plantations in Sumatra (Indonesia). MSc Thesis, Georg-August-Universität Göttingen

Lach L, Parr CL, Abott KL (2010) Ant ecology. Oxford University Press, Oxford, UK

Laliberté E, Legendre P (2010) A distance-based framework for measuring functional diversity from multiple traits. Ecology 91:299-305.

Laliberté E, Shipley B (2014) FD: measuring functional diversity from multiple traits, and other tools for functional ecology. R package version 1.0-11

Laliberte E, Wells JA, DeClerck F, et al (2010) Land-use intensification reduces functional redundancy and response diversity in plant communities. Ecol Lett 13:76-86.

Lambin EF, Meyfroidt P (2011) Global land use change, economic globalization, and the looming land scarcity. Proc Natl Acad Sci 108:3465-3472.

Landis DA, Gardiner MM, Werf W van der, Swinton SM (2008) Increasing corn for biofuel production reduces biocontrol services in agricultural landscapes. Proc Natl Acad Sci 105:20552-20557. doi: 10.1073/pnas.0804951106

Landis DA, Wratten SD, Gurr GM (2000) Habitat management to conserve natural enemies of arthropod pests in agriculture. Annu Rev Entomol 45:175-201.

Larsen TH, Williams NM, Kremen C (2005) Extinction order and altered community structure rapidly disrupt ecosystem functioning. Ecol Lett 8:538-547.

Laumonier Y, Uryu Y, Stüwe M, et al (2010) Eco-floristic sectors and deforestation threats in Sumatra: identifying new conservation area network priorities for ecosystem-based land use planning. Biodivers Conserv 19:1153-1174.

Laurance WF, Sayer J, Cassman KG (2014) Agricultural expansion and its impacts on tropical nature. Trends Ecol Evol 29:107-116.

Lee JC, Heimpel GE (2005) Impact of flowering buckwheat on Lepidopteran cabbage pests and their parasitoids at two spatial scales. Biol Control 34:290-301. doi:

10.1016/j.biocontrol.2005.06.002 
Lee JSH, Abood S, Ghazoul J, et al (2014) Environmental Impacts of Large-Scale Oil Palm Enterprises Exceed that of Smallholdings in Indonesia. Conserv Lett 7:25-33. doi: 10.1111/conl.12039

Lefcheck JS, Duffy JE (2015) Multitrophic functional diversity predicts ecosystem functioning in experimental assemblages of estuarine consumers. Ecology 96:2973-2983.

Levey DJ, Byrne MM (1993) Complex Ant-Plant Interactions: Rain-Forest Ants as Secondary Dispersers and Post-Dispersal Seed Predators. Ecology 74:1802-1812. doi: 10.2307/1939938

Lucey JM, Hill JK (2012) Spillover of insects from rain forest into adjacent oil palm plantations. Biotropica 44:368-377.

Lucey JM, Tawatao N, Senior MJ, et al (2014) Tropical forest fragments contribute to species richness in adjacent oil palm plantations. Biol Conserv 169:268-276.

Luck GW, Carter A, Smallbone L (2013) Changes in Bird Functional Diversity across Multiple Land Uses: Interpretations of Functional Redundancy Depend on Functional Group Identity. PLoS ONE 8:e63671. doi: 10.1371/journal.pone.0063671

Luke SH, Fayle TM, Eggleton P, et al (2014) Functional structure of ant and termite assemblages in old growth forest, logged forest and oil palm plantation in Malaysian Borneo. Biodivers Conserv 23:2817-2832.

Luskin MS, Potts MD (2011) Microclimate and habitat heterogeneity through the oil palm lifecycle. Basic Appl Ecol 12:540-551.

Maas B, Clough Y, Tscharntke T (2013) Bats and birds increase crop yield in tropical agroforestry landscapes. Ecol Lett 16:1480-1487.

Maas B, Karp DS, Bumrungsri S, et al (2015) Bird and bat predation services in tropical forests and agroforestry landscapes. Biol Rev doi: 10.1111/brv.12211.

Magurran AE (2013) Measuring biological diversity. Blackwell Publishing, Oxford, UK

Maine JJ, Boyles JG (2015) Bats initiate vital agroecological interactions in corn. Proc Natl Acad Sci 112:12438-12443.

Majer J, Walker TC, Berlandier F (1987) The role of ants in degraded soils within Dryandra State Forest. Mulga Res Cent J 9:15-16.

Margono BA, Potapov PV, Turubanova S, et al (2014) Primary forest cover loss in Indonesia over 2000-2012. Nat. Clim. Change 4:730-735

Mazerolle MJ (2015) AICcmodavg: Model selection and multimodel inference based on (Q)AIC(c). R package version 2.0-3

McGlynn TP (1999) The worldwide transfer of ants: geographical distribution and ecological invasions. J Biogeogr 26:535-548.

Mestre L, Piñol J, Barrientos JA, et al (2012) Effects of ant competition and bird predation on the spider assemblage of a citrus grove. Basic Appl Ecol 13:355-362.

Micheli F, Halpern BS (2005) Low functional redundancy in coastal marine assemblages. Ecol Lett 8:391-400.

Miettinen J, Shi C, Liew SC (2011) Deforestation rates in insular Southeast Asia between 2000 and 2010. Glob Change Biol 17:2261-2270. 
Mitchell MG, Bennett EM, Gonzalez A (2013) Linking landscape connectivity and ecosystem service provision: current knowledge and research gaps. Ecosystems 16:894-908.

Moradi A, Teh CBS, Goh KJ, et al (2014) Decomposition and nutrient release temporal pattern of oil palm residues. Ann Appl Biol 164:208-219.

Morris RJ (2010) Anthropogenic impacts on tropical forest biodiversity: a network structure and ecosystem functioning perspective. Philos Trans R Soc B Biol Sci 365:3709-3718.

Mouillot D, Villéger S, Scherer-Lorenzen M, Mason NW (2011) Functional structure of biological communities predicts ecosystem multifunctionality. PLoS ONE 6:e17476.

Moya-Laraño J, Wise DH (2007) Direct and indirect effects of ants on a forest-floor food web. Ecology 88:1454-1465.

Mumme S (2014) Alteration of functional diversity along a land-use intensification gradient in Sumatra, Indonesia. MSc Thesis, Georg-August-Universität Göttingen

Murphy DJ (2009) Oil palm: future prospects for yield and quality improvements. Lipid Technol 21:257-260.

Naeem S, Chapin III FS, Costanza R, et al (1999) Biodiversity and ecosystem functioning: maintaining natural life support processes. Issues Ecol 4:1-13.

Nájera A, Simonetti JA (2010) Can oil palm plantations become bird friendly? Agrofor Syst 80:203209.

Nakamura A, Catterall CP, House AP, et al (2007) The use of ants and other soil and litter arthropods as bio-indicators of the impacts of rainforest clearing and subsequent land use. J Insect Conserv 11:177-186.

Newbold T, Hudson LN, Hill SL, et al (2015) Global effects of land use on local terrestrial biodiversity. Nature 520:45-50.

Newbold T, Scharlemann JP, Butchart SH, et al (2013) Ecological traits affect the response of tropical forest bird species to land-use intensity. Proc R Soc Lond B Biol Sci 280:20122131.

Norris RF, Caswell-Chen EP, Kogan M (2003) Concepts in integrated pest management. Prentice Hall, Upper Saddle River, NJ

Oksanen J, Blanchet FG, Kindt R, et al (2015) vegan: Community Ecology Package. R package version 2.3-0

Olson JS (1963) Energy storage and the balance of producers and decomposers in ecological systems. Ecology 44:322-331.

Pan Y, Birdsey RA, Fang J, et al (2011) A large and persistent carbon sink in the world's forests. Science 333:988-993.

Peh KS-H, Sodhi NS, De Jong J, et al (2006) Conservation value of degraded habitats for forest birds in southern Peninsular Malaysia. Divers Distrib 12:572-581.

Perfecto I, Vandermeer J (2006) The effect of an ant-hemipteran mutualism on the coffee berry borer (Hypothenemus hampei) in southern Mexico. Agric Ecosyst Environ 117:218-221.

Petchey OL, Evans KL, Fishburn IS, Gaston KJ (2007) Low functional diversity and no redundancy in British avian assemblages. J Anim Ecol 76:977-985. 
Petchey OL, Gaston KJ (2006) Functional diversity: back to basics and looking forward. Ecol Lett 9:741-758.

Petchey OL, Gaston KJ (2002) Functional diversity (FD), species richness and community composition. Ecol Lett 5:402-411.

Petersen H (1975) Estimation of dry weight, fresh weight, and calorific content of various Collembolan species. Pedobiologia 15:222-243.

Peters MK, Fischer G, Schaab G, Kraemer M (2009) Species compensation maintains abundance and raid rates of African swarm-raiding army ants in rainforest fragments. Biol Conserv 142:668 675.

Pfeiffer M, Cheng Tuck H, Chong Lay T (2008) Exploring arboreal ant community composition and co-occurrence patterns in plantations of oil palm Elaeis guineensis in Borneo and Peninsular Malaysia. Ecography 31:21-32.

Phalan B, Bertzky M, Butchart SH, et al (2013) Crop expansion and conservation priorities in tropical countries. PloS ONE 8:e51759.

Philpott SM, Greenberg R, Bichier P, Perfecto I (2004) Impacts of major predators on tropical agroforest arthropods: comparisons within and across taxa. Oecologia 140:140-149.

Philpott SM, Perfecto I, Armbrecht I, Parr CL (2010) Ant diversity and function in disturbed and changing habitats. In: Ant Ecology. Oxford University Press, Oxford, UK, pp 137-157

Philpott SM, Perfecto I, Vandermeer J (2006) Effects of management intensity and season on arboreal ant diversity and abundance in coffee agroecosystems. Biodivers Conserv 15:139-155.

Pierre EM, Idris AH (2013) Studies on the predatory activities of Oecophylla smaragdina (Hymenoptera: Formicidae) on Pteroma pendula (Lepidoptera: Psychidae) in oil palm plantations in Teluk Intan, Perak (Malaysia). Asian Myrmecol 5:163-176.

Pinheiro J, Bates D, DebRoy S, et al (2015) nlme: Linear and nonlinear mixed effects models. R package version 3.1-120

Potineni K, Saravanan L (2013) Natural enemies of oil palm defoliators and their impact on pest population. Pest Manag Hortic Ecosyst 19:179-184.

Potts SG, Biesmeijer JC, Kremen C, et al (2010) Global pollinator declines: trends, impacts and drivers. Trends Ecol Evol 25:345-353.

Poveda K, Martínez E, Kersch-Becker MF, et al (2012) Landscape simplification and altitude affect biodiversity, herbivory and Andean potato yield. J Appl Ecol 49:513-522.

Power AG (2010) Ecosystem services and agriculture: tradeoffs and synergies. Philos Trans R Soc B Biol Sci 365:2959-2971.

Prescott GW, Edwards DP, Foster WA (2015) Retaining biodiversity in intensive farmland: epiphyte removal in oil palm plantations does not affect yield. Ecol Evol 5:1944-1954.

Pringle A (2007) Unit 9: Biodiversity decline. In: The Habitable Planet a Systems Approach to Environmental Science. Annenberg Media, Cambridge, UK, pp 1-32

Rafflegeau S, Michel-Dounias I, Tailliez B, et al (2010) Unexpected N and K nutrition diagnosis in oil palm smallholdings using references of high-yielding industrial plantations. Agron Sustain Dev 30:777-787. 
Rankine IR, Fairhurst TH (1999) Field Handbook: Oil Palm Series Volume 3 - Mature. Potash \& Phosphate Institute, Singapore

R Core Team (2015) R: A Language and Environment for Statistical Computing. R Foundation for Statistical Computing, Vienna, Austria

Rizali A, Bos MM, Buchori D, et al (2008) Ants in tropical urban habitats: the myrmecofauna in a densely populated area of Bogor, West Java, Indonesia. HAYATI J Biosci 15:77-84.

Robinson HC, Chasen FN (1927) The Birds of the Malay Peninsula: a general account of the birds inhabiting the region from the isthmus of Kra to Singapore with the adjacent islands. H. F. and G. Witherby, London, UK

Rubiana R, Rizali A, Denmead LH, et al (2015) Agricultural land use alters species composition but not species richness of ant communities. Asian Myrmecol 7:73-85.

Rundlöf M, Smith HG (2006) The effect of organic farming on butterfly diversity depends on landscape context. J Appl Ecol 43:1121-1127. doi: 10.1111/j.1365-2664.2006.01233.x

Sala OE, Chapin FS, Armesto JJ, et al (2000) Global biodiversity scenarios for the year 2100. science 287:1770-1774.

Sanders D, Platner C (2007) Intraguild interactions between spiders and ants and top-down control in a grassland food web. Oecologia 150:611-624.

Sanders D, van Veen FJ (2011) Ecosystem engineering and predation: the multi-trophic impact of two ant species. J Anim Ecol 80:569-576.

Savilaakso S, Garcia C, Garcia-Ulloa J, et al (2014) Systematic review of effects on biodiversity from oil palm production. Environ Evid 3:1-21.

Scheu S (1992) Automated measurement of the respiratory response of soil microcompartments: active microbial biomass in earthworm faeces. Soil Biol Biochem 24:1113-1118.

Schultz TR (2000) In search of ant ancestors. Proc Natl Acad Sci 97:14028-14029. doi: 10.1073/pnas.011513798

Schultz TR, McGlynn TP (2000) The interactions of ants with other organisms. In: Ants: Standard methods for measuring and monitoring biodiversity. Smithsonian Institution Press, Washington, DC, pp 122-144

Senior MJ, Hamer KC, Bottrell S, et al (2013) Trait-dependent declines of species following conversion of rain forest to oil palm plantations. Biodivers Conserv 22:253-268.

Slade EM, Burhanuddin MI, Caliman JP, et al (2014) Can cattle grazing in mature oil palm increase biodiversity and ecosystem service provision? The Planter 90:655-665.

Sodhi NS, Posa MRC, Lee TM, et al (2010) The state and conservation of Southeast Asian biodiversity. Biodivers Conserv 19:317-328.

Sonnier G, Shipley B, Navas M-L (2010) Quantifying relationships between traits and explicitly measured gradients of stress and disturbance in early successional plant communities. J Veg Sci 21:1014-1024.

Spasojevic MJ, Suding KN (2012) Inferring community assembly mechanisms from functional diversity patterns: the importance of multiple assembly processes. J Ecol 100:652-661. 
Steckel J, Westphal C, Peters MK, et al (2014) Landscape composition and configuration differently affect trap-nesting bees, wasps and their antagonists. Biol Conserv 172:56-64.

Stuntz S, Ziegler C, Simon U, Zotz G (2002) Diversity and structure of the arthropod fauna within three canopy epiphyte species in central Panama. J Trop Ecol 18:161-176.

Swift MJ, Heal OW, Anderson JM (1979) Decomposition in terrestrial ecosystems. University of California Press, Berkley and Los Angeles, California

Swift MJ, Izac A-M, van Noordwijk M (2004) Biodiversity and ecosystem services in agricultural landscapes - are we asking the right questions? Agric Ecosyst Environ 104:113-134.

Teuscher M, Vorlaufer M, Wollni M, et al (2015) Trade-offs between bird diversity and abundance, yields and revenue in smallholder oil palm plantations in Sumatra, Indonesia. Biol Conserv 186:306-318.

Thiollay J-M (1995) The Role of Traditional Agroforests in the Conservation of Rain Forest Bird Diversity in Sumatra. Conserv Biol 9:335-353. doi: 10.1046/j.1523-1739.1995.9020335.x

Throop HL, Archer SR (2007) Interrelationships among shrub encroachment, land management, and litter decomposition in a semidesert grassland. Ecol Appl 17:1809-1823.

Tilman D, Knops J, Wedin D, et al (1997) The influence of functional diversity and composition on ecosystem processes. Science 277:1300-1302.

Toledo-Hernández M, Denmead LH, Clough Y, et al Cultural homegarden management practices mediate arthropod communities in Indonesia. Insect Conserv In revision.

Tscharntke T, Bommarco R, Clough Y, et al (2007) Conservation biological control and enemy diversity on a landscape scale. Biol Control 43:294-309.

Tscharntke T, Clough Y, Wanger TC, et al (2012a) Global food security, biodiversity conservation and the future of agricultural intensification. Biol Conserv 151:53-59.

Tscharntke T, Tylianakis JM, Rand TA, et al (2012b) Landscape moderation of biodiversity patterns and processes-eight hypotheses. Biol Rev 87:661-685.

Turner EC, Foster WA (2009) The impact of forest conversion to oil palm on arthropod abundance and biomass in Sabah, Malaysia. J Trop Ecol 25:23-30.

Turner IM (1996) Species loss in fragments of tropical rain forest: a review of the evidence. J Appl Ecol 33:200-209.

Turner PD, Gillbanks RA (2003) Oil palm cultivation and management. Incorporated Society of Planters, Kuala Lumpur, Malaysia

Vandermeer J, Perfecto I, Nuñez GI, et al (2002) Ants (Azteca sp.) as potential biological control agents in shade coffee production in Chiapas, Mexico. Agrofor Syst 56:271-276.

van Nouhuys S (2005) Effects of habitat fragmentation at different trophic levels in insect communities. Ann Zool Fenn 42:433-447.

Vellend M (2004) Parallel effects of land-use history on species diversity and genetic diversity of forest herbs. Ecology 85:3043-3055.

Verheye W (2010) Growth and production of oil palm. In: Land use, land cover and soil sciences. Encyclopedia of Life Support Systems (EOLSS). UNESCO-EOLSS Publishers, Oxford, UK. 
Vermeulen S, Goad N (2006) Towards better practice in smallholder palm oil production. International Institute for Environment and Development, London, UK

Villéger S, Mason NW, Mouillot D (2008) New multidimensional functional diversity indices for a multifaceted framework in functional ecology. Ecology 89:2290-2301.

Vossbrinck CR, Coleman DC, Woolley TA (1979) Abiotic and Biotic Factors in Litter Decomposition in a Sermiarid Grassland. Ecology 60:265-271. doi: 10.2307/1937654

Wardle DA, Hyodo F, Bardgett RD, et al (2011) Long-term aboveground and belowground consequences of red wood ant exclusion in boreal forest. Ecology 92:645-656.

Way MJ, Khoo KC (1992) Role of ants in pest management. Annu Rev Entomol 37:479-503.

Weibull A-C, Östman Ö, Granqvist \AAsa (2003) Species richness in agroecosystems: the effect of landscape, habitat and farm management. Biodivers Conserv 12:1335-1355.

Whitten T, Damanik, Sengli J, Anwar, Jazanul, Hisyam, Nazayuddin (2000) The ecology of Sumatra. Periplus Editions (HK) Ltd., Singapore

Wielgoss A, Tscharntke T, Buchori D, et al (2010) Temperature and a dominant dolichoderine ant species affect ant diversity in Indonesian cacao plantations. Agric Ecosyst Environ 135:253259.

Wielgoss A, Tscharntke T, Rumede A, et al (2014) Interaction complexity matters: disentangling services and disservices of ant communities driving yield in tropical agroecosystems. Proc $\mathrm{R}$ Soc Lond B Biol Sci 281:20132144.

Wilcove DS, Giam X, Edwards DP, et al (2013) Navjot's nightmare revisited: logging, agriculture, and biodiversity in Southeast Asia. Trends Ecol Evol 28:531-540.

Wilman H, Belmaker J, Simpson J, et al (2014) EltonTraits 1.0: Species-level foraging attributes of the world's birds and mammals. Ecology 95:2027-2027. doi: 10.1890/13-1917.1

Wiwatwitaya D, Takeda H (2005) Seasonal changes in soil arthropod abundance in the dry evergreen forest of north-east Thailand, with special reference to collembolan communities. Ecol Res 20:59-70.

Wood BJ (2002) Pest control in Malaysia's perennial crops: a half century perspective tracking the pathway to integrated pest management. Integr Pest Manag Rev 7:173-190.

Wood BJ (1971) Development of integrated control programs for pests of tropical perennial crops in Malaysia. In: Biological control. Springer, pp 422-457

Woruba DN, Priest MJ, Dewhurst CF, et al (2014) Entomopathogenic fungi of the oil palm pest, Zophiuma butawengi (Fulgoromorpha: Lophopidae), and potential for use as biological control agents. Austral Entomol 53:268-274.

Wright SJ (2010) The future of tropical forests. Ann N Y Acad Sci 1195:1-27.

Zeddam J-L, Cruzado JA, Rodriguez JL, Ravallec M (2003) A new nucleopolyhedrovirus from the oil-palm leaf-eater Euprosterna elaeasa (Lepidoptera: Limacodidae): preliminary characterization and field assessment in Peruvian plantation. Agric Ecosyst Environ 96:69-75. 


\section{Acknowledgements}

Firstly I'd like to thank to my supervisors Teja Tscharntke, Yann Clough and Ingo Grass. Teja and Yann, thank you immensely for giving me the opportunity to be a part of the CRC and the Agroecology group. I appreciate all the advice and support throughout the last (almost) four years, I have learnt a huge amount and have had so many great (and difficult!) experiences and opportunities. Ingo, thanks for jumping in part way through and getting so involved, I have really appreciated your support in the last half of my $\mathrm{PhD}$, it has been a huge help.

I would also like to acknowledge and thank my colleagues within the Agroecology Group for the great working atmosphere, feedback and advice, fun excursions and many infamous Agroecology party buffets.

Working in Indonesia would not have been possible without a huge amount of help from the CRC management, staff, assistants and counterparts in Indonesia and Germany. Mega, Rizky, Mira, Traya, Indri, Yuking and Ozy, you guys are all great-thanks so much for everything!!In particular for putting up with me all that time -$)^{-}$. I appreciate my numerous Indonesian counterparts, Prof. Damayanti Buchori, Dr. Akhmad Rizali, Dr Rika Raffiudin, Dr Idham Harahap, Dwi Ristyadi and Dr Yeni Mulyani for all of their support over my time in Indonesia. I would also like to thank and acknowledge the smallholder farmers, national park rangers, and community members I worked and stayed with during my time in Indonesia. I had so many assistants who helped me complete all my work and hopefully I don't miss any names, but thank you so much to "team gila"- Rado, Victor, Ratna, Winda, Rizky, Susi, Oktiana, Herni, Deri, Juwita, Marisi, Leonarda, Alfianus, Deslian, Davig, Ilham, Arie, and last but definitely not least, the ones that put up with me a reeeally long time, Rico, Derly and Patrick. Rico and Derly, thanks for being wonderfully fun and nice people. Patrick, B09 would be nothing without you! Thanks for everything!

My long stays in Indonesia and the overall EEFForTs project was very difficult at times and getting through it has in large part been to my CRC family, thanks for all the laughs, bintangs, support, mattress surfing, movies, conferences, trips and schroeder moments Kara, Ana, Alex, Manuel, Malte, Andrew, Mick, Vijesh, Marcel, Evelyn, Thomas, Ivonne, Josie, Barbara, Jochen, Martyna, Katja, Natalie, Martin, Tom, Bernhard, Mary, Stefanie, Siria, Mimi, Krissi, Steffen, Syarhul and Anne. Particular shout out goes to my fellow PhD and MSc students in B09 (Kevin, Manuel, Dominik, Fuad, Arite and Edho), being a part of such a large team has only been possible through everyone being so great!

This research was possible due to financial support from the Deutsche Forschungsgemeinschaft (DFG) in the framework of the collaborative German - Indonesian research project Collaborative Research Centre 990: Ecological and Socioeconomic Functions of Tropical Lowland Rainforest Transformation Systems (Sumatra, Indonesia). 
I am grateful for all my friends outside of the CRC that have supported me along the way, in particular the ones that came all the way to Göttingen to visit me (Daniel, Emma, Ash and Richard), it meant a lot!

Most importantly, my family (Mum, Dad, Renee, Mike, Ginni, Ben, Zoey, Millie, Lydia)-I am super lucky to have such a great one! Thanks for putting up with your daughters/step-daughters/sisters perpetual student-ness, it's finally over! You have supported me throughout this crazy four years and everything before with unconditional encouragement and I am and will always be grateful! 


\section{Declaration}

\section{Specific chapter contributions}

I am the first author of the manuscripts included as chapter three, six and seven of this thesis in which I took part in all aspects of study design, data collection and statistical analysis and wrote the majority of the manuscript. Kevin Darras as co-first-author to chapter seven also contributed to all parts of the chapter. I personally contributed to the study design, statistical analyses and a significant amount of writing and editing of all other chapters except Chapter five which I did not contribute to the study design of. I helped supervise the MSc research which was the basis for Chapter two and Chapter four.

I, Lisa Denmead, hereby declare that I am the author of this dissertation entitled 'Ant diversity, function and services across tropical land-use systems in Indonesia'. All references and data sources that were used in the dissertation have been appropriately acknowledged. Furthermore, I declare that this work has not been submitted elsewhere in any form as part of another dissertation procedure.

Göttingen, 28th January, 2016

(Lisa H. Denmead) 


\section{Curriculum Vitae}

Name: Lisa H. Denmead

Current address: Emilienstr. 9, Göttingen 37075, Germany

Permanent address: 75 Motupipi st, Takaka 7110, New Zealand

Phone: +49 (0)15739758490 Email: 1 hdenmead@gmail.com

Citizenship: New Zealand

Date of Birth: 15/04/1987

\section{Education \& Qualifications}

PhD: $\quad$ Biodiversity and Ecology, University of Göttingen, Germany (2012-2016)

Thesis: Ant diversity and function across tropical rainforest transformation systems

MSc:

Animal Biology, University of Western Australia, Australia (2010-2012)

Thesis: The impact land-use intensification on the conservation management of native forest remnants embedded within production landscapes

PGDipSci: $\quad$ Ecology, University of Canterbury, New Zealand (2009)

(Transferred to UWA due to scholarship offer)

BSC: $\quad$ Biology, University of Canterbury, New Zealand (2005-2007)

\section{Awards \& Distinctions}

- Göttingen International conference travel grant, ATBC conference in Honolulu, Hawaii (2015)

- University Postgraduate Award, University of Western Australia (2010-2012)

- Safety-Net Top-Up Scholarship, University of Western Australia (2010-2012)

- Postgraduate Committee member, University of Canterbury (2009)

- Summer Scholarship Recipient, University of Canterbury (2007)

- Student Representative for Biology Department, University of Canterbury (2005-2007)

\section{Relevant Work Experience}

2009 - 2011 Field and lab assistant, University of Canterbury, New Zealand

Assistant within the Royal Society of New Zealand Marsden grant UOC0803:

Riches to rags: does elevated productivity drive ecosystem decay in adjacent natural habitats?

$2007-2008$ Field and lab assistant, University of Canterbury, New Zealand Assistant on a project investigating livestock exclusion and pest control in forest remnants on farmland in Waikato, New Zealand.

\section{Teaching and Supervistion}

2013 - 2014 Master of Science thesis co-supervisor, University of Göttingen

Manuel Toledo Hernández, Thesis topic: Management of homegardens in Indonesian agricultural landscapes and its impact on invertebrate diversity and herbivore predation 
Master of Science thesis co-supervisor, University of Göttingen

Dominik Ganser, Thesis topic: Ecosystem services provided by epiphytic plants in land-use systems of Sumatra, Indonesia

2013 - 2014 Master of Science thesis co-supervisor, Bogor Agricultural University Ratna Rubiana, Thesis topic: The effect of habitat transformation on diversity and community structure of ants in Jambi

2010

\section{Lab demonstrator: Global Change and Biodiversity course, University of} Western Australia

Tasks: Assisting lecturers to tutor labs in computer modelling using R, and field trips relating to restoration and climate change.

\section{Conference attendance}

- New Zealand Ecological Society, November 2015, Christchurch, New Zealand

- Oral Presentation: Single- and multi-trait measures reveal widespread functional diversity loss in human-modified tropical landscapes

- Ecological Society of Germany, Austria and Switzerland (GfÖ), September 2015, Goettingen, Germany

- Oral Presentation: Effects of ant exclusion on above- and below-ground invertebrate communities and associated ecosystem processes across land-use systems.

- Association for Tropical Biology and Conservation (ATBC), July 2015, Honolulu, USA

- Oral Presentation: Functional diversity responses to land-use change across multiple taxa

- Symposium organiser: Consequences of rainforest transformation in the Southeast Asian Archipelago

- $\quad$ ATBC, July 2014, Cairns, Australia

- Oral Presentation: Does biodiversity loss from oil palm plantations impact production?

- International Association for Ecology Congress August 2013, London, UK

- Oral Presentation: Does biodiversity loss from oil palm plantations impact production?

- ATBC, Asian chapter February 2013, Aceh, Indonesia

- Poster Presentation: How does biodiversity loss effect production in oil palm plantations?

- European Ecological Congress, September 2011, Avila, Spain

- Oral Presentation: Balancing biodiversity conservation and agricultural production

- Society for Ecological Restoration International, August 2011, Merida, Mexico.

- Oral Presentation: The effects of agricultural intensification on the restoration of invertebrate communities in adjacent forest remnants

\section{Professional Memberships}

- New Zealand Ecological Society

- Association for Tropical Biology and Conservation 


\section{Publication list}

\section{Submitted/In preparation}

Toledo-Hernández M, Denmead LH, Clough Y, Raffiudin R, Tscharntke T. Arthropod diversity in Indonesian homegardens is influenced by the owners' ethnicity and management practices. In revision, J. Insect Conserv, submitted: $21^{\text {st }}$ October 2015

Clough Y, Krishna VV, Corre MD, Darras K, Denmead LH, Meijide A, Moser S, Musshoff O, Steinebach S, Veldkamp E, Allen K, Barnes AD, Breidenbach N, Brose U, Buchori D, Daniel R, Finkeldey R, Harahap I, Hertel D, Holtkamp AM, Hörandl E, Jaya INS, Jochum M, Klarner B, Knohl A, Kotowska MM, Krashevska V, Kreft H, Kurniawan S, Leuschner C, Maraun M, Melati DN, Opfermann N, Pérez-Cruzado C, Prabowo WE, Rembold K, Rizali A, Rubiana R, Schneider D, Tjitrosoedirdjo SS, Tjoa A, Tscharntke T, Scheu S. Land-use choices, profitability, and consequences for biodiversity and ecological functions in Indonesian smallholder landscapes. In revision, Nat Commun, submitted: $9^{\text {th }}$ November 2015.

Ganser D, Denmead LH, Clough Y, Buchori D, Tscharntke T. Local and landscape drivers of arthropod diversity and decomposition processes in oil palm leaf axils. In revision, Agric For Entomol, submitted: 26th February 2016

Denmead LH, Darras K, Clough Y, Grass I, Barnes AD, Brose U, Buchori D, Jochum M, Kreft H, Mumme S, Prabowo WE, Rizali A, and Tscharntke T. Single- and multi-trait measures reveal widespread functional diversity loss in human-modified tropical landscapes. In review, Ecosphere, submitted: $8^{\text {th }}$ December 2015

Denmead LH, Darras K, Diaz P, Grass I, Tscharntke T, Clough Y. The role of ants, birds and bats in oil palm plantations. In review, Ecology, submitted: $14^{\text {th }}$ March 2016

Nurdiansyah F, Denmead LH, Clough Y, Wiegand K, and Tscharntke T. Landscape context affects insect biocontrol in oil palm plantations. In review, Agric, Ecosyst and Environ, submitted: $23^{\text {rd }}$ March 2016

Allen K, Barnes AD, Kreft H, Corre MD, Jochum M, Veldkamp E, Clough Y, Daniel R, Darras K, Denmead LH, Haneda NF, Hertel D, Knohl A, Kotowska MM, Kurniawan S, Meijide A, Rembold K, Prabowo WE, Schneider D, Tscharntke T, Brose U. Tropical land use imposes direct and cascading impacts on biodiversity from bacteria to birds. To be submitted to Nat Commun, April 2016.

Denmead LH, Clough Y, Grass I, Klarner B, Krashevska V, Rizali A, Scheu S, Liza W, Tscharntke T. Ants affect belowground invertebrate communities and associated ecosystem processes across tropical land-use systems. To be submitted to Ecol Entomol, May 2016

\section{Published}

Rubiana R, Rizali A, Denmead LH, Alamsari W, Hidayat P, Hindayana D, Clough Y, Tscharntke T, Buchori D (2015) Agricultural land use alters species composition but not species richness of ant communities. Asian Myrmecol 7:73-85. 
Didham RK, Barker GM, Bartlam S, Deakin EL, Denmead LH, Fisk LM, Peters JMR, Tylianakis JM, Wright HR, Schipper LA (2015) Agricultural intensification exacerbates spillover effects on soil biogeochemistry in adjacent forest remnants. PLoS ONE 10:e0116474. doi: 10.1371/journal.pone.0116474

Denmead LH, Barker GM, Standish RJ, Didham RK (2015) Experimental evidence that even minor livestock trampling has severe effects on land snail communities in forest remnants. J Appl Ecol 52:161-170.

Didham RK, Denmead LH, Deakin EL (2012) Riches to rags: the ecological consequences of land use intensification in New Zealand. In: Land use intensification: effects on agriculture, biodiversity and ecological processes, CSIRO Publishing. Melbourne, pp 7383

Didham RK, Barker GM, Denmead LH, Floyd CG, Watts CH (2009) The interactive effects of livestock exclusion and mammalian pest control on the restoration of invertebrate communities in small forest remnants. N Z J Zool 36:135-163. 